\title{
EDUCAR PARA TRANSFORMAR
}

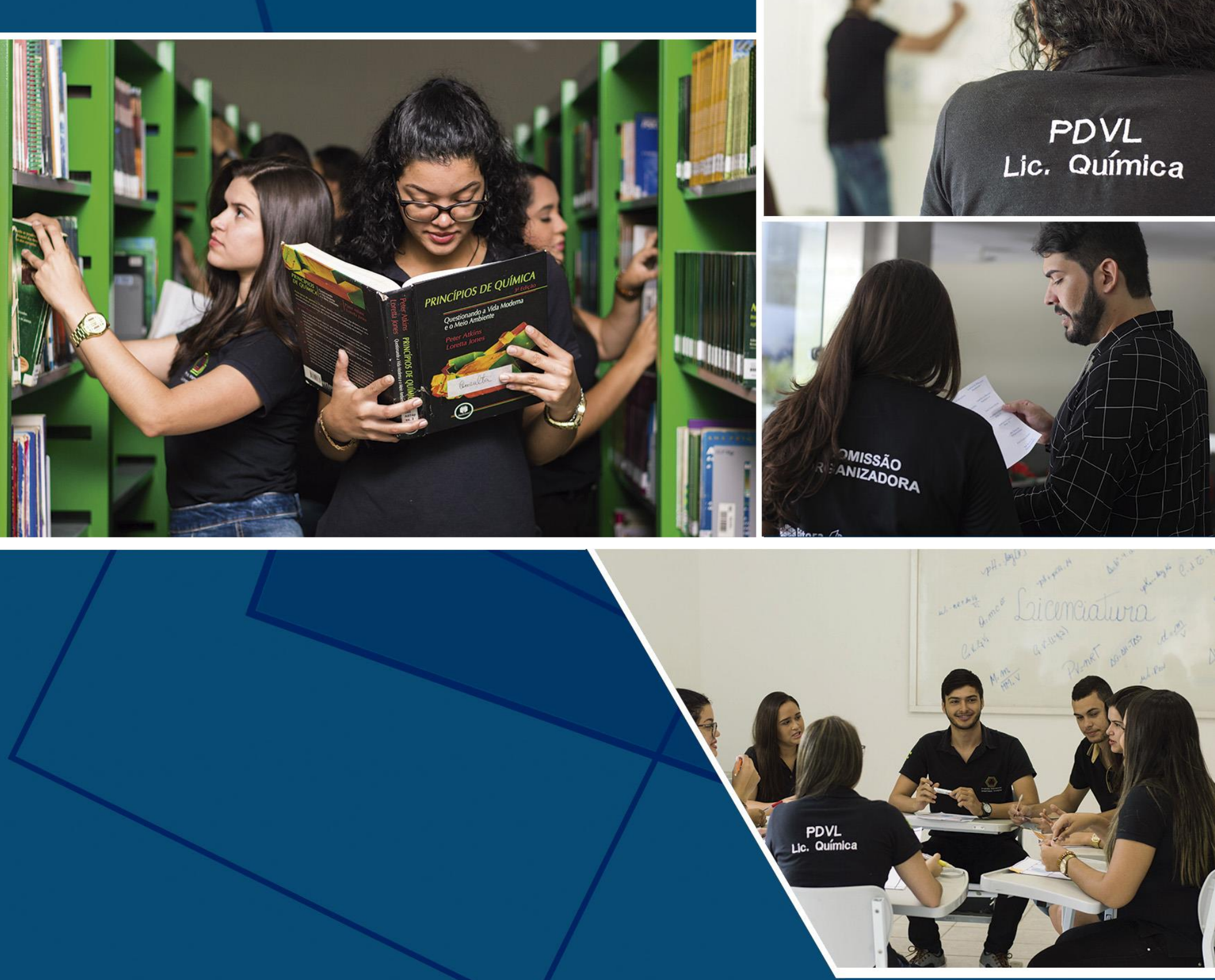

AYRTON MATHEUS DA SILVA NASCIMENTO RENATA JOAQUINA DE OLIVEIRA BARBOZA ROSIVÂNIA DA SILVA ANDRADE

\section{$\rightarrow$ Editora IIDV}




\section{Dados Internacionais de Catalogação na Publicação (CIP)}

(Câmara Brasileira do Livro, SP, Brasil)

Educar para transformar [livro eletrônico] / organização Ayrton Matheus da Silva Nascimento, Renata Joaquina de Oliveira Barboza, Rosivânia da Silva Andrade. -- 1. ed. -- Recife: Instituto Internacional Despertando Vocações, 2019. $1 \mathrm{Mb}$; PDF

ISBN 978-65-991061-3-2

1. Cientistas - Educação 2. Educação 3. Educação Finalidades e objetivos 4. Transformação educacional

5. Professores - Formação I. Nascimento, Ayrton Matheus da Silva. II. Barboza, Renata Joaquina de Oliveira. III. Andrade, Rosivânia da Silva.

Índices para catálogo sistemático:

1. Educação 370.1

Maria Alice Ferreira - Bibliotecária - CRB-8/7964 


\section{EDUCAR PARA TRANSFORMAR}

$1^{\mathrm{a}}$ Edição

$$
\text { Recife - PE - Brasil }
$$

INSTITUTO INTERNACIONAL DESPERTANDO VOCAÇÕES 2019 


\section{LIVRO DOS TRABALHOS PREMIADOS NO VI CONGRESSO \\ INTERNACIONAL DAS LICENCIATURAS - VI COINTER PDVL 2019}

ORGANIZADORES: Ayrton Matheus da Silva Nascimento

Renata Joaquina de Oliveira Barboza

Rosivânia da Silva Andrade

EDITOR: Ayrton Matheus da Silva Nascimento

DIAGRAMAÇÃO: Anderson Soares da Silva / Mariana Almeida Ferreira de Lima

ISBN: 978-65-991061-3-2

DOI: $\underline{10.31692 / 978-65-991061-3-2}$

EDITORA: Instituto Internacional Despertando Vocações (IIDV)

Edição Digital 2019. Direitos exclusivos reservados para todos os países. Proibida sua reprodução total ou parcial, para uso privado ou coletivo, em qualquer meio impresso ou eletrônico de acordo com as leis de Propriedade Intelectual.

Digitalizado no Brasil / Digitalizado en Brasil/ Digitized in Brazil. 


\section{PREFÁCIO}

Este livro faz parte dos trabalhos aprovados, apresentados e premiados no VI Congresso Internacional das Licenciaturas - VI COINTER PDVL foi uma realização do Instituto Internacional Despertando Vocações (IIDV), que teve o compromisso com a democratização do conhecimento e com uma Educação de qualidade e teve como objetivos: discutir os caminhos e perspectivas dos estudos na área; divulgar os conteúdos e resultados de pesquisas; estabelecer trocas de experiências entre docentes investigadores do Brasil e do exterior, contribuir na formação dos estudantes e estimular a geração de novas redes de cooperação multicêntricas. A intenção é, dessa forma, foi estimular, numa perspectiva plural, conversações e reflexões sobre a área, em diversos âmbitos.

A importância do VI COINTER-PDVL, foi a necessidade de ofertar aos estudantes e docentes, maior possibilidade de participação em eventos internacionais, que permitiram a troca de saberes e fazeres entre instituições parceiras e potenciais parceiras. Foram convidados pesquisadores do Brasil e do exterior com ampla experiência e produção em seus campos de estudo, onde apresentaram em conferências e mesas redondas os resultados de suas pesquisas. Todas as sessões foram seguidas de debates, possibilitando maior interface entre pesquisadores, estudantes de pós-graduação e graduação, professores universitários, de Educação Básica, além de pessoas da comunidade interessadas no tema.

Destacamos que as discussões contemplarão os seguintes eixos temáticos: Formação de Professores, Aprendizagem de Conceitos, Currículo e Políticas Educacionais, Avaliação da Aprendizagem, Didática das Ciências, Jogos Didáticos em Educação, Movimento CTSA, Planejamento e Gestão, Tecnologia na Educação, Processos de Ensino e Aprendizagem, Educação Empreendedora e Psicopedagogia.

Esp. Ayrton Matheus da Silva Nascimento (Coordenador do COINTER PDVL 2019) Renata Joaquina de Oliveira Barboza (Coordenadora do COINTER PDL 2019) MSc. Rosivânia da Silva Andrade (Coordenadora do COINTER PDVL 2019) 


\section{PRESIDENTE DO IIDV 2019}

Dr $^{\mathrm{a}}$. Kilma da Silva Lima Viana

COORDENADOR GERAL DO PDV 2019

MSc. Erick da Silva Lima Viana

COORDENADORA GERAL DO PDVL 2019

$\mathrm{Dr}^{\mathrm{a}}$. Kilma da Silva Lima Viana

COORDENADOR EXECUTIVO DO COINTER PDV 2019

Esp. Ayrton Matheus da Silva Nascimento

PRESIDENTE DA COMISSÃO CIENTÍFICA DO VI COINTER PDVL 2019

Esp. Ayrton Matheus da Silva Nascimento

PRESIDENTE DA COMISSÃO CIENTÍFICA DO VI COINTER PDVL 2019

MSc. Rosivânia da Silva Andrade

PRESIDENTE DA COMISSÃO CIENTÍFICA DO VI COINTER PDVL 2019

Renata Joaquina de Oliveira Barboza

MEMBROS DA COMISSÃO CIENTÍFICA DO VI COINTER PDVL 2019

\begin{tabular}{|l|c|}
\hline \multicolumn{1}{|c|}{ NOME } & ÁREA \\
\hline ADAUTO GOMES BARBOSA NETO & Biologia \\
\hline ALAN GUSTAVO FERREIRA & Matemática \\
\hline ALESSANDRA M. T. A. DE FIGUEIRÊDO & Química \\
\hline ANA QUELE GOMES DE ALMEIDA DIAS & Pedagogia \\
\hline ANDREZA SANTANA DA SILVA & Matemática \\
\hline ANTONIO GUTEMBERG RESENDE LINS & Matemática \\
\hline AYRTON MATHEUS DA SILVA NASCIMENTO & Química \\
\hline CARMEM SARA PINHEIRO DE OLIVEIRA & Biologia \\
\hline CHARLES TERUHIKO TURUDA & Física \\
\hline CÍCERO BATISTA DO NASCIMENTO FILHO & Geografia \\
\hline CLÁUDIA REGINA DE LIMA & Biologia \\
\hline DAVID GADELHA DA COSTA & Biologia \\
\hline DEIVISSON SILVA MOTA & Física \\
\hline EDSON FRANCISCO DO CARMO NETO & Biologia \\
\hline ELIEMERSON DE SOUZA SALES & Química \\
\hline EVERALDO SEBASTIÃO DA SILVA & Física \\
\hline ÉZIO RAUL ALVES DE SÁ & Química \\
\hline FABIANA GOMES DA SILVA & Pedagogia \\
\hline FERNANDA FREITAS SOUZA & Biologia \\
\hline FERNANDO CLEYTON H. DE MENDONÇA SILVA & Química \\
\hline FRANCISCO DE ASSIS ARAÚJO BARROS & Química \\
\hline FRANCISCO DE ASSIS PEREIRA NETO & Química \\
\hline FRANKLIN FERNANDO FERREIRA PACHÊCO & Matemática \\
\hline GABRIEL HENRIQUE DE LIMA & Biologia \\
\hline GERLIANE ROCHA DE ARAÚJO & Matemática \\
\hline GETULIO EDUARDO RODRIGUES DE PAIVA & Educação Física \\
\hline GIZELE SANTIAGO DE MOURA SILVA & Educação Física \\
\hline GLEICE ALVES DA COSTA & \\
\hline & \\
\hline
\end{tabular}




\begin{tabular}{|c|c|}
\hline INÊS GIRLENE DOS SANTOS MONTEIRO & Química \\
\hline IVAN CARLOS DA COSTA BARBOSA & Química \\
\hline JAKELINE MOREIRA DA SILVA & Biologia \\
\hline JAQUELINE COSTA DA SILVA LIMA & Pedagogia \\
\hline JEAN CLAUDE DE SOUZA GOMES & Geografia \\
\hline JOCIMARIO ALVES PEREIRA & Química \\
\hline JOSÉ ARTHUR DA SILVA SANTOS & Química \\
\hline JOSÉ JAILSON LIMA BEZERRA & Biologia \\
\hline JOSÉ LUCAS DE ARAÚJO & Biologia \\
\hline JOSÉ ROBERTO HENRIQUE SOUZA SOARES & Geografia \\
\hline JOSE RONIERO DIODATO & Pedagogia \\
\hline KARLA JEANE VILELA DE OLIVEIRA & Biologia \\
\hline KARLA REGINA FREITAS E SILVA & Biologia \\
\hline LIDIANE MARIA DE SOUZA & Física \\
\hline LUCIELMA BERNARDINO COELHO DE ARRUDA & Biologia \\
\hline LUIS PAULO BALDISSERA SCHORR & Matemática \\
\hline LUIZA CARLA CARVALHO SIQUEIRA & Biologia \\
\hline MAGADÃ MARINHO ROCHA DE LIRA & Pedagogia \\
\hline MAIRA CRISTINA DE OLIVEIRA SILVA & Geografia \\
\hline MANUEL BANDEIRA DOS SANTOS NETO & Química \\
\hline MANUELLE PATRICIA RAMOS VIEIRA & Pedagogia \\
\hline MARIA GISLAINE PEREIRA & Biologia \\
\hline MARIA MANUELA FIGUERÊDO SILVA & Matemática \\
\hline MARIA TATIANA DA SILVA SANTOS & Química \\
\hline MARIA TRINIDAD PACHERREZ VELASCO & Letras \\
\hline MARÍLIA NAYARA CLEMENTE DE ALMEIDA LIMA & Informática/Computação \\
\hline MAYRA DARLY DA SILVA & Matemática \\
\hline PAULO GARCEZ LEÃES & Pedagogia \\
\hline RAFAELA ALVES DE OLIVEIRA & Biologia \\
\hline RANNYELLY RODRIGUES DE OLIVEIRA & Matemática \\
\hline RENATA JOAQUINA DE OLIVEIRA BARBOZA & Química \\
\hline ROSANA MARIA DA SILVA & Matemática \\
\hline ROSIVANIA DA SILVA ANDRADE & Química \\
\hline SAMUEL LIMA DE SANTANA & Biologia \\
\hline SANDERSON HUDSON DA SILVA MALTA & Química \\
\hline SERGINA MARIA XAVIER FALCÃO FERREIRA & Matemática \\
\hline SERGIO BITENCOURT ARAÚJO BARROS & Química \\
\hline SHEILA CIBELLE DE FRANÇA SILVA & Pedagogia \\
\hline SUZANA CINTHIA GOMES DE MEDEIROS SILVA & Pedagogia \\
\hline THAMARA DE MEDEIROS AZEVEDO & Biologia \\
\hline THIAGO DA SILVA FREITAS & Biologia \\
\hline
\end{tabular}




\section{SUMÁRIO}

JOGO DIDÁTICO COMO PROPOSTA NO ENSINO DE BOTÂNICA: DESENVOLVENDO METODOLOGIA INOVADORA COM ALUNOS DE UMA ESCOLA ESTADUAL DE FLORIANO (PI)

Felipe Martins Avelino; Caio Martins Avelino; Luan Cristian Morais da Silva; José da Guia da Conceição Ferreira; Michelle Mara de Oliveira Lima

DOI: $\underline{\text { https://doi.org/10.31692/978-65-991061-3-2.1-13 }}$

ANÁLISE DA ABORDAGEM SOBRE ÁREA DE FIGURAS PLANAS PROPOSTA PELA BASE NACIONAL COMUM CURRICULAR PARA O PROCESSO DE ENSINO E APRENDIZAGEM DA MATEMÁTICA NA EDUCAÇÃO BÁSICA

Franklin Fernando Ferreira Pachêco; Andreza Santana da Silva; Alan Gustavo Ferreira

DOI: https://doi.org/10.31692/978-65-991061-3-2.14-26

EDUCAÇÃO AMBIENTAL EM UMA ESCOLA DO ENTORNO DA RPPN FAZENDA ALMAS: VIVENCIAS INTEGRADORAS COM DISCENTES NO CARIRI PARAIBANO. Karoline Maria da Silva Soares; Myller Gomes Machado; Francisco José Pegado Abílio DOI: https://doi.org/10.31692/978-65-991061-3-2.27-45

ATIVIDADE ENZIMÁTICA COMO FERRAMENTA DIDÁTICA PARA O ENSINO E APRENDIZAGEM DA BIOLOGIA EM UMA TURMA DO PRIMEIRO ANO DO ENSINO MÉDIO DE UMA ESCOLA PÚBLICA, LOCALIZADA EM URUÇUÍ-PI.

Vanessa Sousa da Costa; Felix Gomes da Costa; Yasmim Alline de Araújo Castro; Ícaro Fillipe de Araújo Castro

DOI: https://doi.org/10.31692/978-65-991061-3-2.46-58

A MONITORIA PARA ALUNOS SURDOS E CEGOS NO IFRN NATAL - CENTRAL: UMA PROPOSTA PARA O ENSINO ESCOLAR

Jéssica Eduarda dos Santos Silva; Arnaldo André de Sousa Júnior; Geraldo Felipe de Souza Filho; Vanessa Gosson Gadelhas de Freitas Fortes

DOI: https://doi.org/10.31692/978-65-991061-3-2.59-73

APRENDIZAGEM DAS REGULARIDADES ORTOGRÁFICAS: ESTRATÉGIAS PARA RESOLVER DESAFIOS DESENVOLVIDAS POR ALUNOS DURANTE A REALIZAÇÃO DE JOGOS ORTOGRÁFICOS

Shirley Thayza Soares de Souza; Rosy Karine Pinheiro de Araújo; Ana Cláudia Rodrigues Gonçalves Pessoa

DOI: https://doi.org/10.31692/978-65-991061-3-2.74-90

CENÁRIO DO ATENDIMENTO EDUCACIONAL ESPECIALIZADO AOS ALUNOS SURDOS NAS ESCOLAS PÚBLICAS DO MUNICÍPIO DE URUÇUÍ-PI

Felix Gomes da Costa; Vanessa Sousa da Costa; Isabela de Sá Costa Sousa; Miguel Antônio Rodrigues

DOI: https://doi.org/10.31692/978-65-991061-3-2.91-106

CONSTRUINDO SABERES COM O PIBID: A PRODUÇÃO DE MATERIAIS DIDÁTICOS PARA O ENSINO DE BIOLOGIA

Marcelo Augusto Barros Oliveira; Wanderson Mateus Bispo da Silva; José da Guia Conceição Ferreira; Paloma de Jesus Cipriano; Elkejer Ribeiro da Cruz

https://doi.org/10.31692/978-65-991061-3-2.107-109 
UTILIZAÇÃO DE UM SIMULADOR DO MOVIMENTO OBLÍQUO PARA ENSINO DE FÍSICA NUMA PERSPECTIVA DE TECNOLOGIA ASSISTIVA: FERRAMENTA DIDÁTICA INOVADORA PARA ESTUDANTES COM DEFICIÊNCIA VISUAL

Natália de Souza Brito; Sérgio Marivaldo dos Santos; Cecília Leite de Albuquerque; Kássio Marques e Silva; Hércules Santiago Silva

DOI: https://doi.org/10.31692/978-65-991061-3-2.110-113

I ENCONTRO SOBRE GESTÃO PARTICIPATIVA NA EDUCAÇÃo BÁSICA IFPI/CAMPUS FLORIANO E ESCOLAS PARCEIRAS

Vinícius da Luz Silva; Ana Raionara e Silva Tavares; Francisca Tannyery da Silva Nascimento; Roniê Ferreira Roza; Sebastiana Ceci Sousa.

DOI: https://doi.org/10.31692/978-65-991061-3-2.114-117

"CARA A CARA COM A CÉLULA": PROPOSTA DE UM JOGO PARA O ENSINO DE BIOLOGIA CELULAR

Maria Emília Oliveira de Carvalho; Gustavo de Barros Silva; Jaqueline Inez de Santana; João Vitor da Silva; Ana Cristina Lauer Garcia

DOI: https://doi.org/10.31692/978-65-991061-3-2.1-13

AS CONCEPÇÕES DOS ESTUDANTES DO ENSINO FUNDAMENTAL SOBRE O CONCEITO DE POLUIÇÃO: SEGUNDO A TEORIA DE REPRESENTAÇÃO SOCIAL Henllayane Nathani de Amorim Amaral; Ediangela Soares Silva do Nascimento; Ricardo Ferreira das Neves.

DOI: $\underline{\text { https://doi.org/10.31692/978-65-991061-3-2.1-13 }}$

\section{A CONFECÇÃO DE UMA CARTILHA EDUCATIVA PARA O ENSINO DO CICLO DA ÁGUA}

Ewerton Henrique da Conceição; Levi Araujo Bezerra; Luiz Carlos Alves de Souza

DOI: https://doi.org/10.31692/978-65-991061-3-2.1-13

O QUÍMIDOMINÓ: UMA PROPOSTA DE JOGO DIDÁTICO DE DISTRIBUIÇÃO ELETRÔNICA DE LINUS PAULING PARA OS ALUNOS DO $1^{\circ}$ ANO DO ENSINO MÉDIO

Maria Grasielly da Silva Nascimento; Matheus Alves Barbosa; Renata Joaquina de Oliveira Barboza; Kilma Lima da Silva Viana; Ayrton Matheus da Silva Nascimento

DOI: https://doi.org/10.31692/978-65-991061-3-2.1-13

OFICINA DE BARALHO MATEMÁTICO: UMA PROPOSTA LÚDICA PARA O ENSINO-APRENDIZAGEM DAS OPERAÇÕES BÁSICAS

Wesley Matheus Moura Balbino; Cleiton Pedrosa de Sales; Pedro Alexandre Linhares Lima; Iago Reis Santos; Francismar Holanda .

DOI: https://doi.org/10.31692/978-65-991061-3-2.1-13

LEI DO RESFRIAMENTO DE NEWTON:TEORIA E PRÁTICA

Pedro Augusto Soares da Silva; Nallyson Francisco Silva Souza; Leandro Campos da Cunha; José Gomes Ferreira Filho; Roberto Arruda Lima Soares

DOI: https://doi.org/10.31692/978-65-991061-3-2.1-13

QUEM SOU EU NA PALEONTOLOGIA": PROPOSTA DE JOGO DIDÁTICO PARA O ENSINO DE PALEONTOLOGIA

Gustavo de Barros Silva; João Vitor da Silva; Jaqueline Inez de Santana; Maria Emília Oliveira de Carvalho; Emanuel Souto da Mota Silveira

DOI: https://doi.org/10.31692/978-65-991061-3-2.1-13 


\section{A IMPORTÂNCIA DO INTÉRPRETE DE LIBRAS NA EDUCAÇÃO BÁSICA}

Ediangela Soares Silva do Nascimento; Henllayane Nathani de Amorim Amaral; Rafaela Alcântara Barros de Oliveira

DOI: https://doi.org/10.31692/978-65-991061-3-2.1-13

UMA EXPERIÊNCIA DE INCLUSÃO DE ALUNAS CEGAS DO CURSO DE LICENCIATURA EM FÍSICA DO IFRN NA DISCIPLINA DE CÁLCULO DE FUNÇÕES DE UMA VARIÁVEL

Rita de Cássia Paulo dos Santos; Wellington Muniz de Souza; Caio Vasconcelos Pinheiro da Costa; Tácio Vitaliano da Silva; Rainelly Cunha de Medeiros .

DOI: https://doi.org/10.31692/978-65-991061-3-2.1-13

O USO DA TABELA PERIÓdiCA COMO RECURSO LÚDICO FACILITADOR DA APRENDIZAGEM DE UMA DISCENTE COM SÍNDROME DE DOWN

Bruno Galdino Lopes; José Leonardo Alves Ferreira; Márcio Jean Fernandes Tavares; Niely Silva de Souza; Alessandra Marcone Tavares Alves de Figueirêdo

DOI: https://doi.org/10.31692/978-65-991061-3-2.1-13 


\title{
JOGO DIDÁTICO COMO PROPOSTA NO ENSINO DE BOTÂNICA: DESENVOLVENDO METODOLOGIA INOVADORA COM ALUNOS DE UMA ESCOLA ESTADUAL DE FLORIANO (PI)
}

\section{ENSEÑANZA DE JUEGO COMO SE PROPONE EN EDUCACIÓN BOTANICA: DESARROLLO MÉTODO INNOVADOR CON ESTUDIANTES DE UNA ESCUELA ESTATAL FLORIANO (PI)}

\section{GAME TEACHING AS PROPOSED IN BOTANICA EDUCATION: DEVELOPING INNOVATIVE METHOD WITH STUDENTS OF A STATE SCHOOL FLORIANO}

(PI)

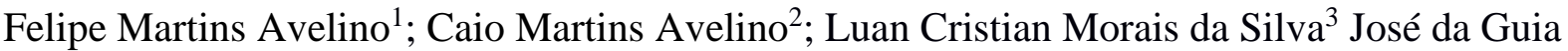 \\ da Conceição Ferreira ${ }^{4}$; Michelle Mara de Oliveira Lima ${ }^{5}$
}

DOI: https://doi.org/10.31692/978-65-991061-3-2.1-13

\begin{abstract}
RESUMO
A Botânica é o ramo da biologia que estuda as plantas. A dificuldade de despertar nos alunos o interesse pela Botânica é um desafio em algumas salas de aula, principalmente se a proposta de ensino for baseada em métodos convencionais, restritos aos livros didáticos e aulas expositivas. Os desafios do Ensino de Botânica podem ser atribuídos à falta de confiança e capacitação dos professores acerca dos conteúdos de botânica. A utilização de recursos que proporcione uma aplicação lúdica do conteúdo torna-se de suma importância pois os alunos podem apresentar melhor receptividade e mais interesse pela botânica. O objetivo do trabalho foi analisar a aplicação e avaliação de um jogo didático, denominado "Velha Botânica", como recurso didático para o ensino e aprendizagem dos grupos vegetais presentes na botânica e suas principais características. O jogo foi aplicado com 24 alunos no $2^{\circ}$ ano do ensino médio de uma escola estadual de Floriano (PI). Os dados foram coletados através aplicação de um questionário antes(pré-teste) e após (pós-teste) à aplicação do jogo. Nos resultados, observou-se que o entendimento dos alunos sobre as características dos grupos de plantas avasculares e vasculares foi bastante positivo, principalmente quanto as diferenças básicas dos grupos de plantas e a importância do fruto como característica evolutiva das angiospermas. A maioria dos alunos conseguiu alcançar o objetivo de compreende e apreender o conteúdo de uma maneira divertida e lúdica. Os alunos destacaram também a importância da contribuição do jogo didático para sua aprendizagem no conteúdo de botânica.
\end{abstract}

Palavras-Chave: Ensino, Jogo, Aprendizagem.

\section{RESUMEN}

La botánica es la rama de la biología que estudia las plantas. La dificultad para despertar el interés de los estudiantes en la botánica es un desafío en algunas aulas, sobre todo si la propuesta de enseñanza se basa en métodos convencionales restringidas a los libros de texto y

\footnotetext{
${ }^{1}$ Licenciatura em Ciências Biológicas, Instituto Federal do Piauí - Campus Floriano, Felipe1.3000@hotmail.com ${ }^{2}$ Licenciatura em Ciências Biológicas, Instituto Federal do Piauí - Campus Floriano, caiomartins1996@hotmail.com

${ }^{3}$ Licenciatura em Ciências Biológicas, Instituto Federal do Piauí - Campus Floriano, luancristianmorais@gmail.com

${ }^{4}$ Licenciatura em Ciências Biológicas, Instituto Federal do Piauí - Campus Floriano, josedaguiag30@outlook.com

${ }^{5}$ Mestre em Ensino de Biologia, Instituto Federal do Piauí - Campus Floriano, michellelima@ifpi.edu.br
} 
conferencias. Los retos de la enseñanza Botánica pueden atribuirse a la falta de confianza y la formación de los profesores sobre el contenido botánico. El uso de los recursos para proporcionar una aplicación lúdica de contenido se convierte en muy importante porque los estudiantes pueden proporcionar una mejor capacidad de respuesta y más interés por la botánica. El objetivo fue analizar la implementación y evaluación de un juego educativo llamado "Viejo Botánica" como recurso didáctico para la enseñanza y el aprendizaje de los grupos de plantas en la botánica y sus principales características. El juego se aplicó a 24 estudiantes en el segundo año de la escuela secundaria a una escuela estatal de Floriano (PI). Los datos fueron recolectados mediante la aplicación de un cuestionario antes (pretest) y después (post-test) la aplicación del juego. En los resultados, se observó que los estudiantes la comprensión de las características de los grupos de plantas avasculares y vasculares fue muy positiva, especialmente en relación con las diferencias básicas de los grupos de plantas y la importancia de la fruta como rasgo evolutivo de las angiospermas. La mayoría de los estudiantes lograron alcanzar el objetivo de entender y comprender el contenido de una manera divertida y lúdica. Los estudiantes también hicieron hincapié en la importancia de la contribución juego didáctico a su aprendizaje de los contenidos de la botânica.

Palabras Clave: Ensenanza, juego, aprendiendo.

\begin{abstract}
Botany is the branch of biology that studies plants. The difficulty to arouse students' interest in the Botany is a challenge in some classrooms, especially if the teaching proposal is based on conventional methods restricted to textbooks and lectures. The challenges of Botany Teaching can be attributed to lack of confidence and training of teachers about the botanical content. The use of resources to provide a playful application of content becomes very important because students can provide better responsiveness and more interest in botany. The objective was to analyze the implementation and evaluation of an educational game called "Old Botany" as a teaching resource for teaching and learning of plant groups in the botany and its main features. The game was applied to 24 students in the 2nd year of high school to a state school of Floriano (PI). Data were collected by applying a questionnaire before (pretest) and after (post-test) the application of the game. In the results, it was observed that students' understanding of the characteristics of avascular and vascular plant groups was very positive, especially regarding the basic differences of plant groups and the importance of the fruit as evolutionary trait of angiosperms. Most students managed to achieve the goal of understand and grasp the content in a fun and playful way. Students also stressed the importance of the didactic game contribution to their learning the contents of botany.
\end{abstract}

Keywords: Teaching, game, learning.

\title{
INTRODUÇÃO
}

A Botânica é o ramo da biologia que estuda os vegetais. Teve início com o estudo sobre plantas medicinais, pois os primeiros registros sobre plantas foram apresentados pelos egípcios e os gregos também deixaram registrados das suas observações sobre os diversos tipos de plantas, há também descrições de plantas e suas aplicações no combate a diferentes tipos de doenças na história (MARTINS-DA-SILVA, 2014). O ensino de botânica é bastante interessante, porém a abordagem meramente descritiva utilizada, na maioria das vezes, pelos professores, pode desestimular os alunos fazendo com que percam o interesse pelo conteúdo (MELO, 2012). Entretanto, estudos recentes afirmam que ao utilizar recursos que propiciem a 
aplicação lúdica do conteúdo, os alunos apresentam melhor receptividade é mais interesse pela botânica (ESTRELA; VIANA; SANTANA, 2017).

De acordo com Arrais, Souza e Masrua (2014), as dificuldades do Ensino de Botânica são atribuídas à falta de confiança dos professores acerca da abordagem do tema. Como discutido por Salatino e Buckeridge (2016), muitos professores tiveram uma formação insuficiente em botânica, a consequência disso são professores sem motivação de nutrir nos seus alunos o aprazer de aprender botânica.

É importante desde do início cultivar o interesse dos alunos pelo aprendizado em botânica. De acordo com Raven (2007), as plantas, participam de nossas vidas de diversas maneiras além de fontes de alimento, nos fornecendo fibras para vestuário, madeira para mobiliário, abrigo e combustível, papel para livros, substâncias para produção de remédios e também o oxigênio que respiramos. $\mathrm{O}$ estudo das plantas ou de botânica nos garantiu melhor compreensão da natureza de toda a vida existem na terra. Portanto, somos completamente dependentes das plantas e por este motivo importância de ensinar o devido valor que as plantas tem no ecossistema (SALATINO; BUCKERIDGE, 2016).

Segundo Melo (2012), a dificuldade de despertar nos alunos o interesse pela Botânica é um desafio em algumas salas de aula, principalmente se a proposta de ensino for baseada em métodos convencionais, restritos aos livros didáticos e aulas expositivas, não surtirá nenhum efeito positivo na aprendizagem dos alunos. Nesse sentido, Araújo (2011), relata que enquanto os professores estiverem duvidosos em relação as aulas expositivas cheias de palavras e definições a serem meramente decoradas pelos alunos o ensino será cada vez mais desinteressante. Portanto, se não houver interesse dos professores em trabalhar novos métodos e técnicas que desenvolva nos alunos um aprender significativo.

De acordo com Silva (2014), o ensino dos conteúdos de botânica e de biologia de modo geral é importante escolher atividades que enalteça a relevância do conteúdo para a pessoa, sendo que é importante que possua o envolvimento do diversos contexto econômico, socioambiental no ensino de botânica e biologia, tal como destacando a utilização das plantas nesses diversos aspectos, permitindo aos estudantes compreender as relações entre o ser humano e a natureza intermediado pela tecnologia.

Muitos autores destacam a importância dos jogos no ensino, como um recurso didático, sendo fundamental no processo de ensino e aprendizagem. Segundo Neves et al. (2014), o lúdico como abordagem na sala de aula, a partir da aplicação de jogos didáticos pode proporcionar novas formas de acesso à informação e de produção de novos conhecimentos, motivando o interesse do aluno a buscar novas maneiras de estudar os conteúdos programáticos, 
colaborando assim, para a melhoria da qualidade do ensino de biologia e botânica no brasil.

Neste sentido, este trabalho propõe o uso de um recurso que procurou proporcionar um contexto lúdico, integrando os grupos vegetais presentes na botânica e suas principais características, para uma abordagem chamativa, no intuito de buscar o interesse do aluno ao assunto apresentado.

\section{FUNDAMENTAÇÃO TEÓRICA}

O ensino biologia é marcado prioritariamente por aulas teóricas e pela exploração subvalorizada e descontextualizada da realidade, construída e reproduzida pelo professor, esta característica uma das principais responsáveis pela continuidade da prática docente tradicional (SANTOS; NETO, 2017). No ensino de Biologia há uma ausência de vinculação entre o que se está sendo abordado na teoria e prática, os conteúdos são tratados de forma distante da realidade dos alunos, com isso o professor precisará promover nos alunos um raciocínio teórico e indagações dos conteúdos presente no seu cotidiano (MELO, 2010).

O ensino de botânica é visto pelos alunos do ensino fundamental e médio como um assunto de difícil compreensão, entediante e fora do contexto moderno. Os alunos não consideram como matéria importante para sua vida, a botânica se tornou lamentavelmente um assunto descartável para os alunos. A cegueira botânica é um termo utilizado para explicar porque os alunos não gostam de botânica, este termo descreve que as pessoas não percebem a importância das plantas para biosfera e o seu cotidiano, e também os aspectos morfológicos e biológicos presentes nas plantas, achando que as plantas são seres inferiores aos animais, ou seja, indignos de alguma atenção (SALATINO; BUCKERIDGE, 2016).

O processo de ensino-aprendizagem em botânica, se desenvolve dentro de um contexto considerado estático, desinteressante e que leva à falta de motivação por parte dos educandos (SALATINO; BUCKERIDGE, 2016). Batista e Araújo (2015), destacam também preocupação em relação aos resultados negativos apresentados no processo de ensino-aprendizagem de botânica. Visto que o professor acaba utilizando-se de um modelo convencional de ensino, de maneira que acaba fugindo da realidade da escola e da vida do aluno (BONFIM et al., 2015).

O ensino da Botânica, bem como uma grande parte dos conteúdos relacionados às disciplinas de Biologia é marcado por diversas barreiras e dentre as mais evidentes encontramse o desinteresse e a falta de motivação dos alunos por esse conteúdo, a falta de desenvolvimento de novas metodologias e de materiais didáticos voltados para o aproveitamento dessa área (MELO, 2012).

Nas aulas de Botânica é evidente a dificuldade dos professores em utilizar recursos 
pedagógicos, onde acaba limitando o poder do conhecimento a ser adquirido pelos estudantes (BONFIM et al., 2015). Logo, os professores apresentam esta dificuldade por não haver uma relação harmônica e proveitosa com os recursos didáticos, porque nãos estão familiarizados a utilizar recursos didáticos para facilitar a aprendizagem dos alunos nos conteúdos de biologia e botânica (NICOLA; PANIZ, 2016).

O professor deve dispor de prática docente que se utilize de pedagogias diferenciadas, visto que o mundo globalizado é nossos alunos anseiam por formas de ensinar mais dinâmicas, atraentes e contextualizadas em que eles sejam os sujeitos ativos desse processo, baseando-se no construtivismo para o processo de ensino e aprendizagem na Educação em Ciências, afim de construir-se um sentido ao conteúdo da disciplina (ARAÚJO, 2013).

O uso de novas tecnologias na educação pode propiciar a quebra de barreiras, além de ajuda no desenvolvimento de novos conhecimentos, havendo a necessidade de focar na formação de educadores para que possam desenvolver novas metodologias de ensino, voltadas para utilização de novas tecnologias de aprendizagem ou desfrutar o máximo da tecnologia que se tem à disposição (DA SILVA; CORREA, 2014).

A simples reproduções de conhecimento na sala de aula não favorece o aprendizado dinâmico dentro da sala de aula, não viabilizado a correta assimilação dos conceitos e sua aplicação em situações de vivências distintas, por parte do discente. Contudo o ensino de Botânica dispõe-se da urgência da necessidade de uma nova prática pedagógica, não se utilizando de modelos e receitas prontas (MOUL; DA SILVA,2017).

O uso de recursos diversificados em sala de aula e a construção de conceitos de pluralismo metodológico acaba tornam-se indispensável, visto que a necessidade é evidente de diversificar os materiais didáticos e modalidades didáticas na sala de aula, propiciando o melhor ensino é motivação dos alunos em relação aos modos de aprender. Assim á possibilita de inserir todos os alunos naquilo que é discutido em sala de aula (SANTANA; CASASCO; SESSA, 2016).

\section{METODOLOGIA}

A metodologia aplicada teve abordagem qualitativa e quantitativa. A pesquisa foi realizada na Escola Estadual Ceti Fauzer Bucar em Floriano, Piaui. A partir da análise dos dados obtidos da pesquisa, verificou-se que quantidade de alunos participantes da pesquisa foi de 24 alunos do $2^{\mathrm{a}}$ ano do ensino médio, sendo que a maioria dos alunos da turma é constituída $62,5 \%$ do sexo feminino é 37,5\% do sexo masculino. Em relação a idade dos alunos observou-se que apresentava idade entre 15 até 19 anos de idade. 
Foi aplicado o pré-questionário para diagnóstico, antes da aplicação do jogo didático sobre botânica. O questionário apresentava perguntas abertas e fechadas com 6 perguntas: 4 eram referentes aos grupos vegetais e suas características e 2 questões referente a metodologia utilizada no trabalho. O jogo "Velha Botânica" executado com os alunos, possuem uma fácil interatividade. Ao iniciar, o jogador é apresentado a uma tela com o nome "velha botânica" e o nome jogar e instruções (Figura 1).

Figura 1- O jogo didático aplicado aos estudantes $2^{\circ}$ série do ensino médio da escola Ceti Fauzer Bucar, Floriano-PI
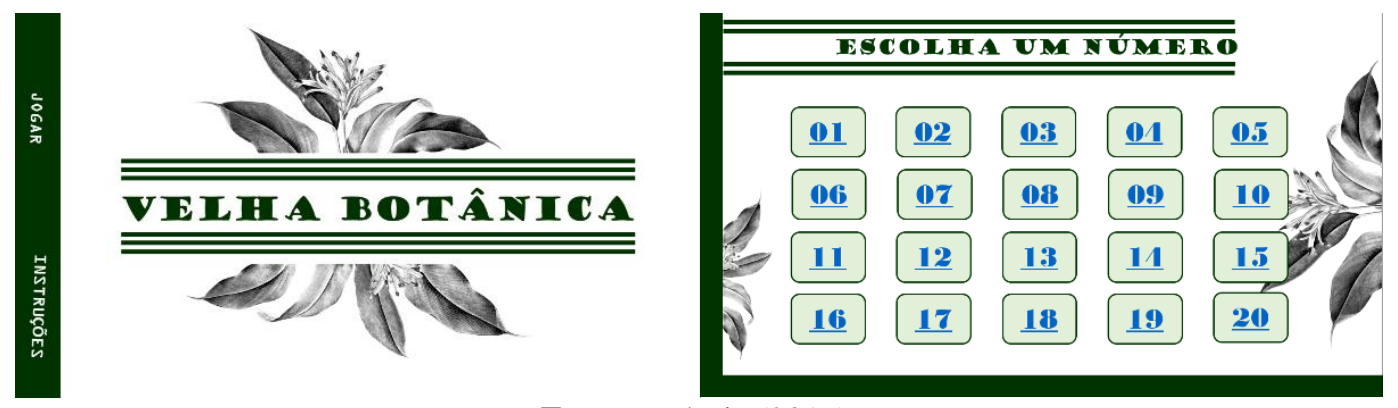

Fonte: Própria (2019).

O jogo foi construído no programa PowerPoint e apresentava 20 questões sendo todas objetivas embasadas no conteúdo abordado, as perguntas apresentavam quatros alternativas A, B, C e D (Figura 2). O intuito do jogo é servir de instrumento que leva os alunos por uma viagem virtual pelo mundo da botânica e seus grupos vegetais e que possibilita aos alunos testarem seus conhecimentos adquiridos e aprendidos durante as aulas anteriores, de maneira dinâmica, divertida e inovadora.

Figura 2 - Perguntas do jogo didáticos velha botânica.

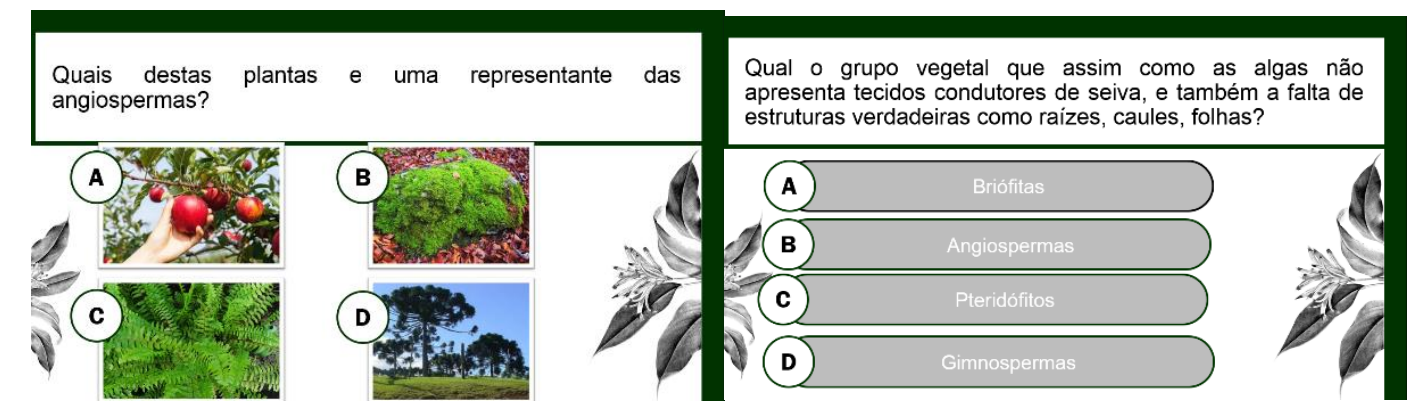

Fonte: Própria (2019)

Os alunos foram divididos em 2 grupos, após esta divisão dos grupos foram ditas as regras do jogo, onde cada grupo escolheria um jogador para representar seu grupo. O jogador em questão escolheria um número que designaria a uma pergunta no jogo, caso o jogador 
respondesse a pergunta escolhida corretamente, colocaria um ponto preto ou branco no tabuleiro de acordo com a cor escolhida para representar o grupo (Figura3). Ao término do jogo foi aplicado pós-questionário para os alunos responderem.

Figura 3 - Aplicação do jogo didático em sala de aula e o tabuleiro utilizado.

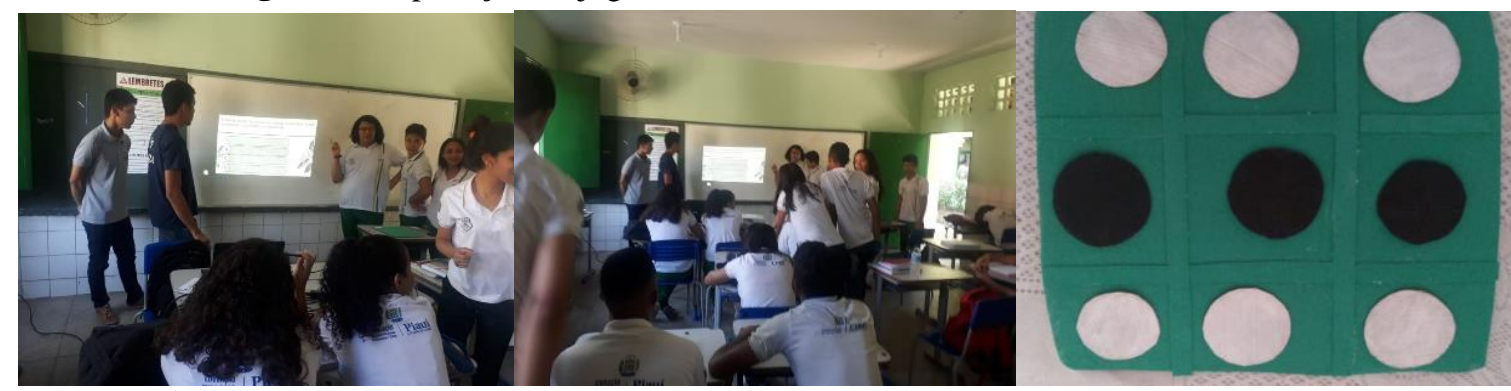

Fonte: Própria (2019)

\section{RESULTADOS E DISCUSSÃO}

Durante aplicação do jogo didático foi possível observar que os alunos estavam bem animados e curiosos para atividade lúdica, durante o decorrer da atividade os mesmos estavam bem participativos e comunicativos, em alguns momentos esclarecendo eventuais dúvidas que surgiam durante a aplicação do jogo.

De acordo com as Orientações Curriculares para o Ensino Médio (BRASIL, 2006), o jogo oferece o estímulo e o ambiente propícios que favorecem o desenvolvimento natural e criativo dos alunos e permite a interatividade entre aluno e professor expandir seus conhecimentos de métodos e técnicas ativas de ensino, desenvolvendo capacidades pessoais e profissionais para estimular nos alunos a competência de comunicação e iniciativa, mostrando uma nova maneira, lúdica, prazerosa e participativa de aprender os conteúdos, levando uma maior acomodação e a apropriação de novos conhecimentos.

No que se refere ao conhecimento dos alunos sobre o grupo de plantas que não apresenta vasos condutores de seiva, no pré-teste 17 alunos apontaram as briófitas como alternativa correta, após a aplicação do jogo 18 alunos que compreenderam que as briófitas são plantas avasculares (Figura 4). Segundo Raven (2007), as briófitas são plantas pequenas, crescem em locais úmidos e não apresentam tecidos de condução de seiva, chamados de xilema e floema, estes só estão presentes nas plantas vasculares. De acordo com Wolski e Tolomeotti (2013), a utilização de metodologias diferenciadas que busque a participação ativa do aluno no processo ensino aprendizagem, e extremamente importante, logo porque, a interação proporcionar aos alunos uma aprendizagem significativa.

Segundo Chaves (2015), o jogo didático como estratégia de ensino no contexto da sala aula só tem a contribuir nos estímulos positivos aos estudantes em revisar o conteúdo abordador 
pelo professor. Portanto, a influência que os jogos didáticos tem sobre os alunos é bastante positiva para o processo de ensino e aprendizagem.

Figura 4. Avaliação do conhecimento dos alunos da 2 a série do Ensino Médio da Escola Estadual Fauzer Bucar, Floriano (PI) sobre as plantas avasculares.

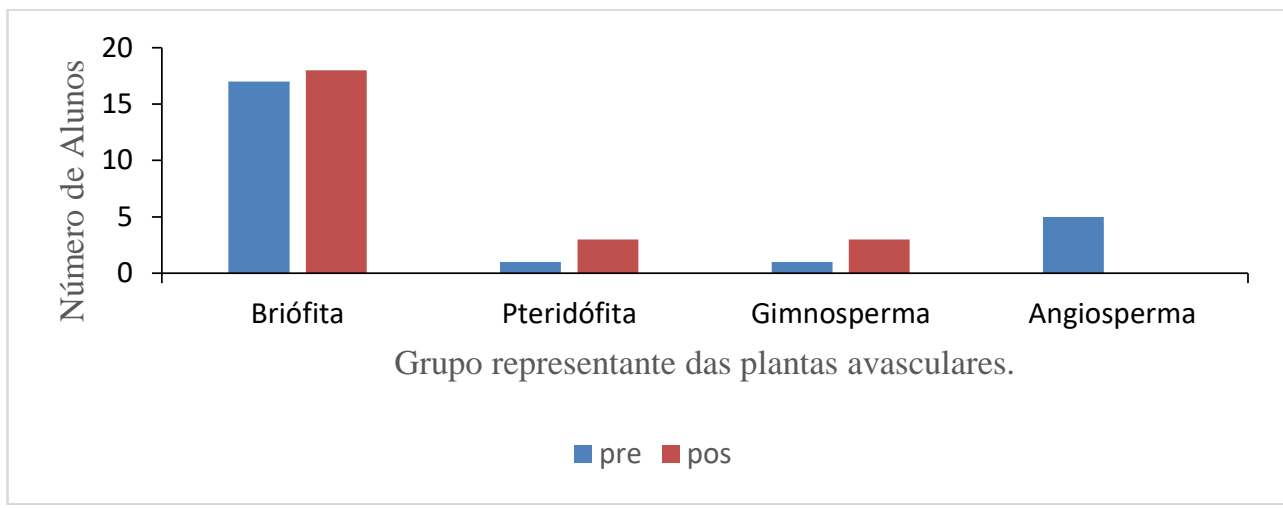

Fonte: Dados da Pesquisa (2019).

Em relação aos conhecimentos sobre o grupo de plantas que apresenta vasos condutores de seiva, não produzem sementes e tem como geração dominante a esporofítica, após a aplicação do jogo, houve um pequeno aumento de 18 alunos que indicaram corretamente as pteridófitas como resposta correta (Figura 5), confirmado assim que estes grupos de plantas vasculares sem sementes que apresenta tecidos condutores de seiva, xilema e floema em sua estrutura (RAVEN et al., 2007).

Figura 5. Avaliação do conhecimento dos alunos da $2^{\mathrm{a}}$ série do Ensino Médio da Escola Estadual Fauzer Bucar Floriano (PI) sobre plantas vasculares sem semente.

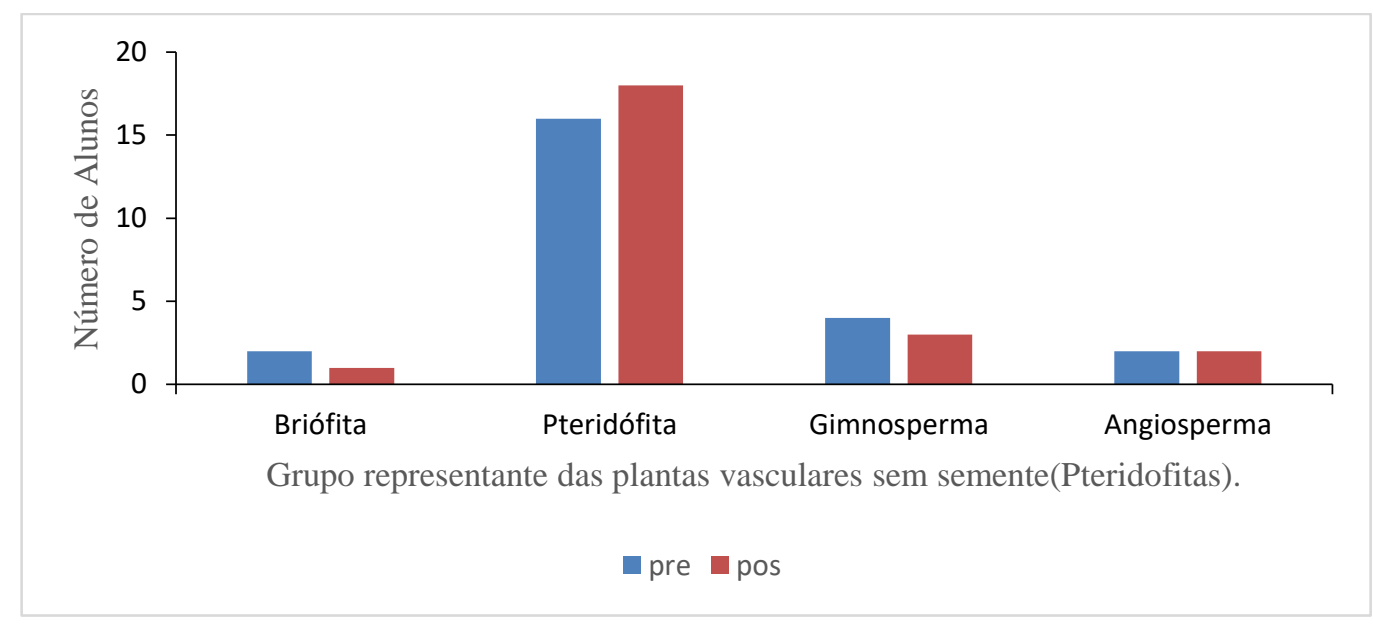

Fonte: Dados da Pesquisa (2019).

Vale destacar que após a utilização do jogo didático houver uma melhora, os 18 alunos apontaram as pteridófitas como plantas que apresenta vasos condutores de seiva. Os jogos 
didáticos influenciam de maneira significativa na construção do conhecimento e facilitando o entendimento dos alunos sobre o conteúdo de difícil compreensão. Segundo Pedroso (2009), é importante o uso de atividades lúdicas como meios de fornecer aos alunos um ambiente agradável, que possibilite o desenvolvimento de habilidades, além de motivar os alunos a participar e a cooperarem diretamente na construção do seu próprio conhecimento

Sobre os conhecimentos prévios dos alunos sobre o grupo vegetal que apresenta fruto no pré-teste 18 alunos relataram que eram as angiospermas que apresenta frutos como característica deste grupo e 6 alunos consideraram que as pteridófitas e as gimnospermas apresentam frutos como características (Figura 6).

Figura 6. Avaliação do conhecimento dos alunos da $2^{\mathrm{a}}$ série do Ensino Médio da Escola Estadual Fauzer Bucar Floriano (PI) sobre os frutos são importantes estruturas, relacionadas a qual dos grupos vegetais.

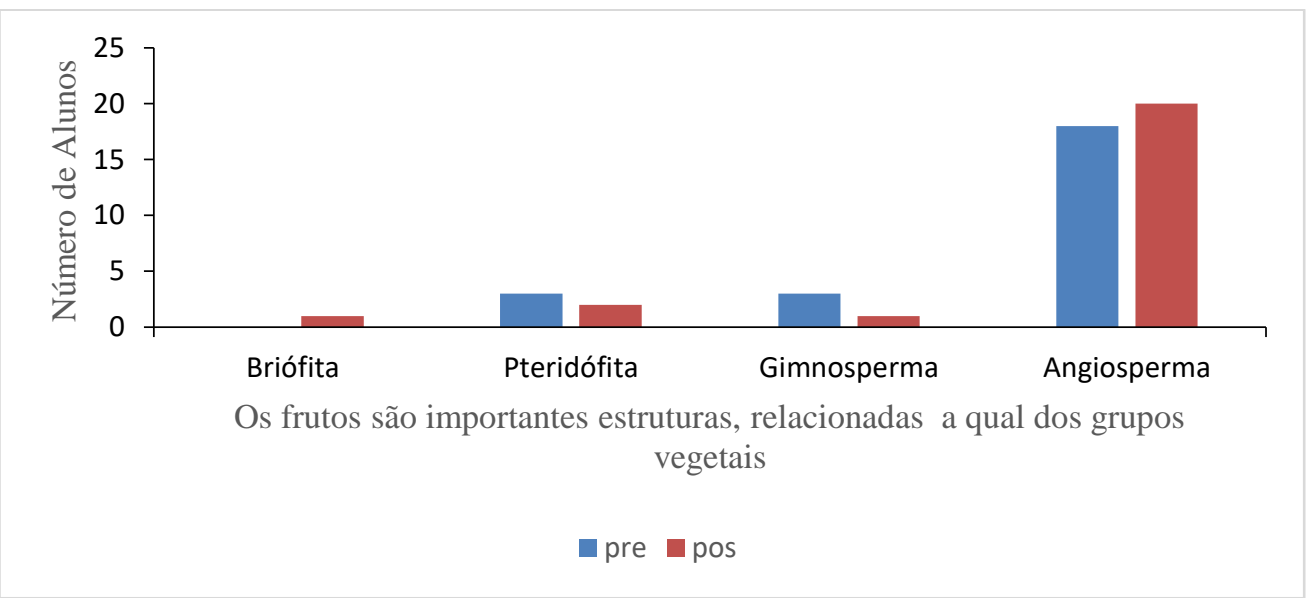

Fonte: Dados da Pesquisa (2019).

Depois da aula com a utilização do jogo didático, 20 alunos apontaram no pós-teste que era as angiospermas. De acordo com Raven (2007), as angiospermas representam um grupo de plantas que tem como característica a flor, fruto e um ciclo de vida que as diferem de todas as outras plantas. Ao verificar que a maioria dos alunos acertaram tanto no pré e pós teste, podemos afirmar que o jogo didático só tem a acrescentar no entendimento e compreensão dos alunos. Portanto, os jogos didáticos têm como finalidade preencher as dúvidas deixadas pelos professores como decorrência de uma educação parada. Segundo Rocha e Rodrigues, (2018), a utilização de um jogo didático e extremamente positiva para o desenvolvimento coletivo, favorecendo a socialização com os colegas, além de colaborar para a construção de novos conhecimentos. Do mesmo modo, para Wolski e Tolomeotti (2013), a proposta de desenvolver novas metodologias de caráter lúdico que busque novos contextos de interação entre aluno e professor e de fundamental importância para o ensino de biologia, logo este tipo de ferramenta que proporciona a colaboração em grupo, e assim promovendo a interatividade e compreensão 
de conceitos.

Com relação opinião dos alunos sobre a utilização do jogo didático se contribuiu para a sua aprendizagem (figura 7), verificou-se que os 23 alunos destacaram que o jogo contribuiu para entendimento do conteúdo abordador no jogo. Segundo Fortuna (2003), destacar a importância da utilização de jogos didáticos no ensino, sendo que o ato de joga desenvolve no aluno a iniciativa, imaginação, raciocínio, a memória, a atenção e a curiosidade e interesse durante uma atividade em sala de aula. Os jogos como recurso didático podem ser instrumento educacional valioso que estimulam os alunos ao maior interesse, facilitando e contribuindo no processo de ensino e aprendizagem, contudo, desde que seja de utilizado de maneira correta pelo professor.

Figura 7. Avaliação do conhecimento dos alunos da $2^{a}$ série do Ensino Médio da Escola Estadual Fauzer Bucar Floriano sobre a contribuição do jogo para a aprendizagem, 2019.

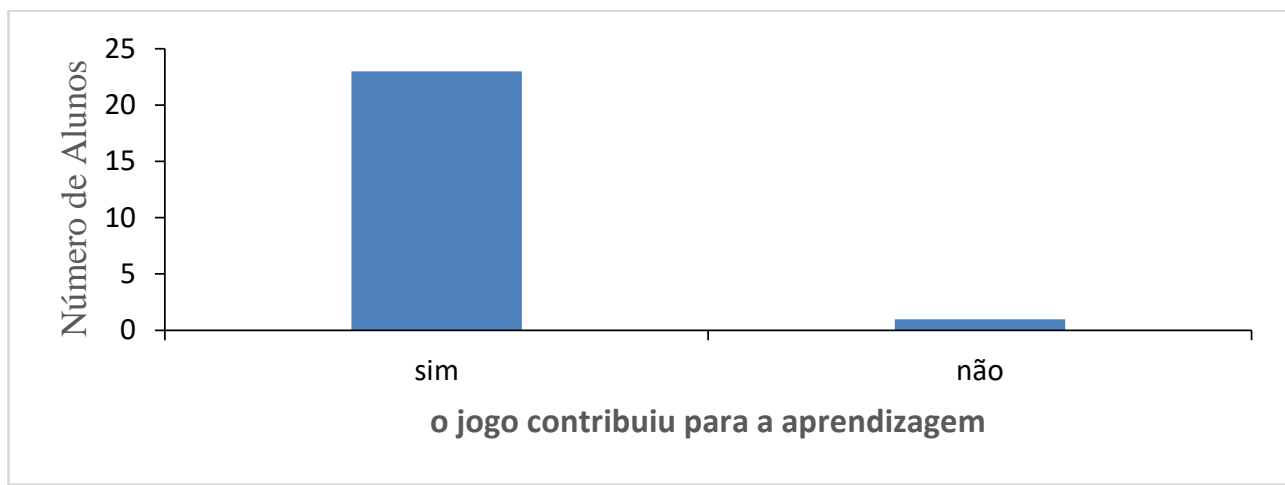

Fonte: Dados da Pesquisa (2019).

De acordo com Wolski e Tolomeotti (2013), “jogos didáticos são um recurso didático lúdico que estimula as várias inteligências, permitindo que o aluno se envolva em tudo que esteja realizando de forma significativa", esta afirmação nos permite concluir que um ambiente com estas características ajuda os alunos, e até mesmo os próprios alunos acabam pedindo formas mais empolgantes e diversificadas que contribuam para este tipo de ambiente. Em relação a isso os alunos foram questionados sobre se preferem aprender com jogos ou exercícios tradicionais, todos os alunos acabaram afirmando que preferem aprender com jogos didáticos do que exercícios tradicionais.

\section{CONCLUSÕES}

A partir dos resultados obtidos da pesquisa demostraram que a partir da utilização do jogo didático "Velha Botânica", evidenciam um bom aproveitamento do recurso didático, observando que o jogo favoreceu aos alunos uma maior assimilação do conteúdo relacionado a 
introdução a botânica. $\mathrm{O}$ avanço no bom desempenho por parte dos alunos se deu a partir da contextualização da atividade da realizada, proporcionando uma aula mais interativa, dinâmica, participativa, motivadora e estimulante. Pois, após aplicação do jogo didático os alunos conseguiram identificar as características dos grupos plantas avasculares e vasculares, compreendendo que as briófitas são plantas avasculares e pteridófitas plantas vasculares sem sementes, além da importância do fruto como característica evolutiva das angiospermas.

Portanto, foi possível verificar que atividades lúdicas tem a função primordial de fazer com que os alunos, sejam mais ativos e participativos durante a aula. Destaca-se a importância a importância do recurso didático para o aprimoramento da aprendizagem sobre o conteúdo de botânica.

\section{REFERÊNCIAS}

ARAÚJO, G. C. Botânica no ensino médio. Monografia (Licenciatura em Ciências Biológicas) - Consórcio Setentrional de Educação a Distância, Universidade de Brasília, Universidade Estadual de Goiás, Brasília, 2011.

ARAÚJO, J. N. O ensino de botânica em uma perspectiva construtivista. In. IX congresso nacional de educação Edurece.2013. FAPEAM, Curitiba, 2013.

ARRAIS, M. G. M.; SOUSA, G. M.; MARSUA, M. L. A. O ensino de botânica: Investigando dificuldades na prática docente. Revista da Associação Brasileira de Ensino de Biologia, n.7, p. 5409-5418, 2014.

BONFIM, L. R. M.; TAVARES-MARTINS, A. C. C.; PALHETA, I. C.; JUNIOR, A. S. M. O ensino de botânica em escolas públicas e particulares no município de Barcarena, Pará, Brasil. ARETÉ. Manaus, Vol.8, Num.17, p.167-176. jul/dez 2015.

BRASIL. Ministério da Educação. Secretaria de Educação Básica. Orientações Curriculares para o Ensino Médio: Ciências da natureza, matemática e suas tecnologias. Brasília: MEC/SEB, 135 p. 2006.

CHAVES, B. E.; et al. Ludo Vegetal: uma nova alternativa para a aprendizagem de Botânica. Revista Brasileira de Biociências, Porto Alegre, v. 13, n. 3, 2015.

DA SILVA, R. F.; CORREA, E. S. Novas tecnologias e educação: A evolução do processo de ensino e a aprendizagem na sociedade contemporânea. Educação \& linguagem. Num.1, p. 2335.mar/maio 2014.

ESTRELA, M. N.; VIANA, G. C. S.; SANTANA, J. C. S. O ensino de botânica de uma forma diferente a partir projeto "BOTÂNICA NA ESCOLA" da sala de ciências do SESC-PB. In. Congresso nacional de educação CONEDU. Pernambuco, 2017.

FORTUNA, T. R. Jogo em aula: recurso permite repensar as relações de ensino aprendizagem. 
Revista do Professor, Porto Alegre, v. 19, n. 75, p. 15-19, 2003.

MARTINS-DA-SILVA, R. C. V.; SILVA, A. S. L.; FERNANDES, M. M.; MARGALHO, L. F. Noções morfológicas e taxonômicas para identificação botânica. Embrapa, Brasília, DF, 2014.

MELO, E. A; ABREU, F.F; ANDRADE, A. B; ARAÚJO, M. I. O. A aprendizagem de botânica no ensino fundamental: Dificuldades e desafios. Revista SCIENTIA PLENA, Sergipe, Vol.8, Num.10, p. 1-8, 2012.

MELO, J. F. R. Desenvolvimento de atividades práticas experimentais no ensino de biologia - um estudo de caso. 75 f. Dissertação (Mestrado Profissional em Ensino de Ciências) - Universidade de Brasília, Brasília, 2010.

MOUL, R. A. T. M.; DA SILVA, F. C. L.. A construção de conceitos em botânica a partir de uma sequência didática interativa: proposições para o ensino de ciências. Revista Exitus. Santarém, Vol. 7, Num. 2, p. 262-282, Maio/Ago 2017.

NEVES, A. L. L. A.; SOUSA, G. M; ARRAIS, M. G. M. A produção de jogos didáticos de botânica como facilitadores do ensino de ciências na EJA. Revista da Associação Brasileira de Ensino de Biologia, São Paulo, v. 1, n. 7, p. 553-563, 2014.

NICOLA, Jéssica Anese; PANIZ, Catiane Mazocco. A importância da utilização de diferentes recursos didáticos no ensino de biologia. A InFor, Inovação e Formação, Revista do Núcleo de Educação a Distância da Universidade Estadual Paulista - NEaD/Unesp , São Paulo, v. 2, n. 1, p.355-381, 2016. ISSN 2525-3476.

PEDROSO, C. V. Jogos didáticos no ensino de biologia: uma proposta metodológica baseada em módulo didático. In. IX Congresso Estadual de Educação-EDUCERE; III Encontro Sul Brasileiro de Psicopedagogia. 2009.

RAVEN, Peter H.; EVERT, Ray F.; EICHHORN, Susan E. Biologia Vegetal. 7. ed. Rio de Janeiro: Guanabara Koogan, 2007.

ROCHA, D. F. da; RODRIGUES, M. da S. Jogo didático como facilitador para o ensino de BIOLOGIA no ensino médio. Revista cippus - Unilasalle,Canoas, RS, v. 8 n. 2 , novembro, 2018.

SALATINO, A. BUCKERIDGE, M. Mas de que te serve saber botânica. Instituto de Biociências, Universidade de São Paulo, São Paulo, 2016.

SANTANA, A. O. R.; CASASCO, E. F. C.; SESSA, P.. Modalidades didáticas no ensino de ciências: O olhar de estudantes da educação básica sobre o processo de aprendizagem. Revista da Associação Brasileira de Ensino de Biologia. [S.L.] Núm. 9. p. 841- 8512016.

SANTOS, E. A. V.; NETO, L. S. Dificuldades no ensino-aprendizagem de botânica e possíveis alternativas pelas abordagens de educação ambiental e sustentabilidade. [S.L.:S.N], 2017.

SILVA, J. N; GHILARDI-LOPES, N.P. Botânica no Ensino Fundamental: diagnósticos de 
AVELINO, et al

dificuldades no ensino e da percepção e representação da biodiversidade vegetal por estudantes. REEC: Revista electrónica de Enseñanza de las Ciencias, v. 13, n. 2, p. 115-136, 2014.

WOLSKI, B. Z D.; TOLOMEOTTI, K. R. B. Atividades lúdicas de aprender e brincar com as células. Cardenos PDE, Paraná, vol 1, 2013 


\title{
ANÁLISE DA ABORDAGEM SOBRE ÁREA DE FIGURAS PLANAS PROPOSTA PELA BASE NACIONAL COMUM CURRICULAR PARA O PROCESSO DE ENSINO E APRENDIZAGEM DA MATEMÁTICA NA EDUCAÇÃO BÁSICA
}

\section{ANÁLISIS DEL ENFOQUE DEL ÁREA DE FIGURAS PLANAS PROPUESTO POR EL CURRÍCULO NACIONAL COMÚN PARA EL PROCESO DE ENSEÑANZA Y APRENDIZAJE DE LAS MATEMÁTICAS EN LA EDUCACIÓN BÁSICA.}

\section{ANALYSIS OF THE APPROACH TO THE AREA OF FLAT FIGURES PROPOSED BY THE COMMON NATIONAL CURRICULUM FOR THE PROCESS OF TEACHING AND LEARNING MATHEMATICS IN BASIC EDUCATION}

\author{
Franklin Fernando Ferreira Pachêco ${ }^{1}$; Andreza Santana da Silva ${ }^{2}$; Alan Gustavo Ferreira ${ }^{3}$
}

DOI: https://doi.org/10.31692/978-65-991061-3-2.14-26

\section{RESUMO}

A presente pesquisa tem por objetivo geral analisar o tratamento da grandeza área proposta pela Base Nacional Comum Curricular para o processo de ensino e aprendizagem da Matemática na educação básica. Para isso, tomou-se como base a noção da conceitualização de área proposta por Régine Douady e Perrin-Glorian no qual discutem que para se construir o conceito de área é interessante que se articule os quadros geométricos, numéricos e das grandezas. Na busca de se alcançar o intuito central da presente pesquisa, em termos metodológicos, os resultados foram categorizados em dois momentos, sendo o primeiro prezando em quantificar o total de objetos de conhecimentos e habilidades que contemplam o conteúdo de área de figuras planas, enquanto no segundo momento analisamos se a ênfase resolutiva das habilidades se apoiam com maior preponderância no quadro geométrico ou numérico, ou ambos, para a abordagem do conteúdo de área ao longo da educação básica. Os resultados expressam que os objetos de conhecimentos e habilidades proposta pela Base Nacional Comum Curricular para o processo de ensino e aprendizagem na educação básica consideram com mais preponderância o quadro numérico para a exploração dos conteúdos de áreas de figuras planas. Verificamos, ainda, que os resultados apontam que a ênfase nas habilidades de conhecimentos para exploração do conceito área se respalda sob o olhar dos aspectos numéricos, por meio do processo de ladrilhamento e uso de fórmulas. A Base Nacional Comum Curricular destaca que os aspectos numéricos são essenciais para a compreensão do conhecimento da área, entretanto esperávamos que houvesse um maior tratamento geométrico para explorar situações de produções de superfícies, comparações de áreas relegando o aspecto numérico, etc, elementos que estão em segundo plano considerando todas as etapas da educação básica. Com o resultado desta investigação esperamos contribuir para a reflexão do pensamento crítico dos pesquisadores que investigam as grandezas geométricas, em especial, a área no sentido de olhar para o presente documento de orientação curricular e verificar todas as suas potencialidades e limitações que são ofertadas para o processo de ensino e aprendizagem na disciplina de Matemática.

Palavras-Chave: Base Nacional Comum Curricular, Área, Educação Básica, Matemática.

\section{RESUMEN}

\footnotetext{
1 Mestrando em Educação Matemática e Tecnológica, Universidade Federal de Pernambuco (UFPE), pacheco.franklin9@gmail.com

2 Mestranda em Educação Matemática e Tecnológica, Universidade Federal de Pernambuco (UFPE), andrezass19@hotmail.com

${ }^{3}$ Mestre em Educação em Ciências e Matemática, Professor de Matemática da Rede Estadual de Pernambuco e da Secretaria Municipal de Educação da cidade do Recife, alan.gustavo@hotmail.com
} 
Esta investigación tiene como objetivo analizar el tratamiento del área propuesta por la Common National Curriculum Base para el proceso de enseñanza y aprendizaje de las matemáticas en la educación básica. Para esto, se basó en la noción de conceptualización del área propuesta por Régine Douady y Perrin-Glorian en la que argumentan que para construir el concepto de área es interesante articular los marcos geométricos, numéricos y cuantitativos. Para lograr el objetivo principal de la presente investigación, en términos metodológicos, los resultados se clasificaron en dos momentos, el primero fue cuantificar el total de objetos de conocimiento y habilidades que contemplan el contenido del área de figuras planas, mientras que en el En segundo lugar, analizamos si el énfasis resolutivo de las habilidades se basa principalmente en el marco geométrico o numérico, o en ambos, para abordar el contenido del área a través de la educación básica. Los resultados expresan que los objetos de conocimiento y habilidades propuestos por la Common National Curriculum Base para el proceso de enseñanza y aprendizaje en educación básica consideran más predominantemente el marco numérico para la exploración de los contenidos de áreas de figuras planas. También verificamos que los resultados indican que el énfasis en las habilidades de conocimiento para explorar el área conceptual está respaldado por los aspectos numéricos, a través del proceso de mosaico y el uso de fórmulas. La National Common Curriculum Base enfatiza que los aspectos numéricos son esenciales para comprender el conocimiento del área, sin embargo, esperamos que haya un mayor tratamiento geométrico para explorar situaciones de producción de superficie, comparaciones de áreas que relegan el aspecto numérico, etc., elementos que están en antecedentes considerando todas las etapas de la educación básica. Con el resultado de esta investigación, esperamos contribuir a la reflexión del pensamiento crítico de los investigadores que investigan las cantidades geométricas, en particular, el área para ver el presente documento de orientación curricular y verificar todas sus potencialidades y limitaciones que se ofrecen al investigador. proceso de enseñanza y aprendizaje en la disciplina matemática.

Palabras Clave: Currículo Básico Nacional Común, Área, Educación Básica, Matemáticas.

\begin{abstract}
This research aims to analyze the treatment of the area proposed by the Common National Curriculum Base for the process of teaching and learning of mathematics in basic education. For this, it was based on the notion of the conceptualization of area proposed by Régine Douady and Perrin-Glorian in which they argue that in order to construct the concept of area it is interesting to articulate the geometrical, numerical and quantity frames. In order to achieve the main purpose of the present research, in methodological terms, the results were categorized in two moments, the first being to quantify the total of objects of knowledge and skills that contemplate the area content of flat figures, while in the Secondly, we analyze whether the resolutive emphasis of skills rests most heavily on the geometric or numerical framework, or both, for addressing area content throughout basic education. The results express that the objects of knowledge and skills proposed by the Common National Curriculum Base for the process of teaching and learning in basic education consider more predominantly the numerical framework for the exploration of the contents of areas of flat figures. We also verified that the results indicate that the emphasis on knowledge skills to explore the concept area is supported by the numerical aspects, through the tiling process and the use of formulas. The National Common Curriculum Base emphasizes that numerical aspects are essential for understanding the knowledge of the area, however we hoped that there would be a greater geometric treatment to explore situations of surface production, comparisons of areas relegating the numerical aspect, etc., elements that are in background considering all stages of basic education. With the result of this investigation we hope to contribute to the reflection of the critical thinking of the researchers that investigate the geometrical quantities, in particular, the area in order to look at the present curriculum guidance document and to verify all its potentialities and limitations that
\end{abstract}


are offered to the researcher. teaching and learning process in the Mathematics discipline. Keywords: Common National Base Curriculum, Area, Basic Education, Mathematics.

\section{INTRODUÇÃO}

O ser humano em sua interação social mobiliza conhecimentos matemáticos nas mais diversas situações cotidianas como, por exemplo, quantificar o total de pessoas que estão presentes ou ausentes em um determinado recinto, medir a distância em quilômetros de duas ou mais cidades, verificar o total de possibilidades de diversificação de roupas que há na cômoda, comparar os valores de dois ou mais produtos no mercado e saber qual possui o menor preço, ou ainda comprar uma mesa no formato retangular. Por esses e outros motivos a matemática é indispensável na formação do cidadão na educação básica, pois ela está em todos os lugares, isto é, tanto no âmbito educacional quanto no contexto social.

O ensino de matemática que se baseia no uso da vivência cotidiana conjuntamente com a matemática formal, proposto no currículo da matemática, está refletido também nos documentos de orientações curriculares a exemplo da Base Nacional Comum CurricularBNCC (BRASIL, 2018) no qual propõe que o professor faça a interligação entre objetos matemáticos, contextualizando com as visões de mundo que os alunos possuem a partir das vivências de situações presentes no cotidiano. Assim, podendo essas contribuir para uma maior compreensão da aplicabilidade desse conhecimento matemático estudado no contexto educacional.

A matemática por ser uma ciência que abrange diversos blocos de conhecimentos (álgebra, grandezas e medidas, números, geometria, e probabilidade e estatística), esta pesquisa frisa seu olhar sobre o bloco das grandezas e medidas pelo seu forte teor social, em especial no conteúdo de área que se encontra presente no decorrer das diversas etapas de escolaridades da educação básica.

O conceito de área está proposto nos documentos curriculares (PERNAMBUCO, 2012; BRASIL, 2018) para que seja iniciado a partir dos anos iniciais do ensino fundamental e que ao longo das etapas de escolaridade continue sendo sistematizado ganhando uma maior complexidade ao ser trabalhado de distintas maneiras. Por exemplo, comparar área de superfícies com ou sem a presença de fórmulas, entender que figuras planas diferentes possuem a mesma área, compreender que área e número, assim como área e superfície são objetos matemáticos distintos.

No que se refere a área, optou-se pela realização dessa temática, pois "diversas recomendações curriculares para o Ensino Fundamental, e também os livros didáticos, têm valorizado o ensino das grandezas e medidas, consideradas como um dos quatro campos em 
que são agrupados os conteúdos matemáticos a serem estudados” (LIMA; BELLEMAIN, 2010, p.167).

Com base nas discussões levantadas, acerca da relevância do conhecimento da matemática no âmbito social e educacional, a presente pesquisa tem por objetivo geral analisar o tratamento da grandeza área proposta pela Base Nacional Comum Curricular (BRASIL, 2018) para o processo de ensino e aprendizagem da Matemática na educação básica. Para isso, tomouse como base a noção da conceitualização de área proposta por Régine Douady e Perrin-Glorian (1989) no qual discutem que para se construir o conceito de área é interessante que se articule os quadros geométricos, numéricos e das grandezas.

Essa pesquisa, em termos metodológicos, por analisar a BNCC (BRASIL, 2018) respalda-se no conjunto de investigações que têm ênfase na abordagem documental. É válido destacar que o conceito de área foi verificado nas três etapas de escolaridades (anos iniciais e finais do ensino fundamental, e ensino médio) do documento de orientação curricular (BRASIL, 2018).

A escolha pela análise da BNCC (BRASIL, 2018) se configura pelo fato desse ser o texto mais recente e que norteia o conjunto de documentos curriculares, e suas propostas (objetivos educacionais) para o processo de ensino e aprendizagem já estarem sendo implementadas para os livros didáticos, e até usadas por professores na condução de suas aulas na educação básica. Por meio dessas considerações, acreditamos que seja relevante refletir sobre como está proposto o conteúdo de área na educação básica, sendo possível verificar se a ênfase proposta pela BNCC (BRASIL, 2018) para a construção desse conhecimento se respalda em sua maior totalidade em aspectos numéricos, relegando os aspectos geométricos e das grandezas.

Em outros termos, a presente pesquisa surge na intenção de situar ao professor e pesquisadores a reflexão de como se dá a abordagem da área na educação. Assim sendo, possibilitando a trabalhar de maneira diversificada, dentro do contexto proposto a ser ensinado, permitindo uma maior pluralidade na construção desse conhecimento matemático.

A seguir apresenta-se a fundamentação teórica, seguido pelos procedimentos metodológicos, análises dos resultados, considerações finais e referências bibliográficas.

\section{A GRANDEZA ÁREA: CONHECENDO A TEMÁTICA}

O conceito da área é bastante discutido no âmbito da Educação Matemática, tanto em território internacional como nacional. Pesquisas realizadas por Douady e Perrin-Glorian (1989), na comunidade francesa, por meio de uma engenharia didática, evidenciam que 
estudantes cometiam alguns erros quanto à essa conceitualização, entre eles:

\begin{abstract}
A superfície unitária sendo uma superfície com certa forma faz com que a possibilidade de medida de uma superfície dependa de S ser efetivamente ladrilhável com elementos daquela forma. Assim, os alunos encontram dificuldade para exprimir a área de um triângulo em $\mathrm{cm}^{2}$ (centímetros quadrados), dada a impossibilidade de cobri-lo com número finito de quadrados.

A área é ligada à superfície e não se dissocia de outras características dessa superfície; Se duas superfícies têm o mesmo perímetro, elas têm a mesma área.

Estende-se o uso de certas fórmulas a situações em que elas não são válidas: por exemplo, produto de duas "dimensões" para obter a área de um paralelogramo ou o produto das três "dimensões", no caso de um triângulo (p.394).
\end{abstract}

Esses erros, segundo as autoras, foram oriundos de duas concepções mobilizados pelos estudantes, denominadas de geométrica e numérica. A concepção geométrica se refere a não percepção dos alunos nas distinções entre a área e superfície. Alunos que se enquadram nessa categoria elucidam que a área está atrelada ao formato da superfície.

Na concepção numérica os alunos não conseguem diferenciar a área do número. Nesse tipo de situação, os alunos consideravam com mais ênfase os aspectos numéricos para o cálculo da área, desprezando outros atributos como a superfície, por exemplo. Apesar dos alunos terem desenvolvido ambas as concepções, não houve indícios de suas articulações, ou seja, mediante uma atividade os estudantes ora frisavam a concepção geométrica, ora a concepção numérica, ora ambas, mas não as articulavam (DOUADY; PERRIN-GLORIAN,1989).

Com base nas dificuldades apresentadas pelos estudantes, Douady e Perrin- Glorian (1989) salientam que para a construção do conceito da área é necessário a articulação entre os quadros geométrico, numérico e das grandezas, e não se deve desenvolvê-las de maneira isoladas, no qual propicia as concepções geométricas ou numéricas. Para essas autoras, o quadro geométrico é aquele em que contempla as superfícies planas (triângulos, quadriláteros e etc.); o quadro numérico é composto pelos números reais não negativos no qual representam as medidas de áreas, por exemplo, 20; 4,7; etc e o quadro das grandezas no qual se localiza a grandeza área evidenciando a relação de ter ou não a mesma área.

Pesquisas posteriores a de Douady e Perrin-Glorian (1989) como, por exemplo, a de Baltar (1996) realizada a partir de uma engenharia didática, em um contexto francês com estudantes, evidenciou que os mesmos erros ainda persistiam, ou seja, os participantes apresentavam as concepções geométrica e numérica, sem articulação entre elas.

Apesar dos resultados das pesquisas supracitadas terem sido semelhantes, cabe ressaltar que Baltar (1996) ao considerar os quadros geométrico, numérico e das grandezas para a construção do conceito da grandeza área, propôs um prolongamento do estudo de Douady e Perrin-Glorian (1989) propiciando três situações que dão sentido a essa temática, portanto, 
denominadas de comparação, medida e produção de superfícies, no qual entende-se que:

As situações de comparação se situam essencialmente em torno do quadro das grandezas. Quando comparamos duas superfícies somos conduzidos a decidir se elas pertencem ou não a uma mesma classe de equivalência. É claro que, com frequência, os quadros geométrico e numérico vão ser necessários para a resolução dos problemas de comparação, mas sua intervenção em geral é secundária com relação à do quadro das grandezas. Nas situações de medida, destacam-se o quadro numérico e a passagem da grandeza ao número por meio da escolha de uma unidade. $\mathrm{O}$ resultado esperado numa situação deste tipo é um número seguido de uma unidade. As situações de produção são diferentes das anteriores do ponto de vista da tarefa cognitiva do aluno. Enquanto nas situações de comparação e medida em geral há apenas uma resposta correta para cada situação, as situações de produção, frequentemente admitem várias respostas corretas. Além disso, apesar de a resposta esperada para uma situação de produção ser uma superfície (objeto geométrico), a intervenção dos outros quadros pode ser tão importante quanto a do quadro geométrico (BELLEMAIN; LIMA, 2002, p. 45).

Essas situações propostas por Baltar (1996) objetivou categorizar quais os possíveis procedimentos usados para resolver atividades que se enquadram em determinado quadro (geométrico, numérico ou das grandezas). Por exemplo, dada duas superfícies distintas quadriláteras (A) e (B), sendo (A) um quadrado e (B) um trapézio, menor que a superfície (A). Em uma determinada atividade que conceba essas superfícies, e não dê a informação que $\mathrm{A}$ > B, os participantes para obter a resolução podem usar a inclusão, sobreposição, decomposição ou recomposição das superfícies e identificar que os conhecimentos mobilizados se adequam com maior ênfase no quadro geométrico. Essa exemplificação pode ser verificada por meio das imagens anexadas no Quadro 1.

Quadro 1: Exemplificação de procedimentos geométricos

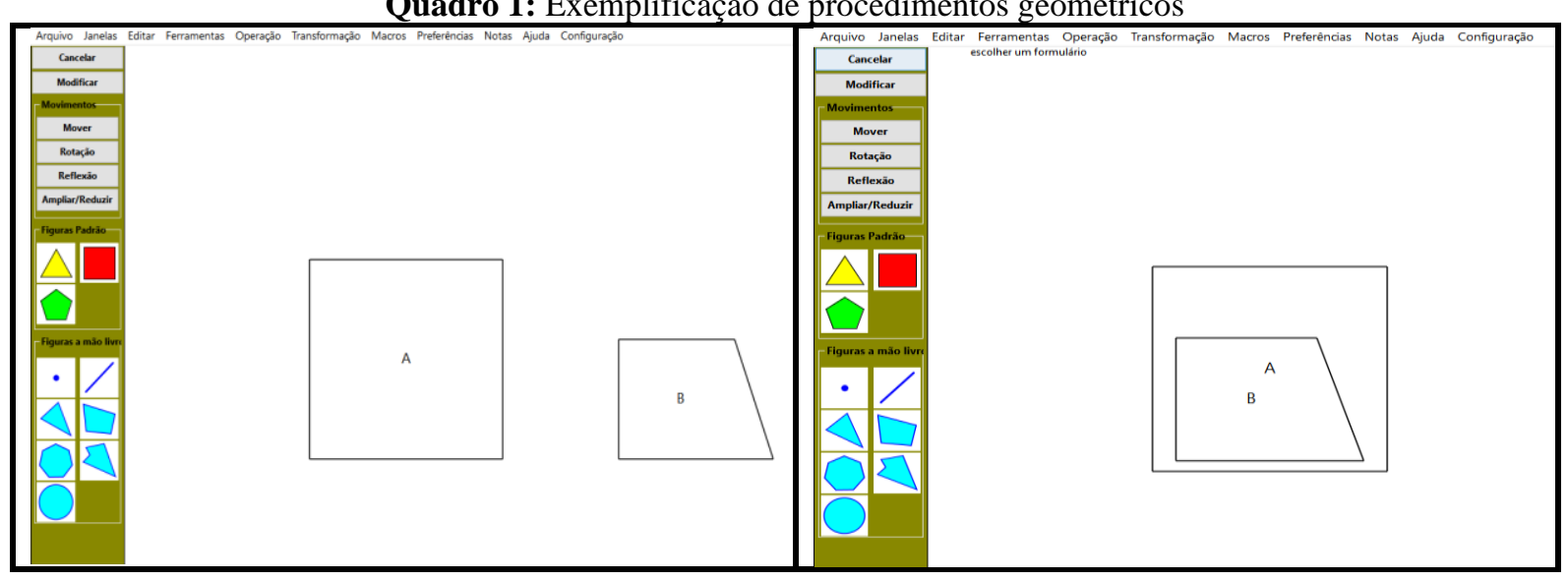

Fonte: Elaborado pelos autores no Apprenti Géomètre 2

A partir do estudo de Baltar (1996), a pesquisadora brasileira Ferreira (2010) incluiu no quadro numérico a situação denominada de mudança de unidade. Desse modo, as pesquisas no Brasil após esse estudo sobre a grandeza área se detiveram em investigar as quatros situações que dão sentido ao conceito de área (comparação, medida, mudança de unidade e produção de superfícies), como se pode perceber nas pesquisas em Santos (2015) e Silva (2016). 
O estudo de Santos (2015) analisou o distanciamento da prática pedagógica do professor de matemática e a abordagem do LD usado por ele no $6^{\circ}$ ano do ensino fundamental com relação ao conteúdo de áreas de figuras planas, sob a ótica da Teoria Antropológica do Didático (TAD) e do conceito da grandeza área de Douady e Perrin-Glorian (1989). Embora o estudo aponte para algumas convergências sobre a relação da prática do professor com o LD, há a ocorrência da distinção, ou seja, do distanciamento como no tipo de tarefa, abordagem do conteúdo no qual o LD explana de uma maneira e o docente segue outro raciocínio, por exemplo.

Silva (2016) investigou como 12 alunos do $6^{\circ}$ ano do ensino fundamental construíram o conceito da grandeza área em três ambientes distintos (papel e lápis, materiais manipuláveis e Apprenti Géomètre 2). Foi perceptível que apesar do trabalho ter sido em distintos ambientes alguns alunos ainda concebiam as concepções geométrica ou numérica, algo que foi ressaltado por Douady e Perrin-Glorian (1989) e Baltar (1996) na comunidade francesa.

É interessante refletir que as pesquisas, mesmos sendo em contexto sociocultural distintos, assim como em épocas, apresentam resultados parecidos. Dessa forma, embora seja uma área muito estudada, a grandeza área abre um leque de possibilidades para investigá-la, pois existem variadas teorias da Didática da Matemática francesa que propiciam estudos sobre essa temática contribuindo para o contexto educacional desse campo de conhecimento.

\section{METODOLOGIA}

A presente pesquisa se propôs a analisar a abordagem da proposta de área nas unidades temáticas da Base Nacional Comum Curricular (BRASIL, 2018) referente à disciplina de Matemática com o intuito de vislumbrar quais os aspectos (geométrico, numérico e das grandezas) estão presentes na construção desse saber.

Esse texto ao adotar um documento para análise, como já descrito na parte introdutória, foi definida como uma pesquisa de abordagem documental. A opção por trabalhar com a BNCC (BRASIL, 2018) se trata por ser o documento de orientação curricular mais recente do Brasil e por seu texto ser concebido como um aporte para a condução do processo de ensino e aprendizagem.

Para se alcançar o intuito central da presente pesquisa, os resultados foram categorizados em dois momentos, sendo eles: primeiramente quantificou-se o total de objetos de conhecimentos que contemplam o conteúdo de área de figuras planas.

Analisou-se no segundo momento se as habilidades da BNCC (BRASIL, 2018) se apoiam com mais ênfase em aspectos resolutivos relacionados aos quadros geométricos ou numéricos, ou ambos, para a abordagem do conteúdo de área ao longo da educação básica. 
Para a análise dos objetos de conhecimentos e habilidades da BNCC (BRASIL, 2018) que se adequam a presente pesquisa consideramos apenas aquelas que possuíam o nome área e que estavam presentes nas unidades temáticas relacionadas à disciplina de Matemática.

Cabe destacar, ainda, que relegamos aquelas que faziam alusão a área em sentido polissémico, ou seja, enfatizavam a área sem ser o objeto investigativo. Por exemplo, temos “Analisar dados apresentados em tabelas simples ou de dupla entrada e em gráficos de colunas ou pictóricos, com base em informações das diferentes áreas do conhecimento, e produzir texto com a síntese de sua análise" (BRASIL, 2018, p.293). Pode-se verificar que a mesma contempla o nome área, mas não ao objeto matemático, e sim a sentido polissémico referindo-se a diversos campos de conhecimentos.

Cabe ressaltar que os dados coletados foram analisados e expostos na mesma ordem descrita nessa seção.

\section{RESULTADOS E DISCUSSÃO}

Os resultados dessa pesquisa estão definidos por meio de dois momentos, como descrito nos procedimentos metodológicos.

Esse documento de orientação curricular, assim como Pernambuco (2012) destacam que o conceito de área seja iniciado a partir do $3^{\circ}$ ano do ensino fundamental. Nos anos posteriores, esse conhecimento ganha um maior contexto ao ser trabalhado por meio de vivências cotidianas, aos outros conteúdos da própria Matemática, e aos variados campos do saber a exemplo da Geografia, Física, etc. Essa diversificação de trabalho para um mesmo conhecimento permite explorar e reafirmar que os conteúdos da disciplina de Matemática são essenciais para a construção da formação do cidadão na educação básica.

A partir das primeiras considerações sobre o objeto investigativo (área de figuras planas), a primeira categorização se deteve em apresentar o quantitativo de objetos de conhecimento e habilidades disposta nas unidades temáticas pelo documento de orientação curricular, BNCC (BRASIL, 2018), que norteiam a proposta para o processo de ensino e da aprendizagem. Para sintetizar esses dados, expomos a Tabela 1.

Tabela 1: Quantidade de objetos de conhecimentos e habilidades sobre área na BNCC 


\begin{tabular}{c|c|c|c|c|c|c|c|c|c|c|c|c}
\hline Ano de escolaridade & $\mathbf{1}$ & $\mathbf{2}$ & $\mathbf{3}$ & $\mathbf{4}$ & $\mathbf{5}$ & $\mathbf{6}$ & $\mathbf{7}$ & $\mathbf{8}$ & $\mathbf{9}$ & $\mathbf{1 0}$ & $\mathbf{1 1}$ & $\mathbf{1 2}$ \\
\hline $\begin{array}{c}\text { Quantitativo de } \\
\text { objetos de } \\
\text { conhecimentos }\end{array}$ & 0 & 0 & 1 & 1 & 2 & 1 & 1 & 2 & - & - & - & - \\
\hline $\begin{array}{c}\text { Quantitativo de } \\
\text { habilidades }\end{array}$ & 0 & 0 & 1 & 1 & 2 & 2 & 2 & 1 & 1 & \multicolumn{3}{|c}{5} \\
\hline
\end{tabular}

Fonte: Dados da pesquisa (2019)

Como expresso na Tabela 1, verifica-se que o presente conteúdo transita durante todas as etapas de escolaridade da educação básica. Apesar dessa realidade, nos dois primeiros anos do ensino fundamental não há exploração do conteúdo de área.

Pode-se observar a partir da Tabela 1 que os objetos de conhecimentos matemáticos estão ausentes em alguns anos escolares $\left(9^{\circ}, 10^{\circ}, 11^{\circ}\right.$ e $12^{\circ}$ anos $)$, apresentando-se apenas habilidades educacionais para serem exploradas no processo de ensino e da aprendizagem. Isso nos permite compreender que à ausência dos objetos de conhecimentos contribuam para um possível não tratamento de maneira clara do que deve ser enfatizado pelo professor no ambiente da sala de aula, visto que nas etapas de escolaridades anteriores sua presença norteia as habilidades de conhecimentos a serem exploradas e alcançadas no ambiente da sala de aula.

Cabe ressaltar que para a identificação dos objetos de conhecimentos e habilidades que se fazem presente na BNCC foram consideramos todos os blocos de conhecimentos da Matemática. Com isso, verificamos que no $9^{\circ}$ ano do ensino fundamental a abordagem do conteúdo de área de figuras planas é explorada por meio da unidade temática da Geometria, enquanto nos demais anos de escolaridade do ensino fundamental sua presença é mediada na unidade temática das Grandezas e Medidas. Já no ensino médio, sua presença se deu por meio da unidade temática Geometria e Medidas (BRASIL, 2018).

Confrontando os quantitativos das habilidades de conhecimentos sobre o conteúdo de área da BNCC (BRASIL, 2018), expressos na Tabela 1, acerca do que discuti Douady e Perrin Glorian (1989) sobre os quadros geométricos e numéricos temos o Gráfico 1. 


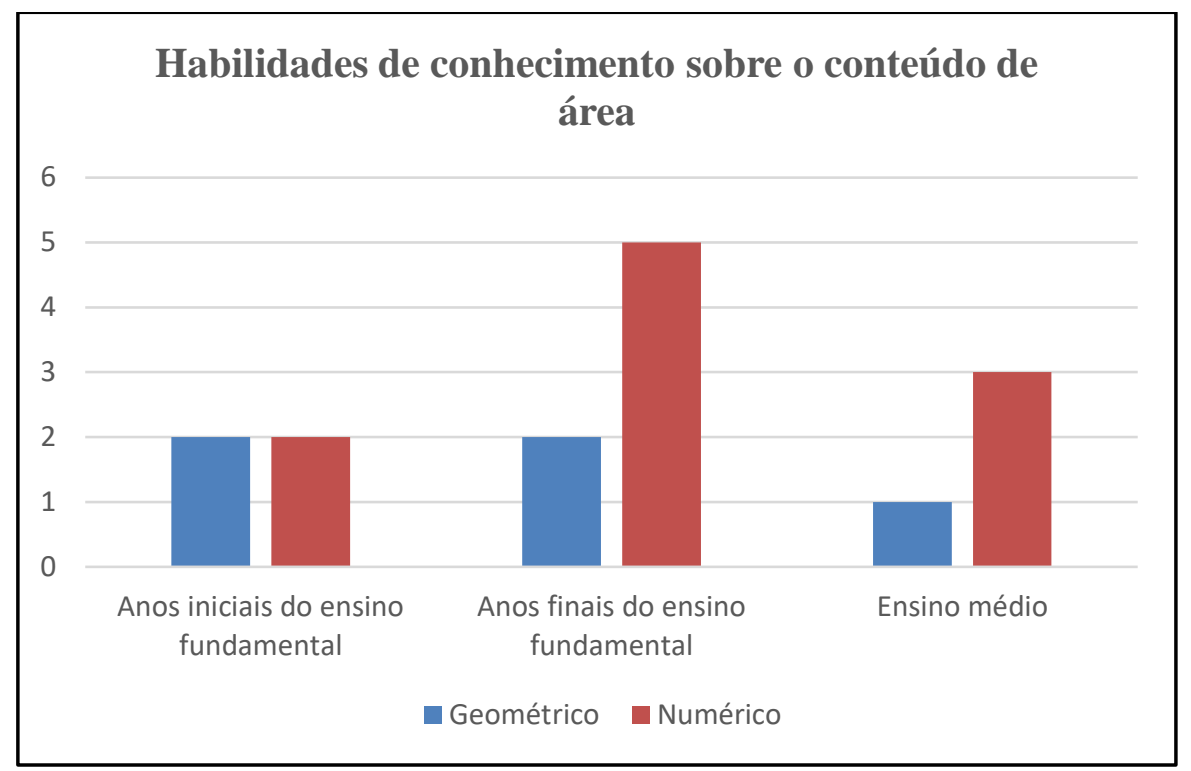

Fonte: Dados da pesquisa (2019)

Os resultados do Gráfico 1 expressam que as habilidades propostas pela BNCC (BRASIL, 2018) consideram com mais ênfase o quadro numérico para a exploração dos conteúdos de áreas de figuras planas. Nos anos iniciais do ensino fundamental existem de maneira igualitária a presença dos quadros geométrico e numérico.

Nas outras etapas de escolaridades (anos finais do ensino fundamental e ensino médio), o quadro numérico se sobressai em relação ao geométrico. Predominando-se o uso de estratégias numéricas para resolver atividades, seja por meio de fórmulas ou ladrilhamento. No ensino médio, por exemplo, cabe destacar que as habilidades estão agrupadas para sua vivência ao longo dos três anos de escolaridade. Embora a presença de superfícies permaneça nas descrições de algumas habilidades verifica-se que as estratégias numéricas são sua ênfase. Para destacar a presente descrição, temos a seguinte habilidade "Propor ou participar de ações adequadas às demandas da região, preferencialmente para sua comunidade, envolvendo medições e cálculos de perímetro, de área, de volume, de capacidade ou de massa" (BRASIL, 2018, p.545).

Apesar do quadro numérico ser relevante para a compreensão de área enquanto grandeza, segundo Douady e Perrin- Glorian (1989), destacamos que o seu uso excessivo, sem articulação com os quadros geométricos e das grandezas, pode ocasionar que a compreensão de área seja explanada apenas por meio do uso de fórmulas, perdendo, nesse sentido a noção da grandeza.

É válido ressaltar que nem sempre é possível mobilizar em uma mesma atividade os quadros geométricos e numéricos, por isso alguns livros didáticos e propostas de orientações curriculares destacam em maior amplitude o trabalho com os aspectos numéricos relacionados 
a área por conceber uma estratégia mais econômica na obtenção de resultados, mediados por meio do uso de fórmulas.

De modo a sintetizar a ênfase das estratégias resolutivas das habilidades de conhecimentos para a exploração do conteúdo de área na Educação Básica temos o Gráfico 2.

Gráfico 2: As habilidades de conhecimentos analisadas sob o olhar dos aspectos geométricos e numéricos

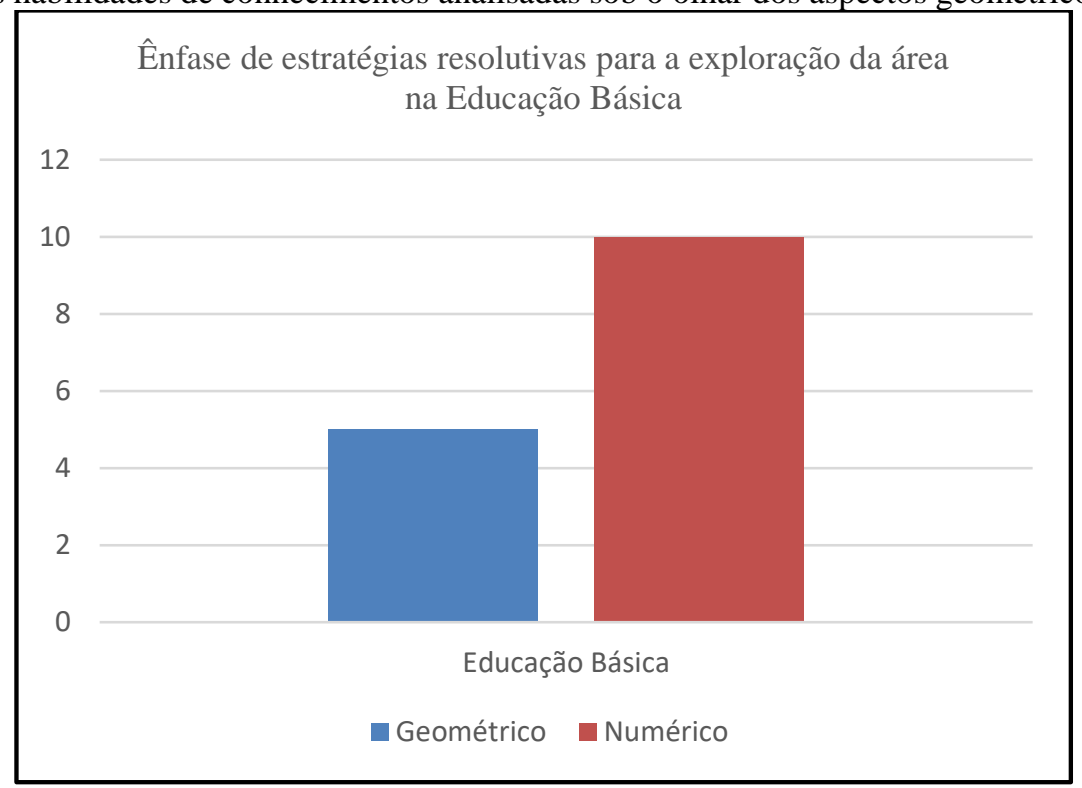

Fonte: Dados da pesquisa (2019)

Os resultados do Gráfico 2 destacam a predominância dos aspectos numéricos para a explanação acerca do conteúdo de área de figuras planas na educação básica.

Por meio dos resultados discutidos ressaltamos que embora a BNCC (BRASIL, 2018) explore com mais ênfase habilidades de conhecimentos sob o olhar dos aspectos numéricos, destacamos que o professor pode explorar outras situações que levem seus alunos a refletirem sobre a importância dos outros quadros (geométricos e das grandezas) de Douady e Perrin Glorian (1989) para o favorecimento da abordagem de área.

É interessante destacar que a BNCC (BRASIL, 2018) é o documento que norteia de maneira nacional a base, e não o teto da educação básica. Em outras palavras, cabe enfatizar que os objetos de conhecimentos e habilidades sobre área na BNCC é o mínimo em comum para se estudar nas escolas das diversas cidades do Brasil.

\section{CONCLUSÕES}

Essa pesquisa ao analisar a BNCC (BRASIL, 2018) teve o interesse de compreender qual a ênfase proposta para exploração do conteúdo de áreas de figuras planas para o processo de ensino e aprendizagem da Matemática na educação básica no ambiente da sala de aula.

Um dos fatores que valem ser ressaltado se trata que os procedimentos dos aspectos 
numéricos para o uso da fórmula e ladrilhamento se sobressaem em comparação aos geométricos (decomposição, recomposição, inclusão, sobreposição, etc). Por ser o documento mais recente que direciona para o processo de ensino e da aprendizagem na Matemática, e outros campos de conhecimentos, essa pesquisa se deteve a analisar a BNCC (BRASIL, 2018) com o interesse de fazer os profissionais da educação compreenderem e refletirem sobre como se dá a abordagem da área na educação básica.

Com o produto/ resultado dessa pesquisa pretendemos contribuir para que o leitor desse texto perceba que se o processo de ensino e aprendizagem já se torna pré-determinado, em muitos casos já definidos, ele assume uma limitação do ponto de vista cognitivo porque os alunos só irão aprender aquilo que está sendo proposto a ser vivenciado. Para que haja uma quebra dessa realidade, o professor deve diversificar sua configuração didática e explorar por meio de outros olhares, com o auxílio dos objetos de conhecimentos e habilidades que está sendo proposto pelos documentos norteadores, a fim de ir além e estimular um processo de ensino menos concentrado no que já está pré-destinado.

Concordamos com a BNCC (BRASIL, 2018) que os aspectos numéricos são essenciais para a compreensão do conhecimento da área, entretanto esperávamos que houvesse um maior tratamento geométrico para explorar situações de produções de superfícies, comparações de áreas relegando aspecto numérico, etc, elementos que estão em segundo plano considerado todas as etapas da educação básica.

Com este estudo, esperamos contribuir para a reflexão do pensamento crítico dos pesquisadores que investigam as grandezas geométricas, em especial, a área no sentido de olhar para a BNCC (BRASIL, 2018) e verificar todas as suas potencialidades e limitações que são ofertadas para o processo de ensino e aprendizagem na disciplina de Matemática.

Ansiamos que nossa ideia abra um leque de possibilidade a mais para o trabalho sobre a temática retratada (grandeza área). Nessa perspectiva, desejamos que essa pesquisa contribua para ampliar as discussões e visões sobre como se trabalhar e entender a grandeza área na perspectiva de olhares distintos.

\section{REFERÊNCIAS}

BALTAR, P. M. Enseignement et apprentissage de la notion d'aire de surfaces planes: une étude de l'acquisition des relations entre les longuers et les aires au collège. 1996. Tese (Doutorado em Didática da Matemática), Université Joseph Fourier, Grenoble, França, 1996.

BELLEMAIN, P.; LIMA, P. Um estudo da noção de grandeza e implicações no Ensino Fundamental. Ed. Geral: John A. Fossa. Natal: SBHMat, 2002. 
BRASIL, S. E. F. Base Nacional Curricular Comum- BNCC. Brasília, 2018, p.600.

DOUADY, R.; PERRIN-GLORIAN, M. J. Un processus d'apprentissage du concept d'aire de surface plane. Educational Studies in Mathematics.v.20, n.4, p. 387-424, 1989.

FERREIRA, L. F. D. A construção do conceito de área e da relação entre área e perímetro no $3^{\circ}$ ciclo do ensino fundamental: estudos sob a ótica da teoria dos campos conceituais. 2010. 191f. Dissertação (Mestrado em Educação). Centro de Educação, Universidade Federal de Pernambuco, 2010. Recife, Disponível em: https://repositorio.ufpe.br/bitstream/123456789/3972/1/arquivo206_1.pdf > acessado em 09/10/2019.

PERNAMBUCO, S. Currículo de Matemática para o Ensino Fundamental com base nos Parâmetros Curriculares do Estado de Pernambuco, Recife, SEDUC-PE, 2012.

SANTOS, M. R. A Transposição Didática do conceito de área de figuras geométricas planas no $6^{\circ}$ ano do ensino fundamental: um olhar sob a ótica da Teoria Antropológica do Didático. 2015. 281 f. Tese (Doutorado em Ensino das Ciências e Matemática) - Universidade Federal Rural de Pernambuco, Recife, 2015. Disponível em: <http://www.tede2.ufrpe.br:8080/tede/bitstream/tede2/5375/2/Marilene\%20Rosa\%20dos\%20 Santos.pdf> acesso em: 07/10/2019.

SILVA, A. D. P. R. Ensino e Aprendizagem de Área Como Grandeza Geométrica: um estudo por meio dos ambientes papel e lápis, materiais manipulativos e no Apprenti Géomètre 2 no $6^{\circ}$ ano do ensino fundamental. 2016. 317 f. Dissertação (Educação Matemática e Tecnológica). Universidade Federal de Pernambuco, Centro de Educação. Recife, 2016. Disponível em: < https://repositorio.ufpe.br/handle/123456789/17427> acesso em 12/10/2019. 


\title{
EDUCAÇÃO AMBIENTAL EM UMA ESCOLA DO ENTORNO DA RPPN FAZENDA ALMAS: VIVÊNCIAS INTEGRADORAS COM DISCENTES NO CARIRI PARAIBANO.
}

\author{
EDUCACIÓN AMBIENTAL EN UNA ESCUELA ALREDEDOR DE RPPN \\ FAZENDA ALMAS: EXPERIENCIAS INTEGRATIVAS CON ESTUDIANTES EN \\ CARIRI PARAIBANO.
}
ENVIRONMENTAL EDUCATION IN A SCHOOL AROUND RPPN FAZENDA ALMAS: INTEGRATIVE EXPERIENCES WITH STUDENTES IN CARIRI PARAIBANO.

\author{
Karoline Maria da Silva Soares ${ }^{1}$; Myller Gomes Machado²; Francisco José Pegado Abílio ${ }^{3}$
}

DOI: $\underline{\text { https://doi.org/10.31692/978-65-991061-3-2.27-45 }}$

\begin{abstract}
RESUMO
A caatinga ocupa cerca de $10 \%$ de todo território brasileiro e é um dos biomas que mais sofre com a ação antrópica. Diante desse cenário surge a importância de trabalhar com a Educação Ambiental (EA) nessa região não apenas para alertar sobre os impactos ambientais que ocorrem na ocorridos, mas também sensibilizar os cidadãos sobre sua convivência com o meio ambiente. Sendo assim, o objetivo dessa pesquisa foi de desvelar para os discentes das escolas do entorno da RPPN Fazenda Almas a efetivação de uma educação ambiental contextualizada para o bioma Caatinga. A metodologia tratou-se de uma pesquisa de natureza aplicada de abordagem qualitativa, utilizando procedimentos técnicos da pesquisa do participante e elementos da teoria do biorregionalismo. O trabalho ocorreu com alunos da EEEFM Bartolomeu Maracajá, no município de São José dos Cordeiros-PB. Para análise da percepção dos discentes foram utilizados questionários estruturados pré e pós-teste onde os alunos foram submetidos a questões ambientais. Quando questionados sobre "o que vem a ser meio ambiente" houve categorias que mais se sobressaíram, no pré-teste $42 \%$ dos alunos possuíam uma visão "generalista", já no pós-teste essa porcentagem caiu para 14\% seguido de "como recurso" expressando-se $25 \%$ no pré-teste e $18 \%$ no pós-teste. Quando questionados sobre "o que vem a ser natureza" 35\% dos alunos possuem uma visão "generalista", aparecendo apenas no préteste, já no pós-teste a nova categoria que surgiu e que mais sobressaiu foi "como ecossistema". Quando questionados sobre "o que vem a ser EA" $40 \%$ dos discentes responderam no pré-teste que é uma "disciplina curricular", já no pós-teste expressou-se uma nova categoria com $40 \%$ da educação ambiental como sendo "crítica". Quando questionados sobre "quais os impactos ambiental ocorridos na região" $60 \%$ dos discentes no pré-teste associaram as "queimadas" e no pós-teste $45 \%$ associaram aos agrotóxicos, sendo um tema bastante trabalhado nas vivências. Quando questionados sobre a RPPN Fazenda Almas 30\% dos discentes já visitaram o local, $60 \%$ dos discentes nunca visitaram e $20 \%$ nunca ouviram falar. As ações realizadas na escola foi bastante importante para que os discentes pudessem conhecer algumas questões ambientais, bem como conhecer o patrimônio da RPPN Fazenda Almas.
\end{abstract}

Palavras-Chave: Educação ambienta. Caatinga. Natureza. Meio ambiente.

\footnotetext{
${ }^{1}$ Graduanda em Ciências Biológicas UFPB - CCEN, e-mail : karol_.soares@ hotmail.com

${ }^{2}$ Graduação em Ciências Biológicas UFPB - CCEN Mestrado em Desenvolvimento e Meio Ambiente (PRODEMA-UFPB); Doutorando em Educação - PPGE/UFPB; Professor do Instituto Federal da Paraíba (IFPB). e-mail: myller.machado@ifpb.edu.br

${ }^{3}$ Professor Dr. Titular, Universidade Federal da Paraíba - CE/DME, e-mail: chicopegado@yahoo.com.br
} 


\section{RESUMEN}

La caatinga ocupa aproximadamente el $10 \%$ de todo el territorio brasileño y es uno de los biomas que más sufre de acción antrópica. Dado este escenario, surge la importancia de trabajar con Educación Ambiental (EA) en esta región no solo para advertir sobre los impactos ambientales que ocurren en el lugar, sino también para sensibilizar a los ciudadanos sobre su coexistencia con el medio ambiente. Por lo tanto, el objetivo de esta investigación fue revelar a los estudiantes de las escuelas alrededor de RPPN Fazenda Almas la realización de una educación ambiental contextualizada para el bioma Caatinga. La metodología fue una investigación de naturaleza aplicada del enfoque cualitativo, utilizando procedimientos técnicos de la investigación participante y elementos de la teoría del bioregionalismo. El trabajo se realizó con estudiantes de EEEFM Bartolomeu Maracajá, en el municipio de São José dos Cordeiros-PB. Para analizar la percepción de los estudiantes, se utilizaron cuestionarios estructurados previos y posteriores a la prueba, donde los estudiantes fueron sometidos a preguntas ambientales. Cuando se les preguntó sobre "qué es el medio ambiente", hubo categorías que se destacaron, en la prueba previa el $42 \%$ de los estudiantes tenía una visión "generalista", mientras que en la prueba posterior este porcentaje se redujo al $14 \%$ seguido de "como recurso". "Expresando el $25 \%$ en la prueba previa y el $18 \%$ en la prueba posterior. Cuando se les preguntó sobre "qué es la naturaleza", el 35\% de los estudiantes tiene una visión "generalista", que aparece solo en la prueba previa y en la prueba posterior, la nueva categoría que surgió y que se destacó fue "como un ecosistema". Cuando se les preguntó sobre "lo que pasa a ser EA", el $40 \%$ de los estudiantes respondió en la prueba previa que es una "disciplina curricular", mientras que en la prueba posterior se expresó una nueva categoría con el $40 \%$ de la educación ambiental como "crítica". Cuando se les preguntó sobre "qué impactos ambientales ocurrieron en la región", el $60 \%$ de los estudiantes en la prueba previa asociaron las "quemaduras" y en la prueba posterior el $45 \%$ asociado con los pesticidas, siendo un tema que fue muy trabajado en las experiencias. Cuando se les preguntó acerca de RPPN Fazenda Almas, el $30 \%$ de los estudiantes ya han visitado el sitio, el $60 \%$ de los estudiantes nunca lo han visitado y el $20 \%$ nunca han oído hablar de él. Las acciones llevadas a cabo en la escuela fueron muy importantes para que los estudiantes pudieran conocer algunos problemas ambientales, así como conocer el patrimonio de RPPN Fazenda Almas.

Palabras Clave: Educación Ambiental. Caatinga. Naturaleza. Medio Ambiente.

\section{ABSTRACT}

Caatinga occupies about $10 \%$ of all Brazilian territory and is one of the biomes that suffer most from anthropic action. Given this scenario emerges the importance of working with Environmental Education (EA) in this region not only to warn about the environmental impacts that occur in the occurred, but also sensitize citizens about their coexistence with the environment. Thus, the purpose of this research was to unveil to the students of the schools around RPPN Fazenda Almas the realization of a contextualized environmental education for the Caatinga biome. The methodology was a research of applied nature of qualitative approach, using technical procedures of the participant research and elements of the theory of bioregionalism. The work took place with students from EEEFM Bartolomeu Maracajá, in São José dos Cordeiros-PB. There were a total of ten pedagogical experiences that took place both in the classroom, with various didactic means, as well as environmental studies at Fazenda Almas. To analyze the students' perception, pre and post-test structured questionnaires were used, where students were submitted to environmental questions. When asked about "what is the environment" there were categories that stood out, in the pretest $42 \%$ of students had a "generalist" view, while in the posttest this percentage dropped to $14 \%$ followed by "as a resource". "Expressing 25\% in the pretest and $18 \%$ in the posttest. When asked about "what 
comes to be nature" $35 \%$ of students have a "generalist" view, appearing only in the pretest, no longer posttest in a new category that emerged and the most prominent was "as an ecosystem". When asked about "what comes to be environmental education", $40 \%$ of the students answered in the pretest that it is a "curricular discipline", no longer in the posttest was expressed a new category with $40 \%$ of EE as "Critical". When asked about "what are the environmental impacts that occurred in the region" $60 \%$ of students did not associate pre-test as "burned" and not posttest $45 \%$ associated with pesticides, being a subject very worked in the experiences. When asked about RPPN Fazenda Almas, $30 \%$ of the students are already qualified in the place, $60 \%$ of the students never heard and 20\% never heard. As the actions performed at the school were important for those who discuss knowing some environmental issues, as well as knowing the heritage of RPPN Fazenda Almas.

Keywords: Environmental education. Caatinga, nature, environment.

\section{INTRODUÇÃO}

A Caatinga cobre quase $11 \%$ do território nacional $\left(844.453 \mathrm{Km}^{2}\right)$, e abriga cerca de 25 milhões de pessoas sendo então, considerada uma das regiões mais populosas do mundo. Todavia, $80 \%$ de seus ecossistemas originais já foram alterados, principalmente por desmatamentos e queimadas. Além do mais, $62 \%$ das áreas susceptíveis à desertificação estão em zonas originalmente ocupadas por Caatinga e apenas 1,5\% do bioma está abrangido por Unidades de proteção, assumindo a posição de bioma brasileiro menos protegido (BRASIL, 2018a).

O efeito combinado entre as condições climáticas próprias da região Semiárida paraibana e as práticas inadequadas de uso e aproveitamento do solo e demais recursos naturais além de acentuar o desgaste da paisagem natural, levando a perda da biodiversidade e esgotamento de recursos naturais, tem disseminado o processo de desertificação nas áreas susceptíveis, no entanto, buscar a Conservação pela gestão não é algo facilmente executável, principalmente quando as propostas de intervenção apresentadas se contrapõem aos padrões comportamentais da comunidade (GADOTTI, 2000).

Além de enfrentar esses desafios, o Cariri paraibano apresenta ainda um quadro de atraso econômico e social muito grave, assim como uma destruição desenfreada do bioma Caatinga, determinada pela estagnação ou declínio das atividades produtivas tradicionais (ABÍLIO; FLORENTINO; RUFFO, 2010), como também uma perceptível e preocupante falta de políticas públicas para a conservação deste bioma, como a implantação de projetos (e seu desenvolvimento) relacionados à Educação Ambiental (EA), o conjunto de todos os fatores citados leva a destruição desenfreada e assim aumenta o processo de desertificação (ou de áreas susceptíveis) que já se alastra por grande parte da Caatinga, com ênfase maior no estado da Paraíba.

Neste sentido, a escola tem papel fundamental e privilegiado para debater as questões 
ambientais e assim criar possibilidades para um processo de ensino-aprendizagem relacionado a elementos da política, sociedade, ética, moral, dentro outros, buscando a formação de cidadãos críticos e reflexivos.

Então nada mais adequado que buscarmos o desenvolvimento da cidadania e formação de uma racionalidade ambiental dentro das escolas. Evidenciando assim a importância dos professores no processo de ensino e aprender, sendo a escola o local mais adequado para a realização de um ensino ativo e participativo, buscando o conhecimento e a importância da Biodiversidade do Bioma Caatinga, para manutenção da vida das populações do Cariri paraibano.

Portanto este trabalho teve como desvelar princípios teórico-metodológicos para a efetivação de uma educação ambiental contextualizada para o bioma Caatinga em uma escola do entorno da RPPN Fazenda Almas.

\section{FUNDAMENTAÇÃO TEÓRICA}

A região Semiárida brasileira abrange aproximadamente 18,2\% da área do país. Já o Nordeste apresenta $86,48 \%$ de seu território na porção Semiárida. O Rio Grande do Norte lidera a lista com 93,4\% do território Semiárido. Depois, vem Pernambuco com 88\%, seguido do Ceará e Paraíba com 86\%. Nos demais estados, também há uma predominância do Semiárido: 69,7\% da Bahia, 59,9\% do Piauí, 50,9\% do Sergipe e 45,6\% de Alagoas. Contabilizando uma extensão territorial de $980.133,079 \mathrm{Km}^{2}$ com a presença de 1.135 municípios. Relacionado à população, é aproximadamente $12 \%$ da população brasileira que vive no Semiárido, o que representa 22.598 .318 habitantes, sendo $42,57 \%$ da população nordestina. Equiparando as populações das regiões Norte e Centro-Oeste com a da região Semiárida, observa-se que esta última supera facilmente as dessas regiões e é apenas $17,48 \%$ menor do que a população residente na região Sul. Portanto, percebe-se claramente a grandeza numérica que representa a população residente no Semiárido brasileiro. Vale ressaltar que esta área foi demarcada diversas vezes ao longo dos últimos 75 anos (MEDEIROS et al., 2012; ASA, 2018; CIRILO, et al., 2007).

Já atualmente, do ponto de vista socioeconômico, o Semiárido é o espaço do Brasil onde é manifestado mais intensamente o fosso que separa a base econômica do crescimento demográfico. A economia vai, muitas vezes, de atividades tradicionais de produtividade a industriais e agroindustriais. Para a maioria da população, o tipo de economia é vulnerável ao fenômeno das estiagens (MACAMBIRA, 2006). Qualquer desequilíbrio na distribuição das chuvas, que não possibilite a criação de animais e a produção agrícola, cria caos na economia 
loco-regional.

A economia atual está interligada com as propriedades dos territórios, uma vez que como afirma Santos, Schistek e Oberhofer (2007), a realidade da situação fundaria, na qual a absoluta maioria das propriedades é constituída de hectares totalmente insuficientes ao necessário para ter uma produção estável é uma consequência direta do modelo da ocupação do Semiárido brasileiro.

Este processo histórico reflete no que temos hoje, a concentração dos territórios para poucas pessoas, como afirma a Articulação no Semiárido (ASA) (2018) o Semiárido é um espaço com grande concentração de terra, da água e dos meios de comunicação, que historicamente sempre estiveram nas mãos de uma pequena elite. Essa situação gera níveis altíssimos de exclusão social e de degradação ambiental e são fatores determinantes da crise socioambiental e econômica vivida na região. Sobre a divisão das terras propícias à agricultura na região, os dados são os seguintes: cerca de 1,5 milhão de famílias agricultoras $(28,82 \%$ de toda a agricultura familiar brasileira) ocupam apenas 4,2\% das terras agricultáveis do Semiárido. Ao passo que 1,3\% dos estabelecimentos rurais com mais de 1 mil hectares, conhecidos como latifúndios, detêm $38 \%$ das terras.

Nesta conjuntura, Vilar Filho (2018) elenca alguns fatores que contribuem para as problemáticas da seca: as iniciativas governamentais que só ocorrem durante as estiagens severas, ou seja, sem continuidade; o desenvolvimento de políticas públicas com uma visão hidraulicista, que a água é a solução para todos os problemas; as iniciativas verticais dos governos, como pouca participação efetiva do povo; a não existência de planos assíduos de convivência com a seca; a inatividade das tecnologias disponíveis.

Sobre o bioma dominante, a Caatinga é o que abrange maior área dentro do Semiárido brasileiro, correspondendo a 63\% da área do Semiárido (ABÍLIO; GOMES; SANTANA, 2010), estende-se diferentemente pelos estados de Sergipe, Alagoas, Bahia, Ceará, Paraíba, Pernambuco, Piauí, Rio Grande do Norte, parte do Maranhão e a região norte de Minas Gerais (BERNARDES, 1999). Caracteriza-se por possuir uma vegetação com adaptações ao clima seco e uma paisagem com significativa riqueza biológica, elevado índice de endemismo em espécies animais e vegetais (ABÍLIO; GOMES; SANTANA, 2010), estimando-se que pelo menos 40\% das espécies da flora identificadas sejam endêmicas (LEAL et al, 2005).

Sobre as causas dos impactos ambientais, o crescimento da população e da densidade populacional contribui para a exploração dos recursos naturais além de sua capacidade de suporte. O aumento da população, assim como das demandas por alimentos, energia e outros recursos naturais vêm provocando importantes impactos na base de recursos naturais das 
regiões da Caatinga (ABÍLIO; FLORENTINO, 2010a).

Pertinente ao estado que foi realizada a pesquisa, a Caatinga é o tipo de vegetação que cobre a maior parte do território Semiárido paraibano e antes de tudo, é preciso superar a ideia de este bioma está relacionado com a pobreza paisagística e de biodiversidade (ARAÚJO; SOBRINHO, 2009).

Mais especificamente, o trabalho foi desenvolvido no Cariri paraibano, este segundo Pereira (2008) localiza-se em áreas tidas como de alta susceptibilidade à ocorrência de processos de desertificação. Além de sofrer degradações naturais, passa por níveis intensos de antropização principalmente no que se refere aos processos de agriculturização e pecuarização.

Segundo Leff (2012), apesar dos avanços verificados, tanto na busca de um modelo de Desenvolvimento Sustentável (DS), como na construção de um Saber Ambiental que incorpora a pluralidade axiológica e a diversidade cultural na formação do conhecimento e da maior consciência geral acerca da necessidade de conservação do meio ambiente, constata-se que o humano continua a subestimar os impactos decorrentes de sua ocupação sobre o planeta, não sendo diferente no Cariri paraibano.

Portanto é extremamente significativo o desenvolvimento de práticas de EA na Caatinga, principalmente em regiões onde o processo de devastação da biodiversidade já está acentuado, necessitando assim uma mudança de postura das sociedades que neste espaço vivem, buscando assim estabelecer novas relações, entendendo que o humano não apenas transforma o ambiente na qual insere-se, mas que ele também é o ambiente.

\section{METODOLOGIA}

Para tanto, tratou-se de uma pesquisa de natureza aplicada (PRODANOV; FREITAS, 2013), de abordagem qualitativa e de procedimentos técnicos da pesquisa participante, onde se utilizou dos pressupostos teórico-metodológicos e elementos da Teoria do Biorregionalismo.

A pesquisa é aplicada, pois busca gerar conhecimentos para solução de problemas que contenham objetivos anteriormente definidos (PRODANOV; FREITAS, 2013). É Qualitativa por permitir explorar dados relativos à vivência dos alunos e compreende-los inserido no próprio contexto, sem, no entanto, privilegiar aspectos numéricos, embora possa fazer uso destes, mas a capacidade de reflexão da realidade de forma contextualizada (GIL, 2016). É pesquisa participante por ser desenvolvida a partir da interação do pesquisador com os alunos (participantes das oficinas pedagógicas) em situações participativas e de investigação (PRODANOV; FREITAS, 2013). Possui elementos da teoria do Biorregionalismo assim, estabelecendo espaços de discussão e análise, como estratégia para compreensão das temáticas 
em relação à EA.

O projeto intitulado "Consolidação e conservação da RPPN Fazenda Almas/PB mediante ao seu Plano de Manejo" foi realizado na Escola Estadual de Ensino Fundamental e Médio Bartolomeu Maracajá - São José dos Cordeiros/PB, com alunos do $7^{\circ}$ ano e da $1^{\circ}$ série, respectivamente, do ensino Fundamental e Médio, no período de abril a dezembro de 2018, com intervalos mensais, sendo trabalhada as mais diversas temáticas em Educação Ambiental, com o intuito de sensibilizar os discentes sobre a importância das unidades de conservação e sua relação com a preservação dos recursos naturais e promoção da qualidade de vida da sociedade.

A RPPN Fazenda Almas é a quarta maior RPPN do bioma Caatinga e a maior do estado da Paraíba. Localiza-se entre o município de São José dos Cordeiros e o município de Sumé (LIMA, 2004) (Figura 01).

A RPPN foi criada em 1990 e tem uma superfície de 3.505 hectares de um total de 5.247 hectares da Fazenda. Esta tem microclima e está numa altitude entre 600 à 780 m, depositária de remanescentes florestais das diversas tipologias florísticas do domínio da caatinga, incluindo diversas espécies ameaçadas de extinção, sítios arqueológicos, rica em patrimônio histórico (ciclo do algodão) e ainda vibrante no seu folclore. A RPPN encontra-se inserida na microrregião do Cariri paraibano, na porção limite entre as Ecorregiões Planalto da Borborema e Depressão Sertaneja Setentrional (VELOSO et al, 2002).

Figura 01 - Localização dos municípios de São José dos Cordeiros e Sumé, onde encontra-se inserida a RPPN Fazenda Almas.

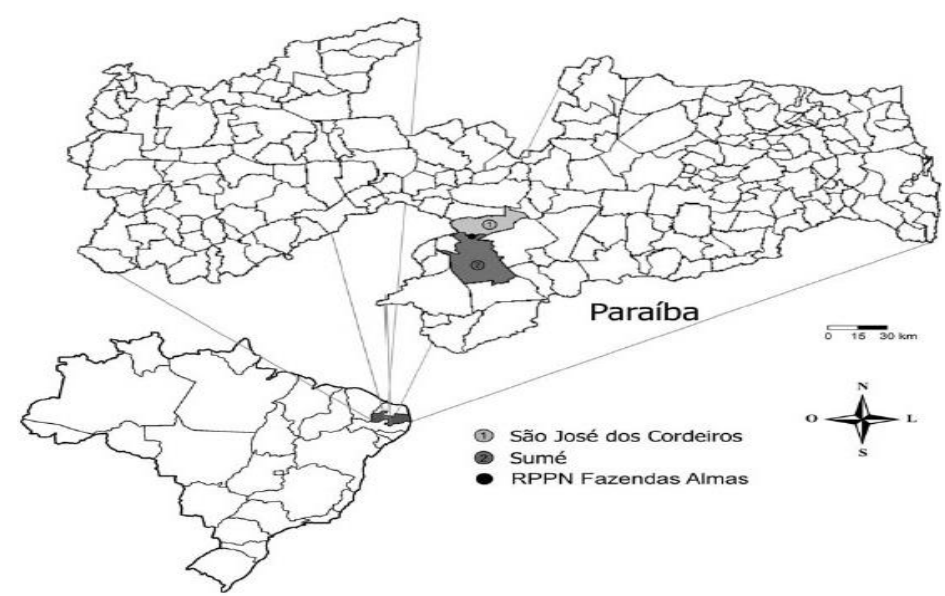

Fonte: Retirado de ARAÚJO, V. F. P. ${ }^{4}$

\footnotetext{
${ }^{4}$ Fonte: ARAÚJO, V. F. P. Arthopoda de Solo em um Ecossistema Semiárido da Região Neotropical: Composição, variabilidade temporal e estratificação. Dissertação (Mestrado) - Universidade Federal do Rio Grande do Norte. Programa de Pós-graduação em Ciências Biológicas, Natal-RN, 2008.
} 
Para diagnóstico da percepção dos discentes, foram utilizados questionários estruturados pré e pós-teste, o uso de questionários pré-teste tem uma suma importância, pois a partir dele podemos encontrar as dificuldades que os discentes apresentam sobre as questões que serão levantadas no decorrer do projeto, assim é possível escolher as melhores estratégias metodológicas, aumentando a eficiência das vivências. Para Richardson (1999) o uso de questionários prévios ajudam a identificar particularidades que irão influir durante a pesquisa.

Dentre as modalidades didáticas, o projeto deu-se principalmente através de exposição dialogada, oficinas pedagógicas (RIBEIRO; FERREIRA, 2001), estudo do meio (ZÓBOLI, 2004) e exposição científica (MANCUSO, 2000; LIMA, 2008).

\section{RESULTADOS E DISCUSSÃO}

Após a análise dos questionários pré e pós-teste dos discentes do $7^{\circ}$ ano da EEEFM Bartolomeu Maracajá, acerca do perfil socioeconômico dos discentes podemos observar pertinente à orientação de sua expressão de gênero, que 52\% dos discentes afirmam ser do sexo feminino e $48 \%$ do sexo masculino. Em relação à ocupação fora da escola, $4 \%$ afirma ser auxiliar de construção, 24\% afirmam praticar algum esporte (futebol ou futsal), $40 \%$ música, $28 \%$ ajudam em casa e $4 \%$ não responderam (Gráfico 1).

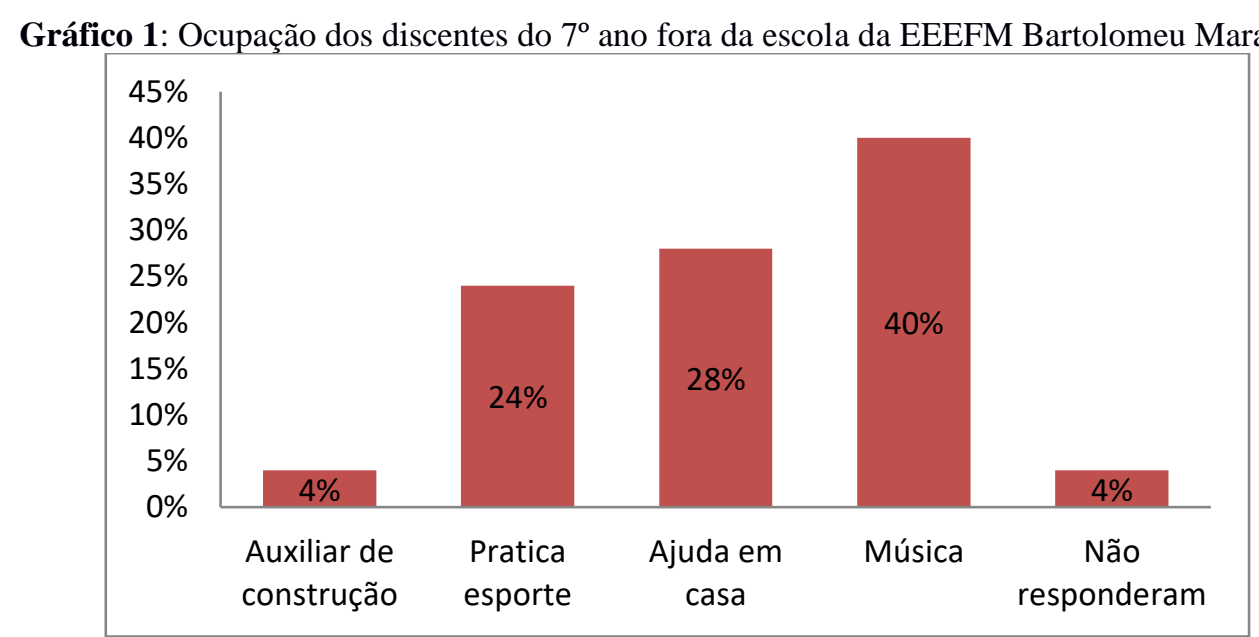

Fonte: Própria (2019).

Uma ocupação bastante citada pelos discentes foi a de "música" (40\%), fato deve-se, pois a cidade possui uma orquestra sinfônica que faz shows durante todo o ano e incentiva os alunos a participarem e tocaram algum instrumento. A presença de música no dia a dia dos discentes pode trazer bastante estímulo, segundo Góes (2009), a principal finalidade da música objetivo da música no espaço escolar é contribui pra o desenvolvimento do aluno por proporcionar a ela ampliação cultural, enriquecimento de sua inteligência e evolução da 
sensibilidade musical. De acordo com Bastian (2009) os discentes que tem a oportunidade de ter experiências musicais são capazes de alçarem maiores níveis de sensibilização e sociabilidade, tornando-se menos agressivos em sala de aula, assim traz diversos benefícios no processo de ensino e aprendizagem.

Quando questionados sobre "No seu ponto de vista, o que vem a ser meio ambiente" os discentes apresentaram as seguintes percepções como mostra no Gráfico 2.

Gráfico 2: Percepção dos discentes do $7^{\circ}$ ano da EEEFM Bartolomeu Maracajá acerca do que vem a ser meio ambiente

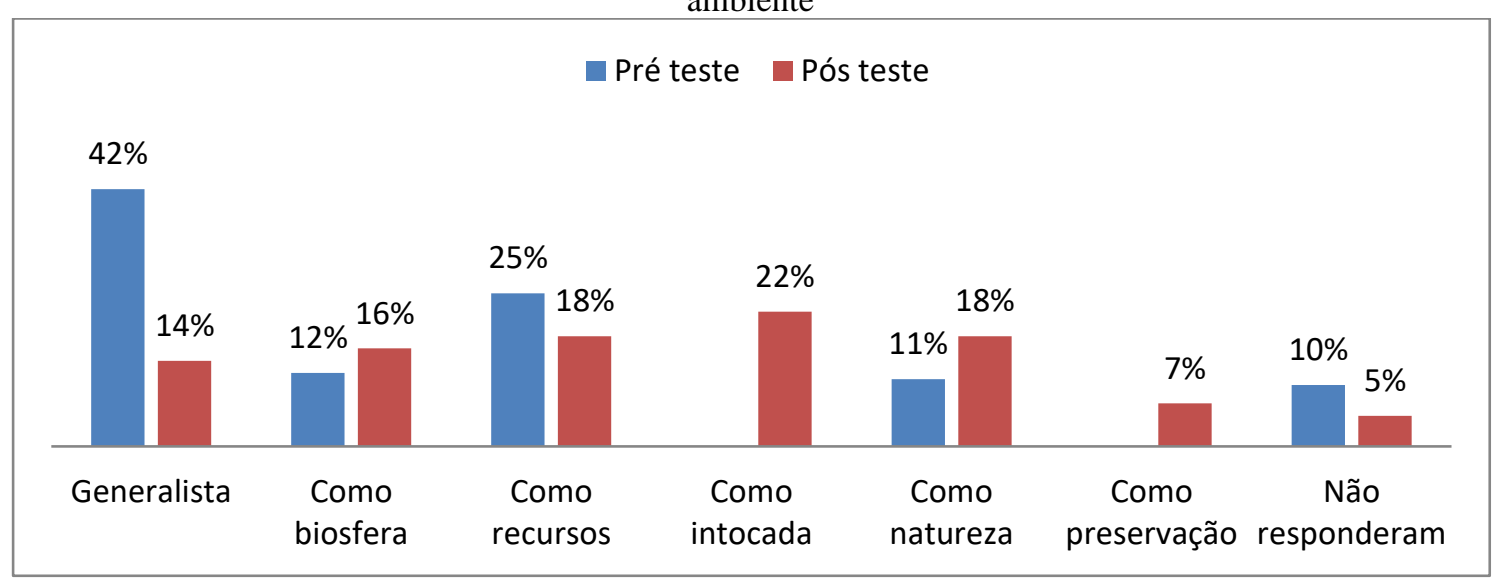

Fonte: Própria (2019).

Em relação à categoria "generalista" podemos observar que houve uma mudança significativa na percepção dos discentes, cerca de $42 \%$ no pré-teste e $14 \%$ no pós-teste, esta categoria pode ser caracterizada como uma visão confusa dos alunos diante à temática. Seguida de "como recurso", esta categoria os discentes enxergam o meio ambiente como fonte de matéria prima, onde representou $25 \%$ no pré-teste e $18 \%$ no pós-teste. A categoria "como biosfera" expressou-se com $12 \%$ no pré-teste e $16 \%$ no pós-teste e pode ser descrita quando o aluno se refere ao meio ambiente como sendo o todo, a terra, onde a cidadania vive (SATO, 2002). A categoria "como natureza" é expressa com $11 \%$ no pré-teste e $18 \%$ no pós-teste, "não responderam" $15 \%$ no pré-teste e $5 \%$ no pós-teste. As categorias "como intocada" e "como preservação" apareceram apenas no pós-teste com $22 \%$ e $7 \%$ respectivamente, as respostas categorizadas aparecem no Quadro 1.

Quadro 1: Respostas dos discentes do $7^{\circ}$ ano da EEEFM Bartolomeu Maracajá acerca do que vem a ser Meio ambiente.

\begin{tabular}{|c|l|}
\hline Categoria & \multicolumn{1}{|c|}{ Respostas } \\
\hline \multirow{2}{*}{ Generalista } & Pré-teste: "É tudo que está ao nosso redor." Aluno $7^{\circ}$ ano. \\
\cline { 2 - 2 } & Pós-teste: "É aquilo que conseguimos ver." Aluno $7^{\circ}$ ano. \\
\hline \multirow{2}{*}{ Como biosfera } & Pré-teste: É o no nosso planeta. Aluna $7^{\circ}$ ano. \\
\cline { 2 - 2 } & Pós-teste: "Tudo que existe na terra". Aluno $7^{\mathbf{0}}$ ano. \\
\hline \multirow{2}{*}{ Como recurso } & Pré-teste: "Tudo que utilizamos". Aluna $7^{\circ}$ ano. \\
\cline { 2 - 2 } & Pós-teste: "Aonde se encontram todos os recursos". Aluno $7^{\circ}$ ano. \\
\hline
\end{tabular}




\begin{tabular}{|c|l|}
\hline Como intocada & Pós-teste: “É parte da natureza intocada pelo homem”. Aluna $7^{\circ}$ ano. \\
\hline Como natureza & Pré-teste: "Faz parte da natureza”. Aluno $7^{\circ}$ ano. \\
\cline { 2 - 2 } & Pós-teste: "É aquilo que é natural”. Aluno $7^{\circ}$ ano. \\
\hline Como preservação & Pós-teste: “É a parte preservada do ambiente.” Aluna $7^{\circ}$ ano. \\
\hline
\end{tabular}
Fonte: Própria (2019)

Foi perguntado aos discentes nos questionários pré e pós-testes "No seu ponto de vista, o que vem a ser natureza"? Podemos perceber as mudanças nas respostas dos alunos antes e após as vivências pedagógicas, como mostra o Quadro 2.

Quadro 2: Respostas dos discentes do $7^{\circ}$ ano da EEEFM Bartolomeu Maracajá acerca do que vem a ser natureza.

\begin{tabular}{|c|l|}
\hline Categoria & \multicolumn{1}{c|}{ Respostas } \\
\hline Generalista & Pré-teste: "É aquilo que conseguimos ver." Aluno $7^{\circ}$ ano. \\
\hline Ecossistema & $\begin{array}{l}\text { Pós-teste: "Natureza é um conjunto de ecossistemas aonde vivem as plantas } \\
\text { e os animais" Aluno, } 7^{\circ} \text { ano. }\end{array}$ \\
\hline \multirow{2}{*}{ Recurso } & Pré-teste: "De onde tiramos nossa água e alimentos. Aluna, $7^{\circ}$ ano." \\
\cline { 2 - 3 } & $\begin{array}{l}\text { Pós-teste: "Natureza são todos os recursos que o ser humano não tocou" } \\
\text { Aluno, } 7^{\circ} \text { ano. }\end{array}$ \\
\hline \multirow{2}{*}{ Lugar } & Pré-teste: "Lugar aonde tem árvores, rios e etc". Aluna, $7^{\circ}$ ano. \\
\cline { 2 - 2 } & $\begin{array}{l}\text { Pós-teste: "Natureza é o lugar aonde os animais vivem em harmonia sem } \\
\text { interferência do homem." Aluna, } 7^{\circ} \text { ano. }\end{array}$ \\
\hline
\end{tabular}
Fonte: Própria (2019).

Para os discentes no pré teste, a maioria das respostas, cerca de $35 \%$ se enquadram na categoria "generalista", este fato pode ter ocorrido pois os discentes não sabiam diferenciar conceitos de meio ambiente e natureza, visto que durante as vivências tais conceitos eram bastante confundidos. Em seguida temos a categoria "como lugar", cerca de 25\% no pré teste e $35 \%$ no pós teste, geralmente aqui estão categorizadas resposta dos discentes falam que é a natureza é onde está fauna e flora, retirando totalmente o ser humano deste contexto. A categoria "como recurso" aparece com $25 \%$ no pré-teste e $15 \%$ no pós-teste, essa categoria possui uma visão mais exploratória da natureza, este fato deve ocorrer, pois o cariri paraibano é um local amplamente devastado por ações antrópicas. A categoria "não responderam" obteve $15 \%$ no pré-teste e $10 \%$ no pós-teste. Por fim a categoria "como ecossistema" (45\%) apareceu apenas no pós-teste e com a maioria das respostas como pode ser visto na Gráfico 3.

Para Sato (2002) a educação ambiental pode auxiliar a sociedade a diagnosticar as causas, os efeitos e assim a complexidade dos problemas ambiental, em consequência disso a necessidade de resolvê-los. 
Gráfico 3: Percepção dos discentes do $7^{\circ}$ ano da EEEFM Bartolomeu Maracajá acerca do que vem a ser natureza.

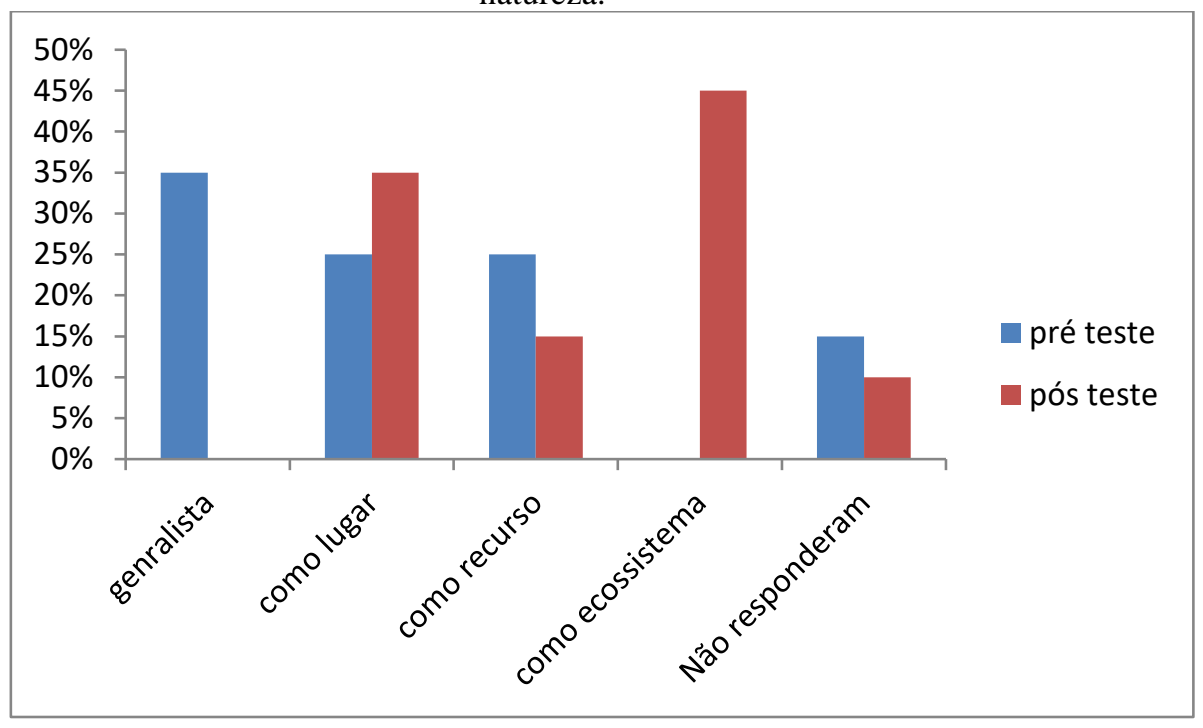

Fonte: Própria (2019)

Quando questionados sobre "o que vem a ser educação ambiental”, 40\% dos discentes responderam no pré-teste que era "disciplina curricular" e 8\% pós-teste, nesta categoria geralmente os alunos confundem essa tipologia como uma disciplina que deve ser ensinada nas escolas e ao decorrer das vivências essa visão vai sendo desconstruída, podemos observar que nesta pesquisa que a porcentagem desta categoria diminuiu drasticamente. $\mathrm{Na}$ categoria "conservacionista" corresponderam a $20 \%$ no pré-teste e $10 \%$ no pós-teste, nesta busca a valorização e a conservação dos recursos naturais. Na categoria "preservacionista" valoriza a preservação dos recursos naturais e nesta pesquisa $10 \%$ dos alunos se enquadraram na mesma no pré-teste e $20 \%$ no pós-teste.

Vale ressaltar que existem diferenças entre preservação e conservação, na conservação o ser humano pode utilizar-se dos recursos naturais de maneira sustentável e preocupando-se com o futuro, já a preservação o ser humano não pode fazer uso dos recursos naturais tornandoos intocáveis, esses conceitos foram amplamente debatido com os discentes. Na categoria "sensibilizadora" enquadram-se $10 \%$ dos alunos no pré-teste e $14 \%$ no pós-teste, nesta não houve diferença significativa na respostas dos discentes, esta categoria busca sensibilizar os alunos quanto às questões ambientais e a melhor utilização dos recursos naturais. A categoria "generalista" apareceu $20 \%$ dos discentes no pré-teste e $8 \%$ no pós-teste, esta categoria representa os alunos que tiveram uma resposta confusa sobre o tema. Por ultimo a categoria "crítica" teve o resulto mais representativo nesta pesquisa, no pré-teste os discentes não categorizaram a educação ambiental como sendo crítica e ao serem questionados responderam que nunca tinham ouvido falar e após as vivências somaram $40 \%$ dos discentes, assim a 
educação ambiental crítica mostra-se totalmente diferente da conservadora e busca problematizar, politizar e levar para os alunos a importância das questões ambientais para a realidade dos mesmos (Gráfico 4).

Gráfico 4: Percepção dos discentes do $7^{\circ}$ ano da EEEFM Bartolomeu Maracajá acerca do que vem a ser educação ambiental.

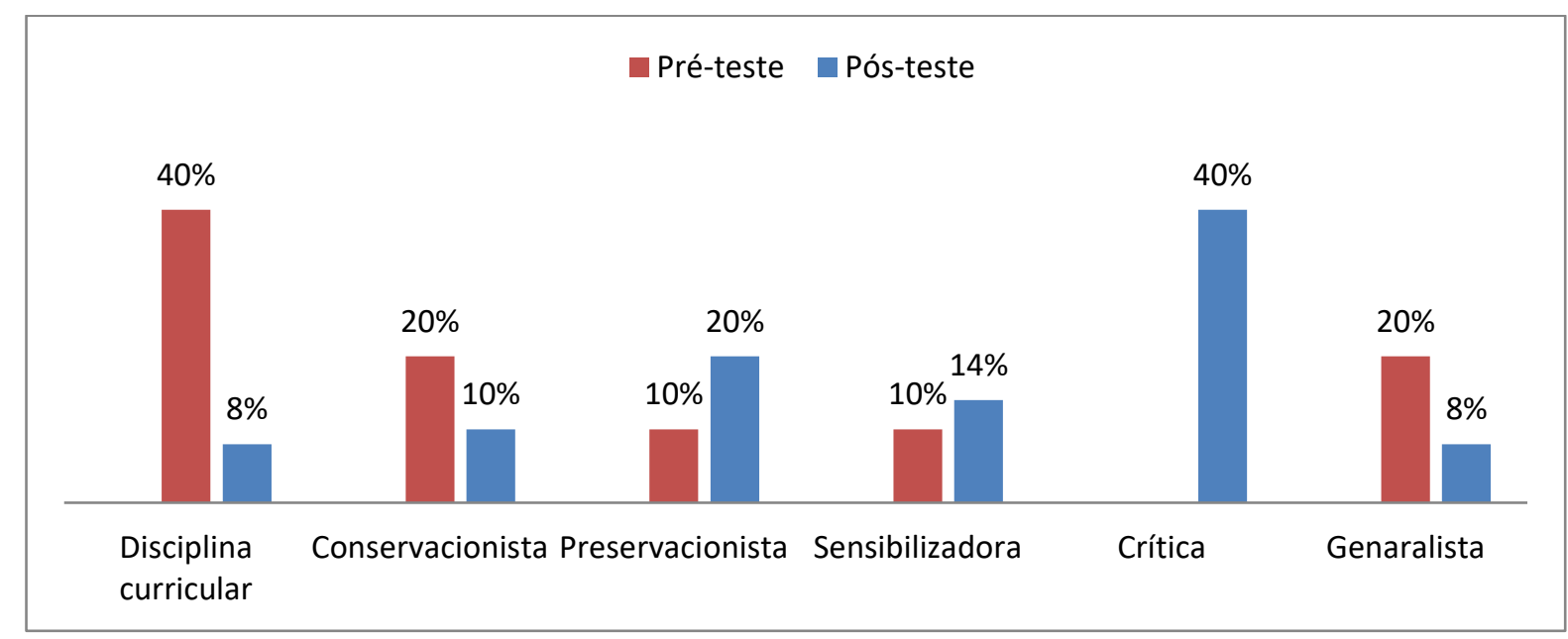

Fonte: Própria (2019).

Acerca dos impactos ambientais que ocorrem na região foi questionado aos discentes “quais os impactos ambientais ocorridos na região", no pré-teste cerca de $40 \%$ não responderam, durante sãs vivências foi possível observar que os alunos até tinha idéia dos impactos ocorridos, mas não conseguiram fazer associação com o termo "impacto ambiental". Ainda no pré-teste $60 \%$ mencionaram "queimadas" e $40 \%$ no pós-teste, $35 \%$ citaram "caça" no pré-teste e $20 \%$ no pós-teste e $50 \%$ mencionaram "lixo" no pré-teste $25 \%$. Houveram categorias que só foram expressas no pós-teste como agrotóxicos com 45\%, agricultura 20\%, pecuária $30 \%$ e desertificação 40\% como podemos observar no Gráfico 5.

Podemos observar que a categoria “desertificação "apareceu apenas no pós-teste e foi a que mais se sobressaiu, a desertificação é causada principalmente pelas queimadas e desmatamentos que ocorrem na região, principalmente pela prática da pecuária e agricultura desenfreada. Segundo Brasil (2016) para ser considerado um impacto ambiental é necessário que haja mudanças físicas, químicas e biológicas causadas pelo ser humano a qualquer forma de matéria e afetem a qualidade dos recursos ambientais, sendo assim, todas as categorias citadas pelos discentes correspondem a um impacto ambiental. 
Gráfico 5: Percepção dos discentes do $7^{\circ}$ ano da EEEFM Bartolomeu Maracajá acerca dos impactos ambientais ocorridos na região.

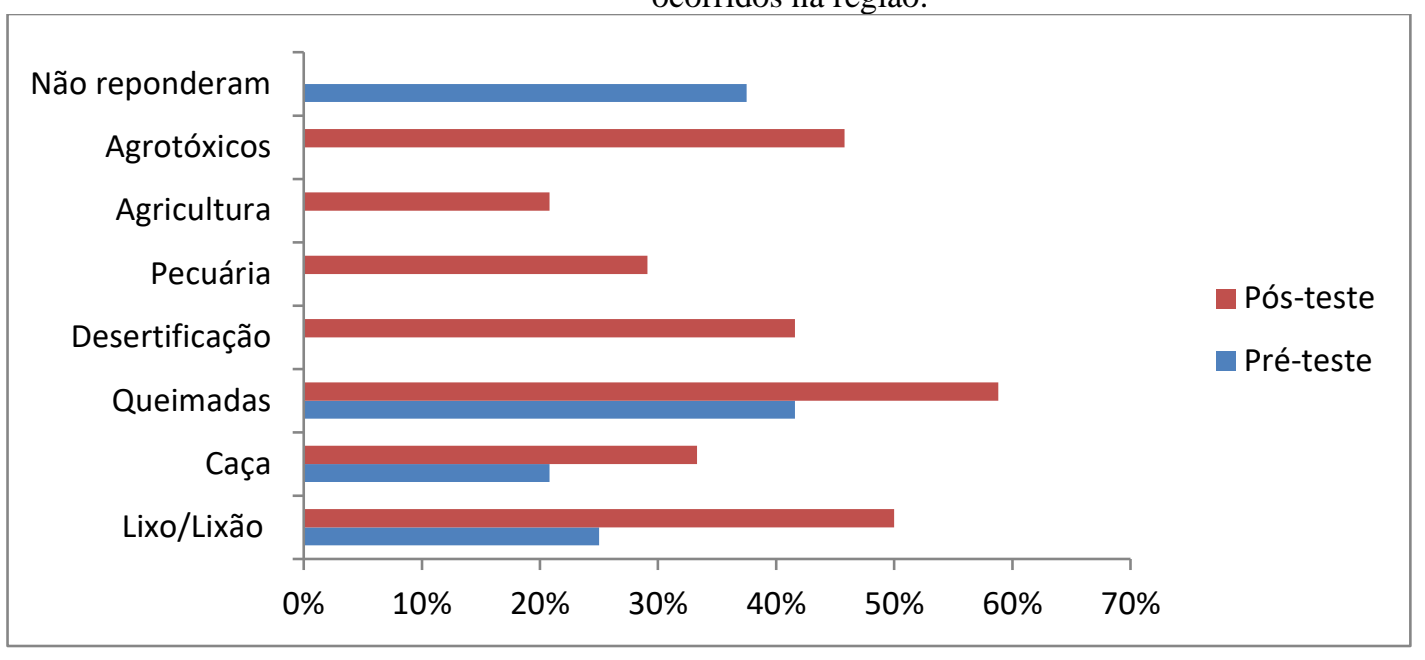

Fonte: Própria (2019)

Quando questionados sobre a RPPN Fazenda Almas 30\% dos discentes já visitaram o local, $60 \%$ dos discentes nunca visitaram e $20 \%$ nunca ouviram falar. Algumas ações em educação ambiental já foram desenvolvidas na escola com professorem e outras turmas.

\section{Atividades Desenvolvidas}

A primeira vivência educativa foi realizada no dia 28 de Abril de 2018 e teve como tema "Educação Ambiental com ênfase na RPPN Fazenda Almas: a importância da conservação da biodiversidade". A importância de iniciar as atividades educativas com uma reflexão acerca da Educação Ambiental decorreu da necessidade de construir um processo de reconhecimento de valores e clarificações de conceitos e, assim, compreender as inter-relações existentes entre o ser humano, suas culturas e seus meios biofísicos (UNESCO, 1977). Após a explicação do projeto os alunos foram submetidos a um questionário pré-teste sobre as possíveis temáticas que seriam tratadas durante o projeto, com a finalidade de identificar as possíveis dificuldades dos conteúdos apresentados.

A segunda vivência educativa foi realizada no dia 11 de Maio de 2018 e teve como temática principal "Conhecendo os Moluscos: caracterização geral do filo. Espécies que ocorrem no Cariri paraibano bem como na Fazenda Almas". Esta vivência foi totalmente voltada à parte prática, onde os alunos eram construtores do próprio conhecimento. A atividade sobre os moluscos foi escolhida por conta da necessidade de levar conhecimento sobre os espécimes ocorridos e não ocorridas na região do cariri paraibano, onde eles tiveram a 
oportunidade de visualizar animais a olho nu e na lupa as principais espécies.

A terceira vivência educativa ocorreu no dia 22 de Junho e teve como tema “Caracterização geral do Semiárido brasileiro, do bioma Caatinga e da RPPN Fazenda Almas", nesta vivência os alunos puderam aprender conceitos e curiosidades sobre o bioma caatinga e também como um primeiro contato com a Fazenda Almas, visto que a maioria nunca tinha ouvido falar. Após a exposição da aula dialogada, os alunos fizeram a atividade "Dinâmica dos conceitos" no qual eles tinham que completar as frases com os principais conceitos expostos na aula. Ao final da explanação os alunos foram divididos em duplas para completarem seus conceitos, em seguida compartilharam com os demais colegas de classe, gerando assim um debate bastante produtivo.

A quarta vivência educativa sucedeu-se no dia 27 de Julho e foi tratada a temática "Fauna e Flora da Caatinga bem como da RPPN Fazenda Almas". Nesta vivência os discentes puderam explorar seus conhecimentos prévios sobre a fauna e flora da região, bem como sua riqueza e importância econômica e para manutenção do equilíbrio ambiental. Além da exposição do conteúdo dialogado, também houve a parte prática, onde os discentes foram divididos em pequenos grupos para aplicação de diversas atividades a primeira deu-se através do jogo caça-palavras, sobre as plantas que ocorriam na região.

A segunda atividade tinha como tema animais endêmicos exóticos, onde eles tinham que recortar e colar em respectivos lugares os animais que ocorriam e não ocorriam na região da Caatinga. Por fim, a terceira e ultima atividade pratica a sala foi reorganizada em dois grupos para o jogo “o que é o que é?” sobre a fauna e flora da região, onde cada grupo tinha direito a uma resposta, caso errasse ou não soubesse.

A quinta vivência educativa teve como tema "Impactos Ambientais ocorridos na Caatinga" e foi realizada no dia 17 de agosto. Após a exposição dialogada houve num debate sobre tais questões os ambientais. Em seguida foi realizada uma atividade em forma de cruzadinha, no qual continham perguntas sobre a temática trabalhada, dentre elas sobre desertificação, agrotóxicos, queimadas, caça predatória, dentre outras. No final os alunos dividiram-se em grupos, escolheram um impacto ambiental que mais chamou atenção e discutiram em forma de pequenos seminários com os outros colegas. Por fim foi mostrado um vídeo sobre "Impactos ambientais na Caatinga" com a finalidade de sensibilizar os alunos.

A sexta vivência educativa ocorreu no dia 14 de setembro e deu-se através de uma exposição dialogada. Teve como conteúdo "Impactos Ambientais ocorridos no entorno da RPPN Fazenda Almas", tendo como objetivo sensibilizar os alunos acerca dos Impactos Ambientais do Cariri paraibano. Após o término da exposição dialogada, houve a execução de 
uma oficina pedagógica que constituiu na confecção de cartazes, os alunos foram divididos em grupos e foi pedido para que eles desenhassem através da sua interpretação pessoal duas situações, a primeira sobre o que seria caatinga e a outra sobre algum impacto ambiental que ocorria na região. Após a construção dos cartazes houve uma pequena apresentação dos grupos, formando assim um debate bastante interativo sobre as temáticas escolhidas que foram: pecuária; lixão a céu aberto; caça predatória; queimadas; desmatamento e biopirataria. Os cartazes construídos foram expostos na VII Mostram Cultural e Científica que ocorreu no mês de novembro.

A sétima vivência educativa ocorreu no dia 19 de outubro e teve como tema "Desenvolvimento sustentável para convivência com o semiárido", foi trabalhado com a turma do $7^{\circ}$ ano conceitos importante que foram vistos durantes os meses anteriores, bem como a importância do desenvolvimento sustentável, quais as dificuldades encontradas para se obter este desenvolvimento, quais as consequências que isso acarreta para a natureza e quais alternativas que poderíamos tomar para que esse desenvolvimento possa ser realizado, tanto pela população como pelas grandes empresas. Ao final da exposição dialogada os alunos foram divididos em grupo, que teve como objetivo produzirem um texto sobre como eles poderiam conviver com o semiárido, em seguida esse texto foi utilizados em um teatro fantoches interpretado pelos alunos. Ao final houve um debate sobre quais as dificuldades que eles encontravam na cidade para executar um desenvolvimento sustentável.

$\mathrm{Na}$ apresentação do teatro de fantoches era possível notar o entusiasmo dos alunos em poder interpretarem a história que haviam escrito, de acordo com Galvão (1996), “os participantes parecem receber bem melhor e armazenar com mais facilidade as imagens, quando são apresentadas através de algo que as encante emocionalmente como é o caso do Teatro de Bonecos".

A oitava vivência educativa ocorreu no dia 16 de novembro, esta atividade sucedeu-se através de um estudo do meio na RPPN Fazenda Almas. Inicialmente foi debatido historicamente como havia sido criada a RPPN, em seguida os alunos seguiram pela trilha da bola, onde houve um debate sobre fauna, flora e os impactos ambientais que ocorriam na região.

A realização de Estudos do Meio é motivadora para os alunos, pois desloca o ambiente de aprendizagem para fora da sala de aula (BRASIL, 2002). Permite a aquisição de atitudes de observação crítica da realidade e despertar da sua curiosidade assim como possibilita a percepção integral da realidade local e obtenção de dados informativos sociais, políticos, históricos, geográficos, econômicos, que o ajudarão a analisar melhor a realidade que o rodeia (ZÓBOLI, 2004). 
A nona vivência educativa ocorreu a VII Mostra Cultural e Científica da Escola Bartolomeu Maracajá/São José dos Cordeiros - PB, onde o grupo GEPEBio/UFPB levou matérias de pesquisa e intervenção que realizam em projetos simultâneos sobre a biodiversidade de moluscos, bem como as atividades apresentadas ao longo dos relatórios mensais deste presente projeto.

A realização da Mostra Cultural nas escolas traz uma série de benefício para alunos, professores e comunidade, pois traz novas idéias que podem ser aplicadas no dia a dia. Mancuso (2000) destaca as seguintes mudanças: O crescimento pessoal e a ampliação dos conhecimentos, pois alunos e professores mobilizam-se para buscar e aprofundar temas científicos que, geralmente, não são debatidos em sala de aula; a ampliação da capacidade comunicativa devido à troca de ideias, ao intercâmbio cultural e ao relacionamento com outras pessoas; o desenvolvimento da criticidade com o amadurecimento da capacidade de avaliar o próprio trabalho e o dos outros; maior politização dos participantes devido ampliação da visão de mundo, à formação de lideranças e à tomada de decisões durante a realização dos trabalhos.

A décima vivência educativa ocorreu no dia 08 de dezembro, sucedeu-se através de um estudo do meio na RPPN Fazenda Almas, com os alunos do $1^{\circ}$ ano da Escola Bartolomeu Maracajá. Nesta atividade os alunos puderam conhecer os espaços comuns da fazenda e realizaram a trilha da Pedra da Bola, onde puderam ver diversas espécies de vegetais através das placas de identificação contidas na trilha.

\section{CONCLUSÕES}

Após análise dos questionários pré e pós-teste pôde-se notar uma diferença significativa na visão dos discentes em relação ao conceito de natureza, onde no pré-teste sobressaiu-se a visão "generalista" onde no pós-teste não se manifestou, aparecendo uma nova categoria denominada "como ecossistema". Sobre conceito de meio ambiente houve uma queda significativa da categoria "generalista" no pós-teste dando assim espaço para outras categorias como "preservação" e "intocada". Quando ao conceito de EA no pré-teste sobressaiu-se também a categoria "generalista" e no pós-teste a de EA como sendo "crítica. As mudanças nas percepções dos discentes deu-se por meio vivências pedagógicas realizadas, onde participavam ativamente e trouxe algo significativo para a sua realidade fora da escola. Em relação aos impactos ambientais foi possível notar durante as vivências que eles possuíam um conhecimento prévio sobre a degradação ambiental, visto que faz parte da realidade e do cotidiano dos mesmos. As ações realizadas na escola Bartolomeu Maracajá localizada do entorno da RPPN Fazenda Almas trouxeram uma grande importância para a comunidade 
escolar, pois a maioria dos alunos apenas tinha ouvido falar da RPPN, mas nunca tido a oportunidade de visitá-la.

Assim através deste trabalho além de conhecer na teoria, através de fotos mostradas nos slides, algumas turmas da escola puderam visitar a fazenda e conhecer os encantos e belezas que existe no local. Infelizmente nem todas as turmas puderam fazer à visita devido à falta de transporte para deslocá-los ao local. Mesmo com esse empecilho pode-se concluir que o trabalho se mostrou de grande importância para os alunos que tinham uma visão distorcida sobre EA, onde através dos diálogos era notório que houve reflexão sobre todas as temáticas tratadas com possíveis mudanças atitudinais posteriores. Em conversas informas com os alunos fora da sala de aula, era possível perceber o quanto eles estavam entusiasmados com o conteúdo e ansiosos para conhecer os limites da RPPN Fazenda Almas e seu contexto histórico, assim para que essa conscientização pudesse ter um efeito ainda maior, seria interessante a continuidade desta pesquisa nas escolas do entorno, pois é âmbito formal onde se torna possíveis aberturas para tais diálogos.

\section{REFERÊNCIAS}

ABÍLIO, F. J. P.; FLORENTINO, H. S. Impactos ambientais na Caatinga. In: ABÍLIO, F. J. P. (Org). Bioma Caatinga: Ecologia, biodiversidade, educação ambiental e práticas educativas. João Pessoa: Ed. Universitária, 2010a.

ABÍliO, F. J. P.; FLORENTINO, H. S.; RUFFO, T. L. M. Educação Ambiental no Bioma Caatinga: formação continuada de professores de escolas públicas de São João do Cariri, Paraíba. Pesquisa em Educação Ambiental, vol. 5, n. 1, p. 171-193, 2010.

ABÍLIO, F. J. P.; GOMES, C.S.; SANTANA, A.C.D. Bioma Caatinga: caracterização e aspectos gerais. In: ABÍLIO, F.J.P. (Org.). Bioma Caatinga: ecologia, biodiversidade, educação ambiental e práticas pedagógicas. João Pessoa: UFPB/ Ed. Universitária, 2010, p.1330.

ARAÚJO, C.S.; SOBRINHO, J.F. O Bioma Caatinga no Entendimento dos Alunos da Rede Pública de Ensino da Cidade de Sobral - Ceará. Revista Homem, Espaço e Tempo, 2009.

Articulação do Semiárido (ASA). Semiárido - é no Semiárido que a vida pulsa! Disponível em: 〈http://www.asabrasil.org.br/semiarido〉. Acesso em: 26 Abr. 2018.

BASTIAN, H. Música na Escola: a contribuição do ensino da música no aprendizado e no convívio social da criança. São Paulo: Paulinas, 2009.

BRASIL. PCN + Ensino Médio: Orientações Educacionais complementares aos Parâmetros Curriculares Nacionais. Ciências da natureza, matemática e suas tecnologias. Brasília: MEC; SEMTEC, 2002. 
BRASIL. Política Nacional de Meio Ambiente. Lei n ${ }^{6}$ 6.938, de 31 de agosto de 1981. Diário Oficial da República Federativa do Brasil, Brasília, 1981. Disponível em: <http://www.planalto.gov.br/ccivil_03/leis/L6938.htm>. Acesso em: 15 mar. 2016.

BRASIL. Ministério do Meio Ambiente. Caatinga. Disponível em: http://www.mma.gov.br/biomas/caatinga Acesso em: 27 Abr. 2018a.

CIRILO, J. A.; FERREIRA, J. P. L.; CAMPELlO NETTO, M. S. C. Aspectos gerais das regiões semi-áridas, áridas e processos de desertificação. In: CIRILO. J. A. et al. (Org). O uso sustentável dos recursos hídricos em regiões Semi-áridas. Recife: EDUFPE, 2007, p. 19-31.

GADOTTI, M. Pedagogia da Terra. São Paulo: Peirópolis,. 2000.

GALVÃO, M.N.C. Possibilidades Educativas do Teatro de Bonecos nas escolas públicas de João Pessoa. 1996. Dissertação (Mestrado em Educação) - Centro de

Educação, Universidade Federal da Paraíba, João Pessoa, 1996.

GIL, A. C. Métodos e Técnicas de Pesquisa Social. 6 ed. São Paulo: Atlas, 2016.

GOÉS, R. S. A música e suas possibilidades no desenvolvimento da criança e o aprimoramento do código linguístico. Revista do Centro de Educação a Distância CEAD/UDESC. 2 (1), 27-43, 2009.

IBGE. São José dos Cordeiros. Disponível em: <http://www.cidades.ibge.gov.br/xtras/perfil.php?lang=\&codmun=251480\&search= paraiba|sao-jose-dos-cordeiros>. Acesso em: 02 mar. 2016.

LEAL, I.R. et al. Mudando o curso da conservação da biodiversidade na Caatinga do Nordeste do Brasil. Revista Megadiversidade, Belo Horizonte, v. 1, n. 1, 2005.

LEFF, E. Aventuras da epistemologia ambiental: da articulação das ciências ao diálogo de saberes. São Paulo: Cortez, 2012.

LIMA, I. B. Levantamento Florístico da Reserva Particular do Patrimônio Natural Fazenda Almas, São José dos Cordeiros - PB. Monografia. Universidade Federal da Paraíba - UFPB, 2004.

LIMA, M. E. C. Feiras de ciências: o prazer de produzir e comunicar. In: PAVÃO, A.C.; FREITAS, D. Quanta ciência há no ensino de ciências. São Carlos:

EduFSCar, 2008.

MACAMBIRA, D. M. O Semi-árido nordestino: estratégias para o desenvolvimento sustentável. Rev. Princípios, v. 83, p. 33-38, 2006.

MANCUSO, R. Feira de Ciências: produção estudantil, avaliação, consequiências.Contexto Educativo Revista Digital de Educación y Nuevas Tecnologías,

Buenos Aires, v. 6, n. 1, p. 1-5, 2000.

MEDEIROS, S. S. et al. Sinopse do Censo Demográfico para o Semiárido Brasileiro. Campina Grande: INSA, 2012. 
PEREIRA, D.D. Cariris Paraibanos: do sesmarialismo aos assentamentos de reforma agrária. Raízes da desertificação? Tese (Doutorado em Recursos Naturais) - Universidade Federal de Campina Grande, Campina Grande, 2008.

PRODANOV, C.C.; FREITAS, E.C. Metodologia do Trabalho Científico: Métodos e Técnicas da Pesquisa e do Trabalho Acadêmico. Novo Hamburgo: Feevale, 2013.

RIBEIRO, M.M.G.; FERREIRA, M.S. Oficina Pedagógica: uma estratégia de ensinoaprendizagem. Natal: EDUFRN, 2001.

RICHARDSON, R.J. Pesquisa Social: Métodos e Técnicas. 3.ed. Revista eampliada. São Paulo: editora Atlas S.A, 1999.

SANTOS, C. F.; SCHISTEK, H.; OBERHOFER, M. No Semi-árido, viver é aprender. Gráfica Franciscana, 2007.

SATO, M. Educação Ambiental. São Carlos: Rima, 2002.

UNESCO. CONFITEA: Declaração de Hamburgo. Brasília: SESI/UNESCO, 1997.

VELOSO, A. L.; SAMPAIO, E. V. S. B.; PAREYN, F. G. C. Ecorregiões propostas para o bioma Caatinga. Associação Plantas do Nordeste. Instituto da Conservação Ambiental The Nature Conservancy do Brasil. Recife. 76p. 2002.

VILAR FILHO, M. D. O Sertão frugal e verdadeiro - crônica de uma convicção. Disponível em: <http://remabrasil.org:8080/virtual/r/remaatlantico.org/sul/Members/suassuna/artigos/osertao-frugal-e-verdadeiro-2013cronica-de-uma-conviccao-artigo-de-manoel-dantas-vilarfilho/> Acesso em: 12 Abr. 2018.

ZÓBOLI, G. Práticas de Ensino: subsídios para a atividade docente. São Paulo: Ática, 2004. 


\title{
ATIVIDADE ENZIMÁTICA COMO FERRAMENTA DIDÁTICA PARA O ENSINO E APRENDIZAGEM DA BIOLOGIA EM UMA TURMA DO PRIMEIRO ANO DO ENSINO MÉDIO DE UMA ESCOLA PÚBLICA, LOCALIZADA EM URUÇUÍ-PI.
}

\author{
ACTIVIDAD ENZIMATIC COMO HERRAMIENTA DIDACTIC PARA LA \\ PROFESORA Y APRENDIZAJE DE LA BIOBIOLOGÍA EN UNA CLASE DEL \\ PRIMER Año DE LA ESCUELA ALTA EN UNA ESCUELA PUBLICA, UBICADA \\ EN URU-U-PI.
}

\section{ENZYMATIC ACTIVITY AS A DIDACTIC TOOL FOR THE TEACHING AND LEARNING OF BIOLOGY IN A CLASS OF THE FIRST YEAR OF HIGH SCHOOL IN A PUBLIC SCHOOL, LOCATED IN URUÇUÍ-PI.}

\author{
Vanessa Sousa da Costa ${ }^{1}$; Felix Gomes da $\mathrm{Costa}^{2}$; Yasmim Alline de Araújo Castro ${ }^{3}$; Ícaro \\ Fillipe de Araújo Castro ${ }^{4}$
}

DOI: $\underline{\text { https://doi.org/10.31692/978-65-991061-3-2.46-58 }}$

\section{RESUMO}

Para a formação do pensamento e assimilação dos conteúdos científicos trabalhados em ciências e biologia, as aulas práticas são importantes ferramentas ao estimular os discentes pela experimentação, possibilitando assim o diálogo entre o aluno e o mundo que o cerca. $\mathrm{O}$ desempenho dos discentes no processo de ensino-aprendizagem depende diretamente das metodologias utilizadas pelo professor, que tem também por função manter os alunos motivados para o aprendizado de tais conteúdo. Por isso, o presente trabalho tem como objetivo relatar a experiência de uma aula prática com alunos do primeiro ano do ensino médio de uma escola pública de Uruçuí-PI, bem como sua importância para o aprendizado do conteúdo ação enzimática na disciplina Biologia. Para a realização do trabalho, todos os discentes foram informados sobre a pesquisa, bem como seus respectivos fins, e levaram para seus responsáveis assinarem um Termo de Consentimento Livre e Esclarecido (TCLE), permitindo sua participação. Inicialmente, os alunos assistiram uma aula expositiva do conteúdo proteínas e em seguida foi aplicado um pré-questionário com sete questões objetivas de bancas de vestibular, a fim de identificar os conhecimentos prévios dos alunos sobre o conteúdo "atividade enzimática". Num segundo momento foi realizada uma aula prática no laboratório de Biologia, relacionada à atividade enzimática, na qual demonstrou-se a ação da enzima catalase presente no fígado em reação com o peróxido de hidrogênio, em condições de $\mathrm{pH}$ e temperatura normais e alterados. Após a realização da aula prática foi aplicado um novo questionário com as mesmas perguntas, além de duas perguntas discursivas acerca da satisfação dos alunos em relação às aulas práticas. Constatou-se nessa pesquisa que o experimento realizado teve grande aceitação, visto que o grau de satisfação dos alunos foi alto, permitindo observar o conteúdo trabalhado mais próximo da sua realidade, além de se observar uma melhora no rendimento dos participantes após a intervenção didática. Dessa forma, espera-se com esse trabalho contribuir/mostrar a importância de o professor adotar novas metodologias no ambiente escolar,

\footnotetext{
${ }^{1}$ Acadêmica do curso de Licenciatura em Ciências Biológicas, campus Uruçuí do Instituto Federal de Educação, Ciência e Tecnologia do Piauí, e-mail: sousavanessac19@gmail.com

${ }^{2}$ Acadêmico do curso de Licenciatura em Ciências Biológicas, campus Uruçuí do Instituto Federal de Educação, Ciência e Tecnologia do Piauí, e-mail: felixcosta518@gmail.com

${ }^{3}$ Doutoranda em Biologia Celular e Molecular aplicada, Universidade de Pernambuco, e-mail: y.in7@ @otmail.com

${ }^{4}$ Professor mestre do curso de Licenciatura em Ciências Biológicas, campus Uruçuí do Instituto Federal de Educação, Ciência e Tecnologia do Piauí, e-mail: $\underline{\text { icaro.castro@ifpi.edu.br }}$
} 
como as aulas práticas, além de trabalhar o conteúdo de forma dinâmica, estimulando/contribuindo para o processo de ensino-aprendizagem.

Palavras Chaves: Aula prática; Docência; Metodologias.

\section{RESUMEN}

Para la formación del pensamiento y la asimilación de contenidos científicos trabajados en ciencia y biología, las clases prácticas son herramientas importantes para estimular a los estudiantes a través de la experimentación, permitiendo así el diálogo entre el estudiante y el mundo que lo rodea. El desempeño de los estudiantes en el proceso de enseñanza-aprendizaje depende directamente de las metodologías utilizadas por el maestro, cuya función también es mantener a los estudiantes motivados para aprender dicho contenido. Por lo tanto, este documento tiene como objetivo informar la experiencia de una clase práctica con estudiantes de primer año de secundaria de una escuela pública en Uruçuí-PI, así como su importancia para aprender el contenido de acción enzimática en la disciplina de Biología. Para llevar a cabo el trabajo, todos los estudiantes fueron informados acerca de la investigación, así como sus respectivos propósitos, y se llevaron a sus tutores para firmar un Formulario de consentimiento libre e informado (ICF), lo que permite su participación. Inicialmente, los estudiantes asistieron a una conferencia sobre contenido de proteínas y luego se aplicó un pre-cuestionario con siete preguntas objetivas de los exámenes de ingreso, para identificar los conocimientos previos de los estudiantes sobre el contenido de "actividad enzimática". En un segundo momento, se realizó una clase práctica en el laboratorio de biología, relacionada con la actividad enzimática, en la que se demostró la acción de la enzima catalasa presente en el hígado en reacción con peróxido de hidrógeno en condiciones normales y alteradas de $\mathrm{pH}$ y temperatura. Después de la clase práctica, se aplicó un nuevo cuestionario con las mismas preguntas, así como dos preguntas discursivas sobre la satisfacción de los estudiantes con las clases prácticas. En esta investigación se encontró que el experimento fue ampliamente aceptado, ya que el grado de satisfacción de los estudiantes fue alto, lo que permitió observar el contenido trabajado más cerca de su realidad y observar una mejora en el rendimiento de los participantes después de la intervención didáctica. Por lo tanto, se espera que este trabajo contribuya / muestre la importancia del maestro para adoptar nuevas metodologías en el entorno escolar, como clases prácticas, y para trabajar el contenido dinámicamente, estimulando / contribuyendo al proceso de enseñanza-aprendizaje.

Palabras Clave: Clase de práctica; Enseñanza; Metodologías.

\section{ABSTRACT}

For the formation of thought and assimilation of scientific contents worked in science and biology, practical classes are important tools in stimulating students through experimentation, thus enabling dialogue between the student and the world around him. The performance of students in the teaching-learning process depends directly on the methodologies used by the teacher, whose function is also to keep the students motivated to learn such content. Therefore, this paper aims to report the experience of a practical class with first year high school students from a public school in Uruçuí-PI, as well as its importance for learning the enzymatic action content in the Biology discipline. To carry out the work, all students were informed about the research, as well as its respective purposes, and took to their guardians to sign a Free and Informed Consent Form (ICF), allowing their participation. Initially, the students attended a lecture on protein content and then a pre-questionnaire with seven objective questions from the entrance exams was applied, in order to identify students' previous knowledge about the content "enzymatic activity". Secondly, a practical class was held in the biology laboratory, related to enzymatic activity, in which the action of the catalase enzyme present in the liver in reaction with hydrogen peroxide was demonstrated under normal and altered $\mathrm{pH}$ and temperature 
conditions. After the practical class, a new questionnaire with the same questions was applied, as well as two discursive questions about the students' satisfaction with the practical classes. It was found in this research that the experiment was widely accepted, since the degree of satisfaction of the students was high, allowing to observe the content worked closer to their reality, and to observe an improvement in the performance of participants after the didactic intervention. Thus, this work is expected to contribute / show the importance of the teacher to adopt new methodologies in the school environment, such as practical classes, and to work the content dynamically, stimulating / contributing to the teaching-learning process.

Keywords: Methodologies; Practice class; Teaching.

\section{INTRODUÇÃO}

A Biologia é uma área ampla inserida nas ciências da natureza, considerada de suma importância, permitindo ao professor o uso de diversas metodologias que venham a auxiliar o aluno na apreensão dos diversos aspectos da vida e não somente aulas exaustivas e decorebas. Além disso, observa-se que os temas relacionados a essa área têm obtido relevância pelos meios de comunicação, jornais, revistas ou pela rede mundial de computadores-Internet e outros, o que facilita ainda mais para o professor repassar esses conhecimentos, pois pode associaá-los à realidade do aluno, tornando o ensino mais significativo (BRASIL, 2006).

Para a formação do pensamento científico e assimilação dos conteúdos científicos trabalhados, as aulas práticas são de extrema importância ao permitir estímulos ocasionados pela experimentação, possibilitando assim o diálogo entre o aluno e o mundo que o cerca. As aulas teóricas e uma didática com uma abordagem tradicional tornam o ensino distante do aluno; a aula prática, por sua vez, permite uma familiaridade com o assunto ou conteúdo abordado, por consequência a descoberta do sentido da aula (BARTZIK; ZANDER, 2016).

O ensino de Biologia através de aulas práticas possibilita uma interação mais compreensiva e atrativa do discente ao experimentar novos métodos de aprendizagem, que não se restringe apenas ao livro didático (MEIRA et al., 2016); segundo Oliveira e Costa (2016), a utilização de aulas práticas promove a motivação do aluno, despertando seu interesse/curiosidade e criatividade. $\mathrm{O}$ desempenho dos alunos no processo de ensinoaprendizagem pode ser dificultado com a metodologia do professor, sendo muitas vezes lecionada de maneira teórica, tornando um obstáculo para manter a concentração dos alunos para o conteúdo abordado (MEIRA et al., 2016).

$\mathrm{Na}$ Bioquímica encontra-se o estudo das enzimas, que na sua maioria são de origem proteica; essas moléculas possuem um notável poder catalítico, acelerando quase todas as reações biológicas no corpo humano. São altamente especificas para seu substrato e, para que sua atividade enzimática se mantenha estável são necessárias algumas condições ideais, como temperatura e $\mathrm{pH}$ (NELSON; COX, 2014). 
Aulas práticas que demostrem a atividade enzimática podem facilitar a compreensão desse conteúdo. Por exemplo, a atividade da enzima catalase, que realiza a decomposição do peróxido de hidrogênio e está presente em células vegetais e animais, pode ser observada em um experimento simples com batata ou fígado, observando-se a modificação da ação enzimática dessa enzima em condições de $\mathrm{pH}$ e temperatura alterado. Diante do exposto, o presente trabalho tem como objetivo relatar a experiência de uma aula prática com alunos do primeiro ano do ensino médio de uma escola pública de Uruçuí-PI, bem como sua importância para o aprendizado do conteúdo enzimas na disciplina Biologia.

\section{FUNDAMENTAÇÃO TEÓRICA}

A Biologia é o ramo da ciência que se dedica ao estudo/compreensão da vida nos seus mais diversos níveis e complexidades, respondendo a questionamentos sobre esse fenômeno do ponto de vista da ciência atual. A ciência está presente no cotidiano das pessoas, nos meios de comunicação, expandindo o conhecimento científico além das paredes do laboratório de pesquisas, levando para comunidade a importância da vida e de seus estudos. Compreender os fundamentos do pensamento científico é fundamental para viver em harmonia com os avanços sociais atualmente. A biologia é uma das ciências que mais interagem com questões do nosso contexto social (AMABIS; MARTHO, 2016).

As proteínas são moléculas fundamentais das células, essenciais para manutenção da vida, formadas por unidades menores chamadas de aminoácidos que podem constituir mais de 20 tipos. A combinação desses aminoácidos leva à conformação particular de cada proteína, sendo tal estrutura essencial para o seu funcionamento e conferindo às proteínas o desempenho de diferentes funções no organismo; além disso, as proteínas executam a maior parte das funções celulares. As propriedades químicas e mecanismos presentes nessa biomolécula dão a ela a enorme capacidade de sustentar os processos que acontecem nas células vivas. (ALBERTS et al., 2017)

Dentro do grupo das proteínas existe uma importante classe chamada enzimas, que desenvolvem e realizam importantes funções dentro do organismo humano, como por exemplo a aceleração de reações bioquímicas ao diminuir a energia de ativação. Essas extraordinárias moléculas funcionam como catalisadores biológicos, permitindo às células fazer e desfazer ligações de forma controlada. A catálise realizada pelas enzimas nas reações químicas é o que mantem a vida possível dentro das células (ALBERTS et al., 2017).

O conteúdo sobre proteínas e enzimas é muitas vezes mal compreendido pelos discentes, principalmente por ser trabalhado de forma muito teórica, sendo de difícil visualização. Dessa 
forma, o aluno precisa sentir-se atraído pelo conteúdo ministrado em sala de aula para que assim ele interaja e desperte seu interesse. É importante ressaltar que o processo educacional deve sempre estar se atualizando, revisando e propondo formas diferentes de ensino, a fim de que o conteúdo transmitido seja compreendido pelos seus educandos (SOARES; BAIOTTO, 2015).

A realização de experimentos em aula é uma ferramenta de ensino que possibilita ao professor complementar o conhecimento, exemplificar, ilustrar e comprovar o que é visto na teoria, assim aproximando o assunto abordado da realidade do aluno, saindo do abstrato do livro didático. Por ser uma área com conteúdo muito conceituais, a Biologia necessita que o professor contextualize e problematize, estimulando e colaborando para construção do conhecimento de maneira apreciável (FERREIRA, 2017). Segundo Bicudo et al (2017), aulas laboratoriais com experimentos despertam o interesse do aluno para a aprendizagem e novas descobertas.

Segundo Medeiros et al (2017):

"Para a superação desses desafios, as aulas laboratoriais e de campo, os jogos educativos e a aprendizagem-cooperativa são práticas pedagógicas que podem ser utilizadas pelos professores para diversificação de suas práticas e para o estímulo e desenvolvimento de competências junto aos estudantes, facilitando, assim, o ensino da Biologia"

De acordo com Nicola e Paniz (2016), o ensino tradicional ainda prevalece nas escolas, com a utilização de recursos como o quadro e giz, sendo o aluno passivo do processo de aprendizagem sem interagir para viabilizar a mesma. Neste contexto apresenta-se o ensino de Biologia e Ciências que, além das aulas serem ainda muito convencionais, é constituído por termos técnico empregados, que acabam sendo caracterizados pelos alunos como um desestímulo para a aprendizagem dos conteúdos. Contudo, a utilização de novas estratégias metodológicas possibilita o entendimento dos alunos no sentido de formação de novos conhecimentos.

\section{METODOLOGIA}

A pesquisa é caracterizada como básica, com abordagem qualitativa, do tipo estudo de caso e dessa forma, permite compreender e classificar o desempenho dos processos vivenciados por grupos sociais, bem como descrever a complexidade e analisar interações de variáveis especificas (RICHARDSON, 2015). A pesquisa foi composta por 30 alunos, na faixa etária de 14 a 17 anos, sendo nove alunos do sexo masculino e vinte e um do sexo feminino.

Para se conhecer a importância de uma aula prática foi utilizado como público alvo da ação educativa alunos de uma turma de primeiro ano do Ensino Médio de uma escola pública, 
localizada em Uruçuí-PI. O nome da instituição utilizada nessa pesquisa não será divulgado, em respeito à preservação do anonimato dos participantes desse estudo. A turma conta com 42 alunos regularmente matriculados no ano de 2019.

Incialmente os alunos da turma foram informados sobre o tema e os objetivos da pesquisa e, em seguida, foi entregue um TCLE (Termo de Consentimento Livre e Esclarecimento), que foi levado para seus responsáveis assinarem e estarem de acordo com a participação dos estudantes em virtude da menoridade, permitindo assim o uso do material gerado através da participação e respostas dos questionários, porém a identidade dos mesmos foi mantida em anonimato.

Em seguida, foi aplicado um pré-questionário com o intuito de identificar o grau de conhecimento sobre o conteúdo enzimas, tendo em vista que são alunos do primeiro ano do Ensino Médio e já haviam visto esse assunto na disciplina de Biologia. O pré-questionário era composto de sete questões objetivas, sendo as mesmas de vestibulares e ENEM que abordavam o assunto atividade enzimática. A aplicação de questionários em pesquisas apresenta-se como um instrumento eficaz na coleta de dados, proporcionando a descrição sobre uma determinada amostra, o que facilita a análise de dados pelo pesquisador (RICHARDSON, 2015).

Alguns dias após a aplicação desse primeiro questionário foi realizada uma aula prática no laboratório de Biologia e Química; a aula foi ministrada com base em um experimento sobre a atividade enzimática de uma enzima específica (catalase) e a demonstração da influência de fatores que alteram atividade enzimática, como $\mathrm{pH}$ e temperatura. Aulas práticas demostram ser uma metodologia muito eficiente na compreensão de conteúdos diversos, visto que só o fato do professor sair do ambiente da sala de aula tradicional e buscar novos mecanismos de aprendizagem, já desperta o interesse do aluno na aquisição de novos conhecimentos (LIMA; GARCIA, 2011).

No início da aula, através de um material audiovisual, foi feita uma breve abordagem do conteúdo enzimas, principalmente no que se refere aos fatores que afetam a atividade das mesmas (pH e temperatura); em seguida, foi demostrada experimentalmente a ação da enzima catalase presente no fígado em reação ao peróxido de hidrogênio, em condições de pH e temperatura alterado. O fígado foi cortado em quatro pedaços e colocado em quatro béqueres, dois pedaços cozidos e dois crus. Usou-se para alterar o $\mathrm{pH}$ do meio extrato de limão e a temperatura foi alterada pelo cozimento do fígado.

Os béqueres com fígado foram classificados como grupo 1, grupo 2, grupo 3 e grupo 4. O grupo 1 foi constituído pelo fígado cru e extrato de limão em um béquer; quando adicionado o peroxido de hidrogênio $\left(\mathrm{H}_{2} \mathrm{O}_{2}\right)$ não ocorreu a formação de bolhas e liberação de gás da reação 
por conta do meio ácido e por conta de o extrato de limão ter alterado o $\mathrm{pH}$ funcional da enzima catalase. $\mathrm{O}$ grupo 2 continha fígado cozido e, quando colocado $\mathrm{H}_{2} \mathrm{O}_{2}$ também não aconteceu a reação, pois com o cozimento do fígado houve elevação da temperatura, não sendo mais a temperatura ideal para enzima funcionar. O grupo 3 estava constituído pelo fígado cozido e com extrato de limão; ao adicionar $\mathrm{H}_{2} \mathrm{O}_{2}$ também não houve reação, pois além do meio ácido, ocorreu alteração da temperatura no cozimento. Somente no grupo 4 foi possível observar a reação acontecer, pois estava cru e a enzima catalase se encontra com os fatores (temperatura e $\mathrm{pH})$ ideais para sua atividade enzimática.

Após a realização da aula prática foi aplicado um novo questionário com as sete questões aplicadas antes da intervenção didática, a fim de analisar os rendimentos dos alunos quanto ao assunto e mais duas questões discursivas referente à metodologia da aula prática. As informações coletadas foram comparadas entre o primeiro e segundo questionário e os dados foram tabulados através do programa Microsoft Excel (2016), o que proporcionou a elaboração de gráficos, permitindo uma melhor apreciação e análise dos resultados.

\section{RESULTADOS E DISCUSSÃO}

A primeira pergunta foi retirada de um vestibular da PUC-RJ e apresentava um contexto e características sobre as enzimas, e posteriormente solicitava aos alunos que relacionasse quatro afirmações destacando a verdadeira. Os alunos no pré-questionário obtiveram apenas 6,7\% de acertos, após a intervenção didática observou-se uma melhora para 46,6\% no pósquestionário.

Segundo Meneses e Nuñez (2018), a compreensão dos conteúdos em sala de aula e a dificuldade de responder questões pode estar associada ao modo fragmentado e descontextualizado de abordar os conteúdos que são ensinados. $\mathrm{O}$ aluno consegue aprender mais quando o assunto que é passado na aula pode ser relacionado com as vivências do seu cotidiano; assim, é importante que o professor faça essa relação, promovendo uma ciência mais significativa, compreendida e aplicada pelos alunos.

Na segunda questão solicitou-se que os alunos identificassem quais fatores não afetam a atividade enzimática, com quatro alternativas. No pré-questionário 13,3\% dos alunos acertaram e no pós-questionário, 40\%. As enzimas são proteínas muito importantes, sua capacidade catalítica e especificidade, entre outros fatores, tornam as enzimas capazes de participar de diversas reações que garantem a manutenção da homeostasia no corpo humano (RODWELL et al., 2017).

Dessa forma, é necessário que o conteúdo enzimático seja abordado no ensino médio 
para que os alunos tenham conhecimento da importância dessas moléculas no organismo, bem como os fatores que podem alterar sua atividade enzimática, consequentemente prejudicando a saúde. Posto isso, aulas práticas se mostram como uma boa estratégia na assimilação de conteúdos propostos, principalmente através de experimentos em que o aluno consegue observar e aproximar da sua realidade, resultando em um indivíduo mais ativo e tornando os assuntos científicos mais compreensíveis (MARTINS; SILVA; SANTOS, 2019).

Quando questionados sobre o processo de desnaturação que as proteínas sofrem quando são expostas a modificações das condições ideais do seu funcionamento (PUC-RIO), no préquestionário obteve-se $30 \%$ de acertos e no pós-questionário, 86,7\%. Em seguida, na quarta questão indagou-se aos alunos o mecanismo pelo qual as enzimas reconhecem seu substrato (UFMA); antes da aula prática, 6,7\% marcaram ser através da forma tridimensional das moléculas e após a intervenção, na qual foi demostrado, por meio de um material didático, como a conformação de um substrato é fundamental para a ligação com a enzima, 66,7\% de acertos. Para Bartzik e Zander (2016), as aulas práticas tornam-se uma importante ferramenta para um aprendizado mais eficaz, proporcionando um ensino diferente que facilita a apreensão de conteúdos científicos trabalhados teoricamente em sala de aula.

$\mathrm{Na}$ aula prática foi abordado diversos aspectos sobre enzimas com demonstrações; assim, na quinta questão solicitou aos alunos que identificasse qual afirmação era incorreta sobre as enzimas (UFMT); no primeiro momento somente $16,7 \%$ de acertos e no pósquestionário, 63,3\% de acertos. Questões como essa exigem do aluno atenção, pois foi solicitada no teste a afirmação incorreta, como uma "pegadinha". Dessa maneira, é importante que o professor procure questões bem redigidas e contextualizadas, tendo atenção na elaboração do enunciado (CARVALHO, 2014).

$\mathrm{Na}$ questão seguinte buscava identificar se os alunos compreendiam a relação entre enzima e temperatura; para isso, foi ilustrado um gráfico que representava a atividade enzimática de uma determinada reação em função da temperatura com o ápice da curva em destaque (UFV). No pré-questionário apenas 13,3\% souberam estabelecer essa relação, marcando alternativa correta; após a intervenção didática, $80 \%$ dos alunos acertaram, demostrando um aumento significativo. Na última questão do primeiro questionário, indagouse sobre a definição de enzimas (MACK-SP); no pré-questionário 20\% de acertos e no pósquestionário $46,7 \%$ de acertos.

A análise dos dados permitiu a construção de um gráfico (figura 1) comparativo entre o pré-questionário e pós-questionário com relação ao desempenho dos alunos (\%). Em termos gerais, ao comparar o desempenho inicial e final dos participantes, observa-se que os alunos 
melhoraram seu rendimento, sugerindo que a aplicação de novas metodologias, como aulas laboratoriais, torna-se um importante mecanismo para se adotar no ambiente escolar. De acordo com Júnior, Silva e Wachholz (2019), uma aula que se distancia do tradicionalismo proporciona resultados positivos; assim, cabe ao professor elaborar aulas que contemplem o amadurecimento do aluno com relação aos conteúdos.

Figura 1. Comparação do desempenho nas questões do pré-questionário e pós-questionário de estudantes entrevistados em uma escola federal de ensino médio na cidade de Uruçuí - PI, Brasil.

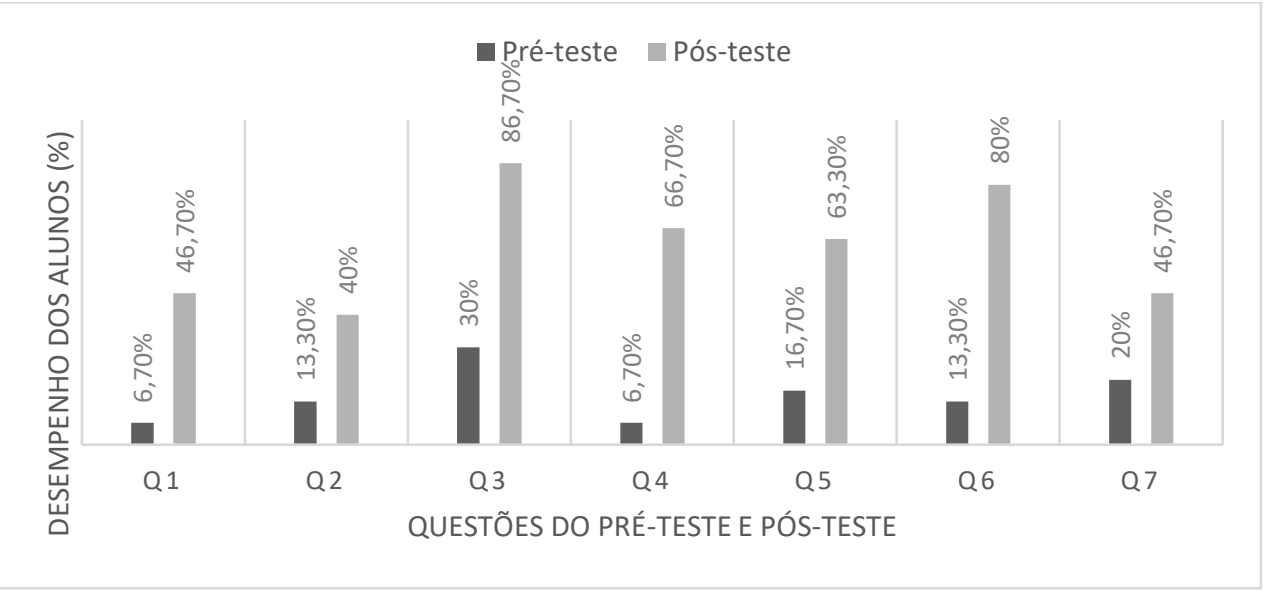

Fonte: Própria (2019).

Após a aplicação da aula prática, foi solicitado que os alunos indicassem em uma escala de 0 a 5 qual seu nível de satisfação com relação à aula prática. Desses alunos, 86,7\% indicaram ser 5, 10\% dos discentes indicaram ser 4, e 3,3\% indicaram ser 3, sendo que, dessa forma nenhum aluno demonstrou insatisfação, visto que não se obteve notas entre 0 e 2 (Figura 2).

Figura 2. Grau de satisfação com a aula prática de estudantes entrevistados em uma escola federal de ensino médio na cidade de Uruçuí - PI, Brasil

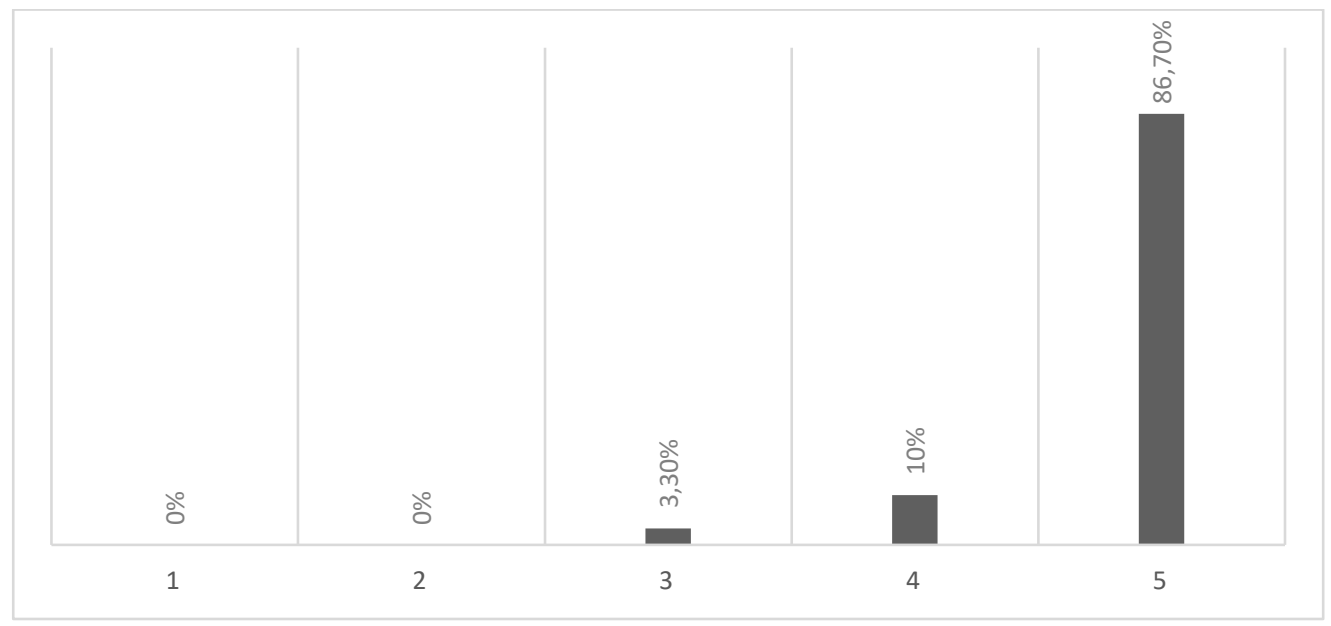

Fonte: Própria (2019). 
Ficou evidente que a realização de aulas práticas desperta o interesse do aluno e contribui significativamente no processo de ensino aprendizagem, o que pode ser observado no fato de que mais da metade dos alunos entrevistados $(86,7 \%)$ denotaram alto nível de satisfação com a aula. Fujita, Martins e Millan (2019) realizaram uma série de experimentos com alunos do ensino médio e também observaram grande satisfação por parte dos alunos com as aulas práticas, destacando que as mesmas movimentam e proporcionam mais participação dos alunos na aula, ampliando a compreensão do conteúdo.

Soares e Baiotto (2015), realizando entrevistas com professores de Biologia de escolas públicas sobre a aplicação de aulas práticas, observaram que $87 \%$ dos professores entrevistados são conscientes da importância de adotar como metodologia de ensino aulas práticas/experimentais; além disso, a maioria dos professores relatou que, quando utilizam recursos disponíveis, saindo do método tradicional, percebem que há maior interesse e motivação por parte dos alunos em aprender.

Em seguida, perguntou-se a opinião dos alunos "você acha que deveria ter mais aulas práticas? E o que mais contribui para seu aprendizado? Justifique”. Em relação a essa pergunta, $100 \%$ das respostas obtidas diziam que deveria ter mais aulas práticas, sendo algumas das justificativas:

\section{Aluno1 "porque não torna a aula chata"}

Aluno 2 "você vendo o experimento fixa o conhecimento."

Aluno 3 "Aulas práticas é uma forma de prender a atenção do aluno na aula e também incentiva a desenvolver pesquisas"

Aluna 4 "Com experimentos conseguimos ver o conteúdo, aprender e interagir mais em sala de aula"

O ensino-aprendizagem de Química e Biologia é favorecido pela utilização de aulas laboratoriais, porém o que se observa é uma ausência desse recurso, principalmente nas escolas públicas. Dessa forma, as aulas se tornam predominantemente teóricas e difíceis de serem entendidas pelos alunos, uma vez que eles não conseguem visualizar esses processos químicos e biológicos, ficando apenas com conceitos abstratos (FUJITA; MARTINS; MILLAN, 2019).

Segundo Moraes e Silva Junior (2015), uma aprendizagem mais significativa precisa estimular a curiosidade dos alunos, a fim de que eles se sintam motivados em aprender tais conteúdos, principalmente com a utilização de experimentos didáticos. O ensino tradicional, que em sua maioria envolve somente a parte conceitual, caracterizado pelos alunos como 
desestimulador para apreensão de novos conteúdos, necessita de novas estratégias. Assim, as aulas práticas surgem como importante ferramenta para atrair a atenção dos alunos.

\section{CONCLUSÕES}

Após a análise dos dados aqui apresentados, ficou evidente que o experimento realizado teve boa aceitação, visto que o grau de satisfação dos alunos foi alto, pois permitiu observar o conteúdo trabalhado mais próximo da realidade do aluno, já que água oxigenada e fígado bovino são materiais simples de obter e conhecidos no cotidiano dos discentes, e que dessa forma podem ser usados por docentes de Ciências/Biologia para melhorar suas aulas bem como o processo de ensino-aprendizagem.

A melhora no rendimento dos discentes com a utilização de uma aula prática ficou evidente também nas respostas dos alunos após a intervenção didática, onde observou-se que em todas as questões o número de acertos foi muito maior após a aula pratica. Dessa forma, esse trabalho estimula a adoção de aulas práticas para o fazer docente, principalmente de conteúdos mais imagináveis e de difícil compreensão e visualização, bem como a realização de pesquisas utilizando outras ferramentas didáticas em sala de aula, para que estas atinjam um maior público docente e possam ser mais praticadas no contexto escolar.

\section{REFERÊNCIAS}

BARTZIK, F.; ZANDER, L. D. A Importância Das Aulas Práticas De Ciências No Ensino Fundamental. Revista @ rquivo Brasileiro de Educação, Belo Horizonte, v.4, n. 8, 2016.

BICUDO, M. O. P.; LIMA, D. B.; SANTOS, S. L. S.; SILVA, L. L. A difusão da biotecnologia em Escolas Municipais de Dois Vizinhos: contextualizando a atividade enzimática. Repositório Institucional, 2017.

BRASIL, Ministério da Educação. Orientações Curriculares para o Ensino Médio Ciências da Natureza, Matemática e suas Tecnologias, vol. 2, 2006.

CARVALHO, P.R. O processo de avaliação e a sua importância para a aprendizagem. Revista de Ensino, Educação e Ciências Humanas, v. 15, n. 3, 2014.

DRESCH, A.; LACERDA, D. P.; ANTUNES JUNIOR, J. A. V. Design Science Research: método de pesquisa para avanço da ciência e tecnologia. Porto Alegre: Bookman, 2015. Disponível em: $\quad$ https://books.google.com.br/books?hl=ptBR\&lr=\&id=matYBQAAQBAJ\&oi=fnd\&pg=PR1\&dq=t\%C3\%A9cnica+de+survey+na+pes quisa\&ots=08EXjO5C4M\&sig=JowMakY0_0uueG4V0o90Oj0Gs14\#v=onepage \&q=t\%C3\% A9cnica\%20de\%20survey\%20na\%20pesquisa\&f=false>. Acesso em: 05/04/2019.

FERREIRA, A. Despertando o olhar científico no ensino de biologia para jovens e adultos (eja). 
Revista Areté| Revista Amazônica de Ensino de Ciências, v. 8, n. 17, 2017.

FUJITA, A. T.; MARTINS, H. L.; MILLAN, R. N. Importância das práticas laboratoriais no ensino das ciências da natureza. Brazilian Journal of Animal and Environmental Research, v. 2, n. 2, 2019.

JUNIOR, A. M.; SILVA, A. A.; WACHHOLZ, F. A IMPORTÂNCIA DE ATIVIDADES PRÁTICAS SOBRE ORIENTAÇÃO E LOCALIZAÇÃO GEOGRÁFICA NO ENSINO FUNDAMENTAL II. Revista Tocantinense de Geografia, v. 8, n. 14, 2019.

LIMA, D. B; GARCIA, R. N. Uma investigação sobre a importância das aulas práticas de Biologia no Ensino Médio. Cadernos do Aplicação, Porto Alegre, v. 24, n. 1, 2011.

MARTINS, A. M.; SILVA, D. M.; SANTOS, M. P. Percepções de alunos e professores sobre as aulas práticas de ciências em escolas estaduais de Formosa (GO). Scientia Naturalis, v. 1, n. 3, 2019.

MEDEIROS, F. V. G.; CATUNDA, A. G. V.; RODRIGUES, M. J. A. M.; CAVALCANTE, C. A. M. Análise da práxis docente em Biologia no ensino secundário português. Ciência \& Educação (Bauru), v. 23, n. 2, 2017.

MEIRA, I. A.; SILVA, A. S.; SANTOS, M. C.; SANTOS, D. S.; FORTUNA, J. L. Ensinoaprendizagem através de práticas laboratoriais de microbiologia. Ciência \& Tecnologia: FATEC-JB, Jaboticabal, v. 8, 2016.

MENESES, F. M. G.; NUÑEZ, I. B. Erros e dificuldades de aprendizagem de estudantes do ensino médio na interpretação da reação química como um sistema complexo. Ciência \& Educação (Bauru), v. 24, n. 1, 2018.

MORAES, J. U. P.; SILVA JUNIOR, R. S. Experimentos didáticos no ensino de física com foco na aprendizagem significativa. Latin-American Journal of Education Volume, v. 9, n. 2, p. 2504-1, 2015.

NELSON, D. L.; COX, M. M. Princípios de bioquímica de Lehninger. 6. ed. Porto Alegre: Artmed, 2014

NICOLA, J. A.; PANIZ, C. M. A importância da utilização de diferentes recursos didáticos no ensino de biologia. Infor, Inov. Form., Rev. NEaD-Unesp, São Paulo, v. 2, n. 1, 2016.

OLIVEIRA, M. A. R.; COSTA, F. S. Atividades práticas e espaços diferenciados para o ensino de Ciências e Biologia. Revista Maiêutica, Indaial, v. 4, n. 1, 2016.

RICHARDSON, R. J. (Ed.). n/a et al. Pesquisa social: métodos e técnicas. 3. Ed. São Paulo: Atlas, 2015.

RODWELL, V. W.; BENDER, D. A.; BOTHAM, K. M.; KENNELLY, P. J.; WEIL, P. A. Bioquímica ilustrada de Harper. 30. ed. Porto Alegre: AMGH, 2017.

SOARES, R. M.; BAIOTTO, C. R. Aulas práticas de biologia: suas aplicações e o contraponto 
COSTA, V. S.; COSTA, F. G.; CASTRO, Y. A. A.; CASTRO, I. F. A.

desta prática. Di@ logus, v. 4, n. 2, 2015. 


\title{
A MONITORIA PARA ALUNOS SURDOS E CEGOS NO IFRN NATAL - CENTRAL: UMA PROPOSTA PARA O ENSINO ESCOLAR
}

\section{MONITOREO PARA ESTUDIANTES SORDOS Y CIEGOS EN EL IFRN NATAL - CENTRAL: UNA PROPUESTA PARA LA ENSEÑANZA ESCOLAR}

\section{THE MONITORING FOR DEAF AND BLIND STUDENTS AT IFRN NATAL - CENTRAL: A PROPOSAL FOR SCHOOL TEACHING}

\author{
Jéssica Eduarda dos Santos Silva ${ }^{1}$; Arnaldo André de Sousa Júnior ${ }^{2}$; Geraldo Felipe de Souza \\ Filho ${ }^{3}$; Vanessa Gosson Gadelhas de Freitas Fortes ${ }^{4}$
}

DOI: https://doi.org/10.31692/978-65-991061-3-2.59-73

\section{RESUMO}

A proposta de inclusão no Instituto Federal de Educação, Ciência e Tecnologia do Rio Grande do Norte - IFRN, Campus Natal Central - CNAT foi abraçada pelo Núcleo de Apoio às Pessoas com Necessidades Educativas Especiais - NAPNE que criou um projeto/pesquisa de monitoria aos alunos com necessidades específicas, procurando incluir e auxiliar esses alunos, tanto no aspecto de ensino-aprendizagem, quanto no aspecto social. A partir de um teste de sondagem foram observadas as dificuldades por parte dos discentes nas áreas de exatas principalmente em física. Logo, em 2018, foram convidados a participar da monitoria de alunos surdos do ensino médio, e foi aberta a proposta para alunos com necessidades especiais NEE de todo o campus Natal-Central, para o ensino de física. Em 2019, foi proposto manter o desenvolvimento do projeto de pesquisa na área de monitoria em que os alunos da Licenciatura em Física do campus, voluntários do NAPNE se prontificaram a atender os alunos tanto com surdez quanto com deficiência visual/cegueira, de forma individualizada ou em dupla, para então desenvolver o conhecimento sobre os fenômenos físicos da natureza, utilizando ferramentas de software, materiais adaptados e monitoria em auxílio às aulas regulares. Os resultados até o momento é a progressão dos conhecimentos dos discentes e a autonomia para a compreensão dos conceitos físicos associados a situação do cotidiano, além da prática de ensino pelos alunos de licenciatura em física. Esta pesquisa tem por objetivo abordar as principais dificuldades no ensinoaprendizagem de alunos com necessidades específicas, e lançar uma proposta para a rede de ensino, no auxílio desses alunos.

Palavras-Chave: Educação, Inclusão, Monitoria, Surdos, Cegos.

\section{RESUMEN}

La propuesta de inclusión en el Instituto Federal de Educación, Ciencia y Tecnología de Rio Grande do Norte - IFRN, Campus Natal Central - CNAT fue aceptada por el Centro de Apoyo a Personas con Necesidades Educativas Especiales - NAPNE, que creó un proyecto para monitorear a los estudiantes. con necesidades específicas, buscando incluir y ayudar a estos estudiantes, tanto en la enseñanza-aprendizaje como en los aspectos sociales. En una prueba de sondeo se observaron las dificultades de los estudiantes en las áreas exactas, principalmente en física. Pronto, en 2018, se invitó a estudiantes sordos de secundaria a participar en el monitoreo, y se abrió la propuesta para estudiantes con necesidades en todo el campus de Natal-Central

\footnotetext{
${ }^{1}$ Licencianda em física, IFRN - CNAT, jessicaeduardasantos@gmail.com

${ }^{2}$ Licenciando em física, IFRN - CNAT, junior-andre50@ hotmail.com

${ }^{3}$ Mestre em ensino de física, IFRN - CNAT, souza.geraldo@academico.ifrn.edu.br

${ }^{4}$ Doutora em educação, IFRN - CNAT, vanessa.fortes@ifrn.edu.br
} 
para educación física. En 2019, se propuso continuar con el desarrollo del proyecto de investigación en el área de monitoreo en el que los estudiantes de pregrado en física, voluntarios de NAPNE se ofrecieron como voluntarios para atender a estudiantes con sordera y ceguera, individualmente o en parejas, para luego desarrollar el conocimiento sobre los fenómenos físicos de la naturaleza, utilizando herramientas de software, materiales adaptados y monitoreo para asistir a las clases regulares. Los resultados hasta ahora son la progresión del conocimiento y la autonomía de los estudiantes para comprender los conceptos físicos asociados con la situación cotidiana, además de la práctica docente de los estudiantes universitarios de física. Esta investigación tiene como objetivo abordar las principales dificultades en la enseñanzaaprendizaje de estudiantes con necesidades específicas, y lanzar una propuesta para la red escolar, para ayudar a estos estudiantes.

Palabras Clave: Educación, Inclusión, Monitoreo, Sordos, Ciegos

\section{ABSTRACT}

The proposal for inclusion in the Federal Institute of Education, Science and Technology of Rio Grande do Norte - IFRN, Campus Natal Central - CNAT was embraced by the Center for Supporting People with Special Educational Needs - NAPNE, created a monitoring project / research for students with specific needs, seeking to include and assist these students, both in the teaching-learning and social aspects. From a probing test it was observed the difficulties on the part of the students in the exact areas mainly in physics. Soon, in 2018, deaf high school students were invited to participate in the monitoring, and the proposal was opened for students with needs across the Natal-Central campus for the teaching of physics. In 2019, it was proposed to continue the development of the research project in the area of monitoring in which students of the undergraduate Physics Degree, volunteers of NAPNE, volunteered to attend students with deafness and blindness, individually or in pairs, for then develop knowledge about the physical phenomena of nature, using software tools, adapted materials and monitoring in support of regular classes. The results so far are the progression of students' knowledge and autonomy to understand the physical concepts associated with the daily situation, in addition to the teaching practice by undergraduate physics students. This research aims to address the main difficulties in the teaching-learning of students with specific needs, and launch a proposal for the school network, to help these students.

Keywords: Education, Inclusion, Monitoring, Deaf, Blind.

\section{INTRODUÇÃO}

Segundo o Instituto Brasileiro de Geografia e Estatística - IBGE, 2010, no Brasil cerca de 3,4\% da população possui deficiência visual (sendo baixa visão e cegueira) e 1,1\% da população possui deficiência auditiva (sendo baixa audição e surdez). De outro lado, em 2018, o Instituto Federal de Educação Ciência e Tecnologia do Rio Grande do Norte - IFRN, Campus Natal Central - CNAT, recebeu alunos com deficiência auditiva na monitoria proposta pelo Núcleo de Apoio às Pessoas com Necessidades Educativas Especiais - NAPNE que em 2019, no IFRN - CNAT se incrementou com discentes com deficiência visual no ensino superior da licenciatura em física.

Percebia-se claramente as dificuldades desses alunos na aprendizagem e nos conteúdos abordados, principalmente na área da matemática o que inercialmente justificamos com o antecedente de um ensino sem profissionais especializados, e sem auxílio às necessidades 
específicas durante o ensino básico, situação que atualmente ainda exclue pessoas com NEE e consequentemente os exclui do conhecimento. Pode-se perceber que muitas escolas ainda não estão preparadas para receber e abraçar as necessidades dos alunos, no que se refere a estrutura física, assim como a sua estrutura de ensino. E por isso, esta pesquisa implementa-se com o intuito de tornar conhecido, principalmente, as necessidades dos alunos com surdez e cegueira e expandir uma proposta para a rede de ensino.

\section{FUNDAMENTAÇÃO TEÓRICA}

A exclusão social está ligada de forma direta ao conceito sociocultural na qual a sociedade está inserida, nesse contexto o poder aquisitivo interfere no quesito de desigualdade social e consequentemente gera a exclusão, para Bichara:

A vivência de uma situação de desigualdade, de diferenciação social ou de exclusão é a privação das oportunidades e dos benefícios da vida social. Estar excluído é ocupar um lugar inferior ao dos demais, onde há, predominantemente, a falta e a necessidade. (Bichara, 2003, p. 35).

A exclusão diante à desigualdade se é perpetuado para toda a sociedade, assim como afirma Stainback, S \& Stainback, W, (1999):

Quando as escolas são excludentes, o preconceito fica inserido na consciência de muitos alunos quando eles se tornam adultos, o que resulta em um maior conflito social e em uma competição desumana. (STAINBACK, S.; STAINBACK, W., 1999, p.140).

No ponto de vista de Dorizat (2004) os alunos com NEE passa a ser inserido no ambiente acadêmico da mesma forma que os alunos considerados 'comuns", entretanto a forma na qual a instituição acolhe esses alunos não está devidamente qualificada para todas as individualidades.

As mudanças ocorridas pelo o processo de inclusão escolar são consideráveis para os alunos com necessidades educacionais especificas - NEE, como comprova Stainback, S. e Stainback, W. (1999):

O fim gradual das práticas educacionais excludentes do passado proporciona a todos os alunos uma oportunidade igual para terem suas necessidades educacionais satisfeitas dentro da educação regular. $O$ distanciamento da segregação facilita a unificação da educação regular e especial em um sistema único. Apesar dos obstáculos, a expansão do movimento da inclusão, em direção a uma reforma educacional mais ampla, é um sinal visível de que as escolas e a sociedade vão continuar caminhando rumo a práticas cada vez mais inclusivas. (STAINBACK, S.; STAINBACK, W., 1999, p.140).

Abordado o tema de inclusão escolar, a resposta imediata de uma gestão escolar é de 
afirmar a existência de um trabalho aplicado a pessoas com NEE, porém o que no geral pode acontecer é que o discente se adapta a rotina da escola, acredita-se que a inclusão ocorre quando o indivíduo se adequa ao meio, quando na verdade deveria ser o meio quem se adeque ao indivíduo com NEE, tal como afirmado por Pergher:

A inclusão escolar consiste na minimização de todas as barreiras à educação de todos os alunos, sendo um processo de adequação da realidade das escolas à realidade do aluno, visto que não é ele quem deve se adaptar a escola, e sim a escola tomar todas as providências possíveis para o aluno ter garantido seu direito à aprendizagem. (PERGHER apud BOOTH e AINSCOW, 2002).

Mediante essa afirmação Stainback, S. e Stainback, W. indica três componentes necessários para se construir uma escola na qual ocorra uma real inclusão:

Há três componentes práticos interdependentes no ensino inclusivo. O primeiro deles é a rede de apoio, o componente organizacional, que envolve a coordenação de equipes e de indivíduos que apóiam uns aos outros através de conexões formais e informais (Stainback \& Stainback, 1990a, 1990b, 1990c; Villa \& Thousand, 1990). Stone e Collicott (1994) descreveram um sistema bem-sucedido de uma rede de três camadas: grupos de serviço baseados na escola, grupos de serviço baseados no distrito e parcerias com as agências comunitárias. Todos esses grupos funcionam em uma base de apoio mútuo para capacitar o pessoal e os alunos. O segundo componente é a consulta cooperativa e o trabalho em equipe, o componente do procedimento, que envolve indivíduos de várias especialidades trabalhando juntos para planejar e implementar programas para diferentes alunos em ambientes integrados (Harris, 1990; Porter, Wilson, Kelly \& den Otter, 1991; Pugach \& Johnson, 1990; Thousand \& Villa, 1990). O terceiro é a aprendizagem cooperativa, o componente do ensino, que está relacionado à criação de uma atmosfera de aprendizagem em sala de aula em que alunos com vários interesses e habilidades podem atingir o seu potencial (Johnson \& Johnson, 1986; Sapon-Shevin, 1990).(STAINBACK, S.; STAINBACK, W., 1999, p.140).

No ano de 1994, foi elaborado na Conferência Mundial em Salamanca, na Espanha, um documento no qual procurava proporcionar uma base para os sistemas educacionais buscando melhor agregar o movimento de inclusão social. Foi a partir da Conferencia em Salamanca que o assunto de inclusão começou a ser discutida e respeitada, como afirma Santos et al (XXI-?):

\footnotetext{
A partir do documento de 1994, as reflexões sobre as necessidades educacionais especiais dos indivíduos passaram a ser respeitadas, e a situação da acessibilidade começou a ser discutida para um melhor desenvolvimento social e educacional das pessoas com necessidades especiais e de todos os indivíduos desfavorecidos. (Santos et al, XXI-?)
}

No Brasil, apenas na década de 90 começou a implantar-se políticas de inclusão, sendo discutidos os temas de acessibilidade, qualidade no ensino e a inclusão dos deficientes no ensino superior (CARVALHO, 2015). Entretanto, atualmente as políticas de inclusão ainda enfrentam dificuldades e possuem necessidades de ajustes, indicando um grande trajeto a percorrer nas ações que auxiliam as pessoas com deficiência (BORGES, 2011).

Sobre o desenvolvimento das habilidades dos alunos com NEE, Borges afirma, 
O processo de inclusão se preocupa em garantir a todos os alunos, independentemente das suas condições especiais, o mesmo direito com relação à educação e ao atendimento das necessidades especificas, para que possam desenvolver suas habilidades.” (BORGES apud SANTOS et al, 2017).

Para a real efetivação do processo de inclusão é de suma importância que as escolas regulares combatam as atitudes discriminatórias, criando um ambiente propicio e acolhedor para que assim seja alcançado uma educação para todos, conforme a Declaração de Salamanca.

A fim de desenvolver as habilidades na área de ciências da natureza especificamente em física, foram utilizadas a Zona de Desenvolvimento Proximal-ZDP, para SILVA, “A Zona de Desenvolvimento Proximal é a distância entre aquilo que o ser humano consegue fazer sozinho e o que ele consegue desenvolver com a mediação do outro". Para isso, foi utilizado um universo de ações do cotidiano, envolvendo os discentes em uma metodologia que concebesse uma visão crítica, criativa e transformadora do mundo no qual estão inseridos.

Portanto, buscando o auxílio de tutores no ensino de alunos com NEE o processo de ensino-aprendizagem passa a ser significativo, como declara SILVA, "Não é possível aprender e apreender sobre o mundo, sobre as coisas, se não tivermos o outro, ou seja, é necessário que alguém atribua significado sobre as coisas, para que possamos pensar o mundo à nossa volta". (SILVA, 2007, p.12). Para isso ocorrer o monitor serve como mediador da construção do conhecimento, atuando diretamente no potencial em que o aluno com tal individualidade é capaz de alcançar com a assistência de um terceiro. Com diferentes recursos educativos, estratégias de ensino, técnicas e a organização específica para o aluno, passa a ocorrer de fato o ensino-aprendizado, como assegurado no Art. 59 da Lei de Diretrizes e Bases - Lei 9394/96.

Para um melhor ensino-aprendizagem é realizado um trabalho no qual os discentes sintam confiança com o tutor e expressem, sem receio, seus valores, suas opiniões e sentimentos, pois:

Se os professores aceitam os alunos como eles são, permitem que expressem seus sentimentos e atitudes sem condenação ou julgamentos, planejam atividades de aprendizagem com eles e não para eles, criam uma atmosfera de sala de aula relativamente livre de tensões e pressões emocionais, as consequências que se seguem são diferentes daquelas observadas em situações onde essas condições não existem. As consequências, de acordo com as evidências atuais, parecem ser na direção de objetivos democráticos (ROGERS apud GOBBI; MISSEL, 1998, p.27).

Com base no modelo construtivista de Vygotsky e a partir da interação entre os monitores e os alunos - sendo fundamental para a Zona de Desenvolvimento Proximal, é aplicado estratégias pedagógicas adequado para cada tipo de deficiência. A cegueira por sua vez é oferecido materiais na qual é mais utilizado o tato, para Domingues et al (2010): “[...] deficiência requer a utilização de estratégias e de recursos específicos, sendo muito 
importante compreender as implicações pedagógicas dessa condição visual e usar os recursos de acessibilidade adequados no sentido de favorecer uma melhor qualidade de ensino.”.

Também utilizando estratégias nos recursos a serem utilizados com os alunos com deficiência auditiva é buscado não só uma melhor qualidade de ensino como também uma maior interação com os monitores e todo o corpo acadêmico, segundo Santos e Chagas:

\footnotetext{
"A inclusão de surdos deve passar primeiramente pela valorização da qualidade do ensino oferecido e por uma atenção especial à formação dos profissionais que trabalham direta ou indiretamente com esses alunos. A escola, como um todo, deve estar apta para atender as necessidades específicas dos alunos surdos, devendo atentar para que haja uma verdadeira interação entre ouvintes e surdos não estando restrita apenas a uma pequena noção da Libras. [..]". Santos e Chagas (2012, p. 10).
}

As formas de tentar driblar todas as barreiras inseridas no processo de inclusão, vem proporcionando ao aluno com NEE ambientes adequados o que facilita a aprendizagem do aluno. De acordo com Juvêncio (2013):

[...] além da limitação proveniente da deficiência no aluno, esta tende a se tornar uma barreira ao aprendizado quando prejudica a sociabilidade, a interação social, a cultura e a história. O desenvolvimento de recursos de acessibilidade é, antes de qualquer coisa, uma maneira de tentar dirimir as barreiras e proporcionar ao aluno com deficiência os ambientes adequados para a aprendizagem.

\section{METODOLOGIA}

Esta pesquisa é qualitativa e tem por objetivo proporcionar ideias que motivam e melhoram o ensino de física (mas também de outras áreas), para alunos com necessidades especiais específicas, em especial para surdos e cegos.

Além de contribuir com a inclusão desses alunos no campus IFRN Natal - Central, sendo essa uma pesquisa-ação que segundo Elliott (1997), permite superar as lacunas existentes entre a pesquisa educativa e a prática docente, ou seja, entre a teoria e a prática, e os resultados ampliam as capacidades de compreensão dos professores e suas práticas, por isso favorecem amplamente as mudanças. Mas também uma pesquisa aplicada, que busca produzir um conhecimento aplicado no cotidiano, auxiliando em uma situação.

Tendo a educação como campo de exploração de ideias para aplicações no ensino de alunos surdos do ensino médio integrado, e alunos cegos e com baixa visão do ensino médio de licenciatura em física. Os monitores que auxiliam no ensino desses alunos, são licenciandos em física do IFRN Natal - Central que utilizam nas monitorias, quadro branco e pincel, projetor e slides, programas e softwares, materiais e textos adaptados, e materiais de laboratório de física.

As monitorias dos surdos acontecem em salas que os monitores reservam com antecedência, com o auxílio de softwares, materiais concretos, tanto adaptados quanto de laboratório, ou uso de quadro e pincel contando com o conhecimento básico de libras dos monitores. 
De mesmo modo, as monitorias dos alunos cegos acontecem em salas reservadas pelos monitores, e se utiliza de materiais adaptados e concretos criados pelos próprios monitores com o intuito de passar o conhecimento através do tatear (tato) do aluno. Além disso são feitos resumos por áudio e auxílio nas dúvidas dos mesmos pelos monitores.

\section{RESULTADOS E DISCUSSÃO}

É inegável que o ensino de alunos com NEE mudou bastante visto que, foi preciso percorrer um longo caminho para que as pessoas com qualquer tipo de deficiência sejam aceitas na sociedade, e por consequência na escolarização. Antes, a sociedade excluiu e segregou pessoas com tais necessidades, até o século XX, mais precisamente na década de 60 a 70, em que foram integrados à sociedade. Essa integração se dava pela aceitação dessas pessoas, mas elas tinham que se adaptar à sociedade, e no âmbito escolar, os alunos com NEE tinham que ser atendidos apenas na classe especial, essa composta apenas de alunos com NEE. É somente na década de 90 que surge o paradigma da inclusão, que vai enfatizar a igualdade de oportunidades para todos, incluindo pessoas com necessidades especiais, tanto na sociedade quanto na escola (MATOS, 2003). É dito processo de inclusão, pois, além de ser uma novidade para a sociedade, tendo em vista a quantidade de séculos que passamos, a inclusão é algo que deve ser feito dia após dia, com o intuito de incluir essas pessoas em todas as áreas da sociedade.

Entrando no âmbito da educação, a possibilidade de inclusão foi proposta por vários movimentos a favor da inclusão, além disso, foi de suma importância a declaração de Salamanca (1994) que afirma o direito de todas as crianças, incluindo alunos com NEE, à educação independente de gênero. A inclusão dita escolar vem garantir esse direito nas escolas, para que projetos político-pedagógicos sejam implementados com o propósito de dar o direito de acesso, ingresso, e permanência de todos os alunos na escola, independentemente do talento, necessidades específicas, origem socioeconômica ou cultural (STAINBACK, S; STAINBACK, W. 1999).

Porém, mesmo com todo o bom impacto causado pela inclusão, é preciso se atentar para as inadequações que ainda fazem parte de nossa sociedade. $\mathrm{Na}$ área da educação, não é difícil conhecer escolas que ainda não estão aptas a inclusão, tanto na parte da estrutura física como também na área do processo de ensino para àqueles que possuem necessidades específicas. $\mathrm{O}$ fato de muitas escolas não admitirem profissionais capacitados para dar assistência às necessidades de alunos com NEE é consequência de não aceitarem os mesmos como alunos da instituição.

A educação inclusiva não exclui a possibilidade de existir uma educação especial, desde 
que ocorram em paralelo. Inclusive, a educação inclusiva depende da existência de suportes especializados, na formação de profissionais especialistas em diferentes tipos de necessidades especiais e de ensino (BLANCO; GLAT, 2007). Por isso, no Brasil, o Atendimento Educacional Especializado - AEE é obrigatório aos alunos com NEE, sendo ofertado no turno inverso ao da classe comum. O AEE auxilia no processo de ensino aprendizado do aluno com NEE, sendo desenvolvido por um profissional especializado que verifica as barreiras para a aprendizagem e adequa materiais, formas de se trabalhar e ambientes que favoreçam o ensino para o aluno em questão, que será observado pelo educador do ensino regular deste aluno, trabalhando em parceria com o AEE.

Esta pesquisa tem a proposta de levar a monitoria como meio de complementar as aulas e tirar dúvidas desses alunos, buscando trabalhar de forma à auxiliar no conhecimento de uma área especifica da área das ciências (física), e colocá-los em nivelamento aos alunos da mesma turma do ensino regular. Contando com a parceria do professor do ensino comum desses mesmos alunos. É aplicado por monitores alunos da licenciatura em física, de forma que aconteça na própria instituição de ensino dos alunos com NEE, o IFRN Natal - Central. Utilizando o auxílio de materiais adaptados e apropriados para um melhor ensino-aprendizagem deles.

A atuação acontece na área da física e matemática, porém os primeiros alunos monitores foram os alunos de física que se disponibilizaram voluntariamente para este trabalho. A área da física é abordada pois, muitos alunos têm dificuldade nessa matéria, sendo formada por teoria e cálculos matemáticos. Além de experimentos físicos em que muitas vezes são abordados a comparação dos resultados teóricos e o resultado experimental. Isso torna essa disciplina complexa para qualquer aluno.

Para melhor abranger toda essa discussão na área da física, os resultados obtidos no ensino de física dos alunos surdos e cegos na tutoria, será dividida em suas necessidades.

\section{Pessoas surdas}

Os surdos totais são aqueles que tem perda total (ou próximo disso) da audição, já o termo deficiente auditivo é utilizado pela medicina, e pode ser considerado aquele que tem perda parcial da audição, porém muitos surdos não utilizam essa terminologia, e acreditam que vai depender do indivíduo e de como ele se enxerga na comunidade surda. Uma pessoa que é surda não se utiliza da linguagem oral, mas da linguagem corporal, denominada LIBRAS no Brasil.

É a partir da LIBRAS que um surdo se comunica e entende o que querem explicar para 
ele. Por isso, na sala de aula é imprescindível a atuação de um intérprete para traduzir a aula falada na linguagem nativa do professor da escola regular para a linguagem da LIBRAS. Essa linguagem, diferente da língua oral que contêm conectivos, é visual e passada de uma forma direta. Por isso, esses alunos têm uma forma abstrata de pensar, e até de socializar-se.

\section{Surdos do projeto de tutoria}

No começo do projeto/pesquisa, segundo semestre de 2018, os monitores trabalhavam com três surdos do ensino médio auxiliando no contra turno das aulas no IFRN Natal-Central. As aulas eram aplicadas no laboratório de mecânica do curso da física, utilizando-se materiais como: régua, fita métrica, calculadora, entre outros. Além de materiais de matemática, como escala cuisenaire, geoplano, materiais de laboratório como massas de ferro, transferidor, quadro, pincel, softwares entre outros

Figura 1 - Coordenadas cartesianas, na foto os alunos analisam as coordenadas com auxílio de tecnologia assistiva e quadro.
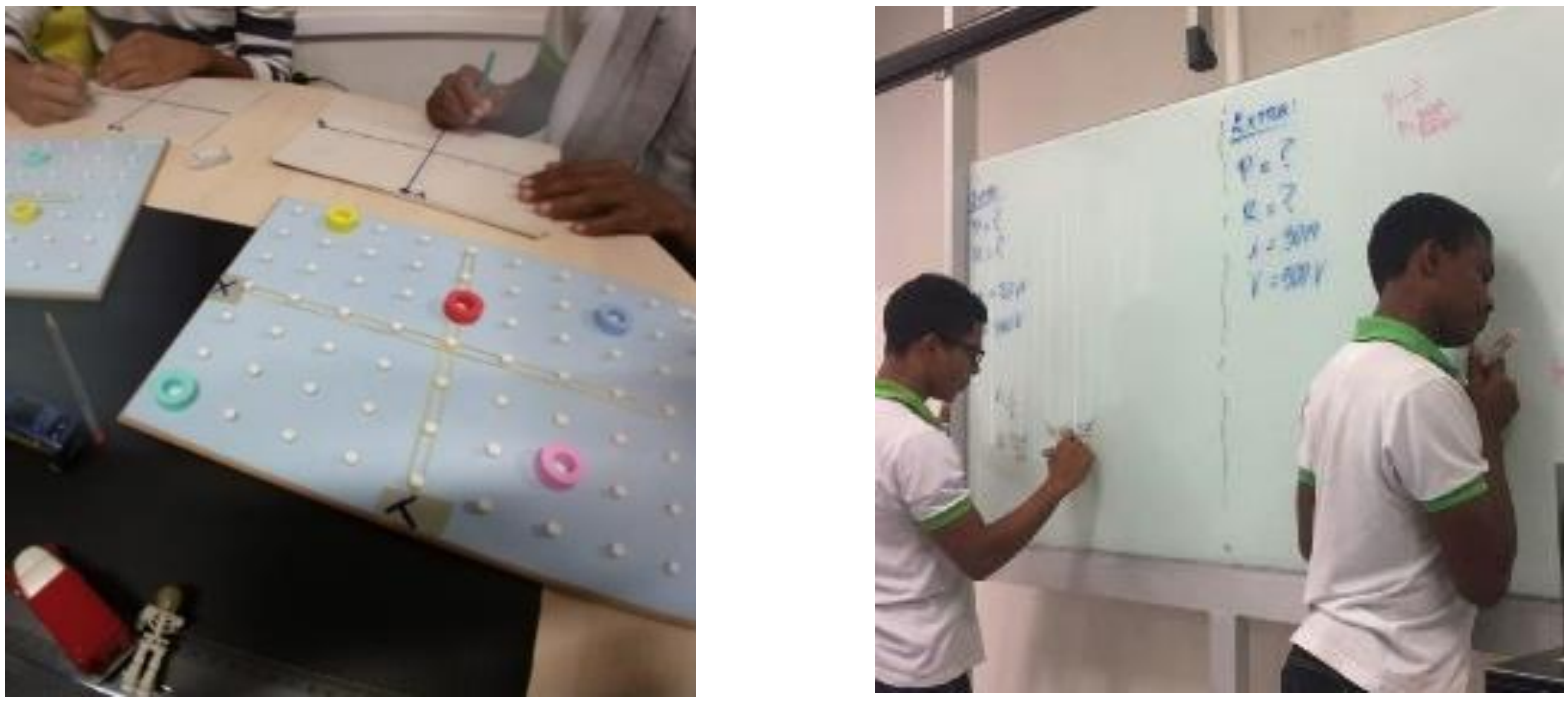

Fonte: Própria (2018,2019).

No começo, os surdos tinham grande dificuldade com matemática básica, e por isso, abordamos os conceitos matemáticos antes de entrar em conceitos físicos. Assuntos que precisavam de noções de tempo, espaço e matemática financeira eram desconhecidos pelos alunos. Isso porque esses alunos não tinham o auxílio de intérpretes no ensino anterior, isso provocou um enorme problema em estudantes que, quando chegavam em sala, eram integrados a turma socialmente, mas excluídos de aprender um novo conhecimento. Apenas no ensino médio integrado do IFRN tiveram auxílio de intérpretes.

A partir das aulas de tutoria em conjunto ao ensino regular em parceria com o intérprete 
em sala de aula e nas tutorias, esses alunos conseguiram aprender conceitos e conhecimentos que antes não eram direcionados a eles. De forma abstrata calcularam a área de quadrados e triângulos utilizando réguas e transferidor para medir ângulos de triângulos e abordar assuntos como teorema de Pitágoras. A tutoria também serviu como um auxílio as aulas de física, depois de ser abordado os conceitos básicos de matemática. Conceitos como velocidade, distância percorrida, aceleração, foram trabalhados de forma abstrata com o auxílio de bonecos, geoplano, e inclusive com o cronômetro correndo ao redor da quadra para calcular velocidade e aceleração.

Figura 02 - Monitoria dos discentes surdos utilizando tecnologias assistivas, questões de velocidade e deslocamento e operações com números inteiros, visando a aprendizagem dos números negativos e

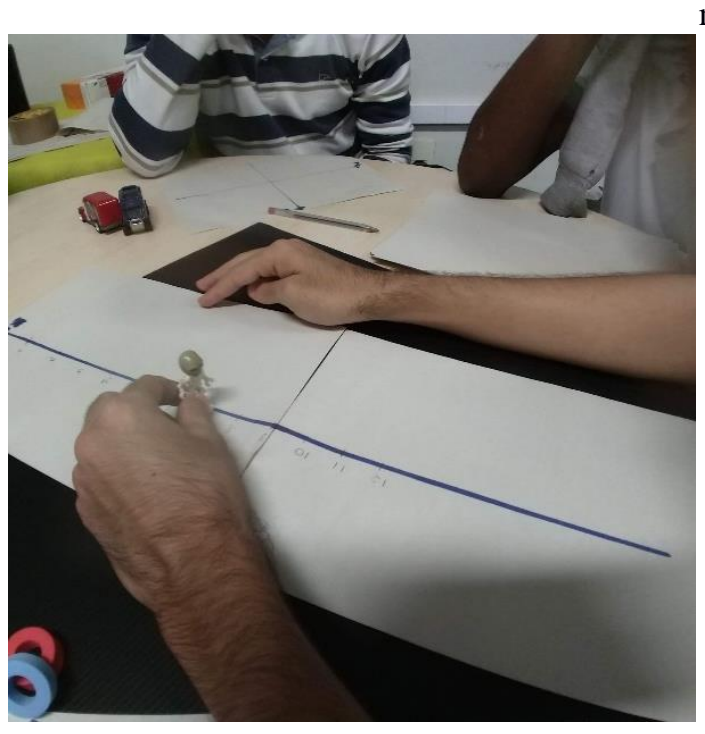
matemática financeira.

Fonte: Própria (2018).

No início de 2019, os surdos conseguiram nivelar e adquirir conhecimentos, dois deles conquistaram a progressão de turma para o segundo ano do ensino médio integrado e continuaram na tutoria contando com o auxílio dos monitores que estão abordando, conteúdos de ondas, óptica, eletromagnetismo e termodinâmica. No mesmo ano, os monitores começaram tutoria com mais três alunos surdos que entraram no IFRN, desenvolvendo os conteúdos do primeiro ano do ensino médio, no quadro e com pincel e utilização das LIBRAS, e se possível utilizando materiais. 
Figura 03 - Monitores aplicando diferentes estratégias para melhor adequar o conteúdo.

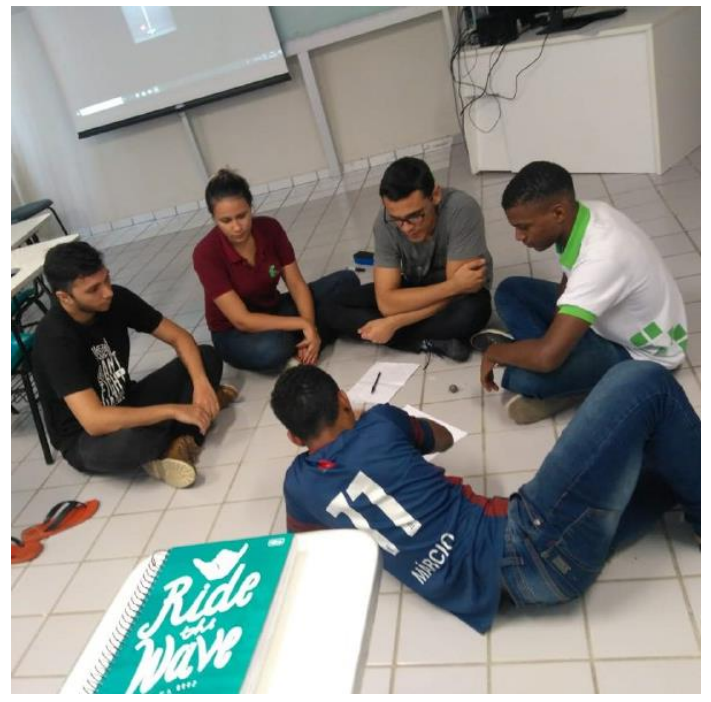

Fonte: Própria (2019).

É importante ressaltar que o método trabalhado com alunos surdos é diferente do método habitual, envolvendo a utilização de objetos concretos e visuais, e por isso algumas adaptações podem ser necessárias para a sala de aula, tanto das aulas regulares quanto das monitorias:

- Posicionar o aluno de forma que possa ver os movimentos do rosto do professor e dos alunos;

- Utilizar materiais visuais e a escrita para que o aluno absorva as informações verbais;

- Utilizando recursos e materiais adaptados;

- Utilizar textos com elementos que favoreçam sua compreensão ligados a língua de sinais;

- Promover a interpretação de textos através de materiais físicos, como pinturas, desenhos;

- Utilizar sempre um meio alternativo de comunicação, como: língua de sinais, linguagem gestual, leitura facial etc.

- Evitar falar de costas, falando sempre o mais claro possível, principalmente para alunos que sabem leitura labial;

- Fornecer uma cópia dos textos antes das aulas;

- Fornecer tempo extra para o aluno responder a provas e testes;

- Evitar ficar de frente a alguma fonte de luz, para não obstruir a visão do aluno;

- Não utilizar o quadro ou material e explicar simultaneamente. 


\section{Pessoas cegas}

É dito cego aquele que perdeu a visão ou está em um estado de quase perda, e deficiente visual aquele que tem problemas de visão, como: miopia, hipermetropia, presbiopia, astigmatismo etc. Esses com deficiência na visão utilizam-se de óculos como um instrumento que auxilia na necessidade que possui. Já o cego, utiliza-se da audição e o tato como meio de entender o mundo a sua volta.

Por isso, na sala de aula é preciso a ajuda do leitor-transcritor, aquele que vai ser os olhos para o aluno cego e ler tudo o que ele precisa saber no quadro e em qualquer folha de atividade, e também transcrever para uma folha tudo o que foi escrito no quadro ou a resposta de algum exercício ou prova.

\section{Pessoas cegas do projeto de tutoria}

No início de 2019, três pessoas cegas entraram no curso de física do ensino superior do IFRN Natal Central. Dois eram totalmente cegos e um com baixa visão. Assim que entraram, a monitoria no ensino de física no contraturno desses alunos foi proposta a eles, e teve o objetivo de ajudar a tirar dúvidas e auxiliar na percepção do conteúdo de forma que eles possam realmente apreender, por meio de objetos e materiais tateados por eles e aulas enviadas por áudio para ouvirem em casa.

Figura 04 - Alunos cegos caminhando pelo campus para obter noções de distância e utilizando materiais adaptados como estratégia de ensino.
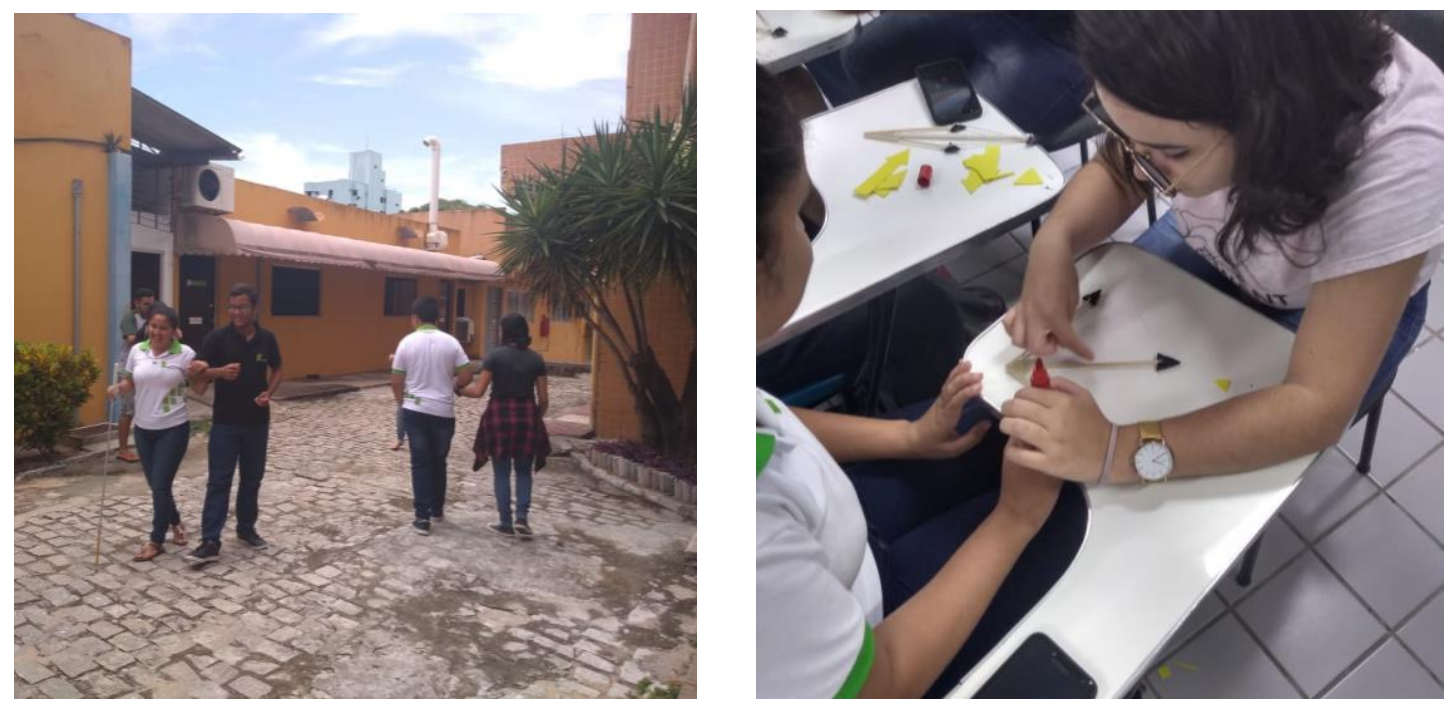

Fonte: Própria (2019).

Inicialmente, eles tinham muita dificuldade pois, no ensino anterior não havia nenhum profissional que os auxiliassem em sala de aula, e não havia monitorias. Apenas frequentavam 
aulas regulares sem nenhum apoio escolar. Mas, depois de participarem das monitorias era perceptível a vontade de aprender de uma das alunas, culminando em sua aprovação na primeira disciplina de física do curso, que no momento está cursando as disciplinas do segundo semestre de 2019.

O trabalho da monitoria com pessoas cegas foi sempre procurar adaptar textos, transformando em áudios, e adaptar materiais, para serem tateados pelos alunos na busca de um melhor entendimento do assunto, como foi feito com o assunto de vetores, velocidade, entre outros, abordados em coordenadas cartesianas.

Figura 05 - Discentes com deficiência visual em monitoria sobre vetores.
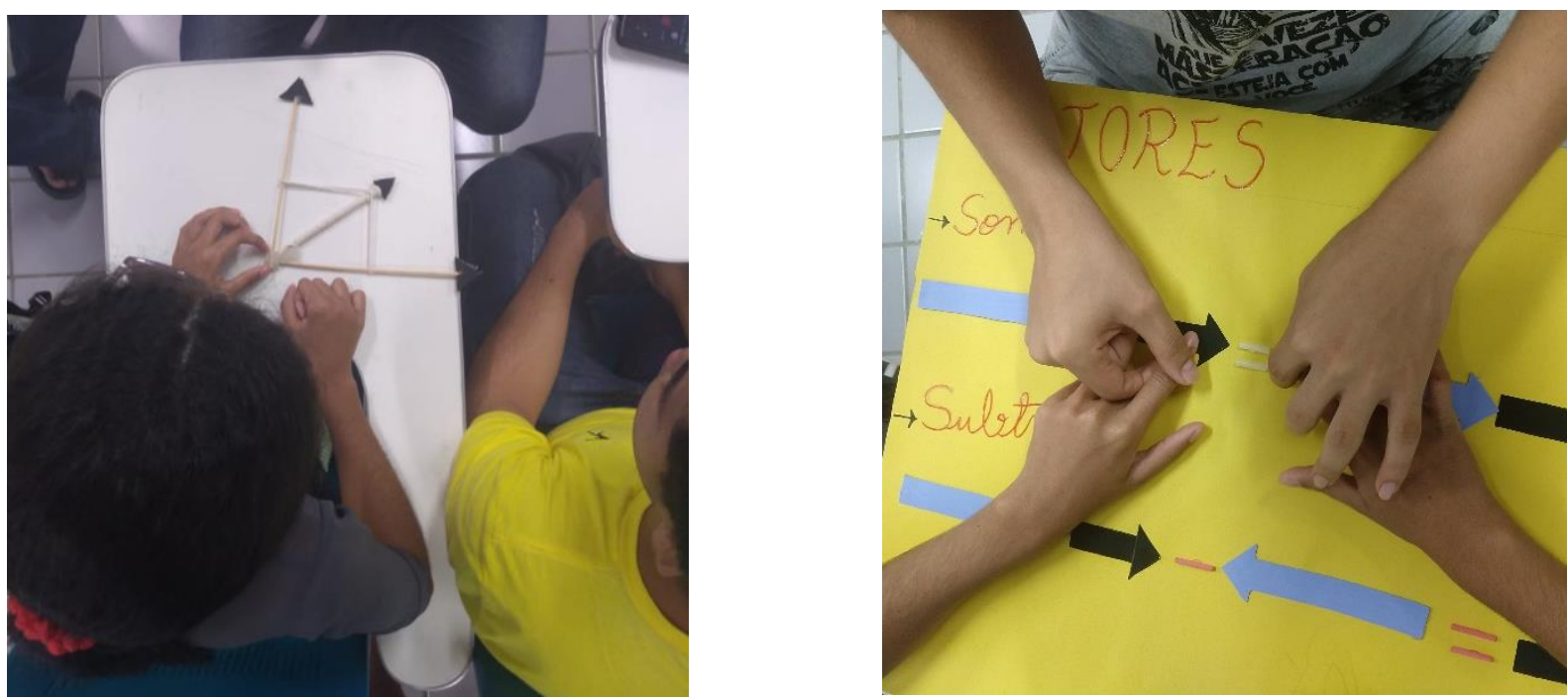

Fonte: Própria (2019).

Portanto, é possível observar que materiais adaptados e áudios são valiosos no ensino a pessoas cegas. Ainda mais com o auxílio do braille, um sistema de escrita tátil, porém não são todos os que compreendem o braille, apenas um dos três alunos era familiarizado com o braille.

A forma de agir em sala de aula para o professor ou monitor é diferente quando na classe existe alunos com cegueira. Levar em conta algumas orientações durante a sala de aula auxiliam os alunos com tais necessidades e é importante para o processo de ensino-aprendizagem deles.

- Posicionar o aluno para favorecer a audição dele na sala de aula;

- Facilitar a locomoção do aluno na sala de aula, para uma maior independência dele, e evitar acidentes;

- Explicar oralmente de forma detalhada todo o material e desenho visual utilizado em sala;

- Oferecer suporte instrucional, físico e verbal para que o aluno possua maior locomoção, referente a orientação espacial, podendo ser oferecida também pelos 
colegas;

- Aumentar o tempo disponibilizado para a realização de atividades e provas;

- Ajudar, apenas, no que for necessário ao aluno;

- Ter um comportamento natural diante do aluno, sem expressar qualquer superproteção ou indiferença;

\section{CONCLUSÕES}

Atualmente, os monitores do projeto estão em tutoria com os surdos do segundo ano e os do primeiro, além dos cegos do ensino superior de física. A evolução dos alunos surdos do segundo ano foi gratificante, pois, passaram de alunos que não entendiam conceitos básicos de matemática, e conceitos do cotidiano como financeiro, horas e distância, para alunos que melhor entendiam esses conceitos e aprendiam novos conceitos que os próprios colegas de sala não tinham conhecimento, de forma a causar um melhor nivelamento com a turma. Isso foi possível principalmente pelo desempenho e vontade de aprender desses alunos.

Já na tutoria com os cegos, uma aluna dos três se destacou e foi aprovada na disciplina de pré-cálculo e elementos de física, sendo essas fundamentais para o andamento do curso. Mais uma vez, isso apenas foi possível pelo esforço e vontade de aprender da aluna, que se dedicou as aulas regulares e as tutorias. Dito isso, é indispensável que o aluno, com ou sem necessidades, possua vontade e dedicação aos estudos para que os conhecimentos sejam realmente concretizados.

Esse processo na vida dos alunos com NEE é possível desde que sejam auxiliados em suas necessidades básicas, pois, todos os alunos são abertos ao conhecimento, afinal, somos seres racionais. E por tudo que foi abordado até aqui, é sugerido o desenvolvimento do trabalho de monitoria como uma proposta de ensino para ambas redes, estaduais e privadas, para que esses alunos também tenham direito ao conhecimento e que nenhuma dificuldade ou necessidade deles se tornem uma barreira na metodologia de ensino, no processo de ensinoaprendizagem e no processo de inclusão de todos os alunos ao ensino.

\section{REFERÊNCIAS}

BOOTH, T.; AINSCOW, M. Index For Inclusion. Portugal: Associação Cidadãos do Mundo, 2002.

Bichara TAC. Exclusão e informalidade: um estudo sobre o lugar social dos vendedores ambulantes do centro histórico de Quito - Equador [dissertação de mestrado]. São Paulo: Pontifícia Universidade Católica de São Paulo; 2003. 
BRASIL. [Constituição (1996)]. Leis de Diretrizes e Bases - LDB. [S. l.: s. n.], 1996.

BORGES, Maria Aparecida. A INCLUSÃO DE ALUNOS COM DEFICIÊNCIA EM CURSOS PRESENCIAIS DE GRADUAÇÃO DA UNIVERSIDADE FEDERAL DE JUIZ DE FORA. 2011. Dissertação (Pós-Graduação em Educação) - Faculdade de Ciências e Tecnologia da Universidade Estadual Paulista, [S. l.], 2011.

Dorizat, A. (2004). Educação De Surdos No Ensino Regular: Inclusão Ou Segregação? Revista do Centro de Educação Especial, n.24, 2004. https://periodicos.ufsm.br/educacaoespecial/article/view/4921/2955.

DEClARAÇÃO DE SALAMANCA: Sobre Princípios, Políticas e Práticas na Área das Necessidades Educativas Especiais, 1994, Salamanca-Espanha.

DIAS, Rayala Santos et al.. Percepção dos Monitores para Alunos com Deficiência Visual nos Cursos de Administração e Ciências Contábeis, [s. l.], 1 dez. 2017.

FRIAS, Elzabel Maria; MENEZES, Maria Christine. INCLUSÃO ESCOLAR DO ALUNO COM NECESSIDADES EDUCACIONAIS ESPECIAIS: contribuições ao professor do Ensino Regular. Inclusão, [s. l.], XXI-?.

Stainback, W., \& Stainback, S. (1999). Inclusão Um Guia Para Educadores. PORTO ALEGRE: ARTMED.

Santos, Alex Et Al. Edueducação Inclusiva E A Declaração De Salamancacação Inclusiva E A Declaração De Salamanca. Educação Inclusiva E A Declaração De Salamanca, [S. L.], Xxi Xxi-?. Disponível Em: Https://Portal.Fslf.Edu.Br/Wp-Content/Uploads/2016/12/Tcc_07.Pdf. Acesso Em: 22 Out. 2019.

SILVA, Daniela Regina da. Psicologia da Educação e Aprendizagem. Associação Educacional Leonardo da Vinci (ASSELVI). - Indaial: Ed. ASSELVI, 2006.

SANTOS, Maria Viviane dos; CHAGAS, Yasodaria Maria Mota. Educação inclusiva para surdos: desafios e perspectivas. IN: Editora Realize, Campina Grande, 2012. 


\title{
APRENDIZAGEM DAS REGULARIDADES ORTOGRÁFICAS: ESTRATÉGIAS PARA RESOLVER DESAFIOS DESENVOLVIDAS POR ALUNOS DURANTE A REALIZAÇÃO DE JOGOS ORTOGRÁFICOS
}

\author{
Shirley Thayza Soares de Souza; Rosy Karine Pinheiro de Araújo; Ana Cláudia Rodrigues \\ Gonçalves Pessoa
}

DOI: https://doi.org/10.31692/978-65-991061-3-2.74-90

\begin{abstract}
RESUMO
O objetivo geral deste estudo foi analisar as estratégias que os alunos desenvolveram para resolver os desafios durante a realização de jogos ortográficos e como essas estratégias interferiram na aprendizagem das regras trabalhadas. Aplicamos 06 jogos de ortografia, abordando regularidades contextuais M/N, C/QU e R/RR. Participaram das sessões de jogos 20 sujeitos ( 10 crianças do $3^{\circ}$ ano e 10 crianças do $5^{\circ}$ ano) do Ensino Fundamental I da rede municipal de ensino da cidade do Recife. Mediante a análise categorial temática de Bardin como técnica de análise do conteúdo, nossos resultados apontaram que durante as aplicações dos jogos, a análise fonológica, a correção das palavras e a verbalização das regras foram estratégias utilizadas entre os sujeitos participantes. Ao final do estudo, evidenciamos um avanço considerável da maioria dos alunos quanto a aprendizagem das regras, demonstrando o progresso positivo e significativo no que tange a aprendizagem dessas regularidades da língua portuguesa.
\end{abstract}

Palavras - chave: regras ortográficas, jogos, mediação.

\section{INTRODUÇÃO}

O ensino da ortografia levanta uma série de questões que endossam o coro das práticas pedagógicas significativas que possibilitem, de fato, a aprendizagem dos sujeitos. O ensino da norma ortográfica de nossa língua materna perpassa por muitas discussões, no entanto, compreender o funcionamento dela é um direito dos sujeitos, assim como a assimilação do sistema de escrita alfabética (SEA).

Sabendo que a norma ortográfica é uma convenção social, o trabalho dela exige uma abordagem que facilite a internalização de todas as suas especificidades. De acordo com Morais (2005), um acordo social determinou que nosso sistema de escrita incorporasse formas únicas na grafia das palavras, porém, isso não se dá de forma homogênea. "Por ser uma convenção que contém não só regras como irregularidades, muitas pessoas imaginam que a ortografia é um acidente histórico desnecessário, que apenas serve para dificultar a tarefa de quem escreve" (MORAIS, 2005, p. 15).

No que tange as notações regulares da língua, o estudo efetivo possibilita uma maior segurança aos sujeitos, uma vez que elas obedecem a um padrão onde é possível prever como se dará a escrita de determinada palavra mesmo sem conhecê-la. Para isso, a observação e a reflexão se fazem necessárias para a compreensão do uso das regularidades ortográficas de nossa escrita, ampliando o entendimento das correspondências letra-som. Em síntese, "a 
ortografia da língua portuguesa é um sistema convencional de representação que prescreve a forma correta de se escrever as palavras, incluindo as letras, a acentuação gráfica e a segmentação das palavras" (TONELI, 2014. p. 77).

Em sua tese de doutoramento, Morais (1995) dialoga sobre três tipos de correspondências regulares em nossa língua: diretas, contextuais e morfológicos-gramaticais. Essas regularidades seguem uma lógica comum nos seus princípios explicativos referentes à norma, ao contrário das irregularidades da língua que demandam a memorização das palavras pela ausência de um padrão. "Com base na distinção do que é regular e irregular, o professor poderá organizar mais claramente seu trabalho, decidindo o que o aluno precisa memorizar e o que ele precisa compreender" (MORAIS, 2003, p. 28).

O ensino da ortografia nas escolas brasileiras ainda é um desafio para crianças e adultos em fase de escolarização. Durante a educação básica, muitas dúvidas referentes à língua acabam se internalizando negativamente nos sujeitos, criando uma espécie de bloqueio ou aversão a língua escrita; essas dúvidas acabam se tornando remanescentes ao longo da vida dos indivíduos - o que deixa a relação com a língua menos atrativa.

Segundo Morais e Silva (2005, p. 61), “em nossa sociedade, e em particular no contexto escolar, a correção ortográfica continua sendo cobrada dos usuários da língua escrita", nessa perspectiva, àqueles que não atendem à norma são alvos de críticas, uma vez que "escrevem com muitos erros". Por sua vez, a escola deve assumir o importante papel de ensinar os alunos a "escrever certo".

Nesse sentido, o ensino da ortografia nas escolas deve ser regido através da reflexão, engajando os estudantes a se apropriarem, de fato, do objeto de conhecimento de modo sistemático, em detrimento das metodologias tradicionais e mecanicistas baseadas exclusivamente na repetição e memorização dos conteúdos.

Como auxílio à aprendizagem da norma, os jogos são instrumentos importantes à prática pedagógica. Com relação a ortografia, os jogos viabilizam a sistematização das regras de modo lúdico, ajudando os alunos a fazerem as correspondências entre fonemas e grafemas através do material concreto, onde é possível visualizar e refletir sobre essas relações divergentes das correspondências orais.

Desta maneira, o uso de jogos no processo de ensino fomenta a aprendizagem dos sujeitos, se pondo como uma forma de incremento às aulas, cabendo aos docentes a mobilização da turma para a construção do conhecimento.

Os jogos de regras ainda são recursos didáticos que motivam os alunos a se envolverem mais durante as aulas, além disso, por seu caráter competitivo, tendem a deixar as aulas mais 
atrativas. Compreendendo que os desafios já estão presentes no próprio recurso, nos perguntamos se as crianças participantes dos jogos procuram criar estratégias para resolver as questões postas pelo jogo, no nosso caso as questões ortográficas; caso criem essas estratégias, como fazem e quais são elas?

Assim o objetivo do estudo foi analisar as estratégias que os alunos desenvolvem para resolver os desafios durante a realização de jogos e como essas estratégias interferem na aprendizagem da regra ortográfica.

\title{
O Ensino da Ortografia
}

Segundo Morais (2005), o ensino da ortografia continua sendo um desafio aos professores, mesmo em face a difusão da importância de práticas pedagógicas que possibilitem a assimilação dos conteúdos de maneira dinâmica e interativa por meio de uma didática pensada às necessidades dos educandos.

Durante a realização e a conclusão de sua pesquisa em meados de $1998^{1}$, Morais (2005) observou que o ensino da ortografia pouco mudou nesse ínterim, muitas práticas do passado se fazem presentes nos modelos de ensino atuais, onde a ortografia é caracterizada como uma área de conhecimento excludente, separando os "bons" dos "ruins" por assim dizer.

Entrementes, entendia-se que apenas uma única perspectiva serviria como suporte à aprendizagem das regras ortográficas - a memorização -, cujas especificidades eram trabalhadas de modo deficitário à compreensão efetiva. No entanto, segundo Morais, apenas os casos irregulares dependem exclusivamente de memorização:

\begin{abstract}
No caso das irregularidades, não há regra ou princípio gerativo que se aplique de maneira mais ou menos generalizada ao conjunto de palavras de nossa língua. Quando grafemas autorizados pela norma se devem unicamente a questões históricas - à etimologia da palavra ou à tradição de uso -, temos que memorizar as formas corretas. Ou consultar o dicionário, no caso de dúvidas muito compreensíveis quando temos que escrever palavras menos frequentes na escrita diária (MORAIS, 2005, p. 19).
\end{abstract}

No caso das correspondências fonográficas regulares (casos que têm regras), elas não dependem da memorização e, sim, de uma abordagem de ensino que favoreça o domínio da norma ortográfica. $\mathrm{O}$ ensino das notações regulares deve ser pensado para que os alunos criem uma consciência sobre como se dá o processo de análise da língua, entendendo que as dificuldades ortográficas podem ser superadas a partir da aprendizagem das regras.

Entendemos que a compreensão do funcionamento do sistema notacional de escrita conecta os aprendizes ao mundo externo, tornando-os agentes dominantes da língua e

1 Pesquisa realizada por Morais e Biruel com o intuito de investigar professoras de $2^{\circ}, 3^{\circ}$ e $4^{\circ}$ ano da rede municipal de ensino da cidade do Recife no qual estavam desenvolvendo o ensino de ortografia. 
produtores de conhecimento, porém, certas posturas e/ou práticas pedagógicas continuam calcadas em metodologias de ensino deficitárias, com a ausência de momentos de reflexão que propiciem a construção da criticidade dos sujeitos. Pois, com alcance da hipótese alfabética da escrita, os educandos já começam a confrontar-se a uma outra seara de particularidades da língua - a ortografia. Ademais, os conhecimentos normativos necessitam de um tratamento alicerçado na reflexão para o desenvolvimento da capacidade cognitiva em relação ao objeto de conhecimento cujo processo esteja em fase de assimilação/construção.

Para Morais (2003), os professores devem estimular seus alunos no desenvolvimento da explicitação da norma através da promoção de diferentes situações pedagógicas que beneficiem a aprendizagem dos sujeitos. Levando em consideração essa questão, compreendemos que os docentes devem lançar mão da observação dentro da sala de aula, ficando atento às dificuldades ortográficas que surgem no dia a dia; tomando essas dificuldades como indicadores de que é necessário fazer uma intervenção para superar esses obstáculos.

Segundo Almeida (2013, p. 23), “até pouco tempo atrás, as práticas de ensino, inclusive o ensino da língua, concebiam, sem qualquer questionamento, o aprendiz como um ser passivo frente ao ato do conhecimento". Tomando como base esse pressuposto, é certo afirmar que o ensino da ortografia nas escolas teve pouca evolução no que se refere a uma metodologia de ensino capaz de instigar a reflexão sobre à norma de modo eficiente, com o objetivo de dar outra visão à ortografia, fugindo das velhas práticas orientadas pela exigência demasiada de cópias textuais com a única intenção de avaliar a grafia, sem ao menos verificar se o nível de explicitação quanto a aprendizagem da língua se desenvolveu nos indivíduos. Sobre a aprendizagem da ortografia, Almeida (2013) dialoga que:

As pesquisas apontam para o fato da aprendizagem da ortografia não estar calcada apenas na memorização [...] há aspectos da norma que são regidos por regularidades, tendo princípios gerativos que, se compreendidos, facilitam a escrita das palavras. Há também, dentro da norma, palavras que não seguem nenhuma lógica, são escritas de acordo com as convenções, ou seja, são arbitrárias e precisam ser memorizadas ou então os escritores devem recorrer a fontes em que haja a escrita conforme a norma culta (ALMEIDA, 2013, p.35).

Sendo assim, através de aulas mais reflexivas, o ensino da ortografia pode ser conduzido através do entendimento de que há casos regulares e irregulares presentes na norma, deixando explícito que a aprendizagem delas nos ajudarão a entender as correspondências de nossa língua, o que facilitará nossa comunicação escrita e, consequentemente, nossa relação com a sociedade de modo geral.

O uso de jogos didáticos como recurso facilitador do processo de aprendizagem da 


\title{
ortografia
}

Com um vasto leque de possibilidades para facilitação do processo de aprendizagem, a Educação configura a busca por métodos de ensino capazes de instigar o interesse dos aprendizes na aquisição do novo conhecimento - especialmente os que seguem normas/padrões, como é o caso da ortografia. Desta forma, para ajudar os alunos a refletirem sobre tais regras, o docente deve buscar recursos que estimulem a curiosidade e o interesse dentro da sala de aula - a destacar o uso de jogos didáticos. Almeida (2013) observou que o uso de jogos didáticos dentro da sala de aula é bastante limitado, mostrando que a queixa dos docentes vem da dificuldade de mediar os momentos de aplicação dos jogos, destacando a inquietude que esse recurso traz à sala de aula. Todavia, os jogos são peças-chave à prática pedagógica e fortes aliados à aprendizagem dos sujeitos. Para Vygotsky:

\begin{abstract}
A criança que sempre participou de jogos e brincadeiras grupais saberá trabalhar em grupo; por ter aprendido a aceitar as regras do jogo, saberá também respeitar as normas grupais e sociais. É brincando bastante que a criança vai aprendendo a ser um adulto consciente, capaz de participar e engajar-se na vida de sua comunidade (VYGOTSKY, 1994, p.82).
\end{abstract}

Levando em consideração os postulados de Vygotsky, compreendemos que o processo de aprendizagem se dá de forma mediada, onde os processos interativos entre professor e aluno favorecem a aprendizagem. Nessa dialética, os professores trabalham no desenvolvimento potencial da criança com relação ao seu nível de desenvolvimento real. Na sua teoria da Zona de Desenvolvimento Proximal (ZDP), Vygotsky (1994, p. 97) diz que: "A Zona de Desenvolvimento Proximal define aquelas funções que ainda não amadureceram, mas que estão em processo de maturação, funções que amadurecerão, mas que estão, presentemente, em estado embrionário".

Essa epistemologia nos revela a necessidade do aprimoramento das práticas pedagógicas, defendendo uma didática mediada que acione todas as capacidades cognitivas dos sujeitos durante o processo de aprendizagem. Portanto, o uso de jogos como instrumento de facilitação da prática pedagógica transforma o processo de ensino, deixando-o prazeroso e atrativo, uma vez que a sala de aula é transformada em um ambiente de ludicidade e de interação entre os alunos e o professor mediador.

Desta maneira, conforme supracitado, esta ferramenta auxilia o processo de aprendizagem para o alcance dos objetivos didáticos. Nesse sentido, as situações-problema trazidas pelos jogos estimulam a elaboração de estratégias de resolução dos desafios propostos, o que ajuda os aprendizes a formularem hipóteses para alcançar um resultado favorável durante sua aplicação; possibilitando a consolidação dos saberes adquiridos durante o processo. 
Podemos dizer, então, que o jogo provoca uma relação de equilíbrio nos sujeitos, acionando os processos de acomodação e assimilação teorizados por Piaget (2013); nessa lógica, o jogo estimula o pensamento dos aprendizes, fazendo-os criar uma linha de raciocínio durante o jogo, construindo assim o seu conhecimento. A partir dessa visão, podemos destacar que os jogos também favorecem o espírito coletivo, não só por estimular a ética e a subordinação à regras - atitudes que fazem parte da vida em sociedade -, mas, também, por criar uma atmosfera que induz os sujeitos a pensarem em estratégias eficazes através dos diálogos e das tomadas de decisões em conjunto, uma vez que cada membro do grupo se ajuda para chegar ao objetivo em comum, viabilizando, assim, a construção do conhecimento coletivo - o que demanda o comprometimento individual dos sujeitos participantes.

\section{METODOLOGIA}

Para a realização desta pesquisa utilizamos a análise de conteúdos proposta por Bardin, que possibilitou a análise categorial dos resultados obtidos. Segundo Bardin (1977, p. 37), a análise de conteúdo se configura como "um conjunto de técnicas de análise das comunicações que visa obter, por procedimentos sistemáticos e objetivos de descrição do conteúdo das mensagens, indicadores que permitam a inferência de conhecimentos relativos às condições de produção destas mensagens", ou seja, mecanismos que buscam a validação do objetivo esperado inicialmente frente aos dados obtidos durante o desenvolvimento da pesquisa.

O trabalho foi desenvolvido em duas turmas de escolas municipais do Recife, sendo uma turma do $3^{\circ}$ ano e outra do $5^{\circ}$ ano. Os alunos foram submetidos a um ditado lacunado inicial, no qual buscou-se identificar quais dificuldades ortográficas eram mais recorrentes nas duas turmas. Após o levantamento dessas dificuldades e, posteriormente, da seleção dos 24 sujeitos participantes (aqueles que apresentavam maior dificuldade nas regras selecionadas para a pesquisa), verificou-se que a maior parte tinha dúvidas quanto a utilização das regularidades ortográficas contextuais do M/N, C/QU e R/RR. A partir desse levantamento, partimos para a seleção e aplicação dos jogos didáticos que trabalhariam essas regras com os sujeitos participantes da pesquisa. Os jogos escolhidos foram adaptados de Almeida (2013).

Foram realizados 09 encontros em cada turma para a aplicação dos jogos, todos previamente agendados com as professoras regentes das salas de aula. As observações pautaram-se na identificação das estratégias desenvolvidas pelos alunos para resolver os desafios durante a realização dos jogos ortográficos e como essas estratégias interferiram na aprendizagem das regras ortográficas trabalhadas. Posto isto, conforme o objetivo proposto pelos jogos de ortografia, o processo se deu de forma mediada por uma professora pesquisadora 
em formação, onde buscou-se fazer uma reflexão sobre a importância da aprendizagem da regra ortográfica.

Os jogos desenvolvidos nessa investigação foram divididos em duas categorias: jogos de classificação e jogos de escrita. Ou seja, cada uma das três regularidades contextuais escolhidas de acordo com a análise dos ditados, foram contempladas com dois jogos distintos. Primeiramente foram aplicados os jogos de classificação e, posteriormente, os de escrita, obedecendo a ordem: M/N; C/QU; R/RR.

Após a reaplicação dos jogos junto às crianças, foi realizado em outro momento a reaplicação do ditado lacunado inicial, dessa vez com o intuito de averiguar o nível de explicitação alcançado pelas crianças com relação às regras trabalhadas. Os resultados obtidos no segundo ditado evidenciaram que a grande maioria dos sujeitos participantes avançaram na compreensão dessas regularidades da norma.

\section{RESULTADOS E DISCUSSÃO}

O início da pesquisa se deu na aplicação de um ditado com o intuito de diagnosticar as dificuldades ortográficas apresentadas pelas turmas de terceiro e quinto ano do Ensino Fundamental I pertencentes à rede municipal de ensino do Recife. Com os ditados em mãos, fizemos um levantamento dos erros ortográficos contextuais mais recorrentes em ambas às turmas, onde foi notado que a maior parte dos sujeitos apresentavam dúvidas quanto uso das regularidades do M/N, C/QU e R/RR. A partir do levantamento inicial, foram selecionados, a princípio, 24 estudantes, sendo 12 crianças do terceiro ano e 12 crianças do quinto ano. No entanto, durante o desenvolvimento da pesquisa que demandou 09 encontros presenciais com os sujeitos participantes das duas turmas, tivemos uma baixa de 04 alunos, sendo 02 deles do terceiro ano e os outros 02 do quinto ano em decorrência de questões familiares e de saúde. Por esse motivo, o número de sujeitos participantes pensando inicialmente para a pesquisa foi reduzido para 20 estudantes.

O quadro 1 a seguir mostra os resultados obtidos durante o período de realização da pesquisa, suscitando que a maioria dos sujeitos participantes avançaram no tocante a compreensão das regras contempladas pelos jogos. 
Quadro 1 - Levantamento dos resultados obtidos durante o período da pesquisa.

\begin{tabular}{|c|c|c|c|c|c|c|c|c|c|c|c|c|c|c|c|c|c|c|c|c|c|}
\hline \multirow{4}{*}{\multicolumn{2}{|c|}{$\begin{array}{c}\text { Regularidades } \\
\text { Contextuais }\end{array}$}} & \multicolumn{20}{|c|}{ Alunos } \\
\hline & & \multicolumn{10}{|c|}{$3^{\circ}$ ano } & \multicolumn{10}{|c|}{$5^{\circ}$ ano } \\
\hline & & 1 & 2 & 3 & 4 & 5 & 6 & 7 & 8 & 9 & 10 & 1 & 2 & 3 & 4 & 5 & 6 & 7 & 8 & 9 & 10 \\
\hline & & \multicolumn{20}{|c|}{ DP } \\
\hline \multirow{3}{*}{$\mathbf{R}$} & Brando & & & & & & & & & & & & & & & & & & & & \\
\hline & $\begin{array}{c}\text { Em início de } \\
\text { palavras }\end{array}$ & & & & & & & & & & & & & & & & & & & & \\
\hline & $\begin{array}{c}\text { Forte entre } \\
\text { vogais }\end{array}$ & & & & & & & & & & & & & & & & & & & & \\
\hline $\mathbf{M}$ & \multirow{2}{*}{$\begin{array}{l}\text { Em final de } \\
\text { sílabas }\end{array}$} & & & & & & & & & & & & & & & & & & & & \\
\hline $\mathbf{N}$ & & & & & & & & & & & & & & & & & & & & & \\
\hline C & \multirow{2}{*}{$\begin{array}{l}\text { Notando o } \\
\text { fonema } K\end{array}$} & & & & & & & & & & & & & & & & & & & & \\
\hline QU & & & & & & & & & & & & & & & & & & & & & \\
\hline
\end{tabular}

\begin{tabular}{|l|l|}
\hline Crianças que avançaram na compreensão das regras. \\
\hline Crianças que permaneceram sem consolidar às regras. \\
\hline Crianças que retrocederam na aplicação do ditado final. \\
\hline Crianças que permaneceram acertando as palavras do ditado. \\
\hline
\end{tabular}

Ao olharmos para o quadro dos resultados obtidos durante o período da pesquisa, é notório que poucos alunos permaneceram sem consolidar às regras contempladas pelos jogos, sendo menor ainda o número de estudantes que retrocederam na aplicação do ditado final.

Esses dados nos mostram que a didática utilizada no processo de sistematização dessas regras de fato influenciou na aprendizagem dos sujeitos, ajudando-os a atingir o nível de explicitação quanto ao uso dessas regularidades da norma. Sendo assim, é certo afirmar que o uso de jogos foi uma estratégia didática fundamental para a assimilação das regras, elucidando que a aprendizagem mediada através desse recurso auxiliou o processo de ensino-aprendizagem de forma satisfatória - o que é evidente no quadro acima.

Como estratégia para ajudar os sujeitos participantes a atingirem os resultados pretendidos, a ludicidade trazida pelos jogos foi articulada com a ideia de dividir os estudantes em grupos, de modo que uma competição entre grupos fosse gerada para aquecer os processos 
de interação e participação entre os alunos para se chegar ao objetivo em comum. Os extratos a seguir mostram algumas situações ocorridas durante o processo de aplicação dos jogos.

Extrato 01 - Regularidade M/N - Jogo de classificação - $3^{\circ}$ ano.

Pesquisadora: Grupo 2, qual foi a palavra que vocês completaram?

Alguns alunos do grupo 2: Pente!

Pesquisadora: A letra escolhida por vocês pra completar a palavra tá correta?

Alguns alunos do grupo 2: Sim!

Pesquisadora: Por quê?

Aluno 8: Porque não tem o $\mathrm{P}$ e nem o $\mathrm{B}$, então é com $\mathrm{N}$ !

Aluno 5: Tá certo, tia!

Pesquisadora: Vocês acertaram! É com N sim, já que não estamos diante de $\mathrm{P}$ e B, usamos o N para as demais consoantes. Agora, qual é a próxima palavra da carta?

Alguns alunos do grupo 2: Sombra!

Pesquisadora: Vocês usaram qual letra pra completar?

Alguns alunos do grupo 2: M!

Pesquisadora: Por quê?

Aluno 7: Porque o $\mathrm{M}$ vem antes de $\mathrm{P}$ e B!

Aluno 3: Ganhamos!

Pesquisadora: Muito bem! Vocês acertaram.

Nesse primeiro extrato, podemos destacar a verbalização da regra do $\mathrm{M} / \mathrm{N}$ como estratégia utilizada pelos alunos. Durante a aplicação desse jogo, foi nítido que os sujeitos participantes se atentavam a todo momento à consoante que sucedia a letra $\mathrm{M}$ ou $\mathrm{N}$ nas palavras presentes em suas cartas.

Extrato 02 - Regularidade M/N - Jogo de classificação $-5^{\circ}$ ano.

Pesquisadora: Grupo 1, qual foi a palavra que vocês completaram?

Alguns alunos do grupo 1: Pombo!

Pesquisadora: A palavra tá correta? A letra escolhida por vocês pra completar a palavra tá correta?

Alguns alunos do grupo 1: Sim!

Pesquisadora: Por quê?

Aluno 7: Porque o $\mathrm{M}$ tem que ser antes de $\mathrm{P}$ e B!

Aluno 4: Todo mundo sabe que é o M!

Pesquisadora: Vocês acertaram! Realmente temos o M antes de P e B. Podem pegar a próxima 
palavra.

Alguns alunos do grupo 1: Em...empada!

Aluno 6: N!

Aluno 7: É com M... EM-PA-DA!

Aluno 6: Ah... aham...

Pesquisadora: Terminaram?

Aluno 6: Sim!

Pesquisadora: Qual foi a palavra?

Aluno 7: Empada! Com M!

Pesquisadora: Muito bem! Acertaram novamente.

Nessa segunda situação com a mesma regularidade, podemos observar que além da verbalização da respectiva regra, os alunos corrigiram uns aos outros quanto a classificação do $\mathrm{M} / \mathrm{N}$ nas palavras de suas cartas. Observamos que no ato da correção, o aluno 7 fala a palavra separando por sílabas, apesar dessa forma não facilitar a escolha do M/N, o aluno 6 aceita de imediato a correção. Apesar dessa atitude do aluno 6 deixar dúvida se ele compreendeu o porquê do uso do $\mathrm{M}$ ou se apenas seguiu a orientação do colega, é possível verificar, de acordo com o quadro 2, que o aluno apresentou êxito na escrita dessa regra.

Extrato 03 - Regularidade M/N - Jogo de escrita $-5^{\circ}$ ano.

Pesquisadora: Agora vocês vão montar as palavras correspondentes às figuras utilizando o alfabeto móvel... vamos lá?

Alguns alunos dos grupos 1 e 2: Sim, tia!

Pesquisadora: Ok. Grupo 2, qual foi a figura de vocês?

Aluno 6: É computador!

Pesquisadora: Vamos lá, montem a palavra.

Aluno 4: Cadê o A? Cadê o D-O?

Aluno 2: Vai precisar do R.

Aluno 4: Cadê o U aqui?

Aluno 2: R! R!

Pesquisadora: Os dois grupos terminaram?

Alguns alunos dos grupos 1 e 2: Sim!

Pesquisadora: Grupo 1, a palavra montada pelo grupo 2 tá correta?

Alguns alunos do grupo 1: Tá sim, tia!

Alguns alunos do grupo 2: Tá sim... É! 
Pesquisadora: Por que vocês escolheram o M e não o N?

Aluno 2: Porque é com M!

Pesquisadora: Mas por quê?

Aluno 7: Porque tem o P... antes do P e do B é M!

Pesquisadora: Sim... muito bem! Agora é com o grupo 1, qual foi a palavra de vocês?

Alguns alunos do grupo 1: Anjo!

Pesquisadora: Grupo 2, tá tudo certo com a palavra?

Alguns alunos do grupo 2: Tá... tá sim!

Pesquisadora: Grupo 2, por que vocês usaram o $\mathrm{N}$ aqui?

Aluno 8: Porque a gente não viu P e nem B... aí é com N!

Aluno 5: Se fosse $\mathrm{M}$ ia tá errado porque $\mathrm{M}$ é antes de $\mathrm{P}$ e $\mathrm{B}$ !

Pesquisadora: Muito bem! Os dois grupos acertaram.

Já no jogo de escrita da mesma regra os alunos iam falando o nome das letras para montar a palavra correspondente à figura da carta. Quando questionados o porquê do uso do $\mathrm{M}$ ou do $\mathrm{N}$ na palavra eles verbalizavam à regra.

Extrato 04 - Regularidade C/QU - Jogo de classificação - $5^{\circ}$ ano.

Pesquisadora: Grupos 1 e 2, esse é um jogo da memória, tá certo? Então vamos prestar atenção nas imagens, os pares devem ser iguais quanto a escrita das palavras, ou seja, tem que ter $\mathrm{C}$ ou QU em cada par. Vamos lá!

Aluno 6 (grupo 2): Coco e caju!

Aluno 7 (grupo 2): Os dois é com C!

Aluno 6 (grupo 2): Ponto de novo!

Pesquisadora: Grupo 1, quais figuras vocês pegaram agora?

Aluno 4 (grupo 1): Caderno e coração!

Pesquisadora: E aí? Formaram o par?

Aluno 8 (grupo 1): Tá certo, tia!

Alguns alunos do grupo 2: É, tá certo!

Pesquisadora: Grupo 2, sua vez!

Aluno 6 (grupo 2): Quiosque e quinze!

Aluno 7 (grupo 2): QU e QU!

Aluno 6 (grupo 2): Outro par!

Pesquisadora: Muito bem! Mais um par! 
No jogo de classificação da regularidade C/QU os sujeitos participantes, em sua maioria, falavam o nome das letras iniciais das palavras correspondentes às figuras a medida que viravam as cartas do jogo, deixando claro que naquele momento, eles estavam acessando mentalmente seu repertório de palavras, buscando trazer à memória a regra em questão que os ajudariam a decidir à escrita da palavra para formarem os pares e pontuar na partida.

Extrato 05 - Regularidade C/QU - Jogo de escrita $-5^{\circ}$ ano.

Pesquisadora: Grupos 1 e 2, agora temos um jogo de trilha! De acordo com o número da casa que o pino de vocês cair através do número sorteado no dado, eu pegarei a figura de mesmo número, ok? Par ou ímpar, vamos lá! (o grupo 1 começou a partida)

Aluno 9 (grupo 1): casinha 5!

Pesquisadora: Pronto, se montar a palavra corretamente vocês irão andar 5 casas, do contrário, permanecerão na marca de início do tabuleiro. A figura é... Colher!

Aluno 8 (grupo 1): É com U ou com O?

Alguns alunos do grupo 1: Cu...co...lherrr...

Aluno 8 (grupo 1): Cu... terminamos, tia!

Pesquisadora: Terminaram? Vamos ver! Grupo 2, vocês acham que eles montaram corretamente a palavra?

Aluno 7 (grupo 2): Tá errado, tia! É com O!

Aluno 6 (grupo 2): É cooolher!

Pesquisadora: Mas acertaram a regra do C ou QU na palavra?

Alguns alunos dos dois grupos: Sim! É com C mesmo!

Pesquisadora: Sim, é com C e escrevemos com O... CO-LHER, embora falamos "culher".

Grupo 2, agora é a vez de vocês! Joguem o dado pra ver o número de casas que vocês irão andar caso acertem a palavra.

Aluno 6 (grupo 2): Eeee... 6!

Pesquisadora: A figura é... brinquedos! Se formarem a palavra corretamente vocês irão permanecer na casa $6 \ldots$ vamos lá!

Aluno 6 (grupo 2): É com B, viu?

Aluno 7 (grupo 2): É com N aí...

Aluno 6 (grupo 2): Terminamos... tá certo, tia!

Pesquisadora: Eles acertaram grupo 1?

Aluno 8 (grupo 1): Tá... tá certo. 
Esse $5^{\circ}$ extrato nos mostra que a sistematização da regularidade C/QU através do jogo surtiu grande efeito à aprendizagem dos sujeitos no desafio da escrita das palavras, porém, outras dúvidas surgiram durante a aplicação do jogo, como exemplificado na pergunta do aluno 8: “É com U ou com O?”, referindo-se a sílaba inicial da palavra colher - tendo o grupo montado a palavra de acordo com o jeito que eles a pronunciam: "culher".

Extrato 06 - Regularidade R/RR - Jogo de classificação - $5^{\circ}$ ano.

Pesquisadora: Agora vocês irão classificar nesse quadro os três tipos de R. Como já vimos, a letra $\mathrm{R}$ vem de diferentes maneiras nas palavras, tendo uma escrita e um som diferente. Por exemplo, temos o RR que fica no meio de palavras e que nunca vem no início ou no final... pra o R ter o som forte no meio das palavras temos que acrescentar outra letra R. Vamos lá, cada grupo ficará com um quadro.

(o aluno 2 verbalizou um pouco sobre o emprego do RR durante a fala da pesquisadora)

Aluno 4 (grupo 2): Barraca é com dois R! BAR-RA-CA... o mesmo de GAR-RA-FA!

Aluno 8 (grupo 1): Aqui... raquete fica com rede.

Pesquisadora: Terminaram de classificar?

Alguns alunos dos 3 grupos: Sim!

Pesquisadora: Então vamos lá! Veremos primeiro o quadro do grupo 1. Todas as palavras foram classificadas corretamente? Vamos ler as palavras que estão na coluna da figura urubu... VARA; ZE-RO; CA-RE-TA; CA-CHOR-RO.

Aluno 6 (grupo 2): Erraram!

Pesquisadora: O R de CA-CHOR-RO tremeu a língua?

Alguns alunos dos 3 grupos: Não!

Pesquisadora: Erraram apenas uma palavra dessa coluna. Vamos pra próxima! A figura é rede! Esse R tá aonde?

Alguns alunos dos 3 grupos: No começo!

Pesquisadora: Ok! Vamos ver uma por uma... RA-QUE-TE; RO-BÔ; MAR-RECO.

Aluno 6 (grupo 2): Errou! Marreco!

(a medida que a pesquisadora ia fazendo a leitura das palavras, os alunos iam dizendo se elas estavam ou não corretas de acordo com a figura da coluna correspondente ao R)

Pesquisadora: Pois é, essa foi a coluna do R inicial, a palavra MAR-RE-CO começa com a letra $\mathrm{R}$ ?

Alguns alunos do grupo 2: É a fila do RR.

Pesquisadora: Veremos a próxima coluna então... a figura é BOR-RA-CHA. Borracha tem 
quantos R?

Alguns alunos dos 3 grupos: Tem dois!

Pesquisadora: Vamos ler... BUR-RO; ROU-PA...

Aluno 6 (grupo 2): Errou... errou!

Pesquisadora: Vamos continuar... TER-RA; XE-RI-FE.

Alguns alunos do grupo 2: Errou de novo!

Pesquisadora: o "RI" tremeu, né? Mas o grupo 1 errou apenas 4 palavras... foram muito bem! Agora é a vez do grupo 2! As figuras do quadro do grupo 2 foram: PI-RU-LI-TO; RO-DO; GAR-RA-FA. Vamos ler a coluna do pirulito primeiro! CA-RA-MU-JO; CA-RI-NHO; CA-RECA; CO-RO-A. Tá tudo certo?

Alguns alunos dos 3 grupos: Acertou!

Pesquisadora: Que tipo de R é esse?

Alguns alunos do grupo 2: É o fraco!

Pesquisadora: Muito bem! Agora vamos pra segunda coluna. Qual é o R aqui?

Aluno 2 (grupo 2): Rapadura!

(alguns alunos riram)

Aluno 6 (grupo 2): É o R do começo!

Pesquisadora: Vamos lá... RA-PA-DU-RA; RE-MÉ-DIO; RA-TOEI- RA; RA-IO. Todas têm o $\mathrm{R}$ inicial?

Alunos do grupo 2: Sim!

Pesquisadora: Muito bem! Acertaram todas as palavras. Agora vamos a última coluna.

Vem que tipo de $\mathrm{R}$ agora?

Aluno 6 (grupo 2): RR!

Pesquisadora: Vamos ver! BE-TER-RA-BA; TOR-RA-DA; BAR-RIO; CI-GAR-RA.

Alguns alunos do grupo 2: Acertamos tudo!

Pesquisadora: Agora é a vez do último grupo! Quadro do grupo 3 agora. As figuras foram: CORA-ÇÃO; RA-PO-SA; CAR-RO. Vamos ver se eles acertaram tudo na primeira coluna? COU-RO; CO-RO-NEL; JA-CA-RÉ; PI-RA-TA. Tudo certo?

Alguns alunos dos 3 grupos: Sim!

Pesquisadora: Agora vem o R de raposa, que é o R do...

Aluno 2 (grupo 2): ... começo!

Pesquisadora: Muito bem! R inicial. E as palavras foram: RÁ-DI-O; RE-MO; RA-BO; RÉGUA.

Alguns alunos do grupo 2: Acertaram! 
Pesquisadora: Agora vem a última coluna! Que R é esse aqui minha gente?

Alguns alunos dos grupos 1 e 2: Dois R!

Pesquisadora: E as palavras foram: JAR-RO; TOR-RE; FER-RO; BAR-RO. Acertaram tudo? Alguns alunos dos 3 grupos: Sim!

O jogo de classificação da regularidade do R/RR evidenciou que os alunos assimilaram bem o uso dos três tipos de R trazidos pelo jogo. Como estratégia utilizada podemos destacar a análise fonológica, onde os estudantes estabeleciam a relação letra-som para segmentação das sílabas das palavras, classificando assim os três tipos do $\mathrm{R}$ em sua respectiva coluna. Este foi o jogo que mais gerou expectativa nos estudantes. Diante do feedback positivo da pesquisadora, alguns membros dos grupos comemoravam e até se abraçavam, nos mostrando que eles realmente estavam gostando do momento de aprendizagem.

É possível observar, ainda, que o grupo 2 classifica a palavra MARRECO na coluna das palavras com $\mathrm{R}$ inicial. O erro pode ter sido provocado pela igualdade do som, ou seja, o som do R é o mesmo nas palavras, apesar da posição diferente.

\section{CONCLUSÕES}

A partir das informações levantadas neste trabalho, concluímos que o processo de ensino-aprendizagem das regularidades contextuais da norma através do uso de jogos trazem, de fato, resultados significativos, mostrando de forma imediata a qualidade da construção desse conhecimento nos estudantes, permitindo que o professor trabalhe de forma mais eficiente nas dificuldades reais apresentadas pelos sujeitos durante a realização dos jogos, permitindo-os alcançar o nível de explicitação almejado.

Sabendo que as regularidades da norma podem ser apresentadas aos estudantes de forma lúdica, é certo afirmar que o uso de jogos se faz necessário para que o processo de aprendizagem se afaste dos moldes de ensino da ortografia vistos no passado - práticas que já foram amplamente discutidas e eliminadas por vários estudiosos haja vista sua ineficiência quanto a aprendizagem da ortografia.

Conforme o exposto ao longo deste trabalho, a ortografia ainda é uma área de conhecimento com muitas lacunas a serem preenchidas no âmbito escolar, e, como consequência dessa "falta de atenção", muitos estudantes acabam se sentindo menos inteligentes por não dominar/entender a norma da própria língua, passando por situações de insegurança/constrangimento quando precisam escrever algo - o que é inevitável.

De acordo com o resultado que obtivemos, destacamos que as estratégias elaboradas 
pelas duas turmas de fato os ajudaram na compreensão das regularidades contextuais que foram sistematizadas pelos jogos. Os sujeitos participantes, em sua maioria, verbalizavam as regras a medida em que os jogos eram aplicados. A análise fonológica das palavras e a correção das palavras entre os participantes também foram estratégias bastante exploradas. Convém ressaltar, que a mediação docente durante os jogos também foi um fator decisivo na aprendizagem das regras.

Por este motivo, fomentamos que a aprendizagem mediada a partir do uso de jogos didáticos foram cruciais para assimilação das regras trabalhadas em nossos sujeitos participantes, deixando explícito que os conhecimentos normativos da língua podem ser assimilados de forma agradável, leve e em conjunto. Por via de regra, é válido deixar claro que a atitude docente também fez toda diferença durante esse processo, uma vez que o clima para a construção da aprendizagem é trazido e conduzido pelo professor.

Sendo assim, cabe aos professores e a escola um melhor tratamento à ortografia, não só por se tratar de um conhecimento imprescindível para a boa comunicação dos sujeitos, mas, também, por se tratar de um direito de compreender verdadeiramente como se dá a organização da língua materna, melhorando assim essa relação.

\section{REFERÊNCIAS}

ALMEIDA, T. P. S. A relação entre a mediação docente e o desempenho ortográfico de alunos participantes de jogos de ortografia. 145 f. Dissertação (Mestrado) - Programa de PósGraduação em Educação. Universidade Federal de Pernambuco. Recife, 2013. Disponível em: http://repositorio.ufpe.br/handle/123456789/13330. Acesso em: 17/07/2018.

Bardin, L. Análise de Conteúdo. Lisboa: Edições 70, 1977.

MORAIS, A. G. Representaciones Infantiles sobre la Ortografia Del Português. Tese de doutorado. Universitat de Barcelona. 1995.

Ortografia: ensinar e aprender. 4. ed. São Paulo: Ática, 2003.

A norma ortográfica do português: o que é? para que serve? como está organizada?. In: SILVA, A.; MORAIS, A. G.; MELO, K. L. R. (Org.). Ortografia na Sala de Aula. 1. ed., 1. reimp. Belo Horizonte: Autêntica, 2005.

MORAIS, A. G.; SILVA, A. A norma ortográfica é uma invenção necessária. In: SILVA, A.; MORAIS, A. G.; MELO, K. L. R. (Org.). Ortografia na Sala de Aula. 1. ed., 1. reimp. Belo Horizonte: Autêntica, 2005.

PIAGET. Jean. A psicologia da inteligência. Rio de Janeiro: Vozes, 2013.

TONELI, N. C. Convenções Ortográficas. In: FRADE, I. C. A. S.; COSTA VAL, M. G.; BREGUNCI, M. G. C. (Orgs.). Glossário CEALE: termos de alfabetização, leitura e escrita 
SOUZA, S. T. S.; ARAÚJO, R. K. P.; PESSOA, A. C. R. G.

para educadores. Belo Horizonte: UFMG/ Faculdade de Educação, 2014. P. 77-79.

VYGOTSKY, L. S. A formação social da mente: o desenvolvimento dos processos psicológicos superiores. 5. ed. São Paulo: Martins Fontes, 1994. 


\title{
CENÁRIO DO ATENDIMENTO EDUCACIONAL ESPECIALIZADO AOS ALUNOS SURDOS NAS ESCOLAS PÚBLICAS DO MUNICÍPIO DE URUÇUÍ-PI
}

\author{
ESCENARIO DE ASISTENCIA EDUCATIVA ESPECIALIZADA PARA \\ ESTUDIANTES DE AF EN ESCUELAS PÚBLICAS EN EL MUNICIPIO DE \\ URUÇUÍ-PI
}

\section{SCENARIO OF SPECIALIZED EDUCATIONAL ATTENDANCE FOR DEAF STUDENTS IN PUBLIC SCHOOLS IN THE MUNICIPALITY OF URUÇUÍ-PI}

\author{
Felix Gomes da Costa ${ }^{1}$; Vanessa Sousa da $\operatorname{Costa}^{2}$; Isabela de Sá Costa Sousa ${ }^{3}$; Miguel \\ Antônio Rodrigues ${ }^{4}$
}

DOI: https://doi.org/10.31692/978-65-991061-3-2.91-106

\section{RESUMO}

Durante muito tempo as pessoas surdas foram tratadas como seres humanos improdutivos, cujo encaminhamento de integração à sociedade estava voltado para o oralismo. No Brasil, somente em 2002 foi assegurada em legislação específica a Língua Brasileira de Sinais como a primeira língua dos surdos, sendo a língua portuguesa a segunda. Atualmente as instituições de ensino devem ofertar serviços educacionais especializados voltados à integração dos surdos no ambiente escolar. Este estudo teve como objetivo analisar o espaço escolar das Escolas Públicas do Município de Uruçuí-PI quanto à estrutura física e de pessoal para o suporte aos alunos surdos, associando essa estrutura ao acesso, permanência e êxito desses estudantes. A pesquisa foi desenvolvida através da aplicação de questionários semiestruturados aos gestores das nove escolas públicas localizadas na zona urbana de município de Uruçuí-PI. Os resultados mostraram que os alunos surdos são matriculados nessas escolas, porém o acompanhamento com suporte de pessoas e com estrutura tecnológica para a inclusão efetiva desse público não acontece da forma como reza a legislação, como se verificou que não existe intérprete de libras nas salas de aulas onde há pessoas surdas matriculadas. Da mesma forma, foi constatado que não existe na configuração dessas escolas ações positivas suficientes para promover a inclusão dos alunos surdos; o que as escolas fazem é apenas promover o aluno para o ano seguinte sob a alegação de amparo legal assistido a esses alunos, o que mostra desconhecimento da complexidade do processo de ensino-aprendizagem, o qual deve ocorrer de forma gradativa em todas as dimensões do ser humano.

Palavras-Chave: surdo, suporte, libras, inclusão.

\section{RESUMEN}

Durante mucho tiempo, las personas frugales fueron tratadas como seres humanos improductivos, cuya referencia a la integración en la sociedad fue condenada en el oralismo. En Brasil, en 2002, el idioma del idioma brasileño como primer idioma de los sordos estaba

\footnotetext{
${ }^{1}$ Acadêmico do curso de Licenciatura em Ciências Biológicas, campus Uruçuí do Instituto Federal de Educação, Ciência e Tecnologia do Piauí, e-mail: felixcosta518@gmail.com

${ }^{2}$ Acadêmica do curso de Licenciatura em Ciências Biológicas, campus Uruçuí do Instituto Federal de Educação,

Ciência e Tecnologia do Piaú, e-mail: sousavanessac19@gmail.com

${ }^{3}$ Acadêmica do curso de Licenciatura em Ciências Biológicas, campus Uruçuí do Instituto Federal de Educação, Ciência e Tecnologia do Piauí, e-mail: isabela7324@gmail.com

${ }^{4}$ Professor mestre do campus Uruçuí do Instituto Federal de Educação, Ciência e Tecnologia do Piauí, e-mail: miguel.rodrigues@ifpi.edu.br
} 
garantizado en una legislación específica. En la actualidad, las instituciones educativas tienen que ofrecer servicios educativos especializados para la integración de las personas sanas en el entorno escolar. Este estudio tuvo como objetivo analizar el espacio escolar de las Escuelas Públicas de Uruçuí-PI con respecto a la estructura física y personal para apoyar a los estudiantes sordos, asociando esta estructura con el acceso, la permanencia y el éxito de estos estudiantes. La investigación se desarrolló mediante la aplicación de cuestionarios semiestructurados a los gerentes de las nueve escuelas públicas ubicadas en el área urbana de Uruçuí-PI. Los resultados mostraron que los estudiantes sordos están matriculados en estas escuelas, pero el apoyo con las personas y la estructura tecnológica para la inclusión efectiva de este público no sucede como lo dice la ley, ya que se encontró que no hay un intérprete de libras en las aulas. clases donde hay personas sordas matriculadas. De manera similar, se encontró que no hay suficientes acciones positivas en la configuración de estas escuelas para promover la inclusión de estudiantes sordos; Lo que hacen las escuelas es simplemente promocionar al estudiante al próximo año por asistencia legal asistida a estos estudiantes, lo que demuestra la falta de conocimiento de la complejidad del proceso de enseñanza-aprendizaje, que debería ocurrir gradualmente en todas las dimensiones de la escuela ser humano.

Palabras clave: sordos, apoyo, libras, inclusión.

\begin{abstract}
For a long time deaf people were treated as unproductive human beings whose mainstreaming towards society. In Brazil, only in 2002 the Brazilian Sign Language as the first language of the deaf was ensured in specific legislation.. Currently educational institutions must offer specialized educational services aimed at the integration of deaf people in the school environment. This study aimed to analyze the school space of the Public Schools of the Municipality of Uruçuí-PI regarding the physical and staff structure to support deaf students, associating this structure to access, permanence and success of these students. The research was developed through the application of semi-structured questionnaires to the managers of the nine public schools located in the urban area of Uruçuí-PI. The results showed that deaf students are enrolled in these schools, but the support with people and technology structure for the effective inclusion of this public does not happen as the law says, as it was found that there is no interpreter of pounds in the classrooms. classes where there are deaf people enrolled. Similarly, it was found that there are not enough positive actions in the configuration of these schools to promote the inclusion of deaf students; What the schools do is just promote the student to the next year on the grounds of legal assistance assisted to these students, which shows lack of knowledge of the complexity of the teaching-learning process, which should occur gradually in all dimensions of the school human being.
\end{abstract}

Key words: deaf, support, pounds, inclusion.

\title{
INTRODUÇÃO
}

A inclusão de pessoas deficientes nas instituições de ensino tem sido alvo de pesquisas e discussões em nível mundial devido à falta de efetividade do processo, principalmente porque as políticas direcionadas ao atendimento desse pública não estão sendo colocadas em prática na grande parte das instituições de ensino, o que direciona para a necessidade de questionamentos que visem a mobilização do poder público e da sociedade para buscarem ações que possam melhorar esse cenário.

Dados do Censo Escolar 2018 (INEP/MEC, 2019) revelaram aumento de 33,2\% em 
relação a 2014 no número de matrículas de alunos com "deficiência, transtornos globais do desenvolvimento e/ou altas habilidades/superdotação em classes comuns (incluídos) ou em classes especiais exclusivas”. A educação brasileira sofreu mudanças com a introdução da educação inclusiva (SANTOS, 2018), e segundo Barbosa, Fialho e Machado (2018) ao ver cada indivíduo com suas peculiaridades e características permite a inclusão de grupos excluídos historicamente por meio da ampliação da participação no ensino regular e sua inserção social.

$\mathrm{Na}$ escola inclusiva todos são considerados iguais, incluir significa, entre outras coisas, a escola modificar sua forma de funcionamento para receber os diferentes alunos e que suas necessidades sejam atendidas, inclusive os que tem necessidades educativas especiais. Nesse contexto se encontra os surdos que enfrentam as maiores dificuldades quando se fala de inclusão, pois o ensino-aprendizagem baseia-se exclusivamente, na maioria das vezes, na comunicação oral (NOGUEIRA; CARNEIRO; SOARES, 2018).

A comunicação faz parte da necessidade dos seres humanos e sua efetividade é fundamental para o desenvolvimento das pessoas, por isso é necessário que se valorize os mecanismos capazes de possibilitar que pessoas com limitações venham a integrar o processo de comunicação. A LIBRAS (Língua Brasileira de Sinais) é uma língua oficializada pela lei $\mathrm{n}^{\circ}$ 10.436 de abril de 2002 e pelo Decreto Federal n ${ }^{\circ} 5.626$ de 22 de dezembro de 2005 como meio legal de comunicação e expressão oficial da comunidade surda no Brasil. A inclusão da LIBRAS na escola como componente curricular, o bilinguismo, tradutor e intérprete de libras/língua portuguesa permitiu uma ampliação dos direitos dos surdos no ensino regular (PASSOS; SANTOS; CAMPELO, 2018), possibilitando o desenvolvimento do mesmo.

Entretanto, segundo Mendonça et al. (2018), apesar da garantia de direitos a educação na Legislação aos surdos, existe ainda impedimentos quanto à implementação como o ensino de LIBRAS como disciplina curricular na Educação Básica, adaptação do currículo e uma formação pedagógica de forma a preparar para entender e conviver com o aluno surdo.

A Legislação garante às pessoas com necessidades especiais o direito ao Atendimento Educacional Especializado (AEE) preferencialmente no ensino regular. Dentro desse cenário de educação inclusiva, como um espaço, que respeita e considera as especificidades de cada aluno com deficiência possibilitando assim o maior acesso, permanência e desenvolvimento de suas potencialidades, que em consequência tornar-se um importante mecanismo facilitador de inclusão para uma educação de qualidade (FERREIRA, 2016).

A problemática dessa pesquisa voltou-se para responder ao seguinte questionamento: Como vem acontecendo a inclusão de alunos surdos nas escolas públicas do município em estudo? Como hipóteses, o estudo apresenta que: a) Apesar dos avanços na legislação que 
regulamenta a inclusão das pessoas surdas nos espaços formais de ensino, ainda existem muitas lacunas que corroboram para o seu fracasso escolar, b) As escolas apresentam estrutura precária para atendimento especializado ao surdo, c) $\mathrm{O}$ acompanhamento especializado dos alunos surdos não acontece regularmente.

Diante do exposto, o presente trabalho tem como objetivo analisar o espaço escolar das Escolas Públicas do Município de Uruçuí-PI quanto à estrutura física e de pessoal para o suporte aos alunos surdos, associando essa estrutura ao acesso, permanência e êxito desses estudantes.

\section{REFERENCIAL TEÓRICO}

$\mathrm{Na}$ antiguidade, até os anos de 1700, a sociedade apresentava comportamentos e percepções variadas em relação ao deficiente; a percepção da sociedade por concepções sociopolíticas aplica-se a todas as deficiências, pois eram vistas todos como iguais e não representavam potencial para a vida produtiva, por isso a sociedade da época não tinha interesse em ofertar serviços para o desenvolvimento dos deficientes, haja vista que a condição de incapacidade fazia parte da concepção da época. Nesse período, os serviços de atendimentos, quando havia, ocorriam em monastérios que ofereciam cuidados e amparo para as pessoas com deficiência e eram realizados por religiosos, no entanto, ainda não havia a preocupação com o desenvolvimento e o tipo de atendimento que era destinado para esse público, o que demonstra que esse eram de caráter assistencialista (MAZZOTTA, 2011).

$\mathrm{O}$ artigo 54 do Estatuto da Criança e do Adolescente (ECA) aponta determinações em relação ao ensino, com base no que estabelece o art. 208 da Constituição Federal de 1988: É dever do Estado assegurar à criança e ao adolescente: "I - ensino fundamental, obrigatório e gratuito, inclusive para os que a ele não tiveram acesso na idade própria; III - atendimento educacional especializado aos portadores de deficiência, preferencialmente na rede regular de ensino" (BRASIL, 2008, p.20).

$\mathrm{O}$ art. $3^{\circ} \mathrm{em}$ seu inciso IV da Constituição Federal de 1988 destaca como um dos seus objetivos fundamentais "promover o bem de todos, sem preconceitos de origem, raça, sexo, cor, idade e quaisquer outras formas de discriminação", e em se tratando da Educação, tem se a seguinte redação em seu artigo 208:

O dever do Estado com a educação será efetivado mediante garantia de: I- educação básica obrigatória e gratuita dos 4 (quatro) aos 17 (dezessete) anos de idade, assegurada, inclusive, sua oferta gratuita para todos os que a ela não tiveram acesso na idade própria; II- progressiva extensão da obrigatoriedade e gratuidade no ensino médio; III- atendimento educacional especializado aos portadores de deficiências, preferencialmente na rede regular de ensino (BRASIL, 1988).

Em matéria de legal de direitos, encontra-se na legislação nacional amparo às pessoas 
com deficiência o Estatuto da Criança e do Adolescente (Lei n. ${ }^{\circ} 8.069$ de 1990), quando estabelece em seu art. 53 que a criança e o adolescente têm direito à educação, visando ao seu pleno desenvolvimento, preparo para o exercício da cidadania e qualificação para o trabalho, com direito à: "I - igualdade de condições para o acesso e permanência na escola; II - direito de ser respeitado por seus educadores" (BRASIL, 2008, p.19).

A Lei de Diretrizes e Bases da Educação Nacional estabelece em seu art. $4^{\circ}$ que o Estado deve ofertar educação escolar pública mediante garantia de III - "atendimento educacional especializado gratuito aos educandos com deficiência, transtornos globais do desenvolvimento e altas habilidades ou superdotação, transversal a todos os níveis, etapas e modalidades, preferencialmente na rede regular de ensino".

O princípio da inclusão apela, portanto, para a educação inclusiva que pretende,
de um modo geral, que todos os alunos, com as mais diversas capacidades,
interesses, características e necessidades, possam aprender juntos, que seja dada
atenção ao seu desenvolvimento global (acadêmico, socioemocional e pessoal),
que, sempre que possível, todos os serviços educativos sejam prestados nas classes
regulares, que se crie um verdadeiro sentido de igualdade de oportunidades
(não necessariamente as mesmas oportunidades para todos) que vise o sucesso
escolar (CORREIA, 2001 p. 125).

São diversos os tipos de necessidades específicas que precisam de acompanhamento especializado nas instituições de ensino, entre essas, a surdez vem sendo discutida para que a comunicação nas escolas ocorra de modo que a aquisição do conhecimento e a interação aconteçam efetivamente.

Existem duas formas de se caracterizar a surdez, o modelo médico, em que ela é vista como uma deficiência, uma limitação de natureza patológica, com o surdo sendo rotulado por aquilo que não é capaz de fazer; ou seguindo a concepção sócio-antropológica da surdez, como uma diferença linguística, encarando o surdo a partir de suas possibilidades, que poderão ser mais ou menos aproveitadas em função da educação que lhe for ofertada (NOGUEIRA; CARNEIRO; SOARES, 2018).

Cultura surda é o jeito de o sujeito surdo entender o mundo e de modificá-lo a fim de torná-lo acessível e habitável, ajustando-o com as suas percepções visuais, que contribuem para a definição das identidades surdas e das "almas" das comunidades surdas. Isso significa que abrange a língua, as ideias, as crenças, os costumes e os hábitos do povo surdo (STROBEL, 2016, p. 29).

A Lei n. ${ }^{\circ}$ 10.436/2002, de 24 de abril, assegura às pessoas surdas a LIBRAS (Língua Brasileira de Sinais) como sua primeira língua, devendo os sistemas educacionais garantir a LIBRAS no ensino. Essa Lei representa um avanço na educação brasileira, posto que reconhece uma língua de sinais brasileira, a legitimidade e importância na cultura do surdo, (GARCIA, 
2015). Tavares e Carvalho (2010) destacam que esse mesmo dispositivo legal determinou que o poder público, bem como as empresas concessionárias de serviço público, devem garantir formas de apoiar o uso e a difusão da Libras como meio de comunicação objetiva e de utilização corrente das Comunidades Surdas do Brasil. Além disso, a mesma previu a inclusão do ensino de Libras nos cursos de Educação Especial, de Fonoaudiologia e de Magistério.

Apesar do avanço evidente nas políticas públicas no referente à inclusão escolar da pessoa surda, enxerga-se, ainda, a necessidade de se ampliar as pesquisas e as discussões sobre o papel dos profissionais da educação no processo e escolarização dos surdos objetivando implementar novas propostas que busquem, conforme Skliar (2005), a formação de professores disciplinado no respeito à Cultura Surda, a fim de contribuir para uma educação que leve o sujeito surdo ao êxito em seu processo de escolarização e inserção social. Nesse sentido, Leonel (2014) afirma que se visualizam, por meio da educação inclusiva, as tentativas em busca de igualdade de direitos, no entanto, ainda é necessário ser solidificadas.

\section{METODOLOGIA}

O estudo foi desenvolvido em todas as Escolas Públicas de Ensino Fundamental da zona urbana do Município de Uruçuí-PI no período de 03 de junho a 19 de julho de 2019, com a participação de nove escolas, sendo quatro da Rede Estadual e cinco da Rede Municipal de Ensino situadas em Uruçuí-PI.

Uruçuí é um município do estado do Piauí cuja atividade predominante atual é o agronegócio e por isso representa uma das cidades mais prósperas em crescimento econômico (IBGE, 2010).

De acordo com o IBGE (2010), o município de Uruçuí (Figura 1), possuía nesse ano uma população de 20.149 habitantes. Em 2016, sua renda per capita era de R \$36.777,46, representando a $685^{\mathrm{a}}$ posição nacional e a $2^{\mathrm{a}}$ posição do estado do Piauí. 
Figura 1: Localização do Município de Uruçuí.

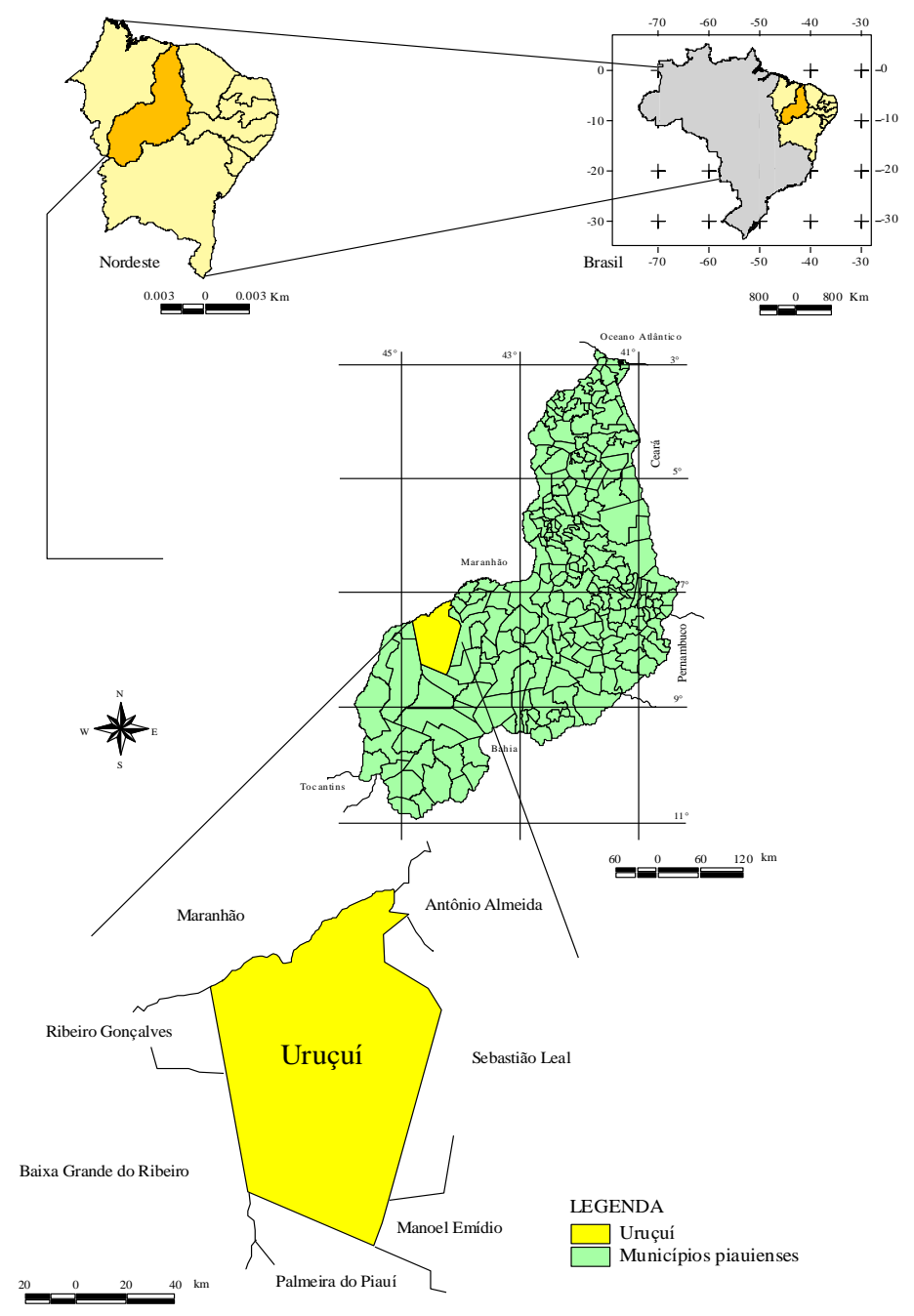

Fonte: IBGE (2010).

Esta pesquisa foi concretizada por meio de entrevistas com roteiro semiestruturado com oito questões, sendo três objetivas e cinco subjetivas, direcionadas conforme parâmetros descritos na tabela 1:

Tabela 1: Definição de categorias da pesquisa

\begin{tabular}{|c|c|c|}
\hline Categorias de variáveis & Unidade & Definição \\
\hline \multicolumn{3}{|l|}{ Quantitativas } \\
\hline $\begin{array}{l}\text { Matrículas de alunos } \\
\text { surdos }\end{array}$ & № de alunos & $\begin{array}{l}\text { Quantidade de alunos matriculados no } \\
\text { ensino fundamental das escolas pesquisadas } \\
\text { no período de } 2015 \text { a } 2019\end{array}$ \\
\hline $\begin{array}{l}\text { Projeção de aprovação de } \\
\text { alunos surdos }\end{array}$ & $\%$ & $\begin{array}{l}\text { \% de alunos surdos aprovados relativamente } \\
\text { ao número de ingressantes nos anos de } \\
2015 \text { a } 2018 \text {. }\end{array}$ \\
\hline \multicolumn{3}{|l|}{ Qualitativas } \\
\hline $\begin{array}{l}\text { Suporte disponível para os } \\
\text { alunos surdos }\end{array}$ & $\begin{array}{l}\text { Descrição do } \\
\text { suporte }\end{array}$ & $\begin{array}{l}\text { Disponibilização de recursos materiais ou } \\
\text { humanos para acompanhamento dos alunos } \\
\text { surdos }\end{array}$ \\
\hline Discussão e socialização & Sim ou não & Formas de realização de discussão e \\
\hline
\end{tabular}




\begin{tabular}{|l|c|l|}
\hline $\begin{array}{l}\text { da inclusão de alunos } \\
\text { surdos na comunidade } \\
\text { escolar }\end{array}$ & $\begin{array}{l}\text { socialização de alunos surdos na } \\
\text { comunidade escolar. }\end{array}$ \\
\hline $\begin{array}{l}\text { Limitação do acesso de } \\
\text { alunos surdos à Escola }\end{array}$ & $\begin{array}{c}\text { Fatores } \\
\text { limitantes }\end{array}$ & $\begin{array}{l}\text { Descrição de fatores que limitam o acesso } \\
\text { dos alunos surdos nas Instituições em estudo }\end{array}$ \\
\hline $\begin{array}{l}\text { Limitação da permanência } \\
\text { e do êxito de alunos } \\
\text { surdos }\end{array}$ & $\begin{array}{c}\text { Fatores } \\
\text { limitantes }\end{array}$ & $\begin{array}{l}\text { Descrição de fatores que limitam a } \\
\text { permanência e o êxito dos alunos surdos nas } \\
\text { Instituições em estudo. }\end{array}$ \\
\hline $\begin{array}{l}\text { Perspectiva de } \\
\text { contratação de intérprete } \\
\text { de Libras }\end{array}$ & Sim ou não & $\begin{array}{l}\text { Possibilidade de contratação de um } \\
\text { intérprete de Libras para acompanhamento } \\
\text { dos alunos surdos }\end{array}$ \\
\hline Libras no currículo & Sim ou não & $\begin{array}{l}\text { Planejamento para a introdução da disciplina } \\
\text { de libras como componente curricular }\end{array}$ \\
\hline
\end{tabular}

Fonte: Própria (2019)

Primeiramente foi lido e entregue aos representantes das escolas o Termo de Consentimento Livre e Esclarecido (TCLE), a fim de que fosse autorizada a participação da escola na pesquisa.

\section{RESULTADOS E DISCUSSÃO}

Os resultados que seguem refletem a realidade de nove escolas públicas do município de Uruçuí, estado do Piauí, no que se refere à implementação de políticas voltadas para o atendimento educacional de pessoas surdas na Rede Regular de Ensino das Escolas em estudo.

A figura 1 mostra o número de alunos surdos matrículas nas Instituições nos últimos cincos anos. Como se pode verificar, são apenas seis alunos regularmente matriculados de 2016 a 2019. Esses números, a priori, não refletem ausência ou presença de políticas públicas efetivas direcionadas para o atendimento especializado aos surdos nas instituições em estudo. Outrossim, mostra que há presença de alunos surdos nessas instituições e, portanto, há necessidade dessas políticas básicas como o intérprete de libras e condições para o êxito e a permanência na escola, o que será apresentado em análise posterior. 
Figura 2. Número de alunos surdos matriculados nos últimos cinco anos nas escolas entrevistados de ensino fundamental na cidade de Uruçuí - PI, Brasil.

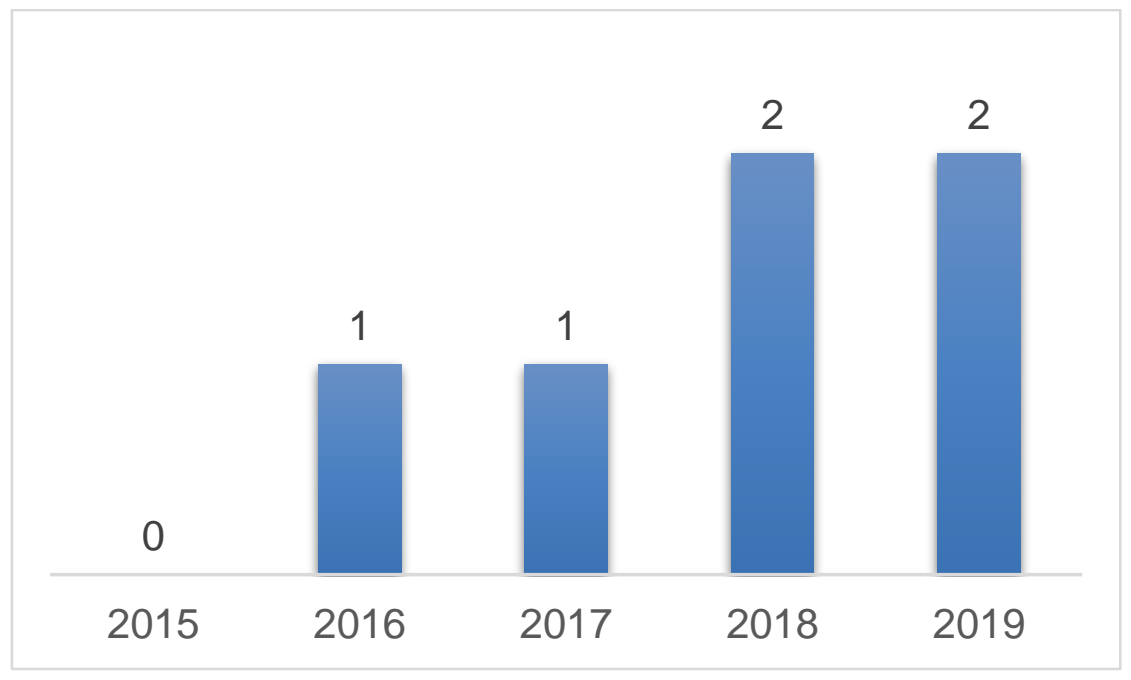

Fonte: Própria (2019).

Ao serem questionados quanto à projeção de aprovação de alunos surdos nas escolas onde há matrículas dos mesmos nos anos em estudo (2015 a 2018), todas as instituições informaram que sempre aprovam os alunos por apresentarem algum tipo de deficiência e entenderem que eles têm a garantia do direito à aprovação. Essa afirmação denuncia o quanto as escolas estão desqualificadas para recepção e integração dos alunos surdos ao processo educacional, uma vez que entendem que a garantia legal do direito à educação dos surdos de forma preferencial na Rede Regular de Ensino, restringe-se à aprovação do aluno, independentemente de seu progresso no campo do conhecimento ou da integração de forma promissora à sociedade.

Endossando essa visão, Sanches e Silva (2019), destacam que "a educação inclusiva requer de todos nós um esforço no que diz respeito à aprendizagem de todos os estudantes, promovendo o bem-estar acadêmico, emocional e social, favorecendo assim o seu desenvolvimento global”. Nesse sentido, não se pode limitar a educação à prática de aprovação, desvinculando-se da responsabilidade com a formação para o exercício da cidadania plena.

Quando indagado aos gestores das instituições a respeito do tipo de suporte oferecido para os alunos surdos em sala de aula, como descrito na figura 2 , seis das instituições afirmaram que há acompanhamento individualizado para os alunos que apresentam algum tipo de deficiência, por meio do apoio às atividades por um profissional da educação sem formação em libras, e as outras três escolas afirmaram não oferecer nenhum suporte aos alunos surdos. Cabe destacar, que nenhuma das escolas realizavam oficinas com os alunos para introduzir a libras e tão pouco apresentava um intérprete de libras durante as aulas ou um acompanhamento 
individualizado por meio do apoio as atividades por um profissional de libras.

Nesse sentido, enfatiza-se que o apoio aos estudantes surdos deve ocorrer por meio de um intérprete de libras, que deve acompanhar todas as aulas ministradas pelos professores fazendo a tradução português/libras (BRASIL, 2005).

"A falta de intérpretes, o despreparo dos professores, o preconceito e discriminação e a falta ou o uso inadequado do material didático pedagógico para este alunado, como por exemplo, filmes legendados, aulas sem material de apoio visual" são fatores que contribuem para o fracasso escolar dos alunos surdos (ANSAY, 2009, p. 114).

Destaca-se que os profissionais da educação que fazem o Atendimento Educacional Especializado nas escolas em estudo que mencionaram a existência desse apoio, são pedagogos que exercem entre outras atribuições, a função de acompanhar as atividades dos discentes surdos. Entretanto, não passaram por formação continuada para qualificação específica, havendo, portanto, a necessidade de as escolas reverem suas práticas à luz dos novos referenciais pedagógicos da inclusão.

Figura 3. Suportes para os alunos surdo nas escolas em estudo.

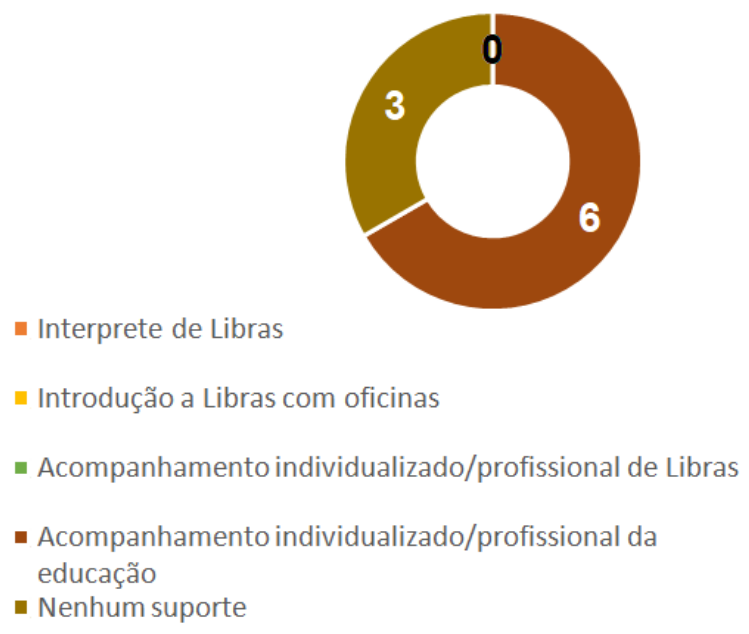

Fonte: Própria (2019)

Em seguida, questinou-se ao gestor se a instituição discutia a inclusão dos alunos surdos na comunidade escolar e, em caso afirmativos, os meios utilizados para esse fim:

$\checkmark$ Três escolas afirmaram descutir o tema em reuniões, palestras e encontros pedagogicos;

$\checkmark$ Uma relatou discutir somente com o corpo docente;

$\checkmark$ Cinco afirmaram não discutir sobre a inclusão de alunos surdos, alegando ser por conta de não possuir esse público matriculado na instituição.

Ao observar as respostas associadas às instituições, no que se refere à discussão da 
inclusão das pessoas surdas, verifica-se que não ocorre de maneira ampla envolvendo toda a comunidade acadêmica, o que seria o ideal, visando à difusão da ideia de que a surdez é apenas uma diferença linguística e, para que pessoas com limitação auditiva possam ser integradas efetivamente à sociedade, sua primeira língua precisa fazer parte primeiramente das organizações educacionais, tendo em vista se tratar de um direito assegurado em lei, para posteriormente passar a fazer parte, de forma progressiva, do dia-dia de todos os cidadãos.

Compreender as necessidades e especificidades de cada educando em uma sala de aula é essencial para o processo de ensino aprendizagem produtivo e inclusivo, assim é preciso que se entenda a cultura das pessoas surdas e que se tenha consciência da importância da introdução da Libras no desenvolvimento educacional destas, pois sendo sua primeira língua precisa ser assegurada, além disso introduzir a libras no ensino é uma forma de ajudar na aprendizagem de um conteúdo ministrado e traz igualdade entre os surdos e os demais alunos da turma. É indispensável que sejam procuradas formas de incluir a todos, uma vez que toda pessoa tem direito a educação, levando em consideração suas necessidades, habilidades e interesses de aprendizagem (SILVA, 2018).

Para Borges e Nogueira (2016), a escola é uma ferramenta de suma importância para vencer/superar a exclusão, ao possibilitar como objetivo uma educação democrática. É importante que a escola seja acessível para todos, independentemente de suas potencialidades ou deficiências. Quando um aluno surdo se introduzir no contexto escolar, é necessária a parceria conjunta de escola e família para promover uma formação surda para a vida em sociedade.

Ao serem questionados sobre os principais fatores que limitam o igresso do aluno surdo na instituição, obteve-se o seguinte resultado:

$\checkmark$ Quatro das escolas relataram ser a falta de profissionais especializados para o acompanhamento dos alunos surdos;

$\checkmark$ Duas afirmaram ser a comunicação entre professor e o aluno surdo;

$\checkmark$ Uma escola afirmou ser a falta de capacitação/qualicação e empenho dos familiares;

$\checkmark$ Uma escola afirmou tratar-se de falta de locomoção/tranporte;

$\checkmark$ Uma escola relatou nenhuma limitação.

Das respostas acima apresentadas associadas à concepção dos gestores, é relevante destacar queo fator limitante que apareceu com maior frequência foi a falta de profissional de libas, seguido da ineficiência da comunicação docente/discente surdo, corroborando com o que se encontra na literatura atual. De acordo com Sanches e Silva (2019), é necessário que o 
professor esteja preparado através de uma formação que permita abordar em sala de aula a valorização da heterogeneidade, a cultura surda, a Libras entre outros, pois as dificuldades de inclusão dos alunos surdos frequentemente estão relacionadas ao processo de ensinoaprendizagem. A parceria do professor-intérprete de Libras em sala de aula é de extrema importância para o desenvolvimento do aluno surdo (SANCHES; SILVA, 2019).

Já a concepção dos gestores sobre os principais fatores que limitam o êxito e permanência do aluno surdo na instituição (Figura 4), obteve-se maior frequência associada à ausência de profissionais qualificados para acompanhar esse aluno no âmbito escolar, seguida da falta de incentivo institucional e a falta de apoio pedagógico aos professores.

Genericamente, pode-se afirmar que a inclusão dos alunos surdos não acontece na prática, pois existe a ausência de proposta/atitudes para um ensino que supere e permita o ensino independente das diferenças entre ouvintes e surdos, tornando a inclusão uma realidade (BORGES; NOGUEIRA, 2016).

Muitas barreiras e dificuldades são enfrentadas pelas escolas para permanência do aluno com deficiência, porque não basta fazer a matrícula desses alunos, ele possui direitos e especificidades que a instituição de ensino precisa atender, não somente para aprendizagem dos conteúdos, mais também para integração dos alunos surdos com os demais. Então oferecer recursos para que o aluno com surdez possa permanecer e se devolver em todas as suas instâncias, seja de cunho moral, intelectual ou física, deve ser vista como prioridade pelas políticas públicas (CARNEIRO, 2018).

Figura 4. Principais fatores que limitam o êxito e a permanência do aluno surdo nas escolas em estudo

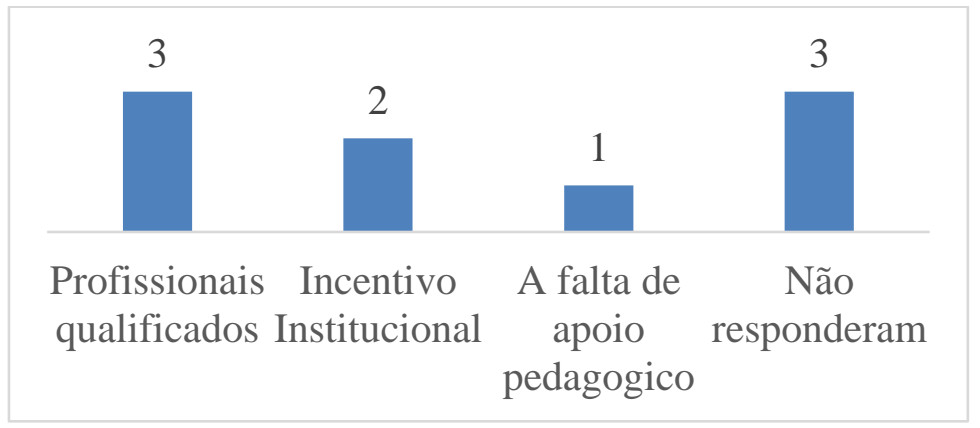

Fonte: Própria (2019)

Na questão seguinte, indagou-se aos gestores sobre a existência de perspectiva para a contratação de um intérprete de libras, caso ainda não exista na Instituição. Verificou-se que todas as escolas não dispõe de intérprete de Libras e a maioria afirmou não ter a perspectiva de contratação, duas das escolas que atualmente não possui matrícula de alunos surdo relatou que poderia contratar, e que dependeria da efetivação dessa matrícula, e uma outra escola relatou 
responsabilidade seria repassada a Secretaria Municipal de Educação, não tendo propriedade para precisar a resposta.

É importante a presença dos interpretes para o aluno surdo, pois esses profissionais possuem habilidades e competências para lidar com esse aluno atendendo as suas necessidades e especificidade da linguagem, pois a comunicação é essencial para a convivência em qualquer ambiente. $\mathrm{O}$ que tem se observado é que apesar da existência de cursos de formação específica para tradutor/intérpretes de libras, quem atua nessa área na maioria das vezes são licenciandos aprovados em exames de proficiência para Libras. Algo que merece atenção das políticas educacionais, pois o aluno surdo que não domina a língua utilizada pela maioria da sala de aula, principalmente pelo professor, depende exclusivamente da Libras para seu aprendizado (BORGES; NOGUEIRA, 2016).

Dessa forma, apesar do reconhecimento da Libras como língua oficial das pessoas com surdez ser recente precisa-se cada vez mais compreender a importância do intérprete de Libra no contexto educacional para a comunicação do aluno surdo, pois seu papel se relaciona com a interação social e cultural para inclusão e inserção dos surdos na sociedade (SOUSA, 2015).

$\mathrm{Na}$ última questão, solicitou-se aos gestores que respondesse se havia perspectiva de introdução da disciplina Libras como componente curricular, contatou-se que todas as escolas não tinham perspectiva de adicionar a disciplina na matriz curricular. Isso é algo que deveria ser repensado e levado em consideração a introdução da disciplina Libras mesmo no ensino básico, uma vez que Libras é a língua natural utilizada pelos surdos brasileiros para se comunicar, dessa forma é importante que essa disciplina seja estudada junto com as outras para que a criança surda possa conviver e aprender a melhorar a interação ouvinte e surdo, além de melhorar seu rendimento escolar (SILVA, 2018).

Segundo Borges, Rocha e Justi (2017) a escola precisa criar mecanismos e suportes, considerando a prática pedagógica da educação inclusiva, o aluno surdo não somente precisa estar na sala de aula com os demais, mais o acolhimento a esse público vai além disso, suas especificidades educacionais especiais precisam ser compreendidas e levadas em conta para seu efetivo desenvolvimento. Assim seu aprendizado necessita de um acompanhamento especializado com um professor com formação em Libras.

\section{CONCLUSÕES}

As escolas em análise recebem as matrículas de alunos surdos, porém a aprendizagem fica comprometida, visto que os resultados mostraram que as escolas de ensino fundamental do município de Uruçuí-PI não dispõem de estrutura favorável ao desenvolvimento do ensino 
inclusivo das pessoas surdas. Tal afirmação é possível a partir da análise da inexistência de profissional de libras em salas com surdos matriculados, bem como do déficit de recursos tecnológicos voltados à facilitação da comunicação com os alunos com surdez.

Além disso, as ações voltadas para a inclusão de alunos com surdez não ocorrem com frequência no ambiente escolar; a discussão sobre a temática não vem sendo difundida amplamente com a comunidade acadêmica, o que caminha em desacordo com a legislação vigente sobre a matéria, uma vez que desde 2002 já existe legislação específica direcionada para orientação de ações que visam à inclusão integral de pessoas surdas.

Assim, é preciso que a sociedade cobre a concretização da execução das políticas públicas asseguradas em lei aos alunos surdos no âmbito escolar, uma vez que o poder público vem negligenciando essa prática.

\section{REFERÊNCIAS}

ANSAY, N. A trajetória escolar de alunos surdos e a sua relação com a inclusão no ensino superior (Dissertação de mestrado). Universidade Federal do Paraná, 2009, Brasil.

BARBOSA, D. S., FIALHO, L. M. F., MACHADO, C. J. S. Educação inclusiva: aspectos históricos, políticos e ideológicos da sua constituição no cenário internacional. Actualidades Investigativas en Educación. v. 18, n. 2, 2018.

BORGES, A. S.; ROCHA, J. S.; JUSTI, J. Inclusão Educacional Do Aluno Surdo: Uma Perspectiva Social E Reflexiva. Professares, v. 6, n. 3, 2017.

BORGES, F. A.; NOGUEIRA, C. M. I. O ensino e a aprendizagem de Matemática para surdos inclusos: o que dizem os intérpretes de Libras?. Educação matemática em revista-RS, v. 2, n. 17, 2016.

BRASIL. Estatuto da Criança e do Adolescente. Diário Oficial da União. Brasília. Imprensa Oficial, 13 de julho de 1990.

BRASIL. Ministério da Saúde. Estatuto da Criança e do Adolescente / Ministério da Saúde. 3. ed. - Brasília: Editora do Ministério da Saúde. 2008.

BRASIL. Lei de Diretrizes e Bases da Educação Nacional. Lei n ${ }^{\circ}$ 9394/96 de 20 de dezembro de 1996, Brasília, 1996.

BRASIL. Constituição da República Federativa do Brasil. Brasília: Gráfica do Congresso Nacional, 1988.

CARNEIRO, M. R. I. Acessibilidade espacial em escolas municipais: estudo de caso da escola de educação básica Elizabeth Ulyssea Arantes, no município de Laguna. TCC (Trabalho de Conclusão de Curso) - Engenharia Civil-Tubarão, 2018.

CORREIA, L. Educação inclusiva ou educação apropriada? In D. Rodrigues 
(Org.), Educação e diferença: Valores e práticas para uma educação inclusiva (pp. 123-142). Porto: Porto Editora, 2001.

FERREIRA, D. C. K. Salas de Atendimento Educacional Especializado (AEE) na rede regular pública de ensino paranaense: desafios, limites e possibilidades do paradigma inclusivo. Revista Educação Especial, v. 29, n. 55, 2016.

GARCIA, E. C. O que todo pedagogo precisa saber sobre LIBRAS: Os principais aspectos e a importância da Língua Brasileira de Sinais. Rio de Janeiro: Wak, 2015.

Instituto Brasileiro de Geografia e Estatística (IBGE - 2010). Cidades. Disponível em: https://cidades.ibge.gov.br/brasil/pi/urucui/panorama. Acesso em: 20 jun. 2019.

INEP. Censo Escolar 2018 revela crescimento de $18 \%$ nas matrículas em tempo integral no ensino médio,2018. Brasília: MEC, 2019.

LEONEL, W.H.S. O processo de escolarização do deficiente intelectual da educação básica e os desafios da prática docente: um debate relevante ao ensino superior. 2014. Dissertação (Mestrado em Psicologia) - Universidade Estadual de Maringá, Departamento de Psicologia. Maringá, 2014.

LEONEL, W.H.S. Politicas e o Processo Ensino Aprendizagem na Educação Inclusiva. Reimpressão Maringá-PR.: UniCesumar, 2018. 228 p.

MENDONÇA, L. M.; CARVAlHO, T. W.; DOMINGUES, L. S.; FARIA, A. C. C. A importância da LIBRAS como Componente Curricular na Educação básica. Educação: Saberes e Prática, v. 7, n. 1, 2018.

MOZZATA, M. J. S.. Educação Especial no Brasil: História e Políticas Públicas. $6^{\text {a }}$. Ed. São Paulo: Cortez, 2011.

NOGUEIRA, C. M. I.; CARNEIRO, M. I. N.; SOARES, B. I. N. LIBRAS. Maringá-Pr.: UniCesumar, 2018.

PASSOS, Y.; SANTOS, W.; CAMPELO, W. Língua de sinais na escola: comunicação como forma de interação entre surdos e ouvintes por meio da LIBRAS na Escola Luiz Nunes de Direito. Littera on line, v. 9, 2018.

SANCHES, I.; SILVA, P. B. A inclusão de estudantes surdos no ensino superior brasileiro: o caso de um curso de Pedagogia. Revista Portuguesa de Educação, v. 32, n. 1, 2019.

SANTOS, M. C. D. O direito das pessoas com deficiência à educação inclusiva e o uso pedagógico dos recursos de tecnologia assistiva na promoção da acessibilidade na escola. InFor, v. 1, n. 1, 2016.

SILVA, A. R. As libras e as contribuições para a inclusão dos surdos nas aulas de Geografia. 2018. 35f. Trabalho de Conclusão de Curso (Graduação em Geografia) Universidade Estadual da Paraíba, Guarabira, 2018.

SOUSA, V. A importância do papel do intérprete de libras no processo de aprendizagem do 
aluno surdo em sala de aula nas escolas de ensino comuns. Cadernos da FUCAMP, v. 14, n. $20,2015$.

STROBEL, K. As imagens do outro sobre a cultura surda. Florianópolis: Ed. da UFSC, 2016.

SKLIAR, Carlos (org.). A surdez: um olhar sobre as diferenças. 3. ed. Porto Alegre: Mediação, 2005.

TAVARES, I. M. S; CARVALHO, T. S. S. Inclusão escolar e a formação de professores para o ensino de Libras (LÍNGUA BRASILEIRA DE SINAIS): Do texto oficial ao contexto. São Paulo: Ed. da Vepeal, 2010. 


\title{
CONSTRUINDO SABERES COM O PIBID: A PRODUÇÃO DE MATERIAIS DIDÁTICOS PARA O ENSINO DE BIOLOGIA
}

\section{CONSTRUYENDO CONOCIMIENTOS CON PIBID: LA PRODUCCIÓN DE MATERIALES DE ENSEÑANZA PARA LA EDUCACIÓN BIOLÓGICA}

\section{BUILDING KNOWLEDGE WITH PIBID: THE PRODUCTION OF TEACHING MATERIALS FOR BIOLOGICAL EDUCATION}

\begin{abstract}
Marcelo Augusto Barros Oliveira'; Wanderson Mateus Bispo da Silva²; José da Guia Conceição Ferreira ${ }^{3}$; Paloma de Jesus Cipriano ${ }^{4}$; Elkejer Ribeiro da $\mathrm{Cruz}^{5}$
\end{abstract}

DOI: https://doi.org/10.31692/978-65-991061-3-2.107-109

\section{INTRODUÇÃO}

O Programa Institucional de Iniciação à docência (PIBID), surgiu como um dos principais instrumentos de fortalecimento do processo de formação inicial docente, que é baseado através da valorização de práticas educativas no ambiente de sala de aula (FRISON; SIMÃO; CIGALES, 2017). O programa teve início após a criação da Portaria Normativa de n³8 em 12 de dezembro de 2007, que dispõe sobre o mecanismo de funcionamento do PIBID e os critérios que devem ser obedecidos, objetivando sempre o incentivo e valorização a formação docente (BRASIL, 2010).

O alinhamento entre o espaço de formação com os estudos teóricos e o ambiente de sala onde o futuro professor irá atuar, tem se tornado cada dia mais importante, o acadêmico necessita de vivencias para que possa moldar sua identidade profissional que será reforçada ao longo da sua carreira. As atividades realizadas no PIBID reforçam a importância da prática docente, pois ao longo dos últimos anos o programa tem se mostrado eficiente e benéfico tanto para os profissionais em formação, quanto para a escola que recebe esses alunos (AMBROSETTI et al., 2013).

Com o PIBID, o acadêmico pode vislumbrar diversas situações que garantem uma bagagem profissional mais solida, isso vai ser importante para que ao assumir protagonismo na sua profissão, este indivíduo já esteja preparado para tudo que surgir e necessitar de resposta rápida. A prática profissional com o PIBID é então uma oportunidade de compreender o "ser professor", com toda a complexidade da profissão e também com toda a beleza que existe em poder contribuir com o processo de formação dos seus alunos.

\footnotetext{
${ }^{1}$ Licenciatura em Ciências Biológicas, IFPI, marcelobarrosaugusto123@gmail.com

${ }^{2}$ Licenciatura em Ciências Biológicas, IFPI, wandersonmatheus42@gmail.com

${ }^{3}$ Licenciatura em Ciências Biológicas, IFPI, josedaguiag30@outlook.com

${ }^{4}$ Licenciatura em Ciências Biológicas, IFPI, paloma-still@outlook.com.br

${ }^{5}$ Mestre em Genética e Toxicologia Aplicada pela Universidade Luterana do Brasil, IFPI, elkejer@ifpi.edu.br
} 
No sistema público, as escolas de ensino básico nem sempre conseguem fazer com que o nível de qualidade seja o ideal, o professor passa por diversas situações que colaboram para a ineficiência do sistema. O pibidiano por ainda estar em processo de formação inicial, vai para as escolas parceiras com uma energia a mais, o que em determinadas situações vai contribuir significativamente para o aprendizado dos educandos.

\section{RELATO DE EXPERIÊNCIA}

O presente trabalho retrata as experiências vivenciadas no âmbito do programa PIBID no curso de Licenciatura em Ciências Biológicas do Instituto Federal de Educação, Ciência e Tecnologia do Piauí - Campus Floriano. O PIBID vem proporcionando aos acadêmicos envolvidos a oportunidade de vivenciar o ambiente de sala de aula na posição de futuros professores, na escola parceira onde as atividades são realizadas os acadêmicos se depararam com as dificuldades enfrentadas pela maioria dos alunos na assimilação de alguns conteúdos. Esse problema fez com que houvesse uma necessidade de intervir rapidamente, pois a principal consequência gerada pela dificuldade dos alunos era os resultados negativos durante as avaliações. Foi proposto então que esses alunos pudessem ter aulas de reforço ministradas pelos pibidianos no período de contraturno, para que assim pudessem solucionar eventuais dúvidas e reparar os pontos onde sentiam maior dificuldade.

As atividades realizadas no período de contraturno são em alguns casos a única oportunidade do aluno conseguir atender suas necessidades enquanto educando, esses espaços de formação ajudam a escola a complementar o processo de formação educativa do aluno (KROLOW; CASTELEINS, 2009). As atividades propostas pelos pibidianos culminaram na realização de uma oficina com produção de modelos didáticos para o ensino de temas como citologia, reprodução e ainda zoologia, que se apresentaram como pontos de maior dificuldade dos alunos, está identificação aconteceu através de levantamento com o professor da disciplina de Biologia.

A realização das aulas em contraturno como método de auxílio para os alunos, ajudou a constatar que parte do bloqueio de aprendizado dos educandos era resultado do pouco tempo dedicado a cada conteúdo unido a falta de assessoria para revisão no ambiente familiar. Buscouse então metodologias de ensino que incentivem um maior protagonismo dos alunos, na oficina realizada durante as aulas, os alunos conhecer melhor as estruturas celulares de organismos procariontes e eucariontes, os principais acontecimentos durante o período gestacional, e ainda as principais características e morfologia dos animais vertebrados.

$\mathrm{Na}$ oficina os alunos mostraram que práticas simples podem trazer resultados positivos, 
e que no estudo de conteúdos mais complexos o professor deve buscar formas de dar um suporte para aqueles que sentem dificuldade para assimilar os conteúdos. A experiência vivida com este trabalho trouxe para os educandos e para os professores em formação uma perspectiva diferente a respeito dos mecanismos de ensino mais utilizados atualmente, isso denota a necessidade de adequação profissional frente aos desafios no processo de ensino aprendizagem.

É inegável que o currículo escolar atual do ensino público está pautado em oferecer o mínimo necessário para que o indivíduo possa se desenvolver enquanto cidadão, mas é impossível não reconhecer também as ineficiências do sistema. O professor por estar à frente da sala de aula tem de se atentar para o perfil de cada aluno, buscando meios de adequar seus métodos de ensino de maneira a atender o seu público. Nesta perspectiva, o PIBID tem se mostrado uma ferramenta muito importante para que o professor em formação tenha a percepção da necessidade dos seus alunos, tanto nos métodos de ensino, quanto nas formas de avaliar.

\section{CONSIDERAÇÕES}

Com base nas experiências vivenciadas no âmbito do PIBID, pode-se considerar que o programa tem contribuído significativamente no processo de formação inicial docente dos licenciandos em biologia. Pela eficiência do programa, o PIBID tem auxiliado estes futuros profissionais mostrando não apenas a importância da prática docente, mas também realizando a articulação de saberes entre teoria e prática para que os resultados sejam os melhores possíveis, e com isso, oferece a oportunidade de ressignificar o que se entende por "ser professor".

\section{REFERENCIAS}

AMBROSETTI, N. B et al. Contribuições do Pibid para a formação inicial de professores. Educação em Perspectiva, v. 4, n. 1, 2013.

BRASIL. Decreto n. 7.219, de 24 de junho de 2010. Dispõe sobre o Programa Institucional de Bolsa de Iniciação à Docência - PIBID e dá outras providências. Diário Oficial da União, Poder Executivo, Brasília, DF, 26 jun. 2010. Seção 1, p. 4.

KROLOW, A. C. M.; CASTELEINS, V. L. Contra turno: Um espaço de desafio para a educação do futuro. In: IX Congresso Nacional de Educação. Anais..., Curitiba. 2009.

FRISON, L. M. B.; SIMÃO, A. M. V.; CIGALES, J. R. Aprendizagens na docência: PIBID e a formação de professores. Revista e-Curriculum, v. 15, n. 1, p. 25-44, 2017. 


\title{
UTILIZAÇÃO DE UM SIMULADOR DO MOVIMENTO OBLÍQUO PARA ENSINO DE FÍSICA NUMA PERSPECTIVA DE TECNOLOGIA ASSISTIVA: FERRAMENTA DIDÁTICA INOVADORA PARA ESTUDANTES COM DEFICIÊNCIA VISUAL
}

\section{USO DEL UNO SIMULADOR DE MOVIMENTO OBLIGO PARA LA EDUCACÍON FÍSICA EM UMA PERSPECTIVA DE TECNOLOGÍA ASISTENTE: HERRAMIENTA DE ENSEÑANZA INNOVADORA PARA ESTUDIANTES COM DISCAPACIDAD VISUAL}

\section{USING AN OBLIGO MOVEMENT SIMULATOR FOR PHYSICAL EDUCATION FROM AN ASSISTANT TECHNOLOGY PERSPECTIVE: INNOVATIVE TEACHING TOOL FOR VISUAL DEFICIENCY STUDENTS}

\author{
Natália de Souza Brito ${ }^{1}$; Sérgio Marivaldo dos Santos ${ }^{2}$; Cecília Leite de Albuquerque ${ }^{3}$; \\ Kássio Marques e Silva ${ }^{4}$; Me. Hércules Santiago Silva ${ }^{5}$
}

DOI: $\underline{\text { https://doi.org/10.31692/978-65-991061-3-2.110-113 }}$

\section{INTRODUÇÃO}

Quando são apresentados estudos do movimento oblíquo no contexto da sala de aula, geralmente são utilizados, exemplos do cotidiano do estudante, como: o lançamento de uma bola de futebol, o arremesso de uma pedra (...) para facilitar a assimilação do que acontece no movimento que é justamente o percurso que esses objetos realizam no contexto real. Porém, para as pessoas com deficiência visual torna-se difícil relacionar a descrição do movimento com a sua vivência, já que contextualização do fenômeno é baseado na visualização. Na lei de Diretrizes e Bases da Educação (LBD), de 1996, no artigo 4 , inciso III, e reafirmado na Lei Brasileira de Inclusão (LBI), de 2015, capítulo IV, deixam claro que é dever do Estado a garantia de atendimento especializado gratuito aos estudantes com necessidades especiais, de preferência, na rede regular de ensino. Para tanto o educador deve receber a capacitação necessária para tal atendimento. Como também é dever do estado, da família, da comunidade escolar e da sociedade garantir aos estudantes uma educação de qualidade deixando-o a salvo de qualquer forma de violência, negligência e discriminação.

Os estudantes com deficiências visuais têm grandes problemas de acesso a materiais didáticos que minimizem as dificuldades inerentes de sua deficiência e melhorem o processo de ensino-aprendizagem. (REGIANE e MÓL, 2010).

A inópia de materiais didáticos para esse público dificulta o processo de interação desses

\footnotetext{
1 Licenciatura em Química, IFPE Campus Ipojuca, natisbrito@hotmail.com

${ }^{2}$ Licenciatura em Química, IFPE Campus Ipojuca, sergiomarivaldo@hotmail.com

${ }^{3}$ Licenciatura em química, IFPE Campus Ipojuca, cecilialeite011@gmail.com

${ }^{4}$ Licenciatura em Química, IFPE Campus Ipojuca, kassiomarques@yahoo.com

${ }^{5}$ Mestre em Química, IFPE Campus Ipojuca, herculessantiago@ipojuca.ifpe.edu.br
} 
estudantes no ambiente escolar. Essa dificuldade de acesso a materiais afeta os docentes em sala de aula, uma vez que essa ausência acaba por debilitar e dificultar a mediação do conhecimento. Apesar de, na maioria das vezes, isso não ocorra a despeito da boa vontade do professor, mas pela ausência desses materiais nas redes de ensino.

[...]E nem sequer se trata, na maior parte dos casos, de má vontade por parte do professor ou indisponibilidade do aluno portador de deficiência. Trata-se, tãosomente, da dificuldade de efetivar, na prática, a "Escola Inclusiva", tão sabiamente arquitetada de formas teóricas, à luz da nossa bem-intencionada legislação. (PEREIRA, 2003).

Baseado nessa perspectiva desenvolvemos um material, numa perspectiva de tecnologia assistiva (TA), que possa melhorar a compreensão dos estudantes com deficiência visual, nos estudos dos fenômenos de movimentos oblíquos, no contexto da sala de aula, gerando uma maior independência e autonomia destes estudantes, num processo de formação verdadeiramente inclusiva e não apenas integradora como acontece na maioria dos casos.

\section{RELATO DE EXPERIÊNCIA}

Foi empregada nesta experiência a metodologia de pesquisa qualitativa em educação direcionada a um grupo de estudantes que apresentam algum tipo de deficiência visual e de baixa visão, na Escola Municipal Cláudio Gueiros Leite, situada na cidade do Cabo de Santo Agostinho-PE, no ano de 2019.

O material didático produzido foi elaborado com uma base de madeira, onde foi adicionado um trilho fixo, no qual podia jungir três arames móveis que são fixados com velcro, podendo atingir os ângulos de trinta, quarenta e cinco e sessenta graus e uma bola plástica que é encaixada nos arames. Nesse protótipo pode-se simular o movimento oblíquo, através do percurso que a bola faz no arame, tornando-o acessível a estudantes cegos ou com algum grau de deficiência visual facilitando o processo de ensino-aprendizagem, pois se trata de um material flexível, funcional e que apresenta escalas em braile.

Na Imagem 1.1 é possível visualizar a base de madeira coberta de E.V.A que foi reciclada de uma porta de guarda roupa velho, com o trilho encontrado em sobras de materiais de uma marcenaria e a escala em braile feita com missangas adesivas.

Através deste material é possível simular o movimento retilíneo uniforme (MRU) no ângulo de trinta graus (Imagem: 1.2), o MRU no ângulo de quarenta e cinco graus (Imagem:1.3) e o MRU no ângulo de sessenta graus (Imagem: 1.4). O estudante com deficiência visual, através do tato, consegue compreender o conteúdo didático através da simulação dos 
movimentos que se dão de forma independente, facilitando a socialização do conhecimento

Imagem 1: Simulador de MRU

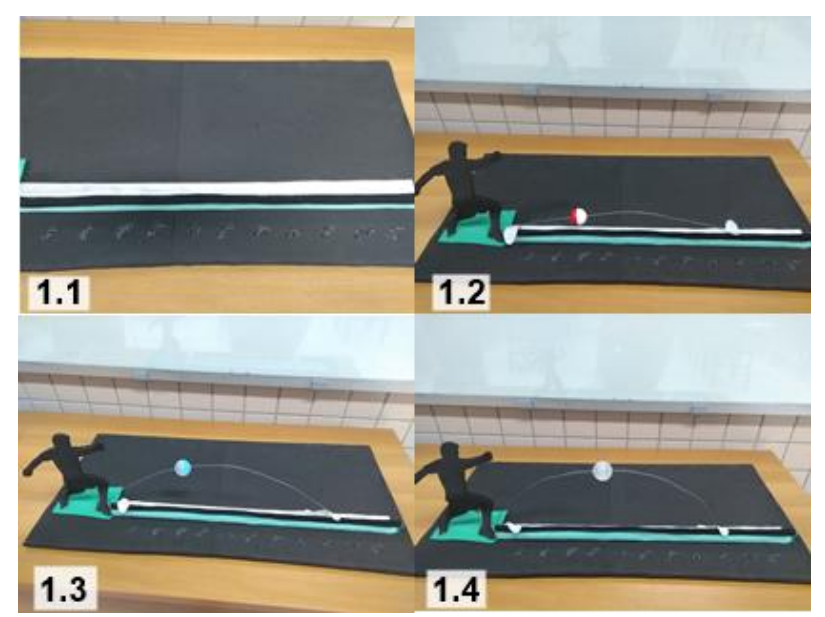

Fonte: Própria (2019).

O instrumento didático elaborado foi apresentado para estudantes com deficiência visual e de baixa visão e a um professor brailista, também com deficiência visual, (Imagem 2).

Imagem 2: Uso do instrumento didático pelos estudantes e professor.

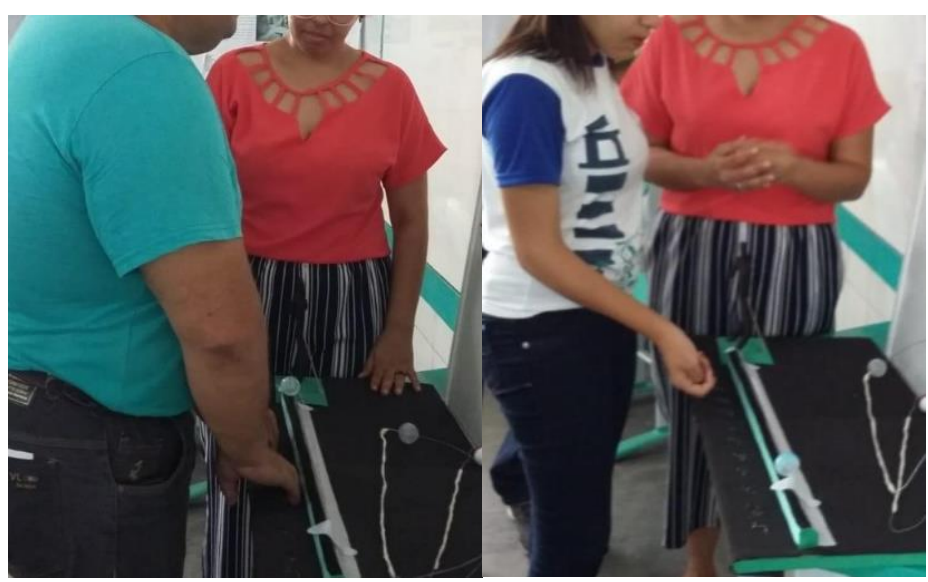

Fonte: Própria (2019).

Na demonstração, cada participante manuseou o simulador individualmente, tateandoo e deslizando as partes móveis. No termino da apresentação, foi distribuído um questionário com relação ao material didático utilizado:

- Você tem dificuldade em compreender os conteúdos de física, abordados nas aulas?

- Você gostou do projeto apresentado?

- O objetivo do projeto era fazer um simulador do movimento oblíquo, para auxiliar durante as aulas de física, você acha que esse objetivo foi alcançado?

- Você acha que deveria ser desenvolvido mais projetos como esse? 
- Em que aspectos você acha que o projeto pode ser melhorado?

\section{CONSIDERAÇÕES}

As respostas dos participantes indicaram que o material didático produzido foi útil para compreensão da temática proposta, mostrando-se também relevante para a promoção de políticas educacionais inclusivas. Outro ponto observado por eles foi que o simulador poderia ter um melhor enquadramento das escalas em braille, para facilitar a diferenciação dos números. Nessas circunstâncias podemos destacar que a boa aplicação desta ferramenta, poderá ajudar na melhor compreensão do MRU por pessoas com deficiência visual e com baixa visão. Analisando as possibilidades futuras existe a intenção de aperfeiçoar e aplicar o método para outros estudantes e implantar escalas numéricas em braille com enquadramento mais preciso para que o material possa torna-se inteiramente acessível.

\section{REFERÊNCIAS}

BRASIL, Constituição da República Federativa do Brasil de 1988. Disponível em: <http://www.planalto.gov.br/ccivil_03/constituicao/constituicao.htm>.Acessado em 03/07/2019.

BRASIL, Lei de Bases e Diretrizes n ${ }^{\circ}$ 9394, de 20 de dezembro de 1996. Estabelece as diretrizes e bases da educação nacional. Disponível em: $<$ https://presrepublica.jusbrasil.com.br/legislacao/109224/lei-de-diretrizes-e-bases-lei-939496>. Acessado em 03/07/2019.

BRASIL, Lei n ${ }^{\circ}$ 13146, de 6 de julho de 2015. Institui a lei brasileira de inclusão da pessoa com deficiência. Disponível em: <http://www.planalto.gov.br/ccivil_03/_ato20152018/2015/lei/113146.htm Acessado em 08/07/2019>.

FAVERO, O.; FERREIRA, W.; IRELAND, T.; BARREIROS, D. Educação Inclusiva. UNESCO. Brasília: 2009.

PEREIRA, F. M. A Deficiência Visual no Ensino Regular. Millenium Online. Lisboa. Portugal: 2003.

FAVERO, O.; FERREIRA, W.; IRELAND, T.; BARREIROS, D. Educação Inclusiva. UNESCO. Brasília: 2009.

REGIANE, A.M.; MÓL, G.S Inclusão de uma aluna cega num curso de Licenciatura em Química. Cidade e Educação. Brasília: 2010. 


\section{ENCONTRO SOBRE GESTÃO PARTICIPATIVA NA EDUCAÇÃO BÁSICA IFPI/CAMPUS FLORIANO E ESCOLAS PARCEIRAS}

\section{ENCUENTRO SOBRE GESTIÓN PARTICIPATIVA EM EDUCACIÓN BÁSICA IFPI/CAMPUS FLORIANO Y PARTNER SCHOOLS}

\section{MEETING ON PARTICIPATORY MANAGEMENT IN BASIC EDUCATION IFPI / CAMPUS FLORIANO AND PARTNER SCHOOLS}

\section{Vinícius da Luz Silva ${ }^{1 ;}$ Ana Raionara e Silva Tavares²; Francisca Tannyery da Silva Nascimento $^{3 ;}$ Roniê Ferreira Roza ${ }^{4 ;}$ Sebastiana Ceci Sousa ${ }^{5}$.}

DOI: $\underline{\text { https://doi.org/10.31692/978-65-991061-3-2.114-117 }}$

\section{INTRODUÇÃO}

Este texto tem por objetivo relatar uma experiência de formação continuada em serviço que envolveu a equipe organizadora do "I Encontro sobre gestão participativa na educação básica IFPI/campus Floriano e escolas parceiras”, que ocorreu no Instituto Federal de Educação, Ciências e Tecnologia do Piauí, localizado no bairro Meladão em Floriano, ação em comemoração aos vinte e cinco anos de instituição como o tema "Educação que transforma vidas". Foram convidados professores e monitores da referida instituição, informados dos objetivos e finalidades do projeto, em seguida foram convidados gestores da rede municipal e estadual de educação da referente cidade e circunvizinha, tais carecem de cursos que venham aprimorar a prática da gestão participativa no âmbito educacional.

O conhecimento prévio dessa realidade possibilitou buscar mecanismos possíveis para auxiliar a intencionalidade da nossa prática pedagógica, possibilitando uma maneira de trabalhar a redefinição da visão sobre a prática da gestão e ampliá-lo no que se pretende compreender sobre a gestão participativa. As ações do ESGPEB abordaram quatro eixos; a) Dimensões: Administrativa e Financeira; b) Gestão Escolar: aspectos legais, registros e documentos escolares; c) Gestão Pedagógica; d) Tecnologias aplicadas à educação; e por fim a socialização da mesa redonda. A formação continuada de gestores com ênfase na gestão ocorreu nos dias 08 e 09 de agosto do ano de 2019, direcionado aos gestores da rede Municipal e Estadual, contou com a participação de 53 gestores, que estiveram presentes no auditório do IFPI/Campus Floriano com carga horária de $16 \mathrm{~h}$.

\footnotetext{
${ }^{1}$ Licenciatura em Ciências Biológicas, Instituto Federal do Piauí, vinicius77luz@ hotmail.com

${ }^{2}$ Licenciatura em Ciências Biológicas, Instituto Federal do Piauí, ronastavares12345@gmail.com

${ }^{3}$ Licenciatura em Ciências Biológicas, Instituto Federal do Piauí, tannyery@gmail.com

${ }^{4}$ Licenciatura em Ciências Biológicas, Instituto Federal do Piauí, ferreiraroza@ bol.com.br

${ }^{5}$ Doutora em Humanidades e Artes com ênfase em Educação, Instituto Federal do Piauí, sceci-sousa@ifpi.edu.br
} 
Dentre as eixos pedagógicos da gestão escolar citados foram ministrados de forma interativa por diretores e coordenadores do campus, socializando conhecimentos e experiências vivenciadas e fazendo conexão entre as redes municipal, estadual e federal de ensino.

O desenvolvimento do projeto se deu numa perspectiva dialética, dialógica, participativa e compartilhada por intermédio de intervenções com gestores de escolas municipais e estaduais, na busca de alternativas eficazes para o enfrentamento de problemáticas que emergem na realidade contemporânea educacional.

\section{RELATO DE EXPERIÊNCIA}

O "I Encontro Sobre Gestão Participativa na Educação Básica IFPI/Campus Floriano e Escolas Parceiras", teve como intuito a formação continuada de gestores, sendo composta por: administrador escolar (diretor); supervisor escolar (coordenador pedagógico) e orientador educacional, tal divisão se faz presente para uma gestão escolar mais eficiente.

Para cada cargo que foi devidamente selecionado para compor a equipe da gestão pedagógica, há uma função específica, atuando também mediante as necessidades da escola juntamente com outros demais profissionais, para que haja um real desenvolvimento qualitativo do trabalho pedagógico.

Tal projeto foi criado com embasamento nas dificuldades que são encontradas ao longo do processo da gestão escolar. Sabe-se que a maneira de gerir de modo educacional consiste em um exercício democrático, havendo assim uma necessidade de novos e mais adaptados conceitos do que realmente seria essa gestão participativa em prol da educação.

$\mathrm{O}$ atual modelo de gestão possui uma devida individualidade que "se fundamenta em objetivos educacionais representativos dos interesses das amplas camadas da população e leva em conta a especificidade do processo pedagógico escolar, processo este determinado por estes mesmos objetivos" (PARO, 1986, p. 87-8, apud, FERREIRA, 2008, p.107).

No decorrer do encontro foram pautadas, mediante aos temas do âmbito escolar, algumas necessidades como o valor do trabalho em equipe de forma harmoniosa, o convívio entre os contribuintes no processo de educação em geral, entre outros. De acordo com Libâneo (2012,p. 411):

\footnotetext{
No caso da escola, a organização e a gestão referem-se ao conjunto de normas, diretrizes, estrutura organizacional, ações e procedimentos que asseguram a racionalização do uso de recursos humanos, materiais, financeiros e intelectuais assim como a coordenação e o acompanhamento do trabalho das pessoas.
}

O encontro teve por objetivo, mostrar a verdadeira importância do gestor educacional no meio escolar, através das articulações no processo de construção de um meio onde haja 
diálogo, participação de toda uma equipe, para o melhoramento do trabalho dos profissionais e consequentemente, para o sucesso do processo educativo.

Os quatro temas trabalhados que foram abordados durante o encontro, estavam devidamente voltados à organização e ao modo de gerir o meio escolar, que puderam promover uma formação técnica política de gestores e instituições da educação básica.

A troca de conhecimentos sobre direitos e como gerir de maneira eficiente uma instituição escolar se faz, mas que necessária no ato de organização desse âmbito, de acordo com Lima (2004, p. 32) para se obter uma determinada padronização qualitativa, haveria a necessidade de uma formação eficiente do professor, salários mais justos, condições favoráveis de trabalho e de qualificação docente, gestão democrática, ampliação do período de permanência do aluno na escola, dentre outros.

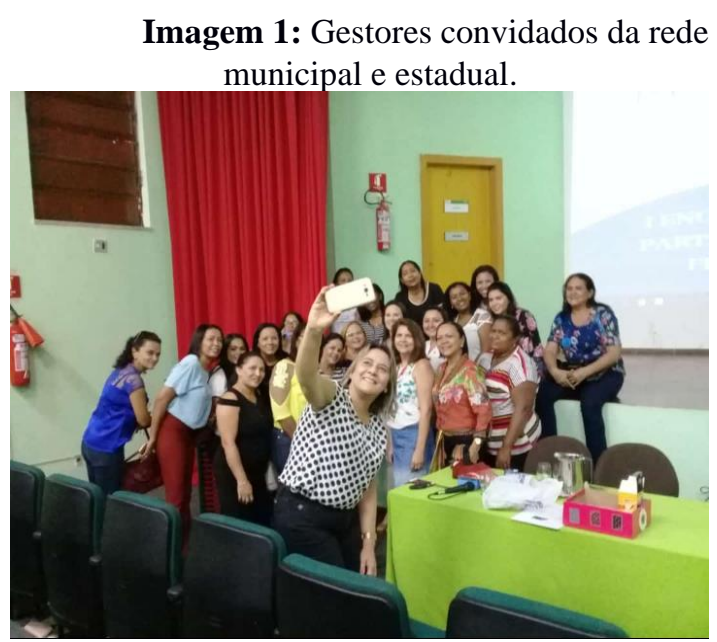

Fonte: Própria (2019).
Imagem 2: Tecnologias aplicadas a gestão escolar, ministrada pelo diretor.

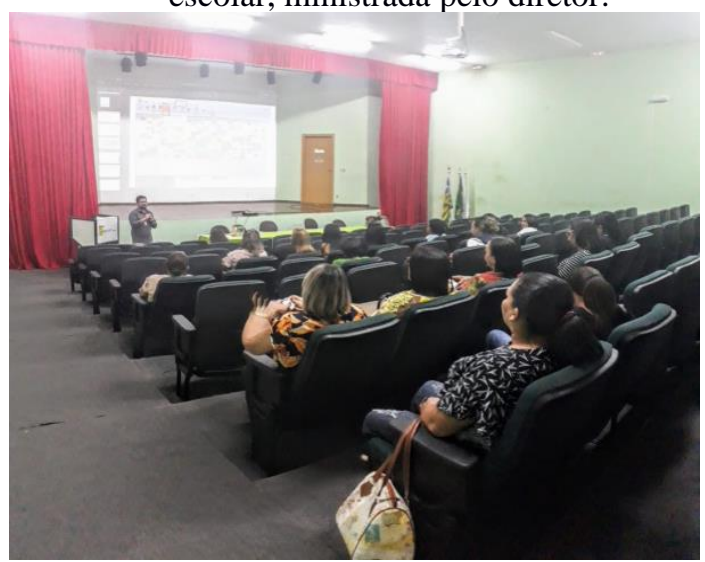

Fonte: Própria (2019).

\section{CONSIDERAÇÕES}

A execução do I Encontro sobre Gestão Participativa na Educação Básica IFPI/Campus Floriano e Escolas Parceiras contribuiu para que os participantes construam uma gestão escolar democrática, e que possam executar um projeto político pedagógico de qualidade. $\mathrm{O}$ curso de formação contínua de gestores veio a enriquecer esses profissionais para uma atuação autônoma, proporcionando aos diretores escolares uma visão global da escola, integrando as diversas disciplinas da gestão como a financeira, a pedagógica, a comunitária, tecnológica e administrativa.

O encontro mostrou-se bastante produtivo, durante os dois dias de encontro, gerando socialização de conhecimentos e experiências sobre gestão com ideias interativas e debates dinâmicos. Nesse sentido, o projeto teve a finalidade de proporcionar um novo processo de 
gestão, onde o exercício democrático se encontre como motor de um novo poder e de uma nova cultura educacional, tendo em vista a necessidade de novos e adaptados conceitos do que literalmente seria uma gestão escolar, voltado necessariamente à diretores e coordenadores de escolas, onde o valor do trabalho em equipe e de forma harmoniosa, trazem resultados positivos e imediatos para o âmbito escolar.

\section{REFERÊNCIAS}

FERREIRA, S. C. (Org.). Gestão Democrática da Educação: atuais tendências, novos desafios. 6. ed. São Paulo: Cortez, 2008.

LIBÂNEO, J. C. Educação escolar: políticas, estrutura e organização. São Paulo: Cortez, 2012.

LIMA, A. B. [org]. Estado, políticas e gestão compartilhada. São Paulo: Xamã, 2004. 


\title{
“CARA A CARA COM A CÉLULA": PROPOSTA DE UM JOGO PARA O ENSINO DE BIOLOGIA CELULAR
}

\section{"FACE TO FACE WITH CELL": A PROPOSED GAME FOR CELL BIOLOGY TEACHING}

\section{“CARA A CARA COM LA CÉLULA": PROPUESTA DE UN JUEGO PARA LA ENSEÑANZA DE BIOLOGÍA CELULAR}

\author{
Maria Emília Oliveira de Carvalho ${ }^{1}$; Gustavo de Barros Silva ${ }^{2}$; Jaqueline Inez de \\ Santana $^{3}$; João Vitor da Silva ${ }^{4}$; Ana Cristina Lauer Garcia ${ }^{5}$
}

DOI: https://doi.org/10.31692/978-65-991061-3-2.118-123

\section{INTRODUÇÃO}

A biologia celular estuda as unidades funcionais dos seres vivos, as células, sendo um importante ramo da biologia. Todavia, por tratar com estruturas microscópicas e submicroscópicas, esta disciplina pode se tornar um desafio para os professores e estudantes, uma vez que a maioria das escolas não possuem recursos que facilitem o ensino, como microscópios e modelos didáticos que tornem menos abstratos os conteúdos trabalhados em sala de aula. Como resultado, muitas vezes as aulas de biologia celular acabam sendo monótonas e desestimulantes para os discentes (OENNING; OLIVEIRA, 2011).

A aplicação de atividades didáticas como os jogos educativos tem sido apontada por diversos autores como uma forma de preencher muitas lacunas deixadas pelo processo de ensino-aprendizagem. Ao mesmo tempo essa prática torna as aulas mais atrativas e motivadoras, servindo como instrumento de apoio para auxiliar e reforçar os conteúdos já estudados, favorecendo o trabalho em grupo, a socialização de conhecimentos prévios e sua utilização para a construção de informações novas e mais elaboradas (KISHIMOTO, 1994; CAMPOS, 2003).

\footnotetext{
${ }^{1}$ Licenciatura em Ciências Biológicas, Universidade Federal de Pernambuco, Centro Acadêmico de Vitória, emiliaoliveira01@ hotmail.com

${ }^{2}$ Licenciatura em Ciências Biológicas, Universidade Federal de Pernambuco, Centro Acadêmico de Vitória, gustavo-456@hotmail.com.br

${ }^{3}$ Licenciatura em Ciências Biológicas, Universidade Federal de Pernambuco, Centro Acadêmico de Vitória, jaquelinesantanaa18@hotmail.com

${ }^{4}$ Licenciatura em Ciências Biológicas, Universidade Federal de Pernambuco, Centro Acadêmico de Vitória, jv3160339@gmail.com

5 Doutora em Genética, Universidade Federal de Pernambuco, Centro Acadêmico de Vitória, alauergarcia@yahoo.com.br
} 
Aqui apresentamos a proposta de um jogo didático intitulado "Cara a cara com a célula" o qual pode ser utilizado no ensino médio como facilitador do processo de ensinoaprendizagem de conceitos estudados em biologia celular.

\section{FUNDAMENTAÇÃO TEÓRICA}

A biologia celular é um dos primeiros temas estudados na disciplina de biologia no ensino médio. Esta é uma área de difícil compreensão pelos estudantes, que alegam ser complicado compreender os assuntos trabalhados, os quais são considerados, muitas vezes, abstratos e distantes do cotidiano dos discentes (SILVEIRA, 2013). Somado a isso, as aulas geralmente são teóricas, mantendo o aluno na passividade, apenas recebendo os conteúdos sem interagir com eles (ROSSETTO, 2010). Essa forma de ensino é comumente considerada desmotivadora pelos alunos, gerando a necessidade de novos encaminhamentos metodológicos pelo professor (ZUANON et al, 2010).

A fim de resgatar o interesse dos estudantes em aprender, as atividades lúdicas, como jogos educativos, têm sido apontadas como alternativas valiosas para tornar as aulas de biologia mais atrativas e dinâmicas. O jogo permite que o aluno brinque e aprenda simultaneamente, sendo uma forma de auxiliar a aprendizagem e de reforço dos conteúdos estudados (JANN; LEITE, 2010). A utilização de jogos no processo de ensino-aprendizagem também é incentivada pelas Orientações Curriculares para o Ensino Médio no Brasil, a qual defende que os jogos estimulam os estudantes ao mesmo tempo que possibilitam aos professores desenvolverem os conteúdos escolares de forma prazerosa e participativa, levando os discentes a uma maior apropriação dos assuntos estudados (BRASIL, 2006). Os jogos didáticos são ferramentas que complementam as aulas teóricas e práticas agregando motivações e desafios para os estudantes (SOSSELA; CROCETTI, 2013).

\section{METODOLOGIA}

Esta é uma pesquisa qualitativa na qual foi confeccionado um jogo denominado "Cara a cara celular", o qual foi produzido com materiais acessíveis, duráveis e de baixo custo, pensando na realidade das escolas públicas atuais. Para sua confecção foram utilizados os seguintes materiais: papelão, caixas de sabonete, cartolina branca, cartolina dupla face (azul, vermelha e verde), fita adesiva transparente e branca, fita isolante branca, cola quente e pistola, palitos de churrasco e cartas impressas. 
Primeiramente foram confeccionadas 20 cartelas em papel cartão (cada uma com 7 x 5 $\mathrm{cm}$ ) compostas pela imagem de uma estrutura ou tipo celular, com sua respectiva identificação. Para cada cartela foram produzidas três cópias, totalizando 60. Cada conjunto de cartelas foi aderido a uma cartolina dupla face em cores diferentes (azul, vermelha e verde).

Foram produzidos dois tabuleiros com caixas (com dimensão de $32 \times 27$ × $8,5 \mathrm{~cm}$ ) recobertas por cartolina branca. Para o acabamento foram utilizadas fita isolante branca e fita durex transparente. Cada tabuleiro foi dividido internamente com três barreiras, sendo gerados quatro espaços de $8 \mathrm{~cm}$. Entre as barreiras foram colocados palitos de churrasco, atravessando a caixa horizontalmente, para dar suporte as cartelas e permitir sua movimentação durante o jogo. Uma caixa produzida com embalagem de sabonete e recoberta com cartolina dupla face verde, foi aderida em frente a cada tabuleiro para abrigar as cartelas durante a dinâmica do jogo. Para armazenar o terceiro lote de cartelas (na cor verde), foi confeccionada uma caixa, também com embalagem de sabonete, recoberta com cartolina branca e fitas adesivas.

\section{RESULTADOS E DISCUSSÕES}

O jogo "Cara a cara com a célula" (Figura 1) foi planejado para ser um material de apoio didático para as aulas de biologia celular no ensino médio. O jogo poderá ser utilizado pelo professor como forma de revisão de conteúdo ou até mesmo como forma avaliativa. O professor deverá acompanhar os estudantes durante o jogo e, a partir das perguntas elaboradas e das respostas dadas, poderá observar quais as principais dificuldades dos estudantes em relação aos assuntos ensinados, a fim de aprimorar esse conhecimento posteriormente.

O jogo será sempre entre dois jogadores, um jogador ficará com o tabuleiro com as cartelas vermelhas e o outro com o tabuleiro com as cartelas azuis. Os jogadores devem estar sentados um de frente para o outro, a fim de evitar a visualização de suas cartelas pelo oponente. Cada jogador deverá sortear uma cartela verde, a qual ficará no suporte em frente ao seu tabuleiro. Cada jogador deverá fazer perguntas ao adversário para tentar adivinhar a cartela sorteada. Será permitido uma única pergunta por jogador a cada rodada e, a seguir, a vez será passada ao seu adversário. A cada pergunta o adversário só poderá responder "sim" ou "não". De acordo com as respostas os jogadores deverão ir abaixando as cartelas que não se enquadram com resposta dada pelo seu adversário. Por exemplo, se o jogador perguntar se a cartela em questão é de uma organela que possui a função de digestão celular e a resposta do seu oponente 
for não, o jogador deverá abaixar a cartela com a imagem do lisossomo, descartando essa possibilidade.

Figura 1. Jogo "Cara a cara com a célula" produzido para o aprendizado da biologia celular. A) Jogo completo. B) Jogo com algumas cartelas abaixadas durante a dinâmica de uma partida.
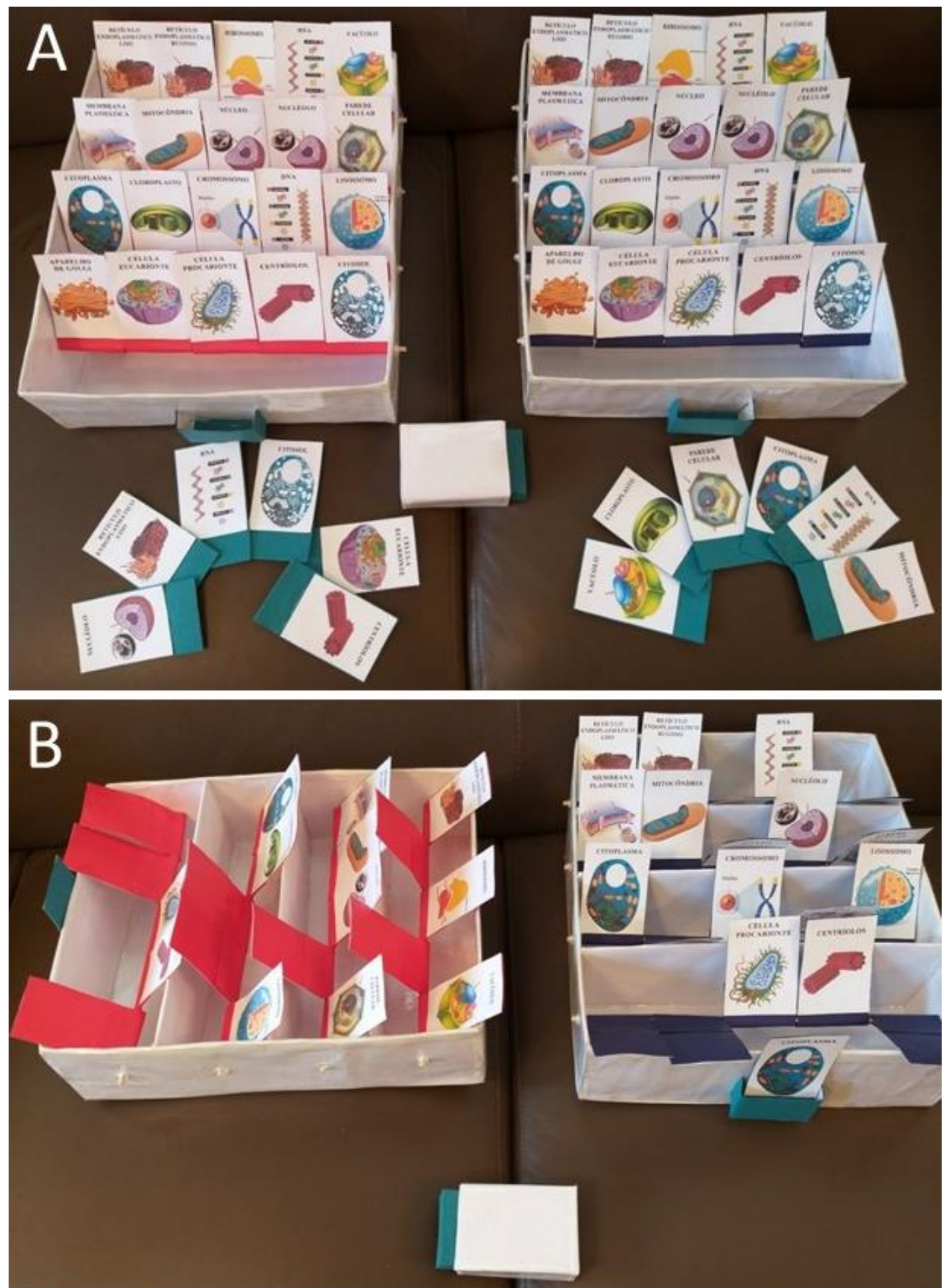

Fonte: Própria (2019) 
Outras regras adicionais incluem o fato de que a primeira pergunta da rodada não poderá eliminar um número grande de cartelas, por exemplo, não poderá ser questionado se a cartela em questão se trata de uma organela, pois assim, descartaria um grande número de cartelas. Não poderão ser feitas perguntas em relação a cor, tamanho ou formato das estruturas presentes nas cartelas. Também não poderão ser feitas perguntas envolvendo o nome da estrutura a ser adivinhada. Serão realizadas cinco partidas, quem vencer a maioria ganhará a disputa. Este jogo também poderá ser disputado por duplas ou em grupos maiores de alunos.

Esse recurso lúdico auxiliará na aprendizagem dos conteúdos de biologia celular, uma vez que os alunos terão que lembrar dos assuntos abordados para poder elaborar as perguntas e responder corretamente aos questionamentos feitos pelo seu oponente. Recursos metodológicos diferenciados tornam o ensino de biologia celular mais dinâmico, fugindo de aulas tradicionais, nas quais o professor é a figura central. Durante o jogo, o aluno desenvolve a iniciativa, a imaginação, o raciocínio, a memória, a atenção, a curiosidade e o interesse, concentrando-se por longo tempo em uma atividade (FORTUNA, 2003).

A partir desta proposta de jogo o aluno pode entender a diferença entre células eucariontes e procariontes e reconhecer as organelas e estruturas celulares encontradas em cada tipo celular. Da mesma forma, poderá compreender a função dos componentes presentes em cada cartela e aprender sobre diferentes componentes celulares.

Muitos autores têm motivado a utilização de jogos didáticos em sala de aula, a fim de contribuir para uma aprendizagem significativa de conteúdos ligados a biologia celular. Os jogos educativos se destacam como eficientes instrumentos envolventes e estimulantes, sendo uma importante alternativa para auxiliar no processo de ensino-aprendizagem (ROSSETTO, 2010; GONÇALVES, 2014). Esta é uma importante estratégia de ensino para a aprendizagem de conceitos abstratos e complexos, favorecendo a motivação, o raciocínio, a argumentação, a interação entre alunos, bem como entre professores e alunos (CAMPOS et al, 2003).

\section{CONCLUSÕES}

O jogo apresentado pode ser utilizado por professores do ensino médio para auxiliar nas aulas de biologia celular, sendo uma ferramenta alternativa para uma aprendizagem mais eficaz deste tema pelos discentes.

\section{REFERÊNCIAS}


BRASIL, MEC, SEB. Orientações Curriculares para o Ensino Médio. Ciências da Natureza, Matemática e suas Tecnologias. Brasília: MEC, SEB, 2006.

CAMPOS, L.M.L.; BORTOLOTO, T.M.; FELÍCIO, A.K.C. A Produção de jogos didáticos para o Ensino de Ciências e Biologia: uma proposta para favorecer a aprendizagem. Cadernos dos Núcleos de Ensino. São Paulo, Brasil. p. 47- 60, 2003.

FORTUNA, T. R. Jogo em aula: recurso permite repensar as relações de ensino-aprendizagem. Revista do professor. Porto Alegre, 2003. v. 19. n. 75. p. 15-19, 2003.

GONÇALVES, R. R.; MARTELO, A. R.; EPPLE, B.; LAUERENCE, C.; DESBESSEL, J.; POST, P. Bingo da Célula: Uma Ferramenta Metodológica para o Ensino de Biologia Celular. Revista Ensino e Pesquisa. v. 12. n. 1. p. 28-47, 2014.

JANN, P. N.; LEITE, M. F. Jogo do DNA: um instrumento pedagógico para o ensino de ciências e biologia. Ciências \& Cognição. v.15. n. 1. p. 282-293, 2010.

KISHIMOTO, T. Jogo, Brinquedo, Brincadeira e Educação. São Paulo: Cortez, 1994.

OENNING, V.; OLIVEIRA, J.M.P. Dinâmicas em sala de aula: envolvendo os alunos no processo de ensino, exemplo com os mecanismos de transporte da membrana plasmática. Revista Brasileira de Bioquímica e Biologia Molecular. Paraná, n. 01, 2011.

ROSSETTO, E. S. Jogo das organelas: o lúdico na Biologia para o Ensino Médio e Superior. Revista Iluminart. Sertãozinho, 2010. v. 1. n. 4. p. 118-123, 2010.

SILVEIRA, M. L. Dificuldades de aprendizagem e concepções alternativas em biologia: a visão de professores em formação sobre o conteúdo de citologia. Natal, 2013. 197 p. Dissertação (Ensino de Ciências Naturais e Matemática). Centro de Ciências Exatas e da Terra, UFRN, 2013.

SOSSELA G. S.; CROCETTI, S. Jogos como facilitadores do Ensino de Biologia. Cadernos PDE. Paraná. v. 1. 2013.

ZUANON, A. C. A.; DINIZ, R. H. S.; NASCIMENTO, L. H. Construção de jogos didáticos para o ensino de Biologia: um recurso para integração dos alunos à prática docente. Revista Brasileira de Ensino de Ciência e Tecnologia. Minas Gerais, 2010. v. 3. n. 3. p. 49-59, 2010. 


\section{AS CONCEPÇÕES DOS ESTUDANTES DO ENSINO FUNDAMENTAL SOBRE O CONCEITO DE POLUIÇÃO: SEGUNDO A TEORIA DE REPRESENTAÇÃO SOCIAL}

\section{REPRESENTACIÓN SOCIAL DE ESTUDIANTES DE CONTAMINACIÓN AMBIENTAL}

\section{SOCIAL REPRESENTATION OF ENVIRONMENTAL POLLUTION STUDENTS}

Henllayane Nathani de Amorim Amaral ${ }^{1}$; Ediangela Soares Silva do Nascimento ${ }^{2}$; Ricardo Ferreira das Neves ${ }^{3}$

DOI: $\underline{\text { https://doi.org/10.31692/978-65-991061-3-2.124-128 }}$

\section{INTRODUÇÃO}

A escola representa um espaço educacional que busca estimular o pensamento crítico e o desenvolvimento dos estudantes oportunizando-os, consolidando os princípios de uma formação para a cidadania e a consciência diante de situações emergenciais, como os impactos da poluição no ambiente (SEGURA, 2001). Assim temas como a poluição podem ser impetrados nas aulas de ciências como problematizadores, de forma a contribuir para a sua reflexão sobre as ações antrópicas ao ambiente. Diante disso, é notório que os estudantes estão imersos em informações culturais que fomentam a sua vida cotidiana e que por vezes, influenciam nas suas interpretações sobre determinados assuntos.

Hoje, por causa do crescente aumento da poluição ambiental em todos os níveis; compreendendo o entendimento do sujeito diante de conteúdos dessa natureza e a partir disso, incentivar desde cedo às práticas de Educação Ambiental.

Nessa direção, Sander (1992) orienta que o processo de transformação da sociedade atual em sociedade sustentável correrá mediante, a prática da cidadania através das informações e conceitos no âmbito educativo, ou seja, a escola precisa instigar os estudantes a refletirem sobre seus posicionamentos a cerca ambiente, inserindo discussões, por exemplo, sobre a poluição. Nesse sentido, a Teoria das Representações Sociais de Serge Moscovici é uma opção para o detalhamento e explicação de acontecimentos sociais, tendo em vista que representam pensamentos e comportamentos comuns aa um grupo de indivíduos (MOSCOVICI, 1978).

Nessa perspectiva, aspiramos saber sobre como estudantes da Educação Básica

\footnotetext{
1 Graduanda em Ciências Biológicas na Universidade Federal de Pernambuco, UFPE/CAV, henllayane16@gmail.com

2 Graduanda em Ciências Biológicas na Universidade Federal de Pernambuco, UFPE/CAV, ediangelacbio@gmail.com

${ }^{3}$ Professor da Universidade Federal de Pernambuco, UFPE/CAV, rico.neves2010@ gmail.com
} 
compreendem. Assim, temos como objetivo: analisar a representação social de alunos do Ensino Fundamental sobre poluição ambiental.

\section{A poluição ambiental: algumas considerações}

Segundo as organizações das Nações Unidas (ONU), poluição ou contaminação ambiental é uma alteração do Meio Ambiente que pode afetar a saúde e integridade dos seres vivos. Representa alterações físicas, químicas ou biológicas resultante das atividades humanas e que podem afetar o equilíbrio do ecossistema e ainda ser causada por fatores naturais antrópicos, gerando impactos que interferem significativamente no ambiente (ARRUDA et al, 2001).

A Lei 9.394/96, em seu Artigo 32, enfatiza que o Ensino Fundamental tem por objetivo a formação básica do cidadão mediante a compreensão do ambiental, natural e social do sistema político, da tecnologia das artes e dos valores da sociedade. No Artigo 36, aponta que os currículos da Educação Básica, possui uma base diversificada que deve fomentar as características regionais e locais da população, envolvendo o conhecimento do mundo físico e natural, e da realidade social e política brasileira (BRASIL, 1996).

Diante disso, os Parâmetros Curriculares Nacionais (PCN) indicam a necessidade de investigação das alterações ambientais, decorrentes da emissão de substâncias, partículas e outros materiais poluidores, buscando alternativas para o controle da poluição (BRASIL, 2000).

Assim, a introdução de temas ambientais nas aulas possibilita a aprendizagem de conceitos básicos e abre um leque de informações complementares, cuja escola pode instigar a reflexão sobre valores e atitudes para a formação de uma consciência ambiental.

\section{A Teoria da Representação Social}

A Teoria da Representação Social (TRS) envolve a produção dos saberes social, aqueles que são produzidos no cotidiano, e que pertencem ao mundo vivido (JOVCHELOVITH, 1998).

Moscovici (1978) considera as representações como algo compartilhado de modo heterogêneo pelos diferentes grupos sociais. Foi na obra "La Psychanalyse, son image et son public", de 1961, que o autor mencionou pela primeira vez o conceito de Representação Social, desenvolvendo a partir deste uma psicossociologia do conhecimento. Dessa forma, o conhecimento é adquirido por meio da compreensão alcançada por indivíduos que pensam, porém, não sozinhos, pois a semelhança dos pronunciamentos feitos por um grupo demonstra o que pensaram juntos sobre os assuntos. 
Para Moscovici (1978), as Representações Sociais são entidades quase tangíveis. Elas circulam, cruzam-se e cristaliza-se incessantemente, por intermédio de uma fala, um gesto, um encontro em nosso universo cotidiano, constituindo, assim, uma modalidade de conhecimento particular que tem por função a elaboração de comportamentos e a comunicação entre os indivíduos.

Assim, tem-se na representação um reflexo da realidade, atuando nas relações dos indivíduos no âmbito físico e social, determinando suas práticas e orientando ações, interações sociais, antecipações e expectativas.

\section{METODOLOGIA}

Por meio de uma pesquisa qualitativa, o estudo foi realizado com uma turma do Ensino Fundamental - Anos Finais, composta por 25 estudantes numa escola pública, em Vitória de Santo Antão.

Para a coleta dos dados foi utilizado um questionário subjetivo baseado na proposta metodológica de Abric (1998), cujo instrumento contemplou dois momentos. Inicialmente, foi solicitado que os alunos escrevessem em uma folha, cinco palavras que elas relacionassem com a poluição ambiental, em ordem de significância. Posteriormente, quando da primeira palavra, com maior grau de importância, os estudantes deveriam descrevê-la.

Para a análise, foi verificado o valor de frequência das palavras que mais apareceram nas respostas dos estudantes, e posteriormente, calculamos as que mais se repetem. Temos então, a representação social dos alunos em relação à poluição ambiental.

\section{RESULTADOS E DISCUSSÕES}

Os resultados encontrados no presente estudo apontam como a palavra mais representativa sobre a poluição recebeu mais destaque entre as demais foi "LIXO" com 14 aparições entre 25 resultados, conforme o quadro 1 e suas considerações a partir do quadro 2 , a seguir:

Quadro 1. Frequência das palavras destaque sobre o conceito de poluição

\begin{tabular}{|l|l|l|}
\hline \multicolumn{1}{|c|}{ Palavra } & \multicolumn{1}{|c|}{ Quantidade } & \multicolumn{1}{c|}{ Frequência } \\
\hline Lixo & 14 & $56 \%$ \\
\hline Desmatamento & 6 & $24 \%$ \\
\hline Queimadas & 3 & $12 \%$ \\
\hline Petróleo & 2 & $8 \%$ \\
\hline
\end{tabular}

Fonte: Própria (2019). 
Quadro 2. Descrições dos estudantes sobre o conceito de Poluição

\begin{tabular}{|c|c|}
\hline Estudantes & Descrições \\
\hline 1. & "O lixo é o mais poluente que tem é o mais que tem pelas ruas" \\
\hline 2. & $\begin{array}{l}\text { "O lixo jogado na rua é uma poluição do ar e do solo, pois não } \\
\text { jogue lixo na rua para não poluir o solo." }\end{array}$ \\
\hline 3. & "O lixo é uma poluição meio grave causando muitas mortes." \\
\hline 4. & $\begin{array}{l}\text { "O lixo é uma das principais poluições pelo brasil que acaba } \\
\text { matando animais marinhos como a tartaruga que pode comer um } \\
\text { saco plástico." }\end{array}$ \\
\hline 5. & $\begin{array}{l}\text { "O lixo é um tipo de poluição o que pode poluir qualquer ambiente } \\
\text { seja ele terrestre ou marinho." }\end{array}$ \\
\hline 6. & "É o resto de algo que não presta e vira lixo." \\
\hline 7. & $\begin{array}{l}\text { "Se você ve uma lixeira perto de você, você vai jogar no lixo ou no } \\
\text { chão eu jogava na lixeira." }\end{array}$ \\
\hline 8. & $\begin{array}{l}\text { "Lixo é muita poluição pra terra agente mesmo que causa esta } \\
\text { poluição por que joga o lixo na atmosfera." }\end{array}$ \\
\hline 9. & $\begin{array}{l}\text { "As pessoas fica jogando lixos nos rios e pega os peixes morrem } \\
\text { por causa dos humanos." }\end{array}$ \\
\hline 10. & "É a poluição que suja os rios." \\
\hline 11. & "É uma coisa que prejudica o meio ambiente." \\
\hline 12. & $\begin{array}{l}\text { "É uma coisa poluída na atmosfera que prejudica o nosso país } \\
\text { causa doenças para o mundo doenças muito ruins." }\end{array}$ \\
\hline 13. & "É a poluição do meio ambiente, que joga o lixo no meio da rua." \\
\hline 14. & "É causado pela população." \\
\hline
\end{tabular}

Ao decorrer do processo de levantamento de dados podemos notar diferenças entre a representação dos alunos previamente sobre poluição. Apesar da palavra "LIXO” persistir em destaque, é perceptível que os estudantes obtiveram maior abrangência das variedades e causas da poluição e não se restringiram apenas aqueles tipos mais comuns, que na maioria das vezes recebe maior visibilidade por causa da mídia.

\section{CONCLUSÕES}

A partir da Teoria da Representação Social foi possível percebermos a significância da relação entre poluição e lixo, oriunda de informações midiáticas e de ações sociais, como percursora desse tipo de problemática. É válido ressaltar, a importância de se trabalhar a poluição logo na infância, pois o indivíduo pode repensar suas práticas ao Meio Ambiente, estimulando a adoção de uma postura mais crítica.

\section{REFERÊNCIAS}

ABRIC, J. A abordagem estrutural das representações sociais. In: Moreira, A. S. P. estudos 
interdisciplinares de representação social. Goiânia: AB, 1998.

BRASIL. Lei de Diretrizes e Bases da Educação Nacional n. 9.394. Brasília: MEC, 1996.

BRASIL. Parâmetros curriculares nacionais: Ciências Naturais. Secretaria de Educação Fundamental. Brasília: MEC/SEF, 1998.

BRASIL, Secretaria de Educação Fundamental. Parâmetros Curriculares Nacionais: Ciências da Natureza, Matemática e suas Tecnologias. Brasília: MEC/SEF, 2000.

JOVCHELOVITCH, S. Re(des)cobrindo o Outro: Para um entendimento da alteridade na teoria das representações sociais. In A. ARRUDA (Ed) Representando a Alteridade. Petrópolis, RJ: Vozes, 1998.

MOSCOVICI, Serge. A representação social da psicanálise. 1.ed. Rio de Janeiro: Zahar, 1978. Representações Sociais: investigação em psicologia social. Petrópolis, RJ: Vozes, 2003.

SANDER, B. Administração da educação no Brasil: é hora da relevância. São Paulo: Cortez, 1992.

SEGURA, Denise de S. Baena. Educação Ambiental na escola pública: da curiosidade ingênua à consciência crítica. São Paulo: Annablume: Fapesp, 2001. 


\section{A COFECÇÃO DE UMA CARTILHA EDUCATIVA PARA O ENSINO DO CICLO DA ÁGUA}

\section{LA COFECCIÓN DE UN FOLLETO EDUCATIVO COMO RECURSO DIDÁCTICO PARA LA ENSEÑANZA DEL CICLO DEL AGUA}

\section{THE COFECTION OF AN EDUCATIONAL BOOKLET FOR WATER CYCLE TEACHING}

Ewerton Henrique da Conceição ${ }^{1}$; Levi Araujo Bezerra ${ }^{2}$; Luiz Carlos Alves de Souza ${ }^{3}$

DOI: https://doi.org/10.31692/978-65-991061-3-2.129-133

\section{INTRODUÇÃO}

A água é um recurso de fundamental importância para a manutenção da vida no planeta, e falar da relevância dos conhecimentos sobre a água, em suas diversas dimensões, é falar da manutenção da espécie humana, da conservação da biodiversidade e das relações biogeoquímicas de interdependência entre os seres vivos e o meio ambiente.

A presença ou ausência de água determina a história, interfere drasticamente em fatores culturais e hábitos comportamentais, determina o futuro de gerações. O planeta terra não teria se transformado em ambiente adequado para a vida sem a água. Desde sua origem, os elementos hidrogênio e oxigênio se combinaram para dar origem ao elemento-chave da existência da vida. (BACCI e PATACA, 2008)

A água é o único composto químico a estar presente na Terra de maneira simultaneamente sob as formas sólida, líquida e gasosa. Estes três estados desempenham papéis no funcionamento do planeta que é comumente chamado de planeta água. A água é constituída de moléculas que sofrem atração por coesão. Essas moléculas no estado líquido estão em constante movimentação, movendo-se verticalmente no sentido da atmosfera terrestre e horizontalmente no sentido da superfície terrestre. Essa agitação é proporcional à energia ou à temperatura direcionada sobre a água. Quando a temperatura se eleva, as moléculas aumentam a agitação da superfície tendem a escapar da massa líquida e ficam livres na atmosfera, em estado gasoso. (MIRANDA, et al, 2010)

Atualmente, a água passou a ser vista como um recurso hídrico e não mais como um bem natural, é usada de forma indiscriminada e quando uma fonte esgota, simplesmente é

\footnotetext{
${ }^{1}$ Licenciando em Ciências Biológicas, Universidade Federal de Pernambuco, ewerton.henri2013@gmail.com

${ }^{2}$ Licenciando em Ciências Biológicas, Universidade Federal de Pernambuco, levitj1.lab@gmail.com

${ }^{3}$ Mestre em educação agrícola, professor do Instituto Federal de Pernambuco Campus Vitória de Santo Antão, nagusto.eaf@hotmail.com
} 
encontrada outra, sem serem avaliadas as consequências ambientais em relação à quantidade e qualidade do que resta, somado ao aumento populacional no último século, a ocupação do solo, à poluição e contaminação dos corpos de águas superficiais e subterrâneos, levou a sociedade a uma crise profunda na qual ameaça a existência das próximas gerações, essa crise, é um dos mais graves problemas a serem enfrentados neste século.

Trabalhar a conscientização do cidadão em relação ao seu ambiente é um dos princípios fundamentais para que aconteça de fato gestão de recursos hídricos. Conhecer para preservar, um ditado tão comum, mas tão pouco levado à prática. Sem a educação a espécie humana não conseguirá desenvolver seus potenciais e cada vez mais será esmagada.

O presente estudo tem por objetivo descrever o processo de confecção de uma cartilha educativa na promoção da educação ambiental, como recurso didático no ensino do ciclo da água.

\section{FUNDAMENTAÇÃO TEÓRICA}

Segundo Victorino, (2007) quase toda a superfície do planeta Terra está coberta por água: água dos oceanos, água dos rios e lagos correspondendo a $1.370 .000 .000 \mathrm{~km}^{3}$ é constituída basicamente por dois tipos: água salgada dos mares e água doce. 97\% do total, é água salgada o que vem a ser impropria restando apenas uma pequena parcela para o consumo humano.

Os impactos da ação humana no ciclo hidrológico e na qualidade das águas são decorrentes de um conjunto de atividades humanas, como, por exemplo o direcionamento de boa parte da água para irrigação, abastecimento público, produção de hidroelétricas, turismo, pesca, transporte, navegação, mineração, recreação entre outros (TEIXEIRA et al, 2014).

Segundo Victorino, (2007) os grandes problemas ligados à água não acontecem por causa da natureza, mas sim pelo mau uso com desperdício, como exemplo em Londres, pela falta de manutenção em canos e dutos das tubulações de água, é perdida uma quantidade de água capaz de encher, diariamente, 300 piscinas olímpicas.

Amorim (2013), aponta que os modelos didáticos, são facilitadores contribuindo para a aprendizagem significava, pois permitem a participação ativa do estudante em seu processo de aprendizagem. Os modelos didáticos complementam o conteúdo dos livros (ORLANDO, et al., 2009, p. 2).

A cartilha é um recurso didático de grande importância para facilitar o entendimento dos conteúdos. As atividades remetem ao leitor um cenário mais próximo da realidade, e desta forma, ela possui um grande potencial para a promoção da educação ambiental, se tornando um 
agente facilitador e um importante instrumento educacional. (SILVA, 2017).

\section{METODOLOGIA}

A metodologia empregada na elaboração da cartilha foi baseada em algumas etapas: a escolha do tema; produção e seleção das ilustrações; preparo do conteúdo, tomando como base a literatura científica, elaboração da cartilha, avaliação do material, por profissionais da educação e por fim o uso da cartilha como recurso didático.

A primeira etapa ocorreu por meio da procura de trabalhos científicos, relacionando os temas "Ciclo da água"4 e "Educação ambiental", foi evidenciada baixa produção de estudos associando esses dois temas, as informações encontradas, foram utilizadas para direcionar o foco do tema, e na elaboração da cartilha.

A fase de produção e seleção das ilustrações, ocorreu em paralelo a fase de preparo do conteúdo, pois dessa forma, as imagens e o texto são complementares, possibilitando assim, um melhor entendimento do conteúdo.

O preparo do conteúdo foi embasado na literatura científica, para garantir a fidedignidade e confiabilidade das informações apresentadas. Alguns websites e livros foram acessados e utilizados como base para confirmar as informações da cartilha.

Na elaboração da cartilha, o conteúdo preliminar foi desenvolvido com o foco de apresentar apenas as informações consideradas essenciais. Esse conteúdo foi submetido ao trabalho de edição. O desenvolvimento dessa fase foi baseado em critérios previamente estabelecidos para todo o processo de produção da cartilha, isto é, a facilidade de leitura e clareza dos conteúdos apresentados.

A cartilha passou por avaliação de quinze estudantes do curso de Licenciatura em Ciências Biológicas da UFPE-CAV, que já haviam cursado as disciplinas de fundamentos da educação, didática e avaliação da aprendizagem, foi submetida também à avaliação de professores especialistas na área da educação, que fazem parte do quadro de servidores da UFPE-CAV.

\section{RESULTADOS E DISCUSSÕES}

A avaliação do material produzido, por parte dos quinze estudantes do curso de Ciências Biológicas da UFPE-CAV e professores especialistas na área da educação da UFPE-CAV, que aprovaram suas informações. Em relação à linguagem, foi avaliada a conveniência e a facilidade

\footnotetext{
${ }^{4}$ Link para acesso das páginas da cartilha: https://drive.google.com/drive/folders/134AahdSeUI91er5Tvdkv_v8TD8fQH_mv?usp=sharing
} 
de compreensão e os conceitos mais importantes estavam sendo abordados de maneira clara e objetiva, voltado para atender o público alvo (crianças dos anos iniciais do ensino fundamental).

Figura 1: Capas da frente e do verso da cartilha.

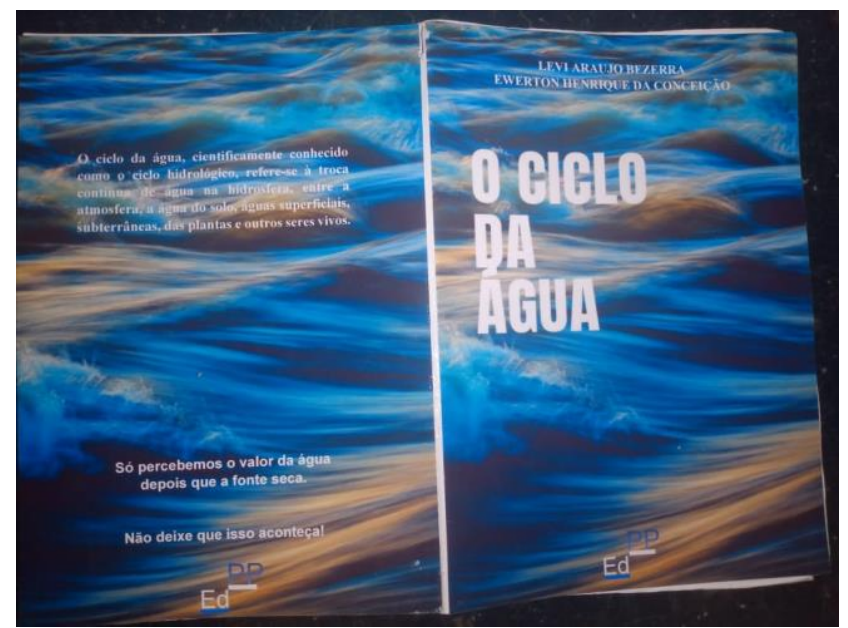

Fonte: Própria (2019)

Silva (2017), afirma, que a cartilha é um recurso didático de grande importância para facilitar o entendimento dos conteúdos. As atividades remetem ao leitor um cenário mais próximo da realidade, e desta forma, ela possui um grande potencial para promover da educação ambiental, tornando-se um agente facilitador no processo de aprendizagem. Corroborando também, Amorim (2013) e Orlando, et al., (2009, p. 2) apontando que os modelos didáticos, contribuem para a aprendizagem significava, pois permitem a participação do estudante em seu processo de aprendizagem.

\section{CONCLUSÕES}

O presente estudo, teve como intuito apresentar o processo de confecção da cartilha o ciclo da água e despertar o interesse sobre o ciclo da água, apresentando um método de ensino interessante capaz de incentivar o conhecimento e promover a educação ambiental.

A cartilha pode ser considerada um material didático de popularização da ciência e uma importante ferramenta de educação ambiental, na promoção da sensibilização da população para a importância da água na manutenção da vida no planeta.

\section{REFERÊNCIAS}

AMORIM, A.S. A influência do uso de jogos e modelos didáticos no ensino de biologia para alunos de ensino médio. 2013. 49f. Monografia (Licenciatura em Ciências Biológicas) Universidade Aberta do Brasil, Centro de Ciências e Saúde, Universidade Estadual do Ceará, Ceará, 2013.

Disponível em: 
http://www.uece.br/sate/index.php/downloads/doc_download/2146-biobeberibeamorim>. Acesso em: 29 jul. 2019.

BACCI, Denise de La Corte; PATACA, Ermelinda Moutinho. Educação para a água.Estud. av., São Paulo , v. 22, n. 63, p. 211-226, 2008 . Disponível em: $<$ http://www.scielo.br/scielo.php?script=sci_arttext\&pid=S0103-

$40142008000200014 \& \operatorname{lng}=$ en\&nrm=iso $>$. Acesso em 30 Jun, 2019.

MIRANDA, Ricardo Augusto Calheiros de; OLIVEIRA, Marcus Vinicius Siqueira de; SILVA, Danielle Ferreira da. Ciclo hidrológico planetário: abordagens e Conceitos. GEOUERJ, Rio de Janeiro, v. 1, n. 21, p. 109-119, 2010. Disponível em:< https://docplayer.com.br/36488154Ciclo-hidrologico-planetario-abordagens-e-conceitos.html>. Acesso em: 11 Ago. 2019.

ORLANDO, T.C. et al. Planejamento, montagem e aplicação de modelos didáticos para abordagem de biologia celular e molecular no ensino médio por graduandos de ciências biológicas. Revista brasileira de ensino de bioquímica e biologia molecular, v.1, n.1, p.117, 2009. Disponível em: < http://bioquimica.org.br/revista/ojs/index.php/REB/article/view/33/29 >. Acesso em: 02 Ago. 2019.

SILVA, Katia Araújo et al. Elaboração de uma cartilha como material educativo para preservação da tartaruga verde (chelonia mydas) em itaipú, niterói, rio de janeiro. Revista Presença, [S.1.], v. 2, p. 35-58, aug. 2017. ISSN 2447-1534. Disponível em: <http://revistapresenca.celsolisboa.edu.br/index.php/numerohum/article/view/117>. Acesso em: 01 ago. 2019.

TEIXEIRA, Vanessa; LINDNER, Josiele; PRESTES, Angelina Martins. Relato da experiência da oficina pedagógica na escola: "o ciclo da água e a necessidade de preservá-la". Revista Eletrônica de Geografia, v.6, n.17, p. 126-137, out. 2014. Disponível em < http://www.observatorium.ig.ufu.br/pdfs/6edicao/n17/7.pdf>. Acesso em: 11 Jun, 2019.

VICTORINO, Célia Jurema Aito. Planeta água morrendo de sede: uma visão analítica na metodologia do uso e abuso dos recursos hídricos. Porto Alegre : EDIPUCRS, 2007.Disponivel em: < http://www.pucrs.br/edipucrs/online/planetaagua.pdf> acesso em: 10 Ago 2019. 


\section{O QUÍMIDOMINÓ: UMA PROPOSTA DE JOGO DIDÁTICO DE DISTRIBUIÇ̃̃o ELETRÔNICA DE LINUS PAULING PARA OS ALUNOS DO $1^{\circ}$ ANO DO ENSINO MÉDIO}

\section{THE CHIMIDOMINO: A PROPOSAL OF A DISTRICT ELECTRONIC LINUS PAULING GAME FOR 1ST YEAR STUDENTS}

\section{THE CHIMIDOMINO: UNA PROPUESTA DE UN DISTRITO DE JUEGO DE PAULING ELECTRÓNICO LINUS PARA ESTUDIANTES DE PRIMER AÑO}

Maria Grasielly da Silva Nascimento ${ }^{1}$; Matheus Alves Barbosa ${ }^{2}$; Renata Joaquina de Oliveira Barboza $^{3}$; Kilma Lima da Silva Viana ${ }^{4}$; Ayrton Matheus da Silva Nascimento ${ }^{5}$

DOI: https://doi.org/10.31692/978-65-991061-3-2.134-139

\section{INTRODUÇÃO}

Os jogos educativos revelam a sua importância em situações de ensino-aprendizagem, ao aumentar a construção do conhecimento, introduzindo propriedades do lúdico, do prazer, da capacidade de iniciação e ação ativa e motivadora, possibilitando o acesso do estudante a vários tipos de conhecimentos e habilidades (MOURA; VIAMONTE, 2005). Os autores também descrevem que o jogo deve propiciar diversão, prazer e até mesmo desprazer, quando escolhido voluntariamente, ensinando algo que complete o indivíduo no seu saber, nos seus conhecimentos e na sua percepção do mundo, facilitando o desenvolvimento da linguagem, criatividade e o raciocínio dedutivo.

Para Almeida, Dantas e Cruz (2013) o jogo como forma de reforçar um conteúdo, ou até mesmo iniciá-lo, em sala de aula é bastante interessante e significativo, já que os alunos realmente conseguem aprender brincando e sem perceber muitas vezes, que está construindo o conhecimento. A partir do lúdico, o professor tem a chance de tornar sua prática pedagógica inovadora, pois além de desenvolver atividades divertidas, o professor pode proporcionar situações de interação entre os alunos melhorando a forma de relacionamentos entre os mesmos.

Segundo Kishimoto (2011) o uso de jogos educativos com fins pedagógicos, nos leva

\footnotetext{
${ }^{1}$ Graduanda do Curso de Química do Instituto Federal de Pernambuco - IFPE - Campus Vitória de Santo Antão, mariagrasielly2019@gmail.com;

${ }^{2}$ Graduando do Curso de Química do Instituto Federal de Pernambuco - IFPE - Campus Vitória de Santo Antão, matheusalves20162903200@gmail.com;

${ }^{3}$ Mestranda do Curso de Pós-Graduação em Educação em Ciências e Matemática - PPGECM - da Universidade Federal de Pernambuco - UFPE - Centro Acadêmico do Agreste - CAA, renata joaquina@ hotmail.com;

${ }^{4}$ Doutora em Ensino de Ciências - UFRPE. Professora do Instituto Federal de Pernambuco - IFPE - Campus Vitória de Santo Antão, kilma.viana@vitoria.ifpe.edu.br;

${ }^{5}$ Especialista em Ensino de Química (UCAM - Prominas), Coordenador do Grupo de Trabalho de Jogos Didáticos do Programa Internacional Despertando Vocações para Licenciaturas (PDVL) do Instituto Federal de Pernambuco (IFPE - Campus Vitória) - E-mail: ayrthon.matheus@ gmail.com;
} 
para situações de ensino-aprendizagem visto que a criança aprende de forma prazerosa e participativa. No que se refere ao aspecto cognitivo, segundo Macedo, Petty e Passos (2005), o jogo contribui para que a criança construa conhecimento e desenvolva habilidades e competências. Nesse sentido, o professor deve procurar proporcionar situações de aprendizagem motivadoras, de acordo com o nível de desenvolvimento cognitivo do aluno, em atividades que possam desafiá-lo, despertando assim seu interesse pelo que está sendo ensinado em sala de aula.

Assim surgiu a ideia de elaborarmos um jogo didático para utilizarmos de uma forma divertida e de despertar a vontade do aluno de querer aprender química. O jogo Químidominó busca estimular a compreensão do conteúdo de distribuição eletrônica de uma forma mais dinâmica. Por isso, o presente trabalho tem como objetivo propor uma intervenção na disciplina de química com uma abordagem lúdica, tendo como base a metodológica, o Ciclo da Experiência Kellyana (CEK).

\section{FUNDAMENTAÇÃO TEÓRICA}

Ultimamente, os jogos didáticos têm ganhado espaço no ambiente escolar, e tem sido como aparelho motivador para a aprendizagem de conhecimentos químicos, à medida que propõe estímulo ao interesse do estudante. Se, por algum meio, o jogo ajuda o alunado a construir novas formas de pensamento, desenvolvendo e enriquecendo a construção de um assunto abordado, por outro lado, também para o professor, o jogo o leva à condição de transportador, estimulador e avaliador da aprendizagem. As propostas de jogos didáticos no ensino, já vem há décadas, não apenas na área de química como em outras áreas do conhecimento. A utilização de jogos didáticos no Ensino de Química é um instrumento pedagógico que ganha visibilidade nas aulas, tornando mais atrativas e divertidas na forma de aprender e tornando uma disciplina agradável e útil (NASCIMENTO et al., 2015).

Kishimoto (2008) nos mostra que muitos professores reconhecem a importância do jogo, através de seu significado associando a função lúdica com a forma pedagógica de como é trabalhado o jogo. Trabalhar com jogos pedagógicos possibilitam aos alunos, uma visão mais ampla e facilidade de assimilar o conteúdo, desafiando-os a buscar respostas cuja construção resulta em uma nova aprendizagem.

A atividade lúdica passou a dar contribuições importantes na área de aquisição do conhecimento. Assim, auxilia no processo de aprendizagem e deixa de ser uma prática somente da realidade da educação infantil, podendo ser utilizada durante todos os níveis de ensino. Nesse caso, pode-se afirmar que é riquíssima a utilização do lúdico na escola como recurso 
pedagógico, pois como diria Alves (2003), o brinquedo desperta interesse e curiosidade, aspectos que contribuem na aprendizagem.

\section{METODOLOGIA}

George Kelly amplia o que ele denominou de Ciclo da Experiência, composto por cinco etapas: antecipação, investimento, encontro, confirmação ou desconfirmação e revisão construtiva. A antecipação segundo Bastos (1992) é o momento em que o aluno recebe o convite para participar de um determinado evento, buscando nas suas concepções ideias relevantes sobre aquele conceito que o ajude a responder ao questionamento realizado.

Neves (2006) ao relatar o sujeito durante a primeira etapa (investimento), afirma que "dependendo de sua capacidade de construir a réplica do evento, ela acaba por se engajar na fase de investimento, quando se prepara para encontrar-se com o evento" (p.25). A etapa seguinte é o encontro quando "o professor apresenta um conjunto de conceitos teóricos, juntamente com uma série de experimentos envolvendo esses conceitos, utilizando diversos recursos didáticos" (BARROS; BASTOS, 2006, p. 4). A quarta etapa consiste na confirmação ou desconfirmação, quando "o indivíduo testa suas hipóteses, confirmando-as ou refutando-as. É onde se depara com situações onde ele testará se seus construtos pessoais (hipóteses) têm validação" (FERREIRA, 2005, p.45). Finalmente, vem a etapa da revisão construtiva. É o momento em que o indivíduo revê seus construtos anteriores, consolida seus conhecimentos e, segundo Ferreira (2005 p.45), "se coloca a repensar toda situação e, se for o caso, ampliar o limite de validade de sua hipótese inicial”.

\section{RESULTADOS E DISCUSSÕES}

O Ciclo da Experiência Kellyana é composto por cinco etapas: Antecipação, Investimento, Encontro, Confirmação ou Desconfirmação e Revisão Construtiva.

$\mathrm{Na}$ primeira etapa, a antecipação, Espera-se, nesta etapa, despertar a atenção dos estudantes e fazer com que eles possam expor suas ideias e conhecimentos prévios sobre o conteúdo, por meio dos saberes construídos na escola.

Na segunda etapa, Investimento, será realizada uma explicação sobre o conteúdo de distribuição eletrônica, destacando os aspectos que os estudantes mostrarem mais dificuldade na etapa anterior. Esperamos que as dúvidas dos estudantes acerca do conteúdo sejam solucionadas, para que eles possam estar preparados para as próximas etapas do CEK.

$\mathrm{Na}$ terceira etapa, Encontro com o acontecimento, será aplicado o jogo didático Químidominó, no qual explicaremos as regras do jogo com uma breve leitura. Esperamos que 
os estudantes participem ativamente durante o jogo, e que este momento contribua para a melhor compreensão do conteúdo. Esperamos também que eles possam vivenciar discussões acerca, do conteúdo e fazer o uso de informações científicas do assunto, visando a construção de conhecimento. Abaixo apresentamos o jogo didático desenvolvido.

O Químidominó é um jogo composto por vinte e oito peças que são dividas ao meio, na qual uma parte contém a distribuição eletrônica e a outra contém o símbolo do elemento (como mostra a figura 1) e uma tabela periódica. No Químidominó são utilizados os vinte e oito menores números atômicos dos elementos da tabela periódica, para melhor identificação da distribuição eletrônica.

Figura 1: Carta do Químidominó

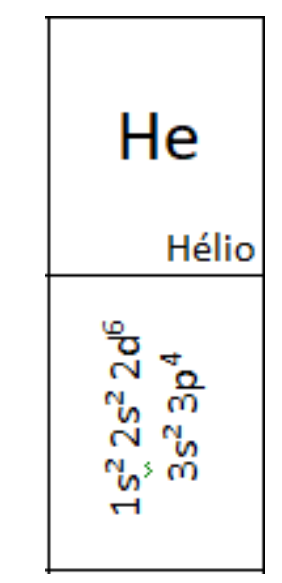

Fonte: Própria (2019).

\section{$\underline{\text { Regras do jogo Químidominó }}$}

1. Dividir a turma em grupos de no mínimo duas e no máximo quatro pessoas;

2. Cada jogador deve conter sete peças;

3. O jogo inicia-se com o jogador que tiver a peça com elemento de maior número atômico, que neste caso é o Níquel (Ni), após a primeira jogada, joga o participante da posição anti-horário;

4. Caso o jogador não tiver a peça correspondente ele passará a vez para o próximo;

5. Vence o jogo quem ficar sem nenhuma peça do Químidominó.

Na quarta etapa, Confirmação ou desconfirmação, vamos analisar a experiência dos alunos de uma forma que confirmem ou desconformem suas hipóteses iniciais acerca do assunto. Esperamos que com este momento eles possam reconstruir suas concepções e compreender propriamente o conteúdo discutido durante a intervenção.

$\mathrm{Na}$ quinta etapa, Revisão construtiva, terá como finalidade realizar uma revisão dos 
conhecimentos do conteúdo, analisando as contribuições da intervenção. Será realizado uma roda de conversa sobre o conteúdo e as atividades realizadas. Esperamos que o CEK facilite a compreensão no conteúdo de distribuição eletrônica e que com o jogo, os estudantes possam sanar suas dúvidas.

\section{CONCLUSÕES}

Esperamos que o Químidominó seja uma atividade alternativa para o ensino e aprendizagem do conteúdo de distribuição eletrônica de Linus Pauling presente na disciplina de Química, e assim promover a participação e interesse por parte dos discentes. Além disso, esperamos que o jogo desenvolvido facilite o trato do conteúdo em sala de aula.

\section{REFERÊNCIAS}

ALMEIDA, E. R. M.; DANTAS, J. S.; CRUZ, M. D. S. Análise sobre importância do uso dos jogos lúdicos na disciplina de matemática no ensino de jovens e adultos. In: Congresso de Iniciação Científica, 9., 2013, Natal. Anais... Disponível em: http://www2.ifrn.edu.br/ocs/index.php/congic/ix/paper/view/1284. Acesso em: 03 de maio de 2014.

ALVES, Rubem. Conversas sobre educação. São Paulo: Verus, 2003.

BARROS, M. A. e BASTOS, H. B. Investigando o uso do ciclo da experiência Kellyana na compreensão do conceito de difração de elétrons. Caderno Brasileiro de Ensino de Física, Florianópolis, v.24, n.1, 2006.

BASTOS, H. F. B. N. Changing teachers' practice: towards a constructivist methodology of physics teaching, Inglaterra, 1992. Tese (Doutorado em Física), Unversity of Surrey. Não publicado.

KELLY, A. G. The Psychology of personal constructs. Vol. 1. New York: Norton, 1955

KISHIMOTO, T. M. Jogo, brinquedo, brincadeira e a educação. São

Paulo: Cortez, 2008.

KISHIMOTO, T. M. Jogo, brinquedo, brincadeira e a Educação. 14 ed. São Paulo :Cortez, 2011.

MACEDO, L.; PETTY, A. L. S.; PASSOS, N. C. Os jogos e o lúdico na aprendizagem escolar. Porto Alegre: Artmed,2005.

MOURA, P. C.; VIAMONTE, A. J. Jogos Matemáticos como recurso ditáctico. Lisboa: APM, 2005. 
NASCIMENTO, A. M. S. et al. Dominós das Funções Oxigenadas: Um Jogo Didático no Conteúdo de Química Orgânica. In: 55² Congresso Brasileiro de Química, 2015, Goiânia - GO. Anais do 55 Congresso Brasileiro de Química, 2015.

NEVES, R. F. das. Interação do ciclo da experiência de Kelly com o Círculo hermenêuticodialético, para a construção de Conceitos de Biologia. 2006. 110f. Dissertação (Mestrado em Ensino de Ciências) - Universidade Federal Rural de Pernambuco, Recife, Pernambuco, 2006.

FERREIRA, N. O. Utilizando o ciclo da experiência de Kelly para investigar a Compreensão do comportamento dual da luz. 2005.151f. Dissertação (Mestrado em Ensino de Ciências) Universidade Federal Rural de Pernambuco, Recife, Pernambuco, 2005 


\title{
OFICINA DE BARALHO MATEMÁTICO: UMA PROPOSTA LÚDICA PARA O ENSINO-APRENDIZAGEM DAS OPERAÇÕES BÁSICAS
}

\section{TALLER DE MATEMÁTICAS: UNA PROPUESTA DIVERTIDA PARA ENSEÑAR Y APRENDER DE OPERACIONES BÁSICAS}

\section{MATHING WORKSHOP: A FUN PROPOSAL FOR TEACHING AND LEARNING OF BASIC OPERATIONS}

\author{
Wesley Matheus Moura Balbino ${ }^{1}$; Cleiton Pedrosa de Sales ${ }^{2}$; Pedro Alexandre \\ Linhares Lima ${ }^{3}$ Iago Reis Santos ${ }^{4}$; Francismar Holanda ${ }^{5}$
}

DOI: $\underline{\text { https://doi.org/10.31692/978-65-991061-3-2.140-145 }}$

\section{INTRODUÇÃO}

Muitos são os desafios encontrados em relação ao aprendizado de matemática, e isso é notório quando nos deparamos com alunos de vários cursos de nível superior fazendo os seguintes questionamentos: "para que vou usar isso?", "será se vou precisar mesmo disso na minha vida?”, “o que isso tem haver com meu curso?”. Isso podemos observar com frequência no decorrer da graduação. Sabemos também que desde cedo a matemática é vista como uma disciplina complexa e que quem domina é considerado superdotado, essa ideia é reforçada pelo modelo tradicional de ensino, fazendo com que muitos procurem por cursos que aparentemente não possuem matemática na sua grade curricular.

\begin{abstract}
É muito comum observarmos nos estudantes o desinteresse pela matemática, o medo da avaliação, pode ser contribuído, em alguns casos, por professores e pais para que esse preconceito se acentue. Os professores na maioria dos casos se preocupam muito mais em cumprir um determinado programa de ensino do que em levantar as ideias prévias dos alunos sobre um determinado assunto. Os pais revelam aos filhos a dificuldade que também tinham em aprender matemática, ou até mesmo escolheram uma área para sua formação profissional que não utilizasse matemática. (SANTOS, 2007, apud, VITTI, 1999, p.32/33).
\end{abstract}

É nesse sentido que, o presente trabalho foi realizado com o intuído de reforçar os conhecimentos básicos de matemática através de um jogo de cartas envolvendo operações como: adição, subtração, multiplicação, divisão, potenciação e radiciação dos alunos dos módulos iniciais dos cursos de Licenciatura em Biologia, Química e Matemática do Instituto Federal de Educação, Ciência e Tecnologia do Piauí - Campus Teresina Central.

\section{FUNDAMENTAÇÃO TEÓRICA}

\footnotetext{
${ }^{1}$ Licenciatura em matemática, Instituto Federal do Piauí - Teresina Central, wesleymathifpi@gmail.com

${ }^{2}$ Licenciatura em matemática, Instituto Federal do Piauí - Teresina Central, cleitonsales1995@ gmail.com

${ }^{3}$ Licenciatura em matemática, Instituto Federal do Piauí - Teresina Central, pedroalexandre406@gmail.com

${ }^{4}$ Licenciatura em matemática, Instituto Federal do Piauí - Teresina Central, iagobtf75@gmail.com

${ }^{5}$ Mestre, Instituto Federal do Piauí - Campus Teresina Central, frholanda@ifpi.edu.br
} 
No modelo tradicional de ensino, muita das vezes, só há um caminho, ou método, do qual o aluno acha que deva seguir para se alcançar o resultado esperado. Entretanto quando isso não acontece, ele acaba se desestimulando e desistindo de aprender determinado conteúdo, levando-o a prosseguir com lacunas no decorrer de sua vida acadêmica. A ideia de se criar um baralho matemático surgiu no sentido de aproveitar a competitividade que há nos jogos, o que gera um interesse maior em se aprender o que se está jogando e, consequentemente, o fortalecimento de alguns conceitos básicos relacionados à matemática.

É bastante comum o aluno desistir de solucionar um problema matemático, afirmando não ter aprendido como resolver aquele tipo de questão ainda, quando ela não consegue reconhecer qual o algoritmo ou processo de solução apropriado para aquele problema. Falta aos alunos uma flexibilidade de solução e a coragem de tentar soluções alternativas, diferentes das propostas pelos professores. (D’AMBROSIO, 1989, p.1).

Contudo os alunos, em sua maioria, não conseguem ter essa pré-disposição para usarem outras ferramentas que possam lhes ajudar a apropriar-se do conteúdo, cabendo ao professor chamar essa responsabilidade para si. O baralho matemático aparece como uma ferramenta que amplia as possibilidades de aprendizagem e fixação dos conteúdos debilitados nos alunos.

O lúdico permite o prazer e a satisfação pelo ato de jogar, ao jogar procura sempre superar o desafio, o que motiva e incentiva a busca pelo saber de forma prazerosa e interativa; já sobre o papel educativo, o jogo educa para experiências sociais em um mundo, que possui leis e regras que precisam ser conhecidas e internalizadas. Além disso, o jogo estimula o desenvolvimento cognitivo, e auxilia na criação de estratégias para a solução de possíveis problemas que surgem no decorrer do processo de aprendizagem. (SILVA, 2015, p.4)

Santos (2015, p.106) afirma: "a escola precisa ser repensada com vistas a criar vários espaços onde o aluno possa aprender a partir de uma aula expositiva, uma roda de debate, uma leitura, a fim de experimentar aquilo que aprendeu na teoria”.

\section{METODOLOGIA}

O jogo intitulado de "Baralho de Matemática" teve a sua aplicação durante uma oficina realizada no âmbito da disciplina de Projeto Integrador IV (PI-IV) com o intuito de contribuir de forma satisfatória para a apropriação de conteúdos básicos de matemática por parte dos alunos do curso de Licenciatura em Biologia, Química e Matemática.

O público alvo da oficina foi composto por 15 (quantidade de alunos total), sendo 5 alunos de Licenciatura em Biologia, 5 alunos de Química e 5 alunos da matemática 
A oficina ocorreu em três momentos. O primeiro momento foi composto pela elaboração das regras do jogo e definição dos materiais utilizados na oficina. O segundo momento foi a oficina de fato, na qual os alunos tiveram uma breve explanação dos conteúdos abordados dentro do Baralho e uma introdução as regras do jogo. O Terceiro de último momento foi composto pela construção do material por parte dos alunos seguido da parte lúdica da oficina (o jogo).

O jogo é composto por 52 cartas, distribuídas em 4 cores distintas, com operações matemáticas com resultado variando de 2 a 13, além de possuir uma carta coringa que assume o valor de 1 .

As regas do jogo foram definidas da seguinte forma:

1. O jogo deve ser jogado por um grupo mínimo de duas pessoas e máximo de quatro pessoas;

2. Cada jogador inicia com três cartas na mão;

3. O aluno pode escolher parar ou continuar pegando cartas;

4. Vence o jogador que possuir o valor mais próximo de 21;

5. Caso todos os jogadores ultrapassem o valor de 21 , vence quem tiver o menor valor em mãos.

Após realizado a aplicação do jogo, foi aplicado um questionário composto por três perguntas, sendo elas: o Baralho de Matemática foi eficiente na consolidação de conteúdos básicos referentes ao ensino de matemática?; Na sua visão de professor, a utilização de recursos lúdicos para o ensino de matemática é válida?; A oficina teve um papel importante na sua formação acadêmica? E todas as perguntas deveriam ser respondidas com uma nota de 1 a 5 , dependendo do nível de satisfação do aluno participante. Eles também poderiam comentar algo a respeito de cada pergunta se quisessem.

\section{RESULTADOS E DISCUSSÕES}

O trabalho alcançou nossas expectativas, pois percebemos que com o uso do material didático e da competitividade houve maior interesse em aprender as regras do jogo e, consequentemente, o resultado das operações. O gráfico abaixo mostra os resultados das perguntas que foram feitas ao término da oficina. Foi feito a média aritmética das notas atribuídas pelos alunos relacionadas a cada pergunta. A avaliação varia de 0 a 5 , de acordo com o nível de satisfação em que tiveram na oficina. As perguntas foram as seguintes:

- Pergunta 1: o Baralho de Matemática foi eficiente na consolidação de conteúdos básicos 
referentes ao ensino de matemática?

- Pergunta 2: Na sua visão de professor, a utilização de recursos lúdicos para o ensino de matemática é válida?

- Pergunta 3: A oficina teve um papel importante na sua formação acadêmica?

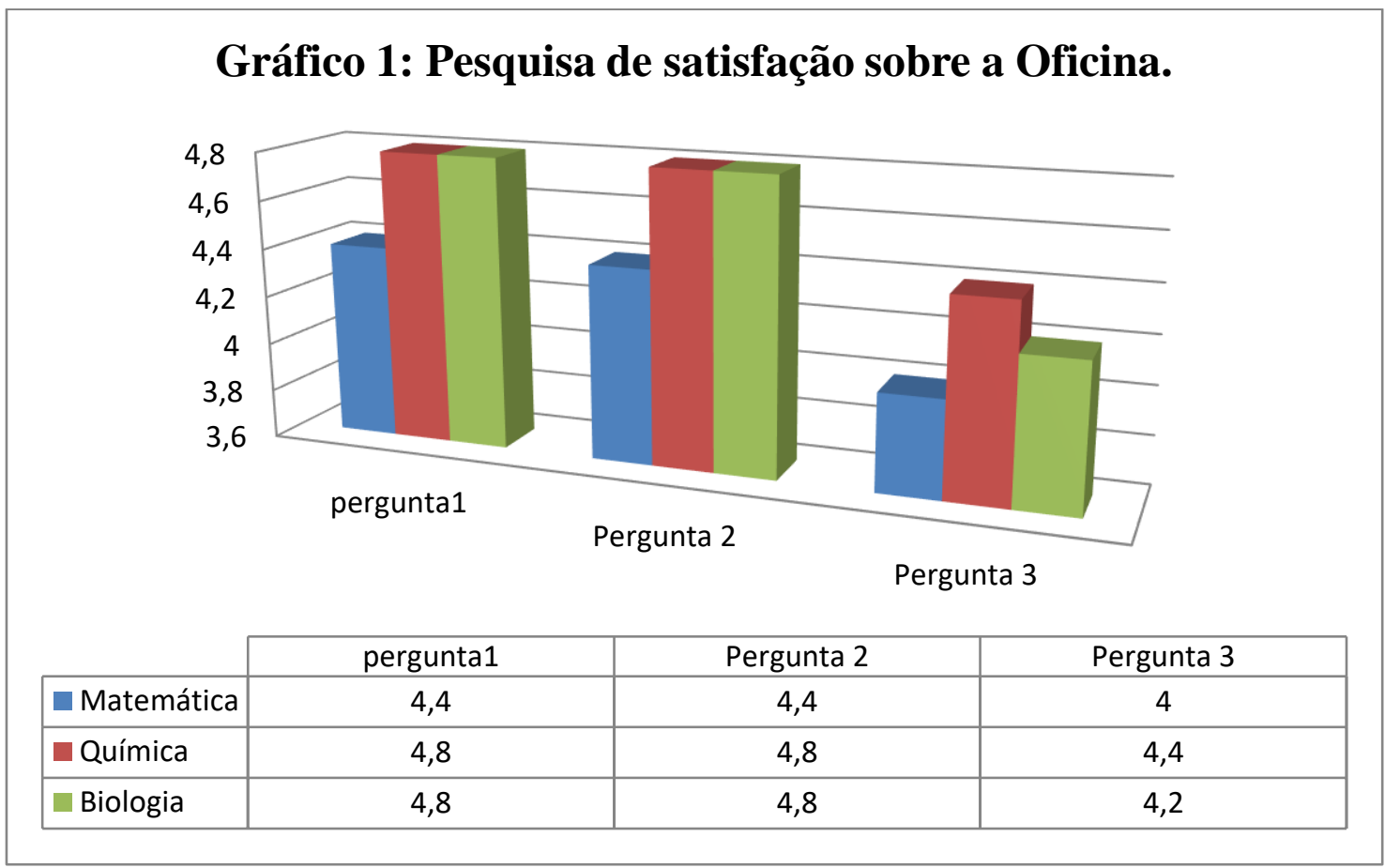

Fonte: Própria (2019).

Alguns alunos quiseram comentaram a respeita da proposta de utilização do Baralho Matemático como ferramenta de ensino. Vejamos a seguir.

- Aluno N (Mat) sobre as três perguntas respectivamente.

Pergunta 1: Sim, gostei. Foi bem eficiente.

Pergunta 2: com certeza, com ela nós podemos expandir nossa didática e aprimorar o entendimento do aluno.

Pergunta 3: foi bem legal, me deu novas ideias para aplicar o ensino da matemática em sala de aula.

- Aluno N (Mat) sobre as três perguntas respectivamente.

Pergunta 1: Sim, pois foi uma maneira lúdico que exercitamos os conteúdos básicos da matemática é consequentemente obtemos o conhecimento de forma prazerosa e mais fácil.

Pergunta 2: Sim, com certeza são uma ferramenta que pode sim complementar bastante no ensino, mais temos que saber utilizá-lo.

Pergunta 3: Sim, pois pude perceber que a utilização de recursos lúdicos pode melhorar o ensino 
do aluno de forma significativa.

- Aluno B (Bio) sobre as três perguntas respectivamente.

Pergunta 1: Sim, de uma forma bem divertida sem perder o real sentido de ensino-aprendizagem (pelo menos foi o q achei).

Pergunta 2: Sim, acredito ser bastante eficiente em uma disciplina que considerada de difícil aprendizagem, pois eu tive e tenho bastante dificuldade com a mesma.

Pergunta 3: Sim, tive a oportunidade de relembrar alguns conteúdos.

- Aluno D (Bio) sobre as três perguntas respectivamente.

Pergunta 1: Sim.

Pergunta 2: Sim, facilita a compreensão do assunto, e é uma maneira divertida de aprender.

Pergunta 3: Sim, porque vendo exemplos é ate uma maneira de estimular as pessoas(os outros, futuros docentes) a utilizarem esse recurso, porque foi muito legal.

- Aluno A (Bio) sobre as três perguntas respectivamente.

Pergunta 1: Sim, pois notei que estava bem elaborado, além da explicação ter sido clara, o que acarretou num boa compreensão dos conteúdos.

Pergunta 2: Extremamente válida, pois sabemos que os alunos comumente apresentam dificuldade de compreensão da disciplina, e com o uso do lúdico, se torna mais simples a compreensão dos conteúdos, além de apresentar-se mais interessante, despertando a curiosidade dos alunos.

Pergunta 3: Sim, pois como futura professora de ciências e biologia, entender conceitos básicos de matemática é essencial para desenvolver com futuros alunos conteúdos como genética, por exemplo.

\section{CONCLUSÕES}

Podemos verificar que, através dos dados obtidos, o trabalho teve uma importância significativa para os graduandos que tiveram participação na oficina, onde o relato dos mesmos nos mostra que o uso de recursos didáticos são indispensáveis para a fixação dos conteúdos e para instigar o aluno a pensar por si próprio. O trabalho teve como objetivo fortalecer os conhecimentos prévios e suprir as deficiências trazidas lá do ensino básico, promovendo, assim, um pensamento crítico e desenvolvendo o raciocínio lógico em cada um deles. A experiência acabou tendo certa importância na vida acadêmica dos graduandos, pois além de ter reforçado alguns conteúdos, serviu também para instiga-los a buscar outras ferramentas que poderiam ser usadas para sanar essas dificuldades, o que nos dar mais opções, mostrando que o ensinar pode ser mais diversificado quanto o que é mostrado geralmente em sala de aula. 


\section{REFERÊNCIAS}

D’AmbrosiO, B. S. Como ensinar matemática hoje? Temas e Debates. Ano II, no 2, 1989.

FALCÃO, Paula; VILA, Magda. Focalização de Jogos em T \& D. Qualitymark. RJ, 2008.

SILVA, J. N. Confecção de jogos matemáticos na sala de apoio a aprendizagem com alunos do $6^{\circ}$ ano do ensino fundamental. PDE, 2015.

SANTOS, Glauco de Souza. Espaços de Aprendizagem. In: BACICH, Lilian; NETO, Adolfo Tanzi; TREVISANI, Fernando de Mello (Orgs). Ensino Híbrido: personalização e tecnologia na educação. Porto Alegre: Penso, 2015.

SMOLE, K. S. DINIZ, M. I. MILANI, E. Jogos de matemática de 6o a 9o ano. Porto Alegre: Artmed. (Série Cadernos do Mathema-Ensino Fundamental), 2007.

SAVI, Rafael; ULBRICHT, Vania Ribas. Jogo digitais educacionais: benefícios e desafios. Renote - Revista Novas Tecnologias na Educação, Porto Alegre, v. 6, n. 1, p. 1-10, jul. 2008. Disponível em: http://seer.ufrgs.br/renote/article/view/14405/8310. Acesso em: 25 jun. 2017. 


\title{
LEI DO RESFRIAMENTO DE NEWTON:TEORIA E PRÁTICA
}

\section{LEY DE REFRIGERACIÓN DE NEWTON: TEORÍA Y PRÁCTICA}

\section{NEWTON COOLING LAW: THEORY AND PRACTICE}

\author{
Pedro Augusto Soares da Silva ${ }^{1}$; Nallyson Francisco Silva Souza ${ }^{2}$; Leandro Campos da \\ Cunha $^{3}$; José Gomes Ferreira Filho ${ }^{4}$; Roberto Arruda Lima Soares ${ }^{5}$
}

DOI: https://doi.org/10.31692/978-65-991061-3-2.146-151

\section{INTRODUÇÃO}

A necessidade de contextualizar situações em sala de aula, onde o professor constrói ocasiões que fiquem mais acessíveis para o entendimento dos alunos, é uma boa abordagem de ensino, pois uma teoria com significado para os alunos pode proporcionar uma melhor aprendizagem. Contudo, a teoria na Matemática tem sua importância, pois leva ao aluno o motivo pelo qual aquele conteúdo foi estudado, revelando as necessidades que fizeram com que o homem buscasse criar e desenvolver respostas para o que acontecia ao seu redor.

Uma boa explanação do conteúdo, por parte do professor, pode induzir nos alunos curiosidades sobre o conteúdo estudado, onde eles por meio da aula prática podem construir um conhecimento mais significativo, observando a importância tanto da teoria quanto da prática no cotidiano das pessoas. Neste trabalho, é observado que o ensino da matemática associando aspectos teóricos e aplicações prática podem ser utilizadas de uma forma a instigar os alunos a confirmarem suas conclusões teóricas. Com isso, aprender matemática se torna mais atrativo e prazeroso, ou seja, a ideia de que a matemática é somente cálculos soltos sem muita aplicação. Com esse tipo de estudo o aluno muda a sua forma de interpretar os diversos acontecimentos, formando cidadãos críticos e construtores do conhecimento.

Este estudo baseou-se nas Equações Diferenciais, na parte da Lei de Resfriamento de Newton, associando a teoria e prática para o desenvolvimento do trabalho. A Lei de Resfriamento de Newton foi utilizada com a intenção de ser simples e compreensível, buscando demonstrar como o aprendizado pode se tornar prazeroso quando conseguimos associar conceitos teóricos ao nosso cotidiano.

\section{FUNDAMENTAÇÃO TEÓRICA}

\footnotetext{
${ }^{1}$ Licenciatura Matemática, IFPI, pedroaugusto.thay00@gmail.com

${ }^{2}$ Licenciatura Matemática, IFPI, nallysonsouza0202@gmail.com

${ }^{3}$ Licenciatura Matemática, IFPI, Ldrocampos@ hotmail.com

${ }^{4}$ Licenciatura Matemática, IFPI, jogofefi@gmail.com

${ }^{5}$ Professor Doutor, IFPI, robertoarruda@ifpi.edu.br
} 
A Lei de Resfriamento de Newton é uma aplicação em equações diferenciais utilizada para resolver problemas relacionados à variação de temperatura, assim como afirma Alitolif (2011),

Esta forma de aplicação é ligada diretamente a física, mas cálculos voltados para as leis de temperatura são de grande utilidade em várias outras ciências, alguns exemplos são os utilizados nas engenharias, na variação de temperatura de uma simples xícara de café durante o seu resfriamento ou no derretimento de uma bola de sorvete, ou ainda no processo de resfriamento de um bolo, entre outras aplicabilidades deste modelo. (ALITOLIF, 2011, p.18).

Um dos motivos da evasão escolar, possivelmente, é ocasionada em suma pela falta de interesse do aluno em acompanhar um conteúdo que não o estimule, uma vez que esses não são apresentados de forma a dar significado em sua vida, pois o professor não traz o conteúdo para a realidade, trata apenas de cenários nunca vistos por estes, fazendo com que o desinteresse tome conta dos alunos. Assim como afirmam, Lisboa e Lucino (2015). Por este motivo, é fundamental que os professores busquem novas alternativas educacionais capazes de manter o interesse entre a matemática escolar aplicada com o meio em que os alunos vivem. Assim, D’Ambósio (1986) complementa que,

O valor da teoria se revela no momento em que ela é transformada em prática. No caso da educação, as teorias se justificam na medida em que seu efeito se faça sentir na condução do dia-a-dia na sala de aula. De outra maneira, a teoria não passará de tal, pois não poderá ser legitimada na prática educativa. (D`AMBROSIO, 1986, p. 43).

\section{METODOLOGIA}

O trabalho foi desenvolvido no sexto módulo do curso de Licenciatura em Matemática, sob a orientação do Pr. Dr. Roberto Arruda Lima Soares, no Campus Teresina Central do Instituto Federal de Educação, Ciência e Tecnologia do Piauí. Este trabalho se estrutura em duas etapas: a primeira visa uma pesquisa bibliográfica sobre a Lei de Resfriamento de Newton através de livros, artigos científicos, documentos, revistas acadêmicas e sites educacionais. $\mathrm{Na}$ segunda etapa fez-se experimento com a utilização de alguns instrumentos (estufa, termômetro digital, objeto de material cerâmico, objeto de material metálico, bloco de anotações, caneta, etc.) e a partir dos dados coletados foi desenvolvida uma situação-problema por meio da Lei de Resfriamento de Newton, com isso, os resultados obtidos por meio do método teórico foram 
comparados com o método prático e posterior análise dos resultados obtidos. O estudo foi realizado por meio da leitura prévia e individual de obras na disciplina de matemática, para as discussões sobre a Lei de Resfriamento de Newton e suas aplicações, foi utilizado neste trabalho computadores com acesso à Internet, livros e artigos científicos que discutem o assunto.

\section{RESULTADOS E DISCUSSÕES}

Na tentativa de contextualizar a união entre teoria e prática através da Lei de Resfriamento de Newton foi realizado um experimento que trabalha com o uso de um termômetro eletrônico medir a temperatura do ambiente (laboratório de materiais), em seguida, o material cerâmico é retirado da estufa e colocado numa superfície em temperatura ambiente $\left(27,8^{\circ} \mathrm{C}\right), \operatorname{logo}$ após, com intervalos de 30 segundos são feitas as medições da temperatura deste material.

Assim, foram obtidos os seguintes valores:

Tabela 1: Resultado do experimento com material cerâmico

\begin{tabular}{|c|c|}
\hline \multicolumn{2}{|c|}{ Resultado do experimento com material cerâmico } \\
\hline Temperatura da estufa & $110,6^{\circ} \mathrm{C}$ \\
\hline Tempo (t) em minutos & Temperatura (T) em ${ }^{\circ} \mathrm{C}$ \\
\hline $0^{\prime}$ & 95,9 \\
\hline $30^{\prime \prime}$ & 93,2 \\
\hline $1^{\prime}$ & 88,4 \\
\hline $1^{\prime} 30^{\prime \prime}$ & 83,3 \\
\hline $2^{\prime}$ & 78,9 \\
\hline $2^{\prime} 30^{\prime \prime}$ & 72,8 \\
\hline $3^{\prime}$ & 69,8 \\
\hline $3^{\prime} 30^{\prime \prime}$ & 65,2 \\
\hline $4^{\prime}$ & 56,9 \\
\hline $4^{\prime} 30^{\prime \prime}$ & 59,7 \\
\hline $5^{\prime}$ & 56,9 \\
\hline & \\
\hline & \\
\hline & \\
\hline & \\
\hline & \\
\hline
\end{tabular}

Fonte: Própria (2018). 
Em seguida com o material metálico foi realizado o mesmo procedimento, onde é retirado da estufa e colocado numa superfície em temperatura ambiente $\left(27,8^{\circ} \mathrm{C}\right), \operatorname{logo}$ após, com intervalos de 30 segundos são feitas as medições da temperatura deste material.

Assim, foram obtidos os seguintes valores:

Tabela 2: Resultado do experimento com material metálico.

\begin{tabular}{|c|c|}
\hline \multicolumn{2}{|c|}{ Resultado do experimento com material metálico } \\
\hline Temperatura da estufa & $110,3^{\circ} \mathrm{C}$ \\
\hline Tempo (t) em minutos & Temperatura $(\mathrm{T}) \mathrm{em}{ }^{\circ} \mathrm{C}$ \\
\hline 0 ' & 90,3 \\
\hline $30 "$ & 76,8 \\
\hline 1' & 67,1 \\
\hline 1'30"' & 60,2 \\
\hline $2^{\prime}$ & 56,7 \\
\hline 2'30" & 53,4 \\
\hline $3^{\prime}$ & 50,4 \\
\hline 3’30" & 47,8 \\
\hline $4^{\prime}$ & 45,3 \\
\hline 4'30" & 43,6 \\
\hline $5^{\prime}$ & 41,9 \\
\hline
\end{tabular}

Fonte: Própria (2018)

Então foram feitos os cálculos por meio da aplicação teórica na Lei de Resfriamento de Newton resolvendo a seguinte situação: Num quarto fechado, cuja temperatura ambiente permanece a $27,8^{\circ} \mathrm{C}$ coloca-se um determinado objeto cerâmico a uma temperatura constante de $95,9^{\circ} \mathrm{C}$. Se após 1 minuto a temperatura do objeto for de $88,4^{\circ} \mathrm{C}$ determine a temperatura deste com intervalo de 30 segundos até o tempo de 5 minutos. Assim como para um objeto metálico à $90,3^{\circ} \mathrm{C}$, que após 1 minuto está à $67,1^{\circ} \mathrm{C}$.

\section{CONCLUSÕES}


O presente trabalho teve como propósito mostrar a importância da fusão entre teoria e prática no ensino/aprendizagem de Matemática, além de conhecer e estudar a história das equações diferenciais ordinárias e a Lei de Resfriamento de Newton. Foi contextualizada a união das aplicações teóricas e práticas através de uma situação-problema resolvida por meio da lei de resfriamento de Newton e de um experimento.

O experimento trouxe a possibilidade de usar o modelo da lei de Resfriamento de Newton em uma prática e comparar os resultados práticos com os já sabidos da teoria como forma de prova, analisando os erros absolutos e relativos para cada intervalo de tempo analisado.

$\mathrm{Na}$ comparação dos valores obtidos foram observadas poucas mudanças nas temperaturas com intervalos de 1 e 5 minutos para o resfriamento do metal e da cerâmica. Com isso, a aprendizagem tornou-se significativa quando foi possível compreender os fenômenos físicos capazes de explicar porque um corpo perde calor com o passar do tempo e que a escolha dos instrumentos da pesquisa também foi influenciada nos resultados.

Por isso, torna importante ressaltar que o docente deve tentar desenvolver práticas pedagógicas diferenciais para auxiliar no desenvolvimento cognitivo do discente, pois quando nos encontramos totalmente envolvidos com a nossa realidade fantástica em estudo surge então à obtenção de novos conceitos como também nos sentimos responsáveis pela nossa própria aprendizagem.

\section{REFERÊNCIAS}

ALITOLEF, S. S. Algumas Aplicações das Equações Diferenciais. Ji Paraná: UNIR, 2011.

D'AMBROSIO, U. Da realidade à ação: reflexões sobre educação e matemática. $1^{\text {a }}$ ed. São Paulo: Summus, 1986.

FRAZÃO, D. Isaac Newton. Disponível em <

https://www.ebiografia.com/isaac_newton > Acesso em nov. 2018.

GHAJAR, A. J.; ÇENGEL, Y. A. Transferência de Calor e Massa: Uma abordagem prática. Tradução de Fátima A. M. Lino. 4ª ed. São Paulo: Bookman, 2012.

LIMA, S. F. Erros e Medições Físicas. Disponível em < http://aprendendofisica.pro.br/pmwiki.php/Main/ErrosMedidasFisicaEEtc > . Acesso em nov. 2018.

LISBOA, J.; LUCINO, M. A. A importância da teoria e prática nas aulas de matemática. Ivaiporã: FIVI, 2015. 
Medição de dados experimentais, incerteza e propagação de erro. Página elaborada pela FEM - FACULDADE DE ENGENHARIA MECÂNICA. Medição de dados experimentais...

PEREIRA, I. M. do N.;BARBOZA, C. M. Teoria e prática na lei de resfriamento de Newton. EMD, p.45-53. 2018. 


\section{“QUEM SOU EU NA PALEONTOLOGIA": PROPOSTA DE JOGO DIDÁTICO PARA O ENSINO DE PALEONTOLOGIA}

\section{“QUIEN SOY YO EM PALEONTOLOGÍA": PROPUESTA DE JUEGO PARA LA ENSEÑANZA DE PALEONTOLOGÍA}

\section{"WHO AM I PALEONTOLOGY": A PROPOSED GAME FOR PALEONTOLOGY TEACHING}

Gustavo de Barros Silva ${ }^{1}$; João Vitor da Silva²; Jaqueline Inez de Santana ${ }^{3}$; Maria Emília Oliveira de Carvalho ${ }^{4}$; Emanuel Souto da Mota Silveira ${ }^{5}$

DOI: $\underline{\text { https://doi.org/10.31692/978-65-991061-3-2.152-157 }}$

\section{INTRODUÇÃO}

A Paleontologia é tida como a ciência responsável por estudar os fósseis (LIMA, 2013), que atuam no reconhecimento dos ambientes antigos de sedimentação, além de contribuir para a identificação das mudanças que ocorreram na superfície do planeta ao longo do tempo geológico. Nesse contexto, a Ciência Paleontológica tem grande importância na compreensão de processos que definiram a dinâmica evolutiva dos seres vivos e consequentemente do planeta (CASSAB, 2010).

Segundo Heirich et al. (2015), o ensino da Paleontologia vem se configurando como debilitado por vários fatores, desde as metodologias adotadas pelos professores até a falta de materiais paradidáticos (livros e réplicas). Merecem também destaque as deficiências dos conteúdos encontrados nos livros didáticos, ausência de espaços de formação específicos e limitadas possibilidades de renovação das práticas metodológicas.

Considerando especificamente a última limitação, destacamos a necessidade de mobilizarmos a busca permanente por recursos e estratégias capazes de mobilizar a participação dos estudantes e colocá-los ao centro das atividades pedagógicas. Novas abordagens estruturadas a partir de princípios lúdicos ganham cada vez mais espaço, reafirmando a necessária renovação da escola e suas práticas.

Diversos estudos (KISHIMOTO 2011; RAU 2007; MACEDO 2005) reforçam a ideia de que o uso de jogos e atividades lúdicas acabam por contribuir, como instrumento facilitador, no processo de ensino e de aprendizagem. Os jogos e atividades integrativas ampliam os canais

\footnotetext{
${ }^{1}$ Licenciatura em Ciências Biológicas, Universidade Federal de Pernambuco, gustavo-456@hotmail.com.br

${ }^{2}$ Licenciatura em Ciências Biológicas, Universidade Federal de Pernambuco, jv3160339@gmail.com

${ }^{3}$ Licenciatura em Ciências Biológicas, Universidade Federal de Pernambuco, jaquelineSantanaa18@hotmail.com

${ }^{4}$ Licenciatura em Ciências Biológicas, Universidade Federal de Pernambuco, emiliaoliveira01@hotmail.com

${ }^{5}$ Mestre em Biologia Animal, Universidade Federal de Pernambuco, emanuelsouto2@globo.com
} 
de interação, diálogo e construção coletiva de novos saberes.

Nesse contexto, apresentamos a proposta de um jogo didático intitulado: "Quem sou eu na Paleontologia?”, projetado a partir da adaptação de um jogo já existente intitulado "Quem sou eu" para ser utilizado no ensino de Biologia como recurso facilitador do processo de aprendizagem de conceitos específicos da Paleontologia.

\section{FUNDAMENTAÇÃO TEÓRICA}

Os Parâmetros Curriculares Nacionais (PCNs) relatam que os jogos lúdicos são ferramentas de relevada importância no processo de ensino, atuando significativamente para uma melhor aprendizagem, sendo considerado como um importante instrumento capaz de gerir desenvolvimento intelectual e senso crítico nos estudantes (MARTINEZ et al, 2008).

Para Marandino et al. (2009), o uso de atividades práticas pelos professores acaba por ocasionar uma participação mais efetiva dos estudantes, ampliando o leque das possibilidades de aprendizado.

O jogo serve como instrumento para facilitar o ensino e aprendizagem e melhorar por consequência o aproveitamento das aulas, já que o aprender por meio de brincadeiras se encontra presente na vida do estudante desde a sua infância (SANTOS, CASTRO \& SILVA, 2012). Contribuindo para um desenvolvimento coletivo, dinâmico e interativo nas áreas cognitiva, afetiva, social e motora, além de trabalhar a construção da autonomia, criatividade, responsabilidade e cooperação dos estudantes (CASTRO \& TREDEZINI, 2014).

Nos dias atuais, os jogos vêm se apresentando como "objetos" de grande aprendizado e relevância para os estudantes, deixando de ser visto como apenas um passatempo e ganhando espaço nas escolas e processos pedagógicos (BÖHM, 2014).

\section{METODOLOGIA}

Este trabalho resulta da reflexão coletiva de estudantes do Curso de Licenciatura em Ciências Biológicas, envolvendo a construção de um recurso de apoio didático interativo para o ensino de Biologia, com foco em conceitos paleontológicos. A intenção é de descrever as etapas e o material necessário para a sua construção.

O jogo denominado "Quem sou eu na Paleontologia?", foi produzido com materiais de fácil acesso, duráveis e de baixo custo, levando em consideração para esta escolha, a realidade das escolas públicas. Para confecção do jogo foram selecionados e utilizados os seguintes materiais: papelão, 1 caixa de sapato, cartolina dupla face (cor azul), EVA nas cores (verde, amarelo, vermelho e roxo), cola branca, cola de isopor, cola quente, fita durex, papel 
madeira, papel camurça (cor bege), 20 envelopes pequenos (marrons), elástico grosso, imagens impressas, cartões com informações impressos, velcro, tesouras, 2 garrafas PET (250ml), farinha, fitas de cetim (cor prata).

De início, a caixa de sapato foi toda coberta externamente por papel madeira e internamente por papel camurça. Na parte superior da caixa, foi aderida a arte com o nome do jogo “Quem sou eu na Paleontologia?”, onde foram utilizados moldes de dinossauros e libélulas produzidos com EVA (em cores variadas) para decoração de toda a caixa (responsável por abrigar o jogo).

Logo em seguida, foram confeccionadas 20 cartas com papelão, sendo utilizadas cartolinas dupla face (azul) para recobrir as mesmas. Onde, na parte anterior das cartas foram coladas imagens do que os estudantes terão que adivinhar quem são e na parte posterior foram colados envelopes marrons, onde no interior de cada um dos envelopes contido nestas cartas foi colocado um cartão impresso com informações paleontológicas extras direcionadas aos grupos de organismos e conceitos remetentes à cada uma das imagens presentes nas referidas cartas.

Para abrigar estas cartas, foi confeccionada uma caixa com papelão, sendo utilizado EVA (verde e roxo) para recobrir a referida caixa confeccionada. Duas cintas foram confeccionadas com papelão, elástico e recobertas por EVA (roxo).

Por fim, foi confeccionada a ampulheta, a partir da junção de duas garrafas PET (de $250 \mathrm{ml}$ cada), onde as bocas foram ligadas por fita durex, sendo utilizada farinha para cronometragem do tempo e duas bases para equilíbrio da ampulheta, estas bases foram confeccionadas com papelão, revestidas de EVA (verde) e fita de cetim (prata). Sendo a duração de cronometragem da ampulheta de em torno de aproximadamente 1 minuto.

\section{RESULTADOS E DISCUSSÕES}

O jogo "Quem sou eu na Paleontologia?", foi planejado para ser um recurso de apoio didático paras as aulas da disciplina de Biologia, com foco nos conteúdos de Paleontologia do ensino médio. Podendo ser o jogo utilizado em sala de aula pelo professor como forma de revisar os conteúdos e até mesmo como instrumento avaliativo.

O jogo será sempre executado entre dois participantes, o jogador mais novo iniciará a partida e o próximo a jogar será o participante a sua frente. Na sua respectiva vez, cada um irá girar a ampulheta a qual será a responsável por delimitar o tempo que cada participante terá para adivinhar qual a imagem contida na carta em sua cinta, quando o tempo finalizar será passada a vez para o próximo jogador. Os participantes deverão responder as perguntas ou 
afirmativas corretamente dentro do tempo estabelecido, se algum deles fazer do contrário será punido, sendo desclassificado da rodada. Assim, se a resposta da sua afirmação estiver correta, o participante ganha a rodada. Caso não, o mesmo poderá continuar tentando enquanto o tempo cronometrado pela ampulheta estiver rolando. O vencedor do jogo será o que primeiro descobrir a imagem contida na carta, caso seja disputada mais de uma rodada, vencerá aquele responsável por acumular o maior número de pontos, ou seja, cartas descobertas.

Desta forma, a partir desta proposta de jogo o estudante poderá entender muitos dos conceitos complexos ligados à Paleontologia, de forma dinâmica, divertida e comprometida com a produção conjunta de conhecimento.

Figura 1: Jogo “Quem sou eu na Paleontologia?” Produzido para o aprendizado dos conteúdos desta ciência.

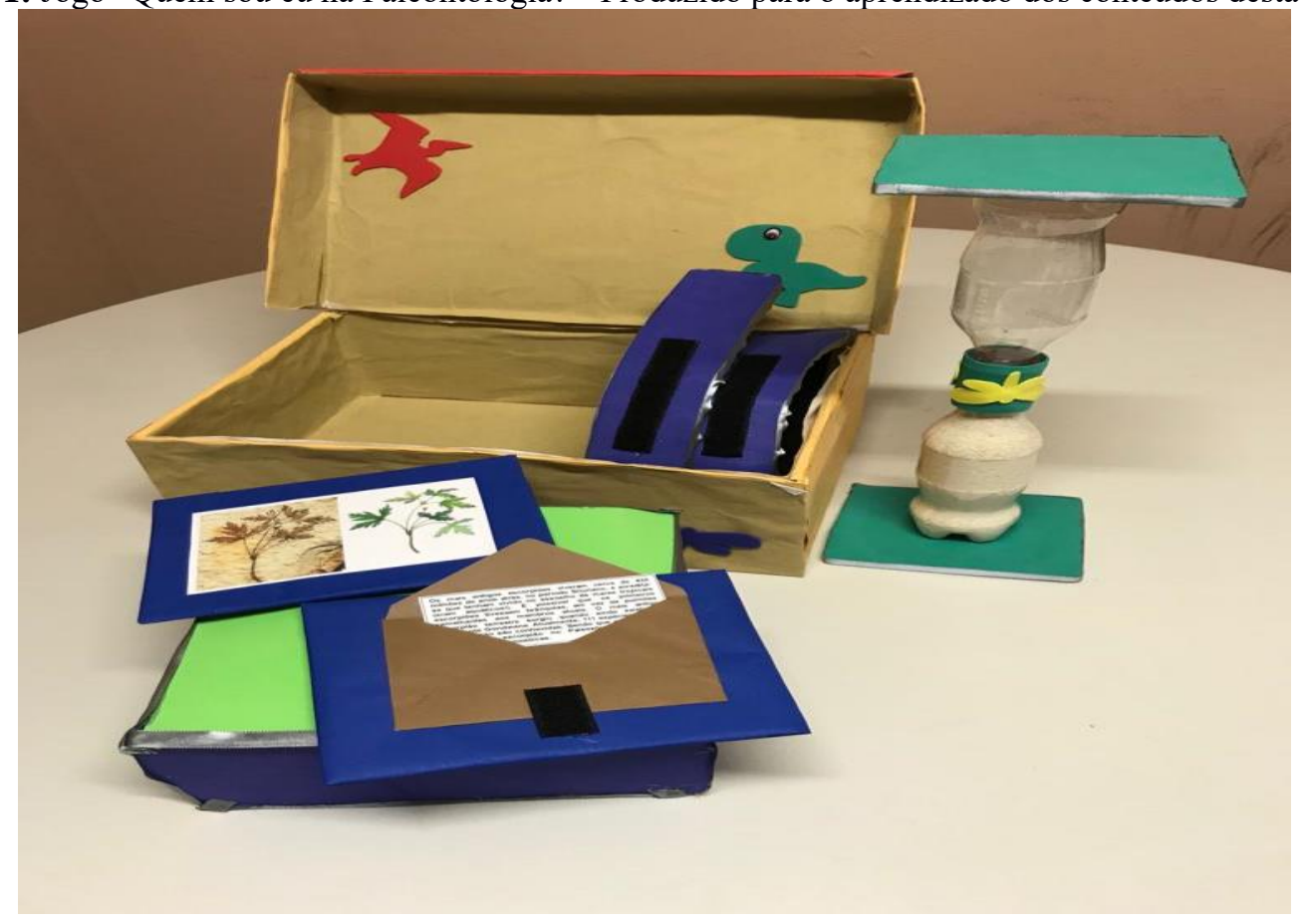

Fonte: Autores (2019). 
Figura 2: Representação de como ocorrem as partidas.

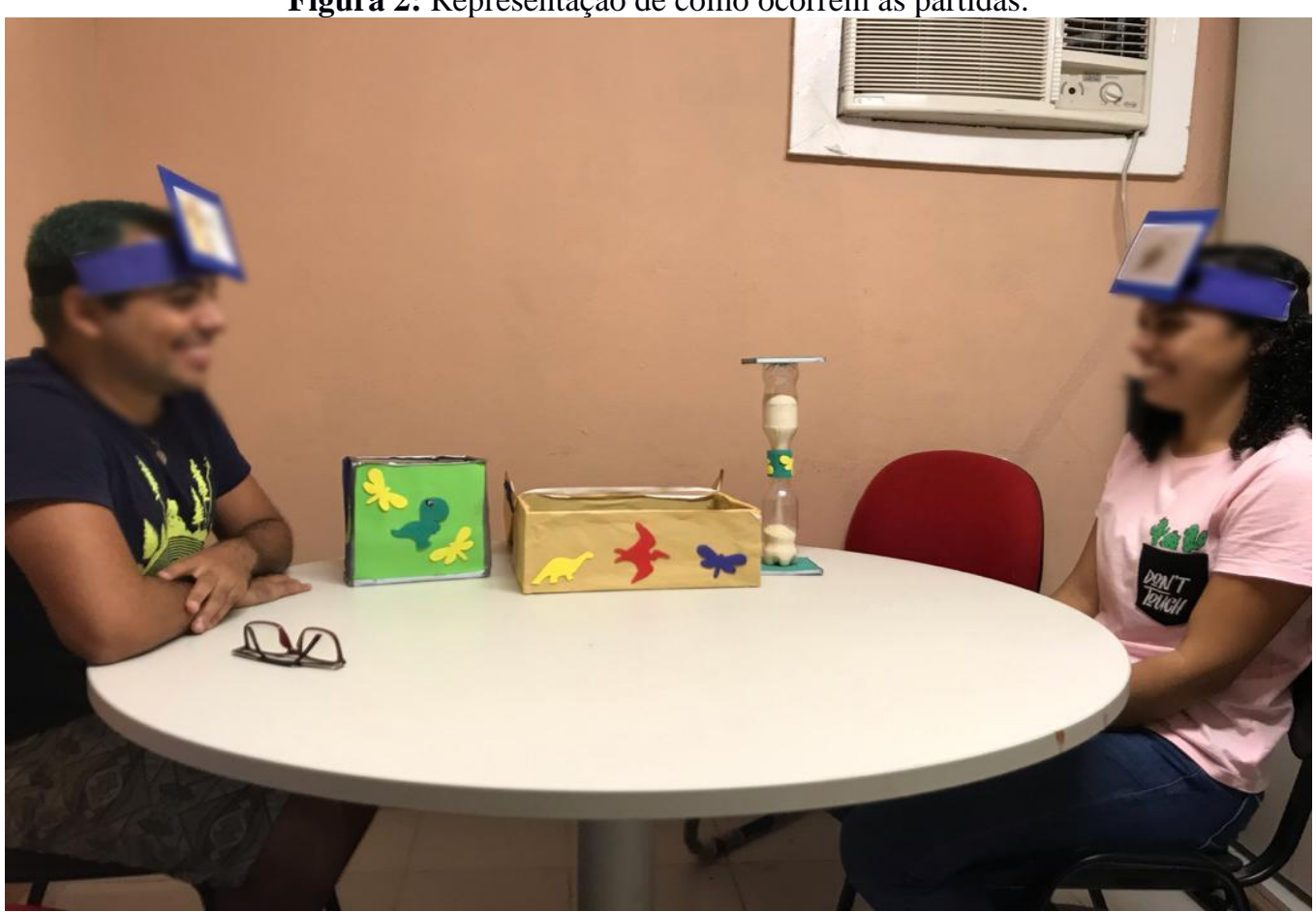

Fonte: Autores (2019).

\section{CONCLUSÕES}

O jogo em questão apresentado pode ser utilizado por professores de Biologia do ensino médio para auxiliar e facilitar o trabalho com conteúdo de Paleontologia, sendo, portanto, uma ferramenta didática alternativa para a aprendizagem.

Destacamos as possibilidades de utilização do recurso e sua vinculação com o desenvolvimento das competências sócio emocionais e todo trabalho de reflexão para a construção do jogo, mobilizando também saberes e o desenvolvimento de habilidades pelos futuros professores envolvidos no processo.

\section{REFERÊNCIAS}

BÖHM, O. Jogo, brinquedo e brincadeira na educação. Disponível em: < http://www.uniedu.sed.sc.gov.br/wp-content/uploads/2017/02/Ottopaulo-B\%C3\%B6hm.pdf>. Acesso em: 31 de jul. de 2019.

CASSAB, R.C.T. 2010. Objetivos e Princípios. In: Car-valho I.S. ed. 2010. Paleontologia. Rio de Janeiro: Interciência, p.3-11.

CASTRO, D. F.; TREDEZINI, A. L. M. A importância do jogo/lúdico no processo de ensino-aprendizagem. Revista Perquirere, 11(1): 166-181, jul. 2014.

HEIRICH, C, M. et, al. Aprendizado da paleontologia no Ensino Básico da Cidade de Tibagi-PR, Paraná, 2015. 
KISHIMOTO, Tizuko M. Jogo, brinquedo, brincadeira e a Educação. 14 ed. São Paulo: Cortez, 2011.

LIMA, F. J. \& BANTIM, R. A. M. 2013. "Introdução ao estudo dos fósseis e os processos envolvidos em sua preservação". In: Sayão, J. M. (ed) Fósseis do litoral norte de Pernambuco: evidências da extinção dos dinossauros.Gráfica Provisual, Recife, 96p.

MACEDO L. RETTY A. L. S. Os jogos e o lúdico na aprendizagem escolar. Porto Alegre: Artmed, 2005.

MARTINEZ, E. R. M.; Fujihara, R. T.; Martins, C. 2008. Show da genética: um jogo interativo para o ensino de genética. Genética na Escola, pag. 24-27.

MARANDINO, M; SELLES, S.E; FERREIRA, M.S. Ensino de biologia: histórias e práticas em espações educativos. São Paulo: Cortez, 2009.

RAU, M. C. T. D. A ludicidade na educação: uma atitude pedagógica. Curitiba: Ibpex, 2007.

SANTOS, J. M.; CASTRO, S. L.; SILVA, T. P. Jogos didáticos no processo de ensino aprendizagem de química. 2012. 


\section{A IMPORTÂNCIA DO INTÉRPRETE DE LIBRAS NA EDUCAÇÃO BÁSICA}

\section{LA IMPORTANCIA DEL INTÉRPRETE DE LA LIBRAS EN LA EDUCACIÓN BÁSICA}

\section{THE IMPORTANCE OF THE LIBRAS INTERPRETER IN BASIC EDUCATION}

Ediangela Soares Silva do Nascimento ${ }^{1}$; Henllayane Nathani de Amorim Amaral ${ }^{2}$; Rafaela Alcântara Barros de Oliveira ${ }^{3}$

DOI: https://doi.org/10.31692/978-65-991061-3-2.158-162

\section{INTRODUÇÃO}

O intérprete de Libras convive com diversos conflitos, aceitação e lutas pela pessoa surda, ele está ligado à inclusão na sociedade, ambiente esse pouco receptivo. O reconhecimento das Libras como Língua é recente, mesmo em toda a sua complexidade, se tornou real e obrigatória, através da Lei $n^{\circ}$ 10.436/2002, estabelecida originalmente no art. 4 o ensino da Língua Brasileira de Sinais - Libras, como parte integrante dos Parâmetros Curriculares Nacionais - PCNs, conforme legislação vigente (BRASIL, 2002). São notáveis os avanços relacionados à pessoa com surdez, através de legislações que efetivaram a interação dos indivíduos surdos com a sociedade. Esse direito foi concretizado através do Decreto n. 5.626/2005, art. 2 em que se considera pessoa surda aquela que, por ter perda auditiva, compreende e interage com o mundo através de experiências visuais, manifestando a sua cultura principalmente pelo uso da Língua Brasileira de Sinais — Libras (BRASIL, 2005).

Ações levaram as pessoas com surdez à sala de aula, e a partir daí que o intérprete contribui no ensino da língua aos estudantes surdos na escola. Leis foram criadas, especificando como deve ser o modo de ensino-aprendizagem, estabelecendo normas e critérios para o acesso das pessoas com deficiência auditiva à comunidade, a partir desse momento as escolas passaram a serem alvos de colocação desses profissionais.

A inclusão da criança surda na escola, não é trata-la de forma diferente aos demais estudantes, consistem em desenvolver o potencial dessas crianças respeitando as diferenças e atendendo as suas necessidades. Para que os estudantes com limitações auditivas tenham um aprendizado completo, a escola deverá incluir no seu material didático, ferramentas visuais e todos os tipos de estímulos para que haja mais interação na sala de aula por parte destes estudantes. (DAMAZIO, 2007, p. 26). Por não participar de uma formação de qualidade o

\footnotetext{
${ }^{1}$ E-mail: ediangelacbio@gmail.com

${ }^{2}$ E-mail: Henllayane16@gmail.com

${ }^{3}$ E-mail: Alcantara.rafaela14@gmail.com
} 
intérprete por diversas vezes ensinava com o conhecimento básico e os materiais que continha em sala de aula para que a aprendizagem se tornasse ativa. Gradativamente as instituições de ensino foram adaptando-se as normas estabelecidas, com os cursos formadores de intérpretes.

\section{FUNDAMENTAÇÃO TEÓRICA}

A educação para surdos começou a ter avanços, porém, o preconceito ainda está presente, a visão deturpada que foi construída contribui para a ideia de que são pessoas incapazes intelectualmente de assimilar o que lhe é proposto, realizar atividades e ocupar cargos importantes. Aquele que não ouve tão bem, ou não percebe algumas manifestações sonoras na medida em que deveria, frequentemente passa a ser distinguido como alguém com perda, com carência, com falta de, com deficiência e como pessoa portadora de uma especificidade (LULKIN, 1998, p. 40). A população ainda não compreendeu que a limitação que a pessoa com surdez apresenta é a falta de audição. A língua de sinais ocorre para os surdos assim como a língua oral para os ouvintes. São suas vozes, é através dos seus olhos que observam o mundo ao seu redor, não falta nada a eles, pelo contrário, os tornam especiais (LABORIT, 1994).

A maior parte das crianças surdas assim como também os jovens e adultos podem aprender a língua de sinais, participando da vida cotidiana e com a comunidade surda, isso ocorre de maneira natural, espontânea, assim como ocorre na linguagem oral, porém, apesar de ser uma prática comum não é unânime. Essa maneira natural de aprender a linguagem de sinais passa de geração a geração, e que vai mudando com o passar dos tempos (SKLIAR, 1998). Um dos motivos da existência de uma barreira entre surdos e ouvintes é a dificuldade de comunicação provocando por diversas vezes a falta de inclusão, por exemplo, na educação básica Língua Brasileira de Sinais não faz parte do componente curricular como, por exemplo, a Língua Portuguesa. Surdos e ouvintes têm línguas diferentes, mas podem viver numa única comunidade, desde que haja um esforço mútuo de aproximação pelo conhecimento das duas línguas, tanto por ouvintes como por surdos (ALMEIDA, 2000, p.3).

Segundo (GOLDFELD, 2002), a linguagem de sinais não se difere muito das linguagens orais, da mesma forma que as pessoas comuns riem, brincam, contam piadas, e nem por isso eles se olham diferentes.

Lacerda (2002) ressalta que a escola é o local onde é realizado o trabalho de interação do intérprete com os demais profissionais e por diversas vezes acredita-se que apenas com a presença desse profissional é possível sanar os problemas relacionados à inclusão da criança surda, mas, ao decorrer do tempo e através de reflexões cautelosas é perceptível que apesar da possibilidade de comunicação, certos problemas e lacunas permanecem como, por exemplo, 
ajustes curriculares e metodológicos.

Gurgel (2010) reforça que por causa da recente regulamentação da profissão, a formação dos intérpretes que atuam na educação é bastante heterogênea e com poucas alternativas. Somente em 2010 através da Lei n 12.319 foi regulamentado o exercício da profissão de tradutor e intérprete de Libras, no art. 4 contém que a sua formação deve ser realizada através de cursos de educação profissional, extensão universitária e formação continuada.

A comunidade surda vem empenhando-se pela defesa dos seus direitos, com o reconhecimento das Libras como língua potencializou avanços nessas conquistas. A inserção da Língua Brasileira de Sinais no currículo da educação básica, assim como o profissional intérprete traria benefícios também na evolução da aprendizagem das crianças surdas, pois, desta maneira a inclusão seria mais efetiva. O ensino da Língua de Sinais deveria ser obrigatório para todos, surdos e ouvintes. Repensar as práticas de como lidar com a surdez na escolarização das pessoas surdas, torna-se urgente mostrar a elas que a dificuldade de aprendizagem não vem delas, mas sim do modo como a escola através de práticas pedagógicas possam ensiná-los (SILVA, 2007).

\section{METODOLOGIA}

A partir do método qualitativo foi utilizada como procedimento metodológico, a pesquisa bibliográfica através de livros, artigos e legislações referentes à educação de surdos com o intuito de compreender a importância da formação de intérpretes da Língua Brasileira de Sinais (LIBRAS) no ensino básico para o desenvolvimento da comunicação e expressão das crianças surdas. Quando investigamos o entendimento das pessoas a respeito de vários fenômenos, conceitos e princípios, nós repetidamente achamos que cada fenômeno, conceito ou princípio pode ser entendido qualitativamente de diferentes maneiras (MARTON, 1986, p.31).

Após leituras referentes à formação de intérpretes para educação de surdos, foi realizado um levantamento qualitativo, num estudo exploratório de modo a expor fundamentos plausíveis, relatando o ponto de vista dos autores pesquisados, bem como as legislações relacionadas com o tema, identificando quais as dificuldades desses profissionais em atender as necessidades dos estudantes surdos.

\section{RESULTADOS E DISCUSSÕES}

O profissional intérprete é indispensável para o desenvolvimento da comunicação e inclusão da pessoa surda na sociedade, à inserção do intérprete de Libras na educação básica 
necessita de planejamento por parte das escolas através de metodologias ativas que permitam desenvolver além da expressão desse estudante a qualidade do ensino. De acordo com Lacerda (2000, p. 57):

a presença do intérprete não assegura que questões metodológicas, levando em conta

a surdez e os processos especiais/próprios de acesso ao conhecimento sejam considerados, ou que o currículo escolar sofra ajustes para contemplar peculiaridades e aspectos culturais da comunidade surda.

É preciso que a formação do intérprete educacional seja interdisciplinar voltada à prática da mediação da aprendizagem, visto que, para interpretação de conteúdos específicos é necessário um profundo conhecimento teórico sobre cada área do conhecimento, desenvolvida na escola, além da interação com os demais profissionais para construir a melhor maneira de aprendizagem.

\section{CONCLUSÕES}

A língua de sinais é um elemento mediador na educação promovendo inclusão desses estudantes na sociedade. O intérprete atualmente exerce a função de auxiliar no processo de desenvolvimento educacional, é o canal comunicativo entre surdos e ouvintes em que na maioria das situações ele é o único que conhece a língua do ambiente escolar.

Portanto, conclui-se que apesar de a responsabilidade do aprendizado do estudante com limitação auditiva na sala de aula ser do professor, o intérprete é indispensável, pois, promove a mediação dos conteúdos programáticos, bem como a interação social desse estudante. Com isso é essencial que esse profissional obtenha uma formação de qualidade para sanar as necessidades dos estudantes durante o processo de construção do conhecimento e comunicação na sala de aula.

\section{REFERÊNCIAS}

DAMAZIO, Mirlene Ferreira Machado. Atendimento educacional especializado: pessoa com surdez. São Paulo: MEC/SEESP, 2007.

ALBRES, Neiva de Aquino. Intérprete Educacional: políticas e práticas em sala de aula inclusiva. São Paulo: Harmonia, 2015.

ALMEIDA, Elizabeth Oliveira Crepaldi de Almeida. Leitura e Surdez: um estudo com adultos não oralizados. Rio de Janeiro: Revinter, 2000.

BRASIL. Lei $\mathbf{n}^{\mathbf{0}} \mathbf{1 0 . 0 9 8}$, de 19 de dezembro de 2000. Disponível em http://www.planalto.gov.br/ccivil_03/leis/L10098.htm. Acesso em 15 de ago. de 2019. 
BRASIL. Decreto no 5.626, de 22 de dez. 2005. Presidência da república, Casa Civil, Brasília, DF, 22 de dez. 2005. Disponível em http://www.planalto.gov.br/ccivil_03/_ato20042006/2005/decreto/d5626.htm. Acesso em 15 de ago. de 2019.

GOLDFELD, Marcia. A criança surda: linguagem e cognição numa perspectiva sociointeracionista. 7. ed. São Paulo: Plexus Editora, 2002.

GURGEL, T. M. A. Práticas e formação de tradutores intérpretes de língua brasileira de sinais no ensino superior Tese. (Doutorado em Educação). Universidade Metodista de Piracicaba. Piracicaba-SP. 2010.

LABORITT, Emmanuelle. O vôo da gaivota. São Paulo: Best Seller, 1994.

LACERDA, Cristina Broglia Feitosa; GÓES, Maria Cecília Rafael. O intérprete educacional de língua de sinais no ensino fundamental: refletindo sobre limites e possibilidades. In: LODI, Ana Cláudia Balieiro et al. (Org.). Letramento e Minorias. Porto Alegre: Mediação, 2002. P. 120-128.

LACERDA, C. B. F. A prática pedagógica mediada (também) pela língua de sinais: trabalhando com sujeitos surdos. Cad. CEDES, 2000.

LACERDA, Cristina Broglia Feitosa. Intérprete de Libras: em atuação na educação infantil e no ensino fundamental. Porto Alegre: Mediação, 2009.

LULKIN, Sérgio Andrés. O discurso moderno na educação dos surdos: práticas de controle do corpo e a expressão cultural amordaçada. In: SKLIAR, Carlos. A surdez: um olhar sobre as diferenças. Porto Alegre: Mediação, 1998. p. 33-50.

MARTINS, Vanessa Regina de Oliveira. Educação de Surdos no Paradoxo da Inclusão com Intérprete de Língua de Sinais: relações de poder e (re)criações do sujeito. 2008. 140 f. Dissertação (Mestrado em Educação) - Programa de Pós- -Graduação em educação, Universidade Estadual de Campinas, Campinas, 2008.

MARTON, F. Phenomenography - A research approach to investigating different understandings of reality. Journal of Thought, 1986. p. 28-49.

SILVA, Fabio Irineu et al. Aprendendo a Língua Brasileira de Sinais como segunda língua. Palhoça: IFSC - Campus Palhoça/NEPES, 2007.

SKLIAR, Carlos (Org.). A Surdez: um olhar sobre as diferenças. Porto Alegre: Mediação, 1998. 


\title{
UMA EXPERIÊNCIA DE INCLUSÃO DE ALUNAS CEGAS DO CURSO DE LICENCIATURA EM FÍSICA DO IFRN NA DISCIPLINA DE CÁLCULO DE FUNÇÕES DE UMA VARIÁVEL
}

\section{UNA EXPERIENCIA DE INCLUSIÓN DE ESTUDIANTES CIEGOS EN EL CURSO DE LICENCIA FÍSICA DE IFRN EN EL CÁLCULO DE FUNCIONES DE UNA VARIABLE}

\section{AN EXPERIENCE OF INCLUSION OF BLIND STUDENTS OF PHYSICS COURSE FROM IFRN IN THE SUBJECT OF CALCULATION OF FUNCTIONS OF ONE VARIABLE}

\begin{abstract}
Rita de Cássia Paulo dos Santos ${ }^{1}$; Wellington Muniz de Souza ${ }^{2}$; Caio Vasconcelos Pinheiro da Costa ${ }^{3}$; Tácio Vitaliano da Silva ${ }^{4}$; Rainelly Cunha de Medeiros ${ }^{5}$
\end{abstract}

DOI: https://doi.org/10.31692/978-65-991061-3-2.163-168

\section{INTRODUÇÃO}

No Brasil, o aumento do número de matrículas de pessoas com deficiência no ensino superior consiste de um movimento atual, resultado de políticas públicas recentes. Esse movimento, porém, não parece ter vindo acompanhado de ações de incentivo à formação docente no tocante às necessidades pedagógicas específicas desse público alvo. Quando se fala em alunos cegos cursando a disciplina de "Cálculo de funções de uma variável”, por exemplo, é comum, inclusive entre professores da área de Matemática, perceber um certo espanto que vem acompanhado da pergunta: como ensinar tais conteúdos para esses alunos? Diante da frágil formação inicial docente e da ausência de uma melhor compreensão sobre as particularidades de cada deficiência, torna-se ainda mais difícil avançar na direção da educação inclusiva.

Segundo Haddad e Sampaio (2010), estima-se que há aproximadamente 4 milhões de indivíduos com baixa visão e 1,2 milhões de cegos no Brasil. A Lei Brasileira de Inclusão - lei no 13.146, de 6 de julho de 2015 - incube ao poder público assegurar-lhes o acesso à educação superior e à educação profissional e tecnológica em igualdade de oportunidades e condições com as demais pessoas. No entanto, o direito de acesso a esses níveis de ensino, por si só, não assegura a compreensão do conteúdo abordado, uma vez que isso requer posturas inclusivas por parte de docentes e colegas. Muitas vezes, barreiras atitudinais e de comunicação tornam o tempo em sala de aula improdutivo para o estudante com deficiência, que parece invisível aos olhos dos que o cercam, talvez pelo "medo" do desconhecido e/ou pelo entendimento

\footnotetext{
${ }^{1}$ Licenciatura em Física, IFRN, e-mail: ritinhahesed@hotmail.com

${ }^{2}$ Licenciatura em Matemática, IFRN, e-mail: wallenmuniz@yahoo.com.br

${ }^{3}$ Mestre em Ciências Climáticas, IFRN, e-mail: caio.vasconcelos@ifrn.edu.br

${ }^{4}$ Doutor em Educação, IFRN, e-mail: taciovsilva@yahoo.com.br

${ }^{5}$ Doutora em Matemática, IFRN, e-mail: rainelly.cunha@ifrn.edu.br
} 
equivocado de que a pessoa com deficiência deve ser tratada como os demais e buscar a sua própria adaptação (FREITAS, FOSSATTI, KORTMANN; 2017). Diante disso, a questão passa a ser agora a inclusão e a permanência desses estudantes nos cursos superiores.

Este trabalho apresenta uma situação de inclusão de duas estudantes cegas do curso superior de Licenciatura em Física do IFRN - campus Natal Central - no desafiador processo de aprendizagem dos conteúdos da disciplina "Cálculo de funções de uma variável”. Esta pesquisa consiste em um relato de experiência coligado à pesquisa-ação e tem por objetivo oportunizar apropriação do conhecimento pelas alunas, bem como compreender os desafios que acompanham a atividade docente na inclusão de pessoas com necessidades educacionais específicas. Ao longo do acompanhamento dessas estudantes, verificou-se a possibilidade de confecção de materiais táteis de baixo custo, incluindo a transcrição em alto relevo de conceitos e regras algébricas para apropriação dos conteúdos da disciplina pelas educandas, com uso dentro e fora da sala de aula.

Pouco se tem documentado sobre a inclusão de pessoas com deficiência no Ensino Superior, indicando uma carência de reflexões e propostas pedagógicas para esse nível de ensino. Freitas et al. (2017) ressaltam a importância de trabalhos como esse:

\footnotetext{
Relatos de uma acessibilidade plena, educação inclusiva, ainda são pontuais, mas devem ser valorizados e servir de exemplo para multiplicação e consolidação do direito ao ensino em todos os níveis e ao longo de toda a vida para todas as pessoas, conforme preconiza a Lei Brasileira da Inclusão.
}

\section{FUNDAMENTAÇÃO TEÓRICA}

De acordo com o Projeto Político Pedagógico do IFRN, o movimento mundial pela inclusão constitui-se em uma ação de caráter político, social e histórico que reconhece e valoriza a diversidade como condição indispensável à constituição de qualquer sociedade. O documento ainda acrescenta que a educação inclusiva se origina nesse contexto, remetendo a uma ação que instaura um nível de importância ao direito de todos à educação. Nesse sentido, deve-se propiciar escolas abertas a todos, em qualquer etapa ou modalidade, e acesso a níveis mais elevados de ensino. Entende-se a inclusão indo além dos limites da deficiência, estendendo-se todos os sujeitos tratados, nos debates das políticas públicas, como "minorias" ou "excluídos". Essa concepção sustenta práticas pedagógicas que, “em vez de pressupor que o aluno deva ajustar-se aos padrões de 'normalidade' para aprender, apontam para a escola o desafio de ajustar-se para atender a diversidade de seus alunos". (BRASIL, 2001b, p. 15).

Não é tarefa fácil incluir o estudante com deficiência em sala de aula. O processo de 
inclusão passa pelo entendimento das particularidades de cada caso. A deficiência visual, que é caracterizada pela limitação ou perda das funções básicas do olho e do sistema visual, por exemplo, requer estratégias metodológicas muito diferentes daquelas que são necessárias a alunos com problemas auditivos.

Sá, Campos e Silva (2007) afirmam que o sistema visual detecta e integra de forma instantânea e imediata cerca de $80 \%$ dos estímulos do ambiente, isso mostra a dependência do ser humano perante a visão. No entanto, segundo os autores, a falta da visão não interfere na capacidade intelectual e cognitiva. Estudantes com deficiência visual têm o mesmo potencial de aprendizagem e podem demonstrar um desempenho escolar equivalente ou superior ao de alunos que enxergam mediante condições e recursos adequados. Os autores ainda destacam que eles podem ser mais lentos na realização de algumas atividades, pois a dimensão analítica da percepção tátil demanda mais tempo, e que precisam manipular e explorar o objeto para conhecer as suas características e fazer uma análise detalhada das partes para tirar conclusões. Essa diferença básica é importante porque influi na elaboração de conceitos e interiorização do conhecimento. É natural, portanto, que as estratégias e situações de aprendizagem para com eles valorizem a estimulação do tato, principalmente.

\section{METODOLOGIA}

Participam desta pesquisa duas alunas com deficiência visual regularmente matriculadas no curso superior de licenciatura em Física do Instituto Federal de Educação, Ciência e Tecnologia do Rio Grande do Norte - IFRN. Elas assistem aula de cálculo em uma turma com 36 alunos, nas segundas e quartas-feiras, no horário vespertino e tem atendimento individualizado no contra turno nas terças e quintas-feiras.

Esta pesquisa é de natureza quantitativa e qualitativa, uma vez que foram considerados aspectos subjetivos, como os depoimentos das alunas participantes e de seus colegas de turma, mas, também, aspectos quantificáveis como o rendimento das alunas nas provas da disciplina. Também pode ser classificada, quanto ao tipo, como um relato de experiência, porém, com algumas características de uma pesquisa-ação, pois, além de expor experiências vivenciadas numa situação específica, os pesquisadores tiveram influência no desenvolvimento e nos resultados obtidos. Para a aquisição dos dados foram utilizados como instrumentos as provas escritas aplicadas na disciplina (porém, de maneira adaptada, tendo em vista as necessidades das alunas), bem como os depoimentos destas e de seus colegas de turma.

Antes de passar a descrição dos procedimentos utilizados, é importante ressaltar que ambas as participantes da pesquisa têm cegueira adquirida, sendo que perderam completamente 
a visão durante a fase da adolescência, de forma que ambas são alfabetizadas, o que foi fundamental para o êxito das intervenções realizadas. Além disso, apenas uma das estudantes consegue ler e escrever em Braille, sistema de leitura com o tato, inventado pelo francês Louis Braille no ano de 1827. Assim, nas intervenções em que as duas discentes estavam presentes, só foi possível a utilização dos recursos táteis e auditivos para se trabalhar os conteúdos. Em alguns momentos, quando apenas a aluna alfabetizada em Braille esteve presente, foi possível ensiná-la alguns símbolos matemáticos específicos do Cálculo Diferencial e Integral para que ela pudesse fazer as suas próprias anotações, tática que, segundo a própria aprendiz, conduzia a uma apropriação mais rápida dos conteúdos.

As intervenções foram realizadas em sala de aula, às segundas e quartas-feiras à tarde, e em horários de atendimento particulares no contraturno. Nas duas ocasiões, os principais conceitos eram apresentados por meio de materiais táteis e em alto-relevo, contudo, nos atendimentos particulares, em geral, eram resolvidos mais exercícios juntamente às alunas. Foram realizadas algumas tentativas de utilização de diferentes materiais táteis como, por exemplo: representações geométricas feitas em papel de $120 \mathrm{~g} / \mathrm{m}^{2}$, produzidas através do desenho espelhado, estando o papel sobreposto a uma camada de EVA (Método 1), ou utilizando cola alto-relevo (Método 2); e propriedades algébricas escritas com cola quente em papel ou cartolina (Método 3).

As provas e listas de exercícios foram produzidas em via escrita, utilizando-se o Método 1, por ser um método mais acessível financeiramente e mais prático, quando a disponibilidade de tempo para a produção é reduzida. As avaliações escritas foram aplicadas em datas diferentes, para cada discente, a fim de que uma não pudesse ter acesso às respostas da outra. As alunas realizaram a leitura das questões, por meio do tato e diante da dificuldade de escrita observada, a professora efetuou a transcrição das respostas narradas por elas.

\section{RESULTADOS E DISCUSSÕES}

Os dados analisados referentes aos encontros com as alunas com deficiência visual apontam para uma aprendizagem significativa em relação aos conceitos e propriedades dos Limites. O rendimento na prova escrita, que tratou do referido conteúdo, foi de mais de $85 \%$ para ambas, resultado que, ao ser comparado ao dos estudantes sem nenhuma limitação, evidencia que "a escolarização e educação da pessoa cega ou com baixa visão é de modo geral viável em todos os níveis, desde que lhe sejam oferecidos os meios necessários para o desenvolvimento de sua autonomia e independência." (ORRICO, CANEJO E FOGLI, 2009, p. 121). Todavia, também foram observadas dificuldades por parte das discentes com deficiência 
em relação a conhecimentos básicos necessários à resolução das questões abordadas como: produtos notáveis, fatoração e equação do $2^{\circ}$ grau. Essas dificuldades se devem a lacunas na formação adquirida no Ensino Básico e ocasionaram problemas para a resolução de limites envolvendo indeterminações.

Foi constatado, dentre os métodos de produção de material avaliados, que aquele que melhor se adequou à dinâmica do dia-a-dia, levando em conta o contexto de pouco tempo disponível por parte da professora da disciplina, foi o Método 1. Um fator que contribuiu para o sucesso desse método foi que a docente já tinha a habilidade de escrever de maneira espelhada, das suas vivências anteriores. Além disso, ela também contou com o apoio de um professor visitante e de um orientando para auxiliá-la nas intervenções em sala de aula e nos momentos de atendimento individualizado.

Também foi verificado que a habilidade dos docentes e alunos (professores em formação) envolvidos com esse processo foi bastante desenvolvida, o que pode ser de grande valia caso ocorram experiências futuras com estudantes que tenham características semelhantes.

\section{CONCLUSÕES}

Com essa experiência, foi possível observar o quanto os cursos de formação de professores (licenciaturas) ainda possuem lacunas do que diz respeito à questão da inclusão. Em geral, nesses cursos, os estudantes não vivenciam experiências com alunos cegos, surdos ou com outro tipo de deficiência, de forma que tendem a apresentar dificuldades em lidar com esse público quando ocorrem situações como a descrita neste trabalho.

No entanto, existindo responsabilidade e interesse em incluir alunos com necessidades educacionais específicas, apesar das lacunas existentes na formação dos docentes, é possível encontrar estratégias que reduzam as dificuldades no seu processo de ensino-aprendizagem. Nesse sentido, desejamos que a inclusão destes seja uma prática incentivada e mais frequente no ambiente escolar.

Além disso, ficou evidente a necessidade de mais de um professor atuando nas turmas em que existem alunos com deficiência. Apesar de, em nosso caso, a deficiência das discentes ser visual, fica claro que esta necessidade se estende também a outras situações.

Por fim, esperamos que o aprendizado relatado neste trabalho em relação aos métodos de produção de material didático e estratégias de ensino para alunos cegos possam servir como ponto de partida para outros profissionais, no processo de inclusão de estudantes com características similares. 


\section{REFERÊNCIAS}

BRASIL, Lei n. 13.005, de 25 de junho de 2014. Aprova o Plano Nacional de Educação - PNE e dá outras providências. 2014. Diário Oficial da República Federativa do Brasil, Brasília, DF, n. 120, p. 1, 26 jun. 2014. Seção 1. Edição Extra.

BRASIL. Ministério da Educação. Parecer CNE/CEB n. 17/2001. Diretrizes Nacionais para a Educação Especial na Educação Básica. Diário Oficial da República Federativa do Brasil, Brasília, DF, n. 158, p. 46.17 ago. 2001. Seção 1.

DUARTE, E. R. et al. Estudo de caso sobre a inclusão de alunos com deficiência no ensino superior. Revista Brasileira de Educação Especial [online], v. 19, n. 2, 2013. Disponível em: http://www.scielo.br/scielo.php?script=sci_arttext\&pid=S1413-65382013000200011. Acesso em: 19 out. 2019.

FREITAS, S. V. D. H.; FOSSATTI, P.; KORTMANN, G. M. L. Inclusão de pessoas com deficiência (PCD) na educação superior: um olhar a partir das políticas de inclusão. In: GIANEZINI, Kelly; GROSS, Jacson (Org.). Estudos contemporâneos em ciências jurídicas e sociais. Florianópolis: Dois Por Quatro; Criciúma, SC: UNESC, 2017. p. 79-97. DOI: 10.18616/cienciasjuridicas04.

ORRICO, H. CANEJO, E. FOGLI, B. Uma reflexão sobre o cotidiano escolar de alunos com deficiência visual em classes regulares. In: GLAT, Rosana. Educação Inclusiva: cultura e cotidiano escolar. Rio de Janeiro: 7 Letras, 2009. p.116-136.

SÁ, E. D. de; CAMPOS, I.M.; SILVA, M.B.C. Atendimento Educacional Especializado Deficiência visual. Brasília: Ministério da educação, 2007. Disponível em:

http://portal.mec.gov.br/seesp/arquivos/pdf/aee_dv.pdf. Acesso em 18 out. 2019. 


\title{
O USO DA TABELA PERIÓDICA COMO RECURSO LÚDICO FACILITADOR DA APRENDIZAGEM DE UMA DISCENTE COM SÍNDROME DE DOWN
}

\author{
EL USO DE LA TABLA PERIÓDICA COMO UN RECURSO DE JUEGO \\ FAVORABLE PARA APRENDER A UN ESTUDIANTE DE SÍNDROME ABAJO
THE USE OF THE PERIODIC TABLE AS A FAVORABLE PLAYING RESOURCE FOR LEARNING A DOWN SYNDROME STUDENT

\begin{abstract}
Bruno Galdino Lopes; José Leonardo Alves Ferreira; Márcio Jean Fernandes Tavares; Niely Silva de Souza; Alessandra Marcone Tavares Alves de Figueirêdo
\end{abstract}

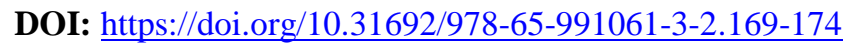

\section{INTRODUÇÃO}

O número de matrículas em escolas regulares no Brasil, de pessoas que apresentam Síndrome de Down (SD), aumentou consideravelmente nos últimos 10 anos (OLIVEIRA, 2015). Entretanto, cada vez mais nota-se a necessidade de ampliar as discussões e apoio por uma política pública de inclusão efetiva de discentes que apresentam esta deficiência, assim como outras. Sob esse viés, diante das necessidades observadas no processo de ensino e aprendizagem e dos debates realizados, a educação brasileira deve ser reestruturada para que os discentes com SD possuam direito à uma educação de qualidade, a qual lhes permitam experimentar, de forma exitosa, o ambiente escolar. Dessa maneira, a inclusão tornou-se uma discussão necessária nos cursos de formação de professores pois, é neste momento, que o futuro docente precisa refletir sobre as realidades encontradas nas escolas e pensar em estratégias que possam auxiliar a pessoa com deficiência na sua escolarização. Uma das estratégias encontradas é utilizar recursos como a contextualização, as Tecnologias da Informação e Comunicação TIC's, aulas experimentais, bem como fazer uso da ludicidade, trabalhando com o concreto.

Neste contexto, o objetivo desse trabalho foi aplicar uma Tabela Periódica, no intuito de auxiliar uma educanda com SD, na aprendizagem de conceitos químicos referentes ao conteúdo "Tabela Periódica”. Tal atividade foi planejada e aplicada pelos discentes do Curso de Licenciatura em Química do Instituto Federal da Paraíba - IFPB - Campus João Pessoa, integrantes do projeto de pesquisa, o qual originou o trabalho em tela.

\section{FUNDAMENTAÇÃO TEÓRICA}

\section{Educação Inclusiva}

Para que a educação seja efetivamente inclusiva, para um discente com SD, esta deve englobar diversos fatores, tanto os relacionados à estrutura escolar, quanto os concernentes à 
relação entre a escola e a família. Para entender como a escola regular está preparada, nos dias atuais, para receber o discente com Síndrome de Down em uma perspectiva de educação inclusiva, é fundamental descrevermos sobre a Lei Brasileira de Inclusão - LBI.

A LBI $n^{0} 13.146$ foi emitida em 06 de julho de 2015, sendo considerada um marco histórico na educação inclusiva. No entanto, outros documentos governamentais, como a Constituição de 1988 e a Lei de Diretrizes e Bases - LDB nº 9.394/1996, já discorriam sobre os direitos das pessoas com deficiência, porém, de forma mais geral. Na Lei Brasileira de Inclusão, os direitos das pessoas com deficiência estão assegurados em seu capítulo IV, artigo 27:

\begin{abstract}
A educação constitui direito da pessoa com deficiência, assegurados sistema educacional inclusivo em todos os níveis e aprendizado ao longo de toda a vida, de forma a alcançar o máximo desenvolvimento possível de seus talentos e habilidades físicas, sensoriais, intelectuais e sociais, segundo suas características, interesses e necessidades de aprendizagem (BRASIL, 2015).
\end{abstract}

No entanto, o que se observa na prática, vai na contramão do que está disponibilizado nos documentos oficiais, ou seja, não existe uma inclusão eficaz nas escolas brasileiras.

\title{
Processo de Aprendizagem
}

O processo de ensino e aprendizagem para pessoas com Síndrome de Down é diferente, pois o desenvolvimento cognitivo é lento, este se dá de acordo com os estímulos que o indivíduo recebe, podendo desenvolver habilidades e potencialidades mais fortes em uma pessoa do que na outra. Dentro desse contexto, essas pessoas apresentam algumas especificidades:

\footnotetext{
A presença do cromossomo 21 extra na constituição genética determina características físicas específicas e atraso no desenvolvimento. Sabe-se que as pessoas com SD quando atendidas e estimuladas adequadamente, têm potencial para uma vida saudável e plena inclusão social. No Brasil nasce uma criança com SD a cada 600 e 800 nascimentos, independente de etnia, gênero ou classe social (BRASIL, 2012, p. $9)$.
}

Segundo Milani (2005, p. 50), “as conexões cerebrais das crianças portadoras da Síndrome de Down são mais lentas e fracas e por isso requerem mais repetições. [...]”. É de fundamental importância estimular corretamente as pessoas com SD, adotando a utilização de atividades que exijam mais da memória visual, da vivência, possuindo metodologia repetitiva, curta e objetiva e de materiais concretos/físicos, pois tais ações reafirmam a absorção do conteúdo, validando o processo de aprendizagem.

Um fator que auxilia o processo de detenção do saber é a utilização de recursos lúdicos/práticos, que reafirma o pressuposto do concreto, juntamente com a execução da ação pelo próprio discente Down, colocando-o como protagonista da ação, aflorando no mesmo o desejo pela obtenção da construção do conhecimento (CAVALCANTI, 2005). Nesse sentido, 
ao despertar a curiosidade aumenta-se o engajamento, a motivação intrínseca e a retenção do conteúdo pelo discente, ou seja, sua aprendizagem. Assim, a motivação seja ela extrínseca e intrínseca, tem papel fundamental e facilitador na aquisição de conceitos.

\section{METODOLOGIA}

O trabalho baseou-se na pesquisa qualitativa, com cunho participante. Segundo Marconi e Lakatos (2011, p. 191), a pesquisa participante "ajuda o pesquisador na identificação e obtenção de provas a respeito de objetivos sobre os quais os indivíduos não têm consciência, mas que orientam seu comportamento".

Enquanto que, "a pesquisa qualitativa preocupa-se em analisar e interpretar aspectos mais profundos, descrevendo a complexidade do comportamento humano. Fornece análise mais detalhada sobre as investigações, hábitos, atitudes, tendências de comportamento etc.” [...] (MARCONI e LAKATOS, 2011, p. 269).

A atividade foi desenvolvida e aplicada no Instituto Federal da Paraíba, Campus João Pessoa, e consistiu em um acompanhamento escolar, de uma discente que apresenta Síndrome Down, a qual possui 24 (vinte e quatro) anos, e está matriculada no $1^{\circ}$ ano do Curso Técnico Integrado ao Ensino Médio de Instrumento Musical. Tal acompanhamento discorreu numa aplicação do conteúdo de "Tabela Periódica", vislumbrando melhorar seu desempenho neste assunto alusivo à disciplina Química. Para isso, foi utilizada uma Tabela Periódica adaptada, construída com materiais alternativos e de baixo custo.

O acompanhamento foi realizado em horário oposto ao das aulas da discente e com a disponibilidade da mesma, para não afetar seu desempenho nas outras áreas. A aplicação foi feita em uma tarde, durante 2 horas, pelos integrantes da equipe de pesquisa, na presença dos pais da estudante Down.

\section{RESULTADOS E DISCUSSÃO}

Para a realização da atividade, foi utilizada uma Tabela Periódica adaptada (Figura 1), com o intuito de facilitar a leitura e a compreensão da discente com Síndrome de Down. Uma vez que, tal recurso lúdico trabalha com o concreto, tão eficaz no processo de aprendizagem, sendo um grande auxiliador e um instrumento imprescindível no acompanhamento do conteúdo supramencionado. 
Figura 1: Tabela Periódica adaptada.

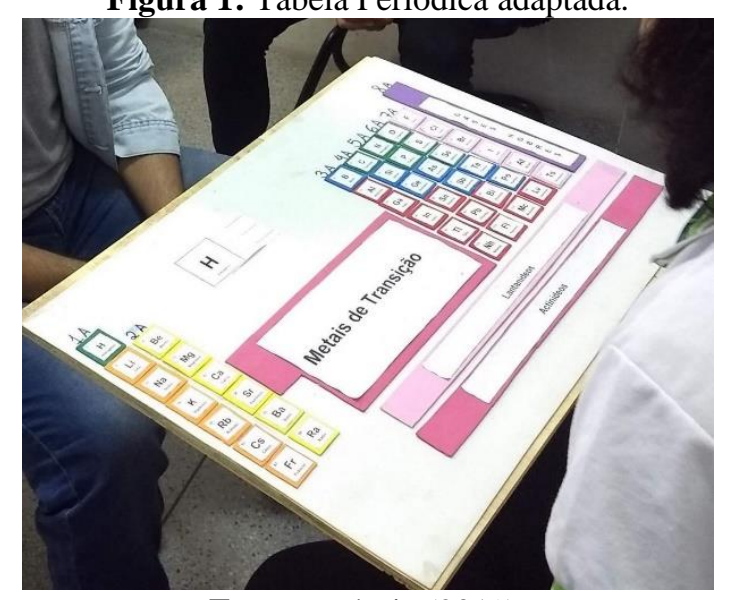

Fonte: Própria (2019).

Durante a atividade (Figura 2), notou-se a facilidade com que a estudante relacionava os nomes dos elementos químicos com os seus respectivos símbolos presentes na tabela. Nesse caso, evidencia-se que o uso de materiais adaptados pode contribuir de forma significativa ao ensino de Química para discentes com Down, facilitando ainda mais a inclusão no processo de aprendizagem (OLIVEIRA et al, 2013).

Figura 2: Apresentação da Tabela Periódica adaptada.

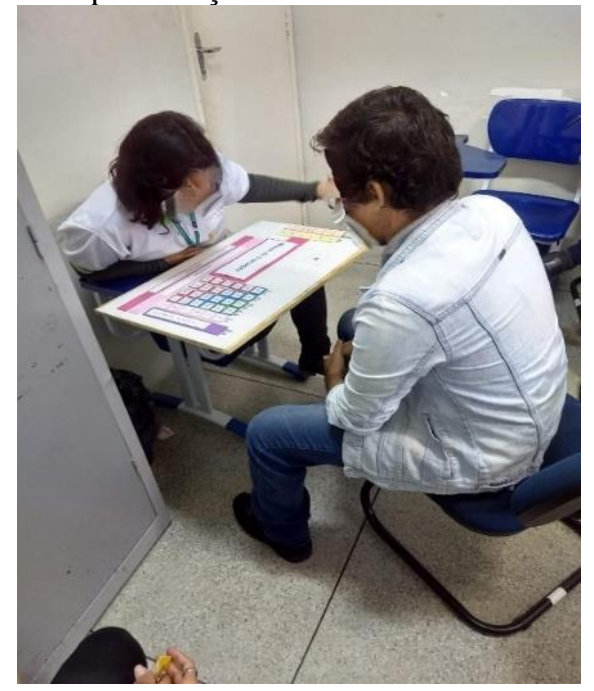

Fonte: Própria (2019).

No decorrer da explanação, foram realizadas perguntas relacionadas ao conteúdo periódico, realizadas de forma verbal com a discente, objetivando avaliar seu nível de aprendizagem. Desta forma, foi possível destacar pontos positivos, pois a discente mostrou entusiasmo para com o material que era de fácil visualização e entendimento.

Tal fato corrobora com Silva (2015), que afirma que a utilização de metodologias 
diferenciadas que estimulem a imaginação e a percepção visual depende da integração neurológica, o que consequentemente, promove a prontidão para o desenvolvimento cognitivo. Desse modo, foi notório que esse método foi capaz de engajar a discente com Síndrome de Down de maneira assertiva e desenvolver ainda mais seus conhecimentos na disciplina Química.

Assim, a discente Down conseguiu responder à todas as questões propostas e manteve 90\% de acertos, realizando a atividade, em todo momento, de forma descontraída e motivada. Vale lembrar que, em toda a execução da proposta, a discente foi devidamente acompanhada pelos pais, que concomitantemente com a equipe de pesquisa, auxiliou-a lendo o assunto, explicando e fazendo repetições para a técnica ser concluída com sucesso.

Fica elucidado, sobretudo, que a utilização de meios pedagógicos como o uso de recursos adaptados no ensino de Química para discentes com Down, pode garantir novas experiências e ajudá-los a desenvolver habilidades nunca antes adquiridas. Por conseguinte, é possível proporcionar a inclusão e colaborar devidamente com as práticas de ensino, garantindo uma melhor compreensão de disciplinas mais complexas e estimulando gradativamente a percepção desses discentes.

\section{CONCLUSÕES}

Durante a atividade, ficou elucidado o quão se faz necessário o uso de metodologias e recursos adaptados, utilizando o concreto, o lúdico, as cores, para uma melhor aprendizagem do educando com SD, pois tais recursos são fundamentais para um efetivo ensino inclusivo. Porém, a escola ainda carece de materiais didáticos inclusivos, esta observação é pertinente, pois é uma realidade enfrentada pela maioria delas, que não dispõem de materiais dessa natureza, nem de investimentos para suprir esse tipo de necessidade e tornar o ensino igualitário para todos.

Portanto, é importante pensar na escola para todos, garantindo a equidade do ensino, respeitando a diversidade e limitações das pessoas com deficiência. Só assim, a inclusão deixará de ser utópica e passará a ser realidade. Uma escola inclusiva aberta à riqueza da diversidade e consciente de suas funções sociais e políticas, se torna um espaço plural, capaz de promover profundas e intensas mudanças sociais.

\section{REFERÊNCIAS}

BRASIL. Diretrizes de atenção à pessoa com Síndrome de Down / Ministério da Saúde, Secretaria de Atenção à Saúde, Departamento de Ações Programáticas Estratégicas. - 
Brasília: Ministério da Saúde, 2012.

BRASIL. Lei Brasileira de Inclusão-LBI n 13.146/15: Estatuto da Pessoa com Deficiência. Brasília, 06 jul. 2015.

CAVALCANTI, L. S. Geografia e práticas de ensino. Goiânia: Alternativa, 2005. 127p.

MARCONI, M. A.; LAKATOS, E. M. Metodologia científica. $6^{\text {a }}$ ed. - São Paulo: Atlas, 2011.

MILANI, D. Down, Síndrome de: como - onde - quando - porquê. São Paulo: Livro Pronto: 2005.

OLIVEIRA, J. S. et al. Ensino de química inclusivo: Tabela periódica adaptada a deficientes visuais. 2013.

OLIVEIRA, C. Dia da Síndrome de Down revela evolução da inclusão no Brasil. 2015. Disponível em: http://portal.mec.gov.br/ultimas-noticias/202-264937351/21167-dia-dasindrome-de-down-revela-evolucao-da-inclusao-no-brasil. Acesso em 18 de outubro de 2019.

SILVA, A. M. E. C. et al. Um olhar sobre o processo de ensino e aprendizagem de crianças com síndrome de Down. Revista Includere, v. 1, n. 1, 2015. 


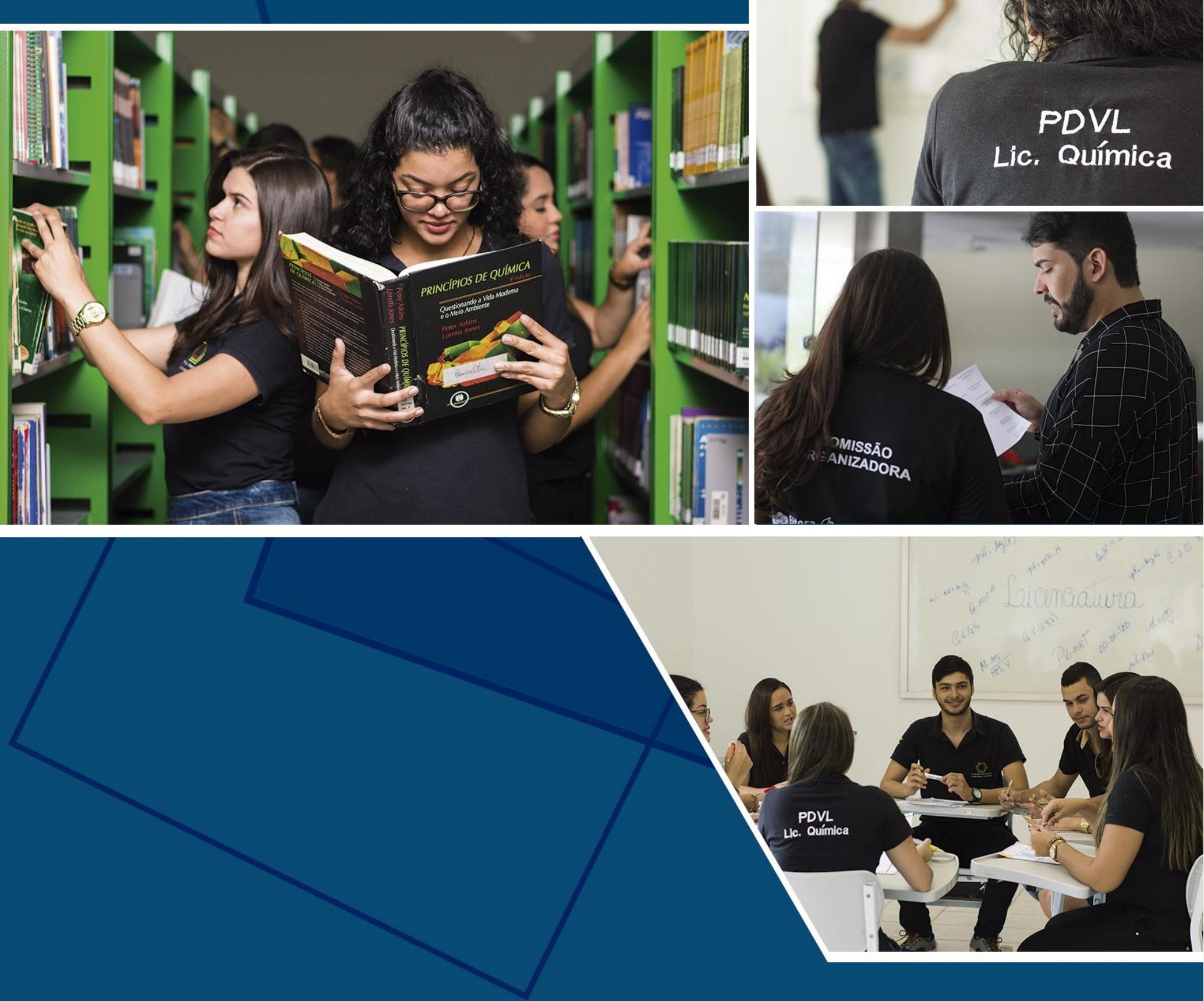

